\title{
FEASIBILITY STUDY INTO THE USE OF 3D PRINTED MATERIALS IN CUBESAT FLIGHT MISSIONS
}

\author{
A Thesis \\ Presented to \\ The Faculty of \\ California Polytechnic State University, San Luis Obispo \\ In Partial Fulfillment \\ of the Requirements for the Degree \\ Master of Science in Aerospace Engineering
}

By

Daniel Fluitt

May 2012 
(C) 2012

Daniel Fluitt

All Rights Reserved 


\section{COMMITTEE MEMBERSHIP}

TITLE: Feasibility Study Into the Use of 3D Printed

Materials in CubeSat Flight Missions

AUTHOR: Daniel Fluitt

DATE SUBMITTED: June 8, 2012

COMMITTEE CHAIR: Dr. Jordi Puig-Suari, Professor

COMMITTEE MEMBER: Dr. Kira Abercromby, Assistant Professor

COMMITTEE MEMBER: Dr. Thomas Mackin, Professor

COMMITTEE MEMBER: Dr. Eric Mehiel, Associate Professor 


\section{Abstract}

Feasibility Study Into the Use of 3D Printed Materials in CubeSat Flight Missions Daniel Fluitt

The CubeSat Program has provided access to space for many universities, private companies, and government institutions primarily due to the low cost of CubeSat satellite development. While these costs are orders of magnitude lower than similarly capable nano-satellite missions, they are still outside of the budgetary constraints of many potential developers including university and high school clubs. Using 3D printed plastics in the production of CubeSat structures and mechanisms presents a large cost savings opportunity that will allow these institutions to participate in the development of these satellites, expanding the educational and scientific impact of the CubeSat Program.

Five rapid prototype plastics manufactured with four different 3D printing technologies were studied to determine their survivability when subjected to the required vibration testing and thermal bakeout that all CubeSats are must pass through before integration and launch. ASTM D638 Type V tensile bar samples of each plastic were procured and subjected to a thermal bakeout and tensile testing to determine the thermal and outgassing effects on their mechanical properties. This information was used to design a concept structure for use in a low budget CubeSat mission. Finite Element Analysis in Abaqus was then utilized to test the integrity of this structure under a worst case load condition derived from the ELaNa 6 launch vibration profile. Results from the analysis show that Objet FullCure720 photopolymer resin, DSM Somos Prototherm 12120 photopolymer resin, and Windform XT carbon fiber filled nylon all provide adequate strength to survive the environmental testing conditions required for this system to proceed through flight integration and launch. 


\section{Acknowledgements}

\section{To the Multidisciplinary Space Technology Lab -}

For the experience of working with you throughout my time at Cal Poly. It has been a wild ride, and I'm glad that I had all of you to share it with.

\section{To Dr. Abercromby and David Knapp -}

For your support in performing all of the thermal bakeout tests. Thank you for the time you sacrificed to make this thesis possible.

\section{To Larry Coolidge -}

For your help in running Cal Poly's 3D printers. Thank you for your time and advice during the production of parts for this thesis and my other projects.

\section{To Walter Holemans -}

For providing the WindformXT samples for me to test. The material is an important part of this study and makes my results more significant. I wish you the best of luck with PrintSat!

\section{To my family -}

For the years of love and support throughout my life and education. None of this would have been possible without you. 


\section{Contents}

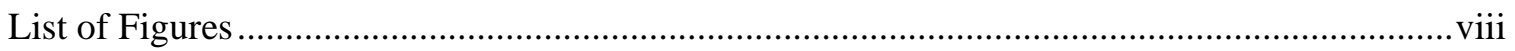

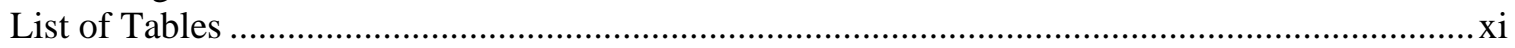

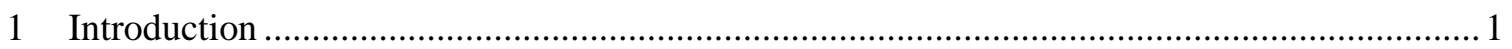

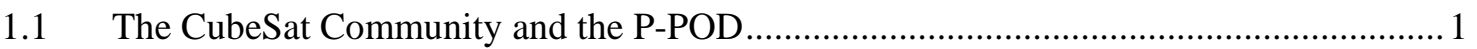

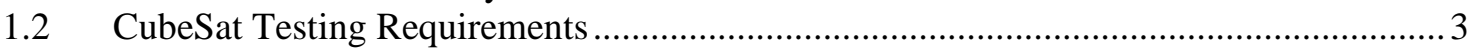

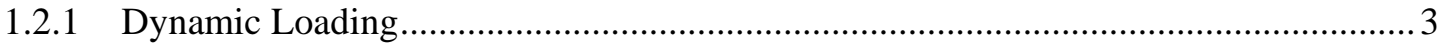

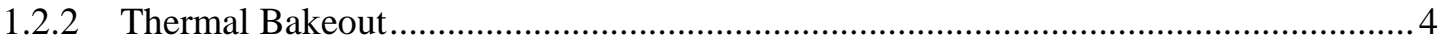

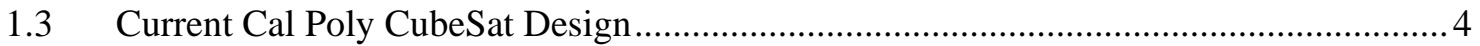

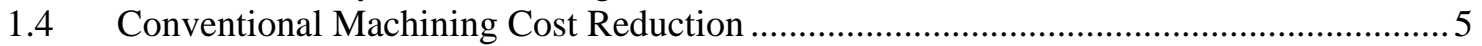

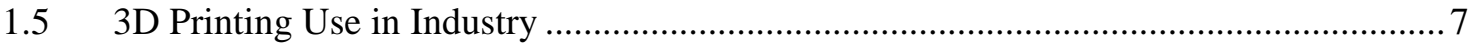

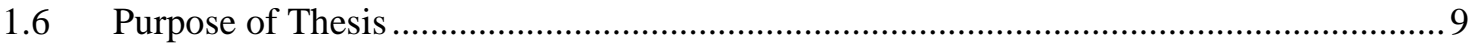

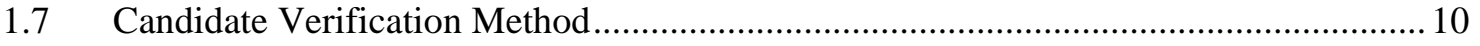

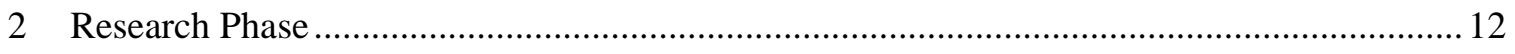

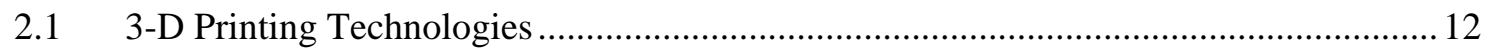

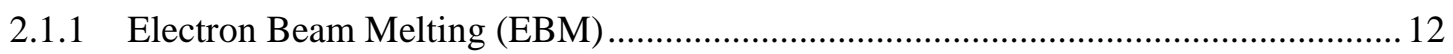

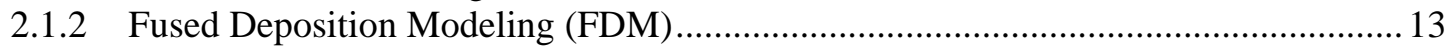

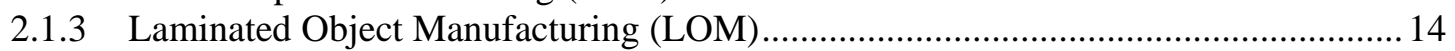

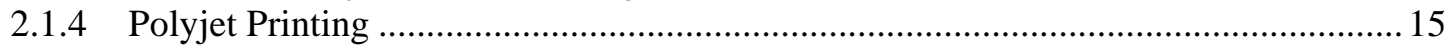

2.1.5 Powder Bed and Inkjet Head Printing ................................................................... 15

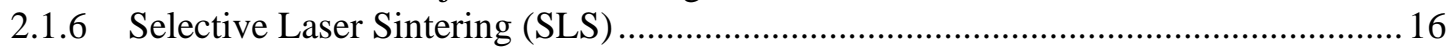

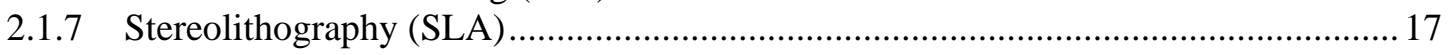

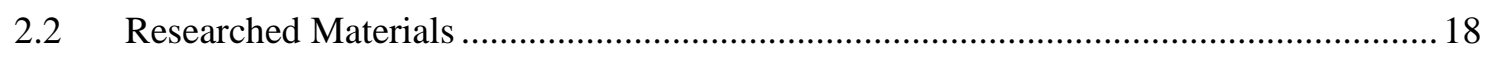

2.2.1 ABS Plastic/Cal Poly's Stratasys Dimension 2000 Fused Deposition Modeler ......... 19

2.2.2 Objet FullCure720 Resin/Cal Poly's Objet Eden 250 Polyjet Prototyper.................... 19

2.2.3 Prototherm 12120 Modeling Resin/Stereolithography from Harvest Technologies ... 19

2.2.4 Watershed 11122 XC Modeling Resin/Stereolithography from ProtoCam ................. 20

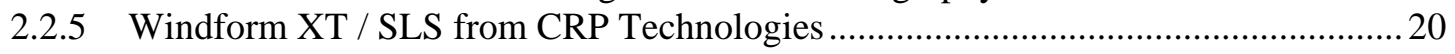

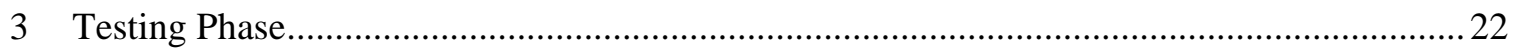

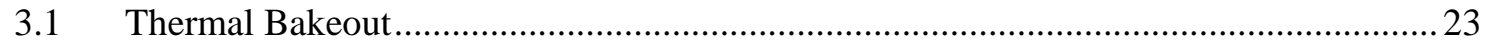

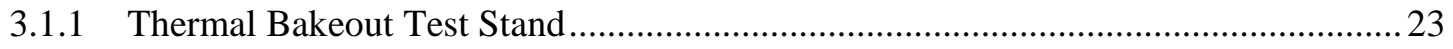

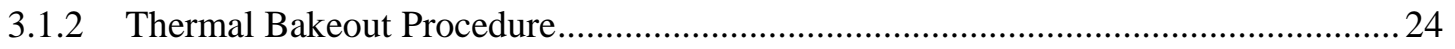

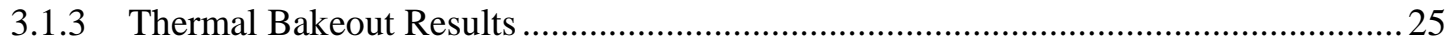

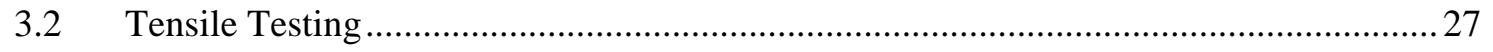

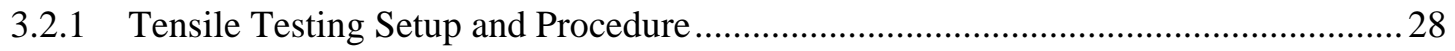

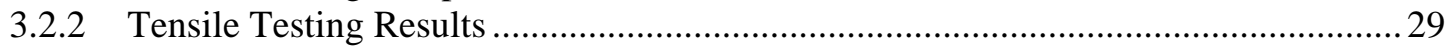

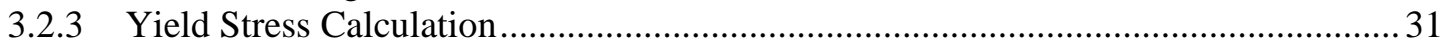

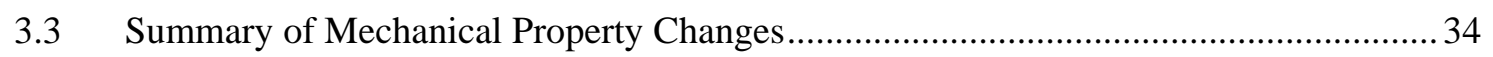

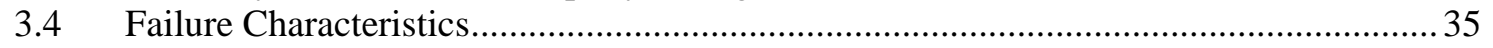

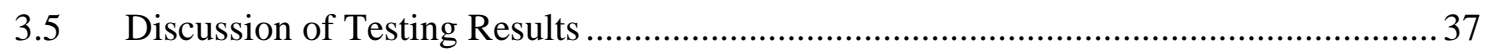

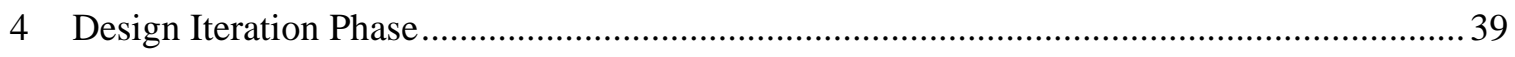

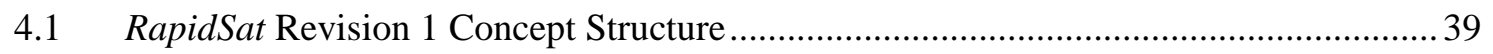




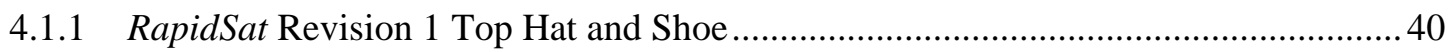

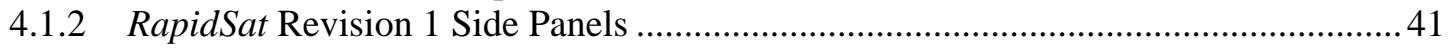

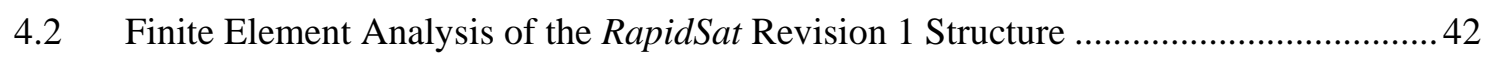

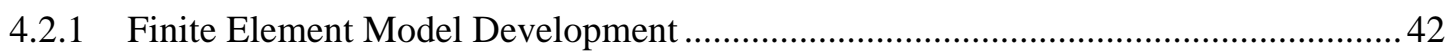

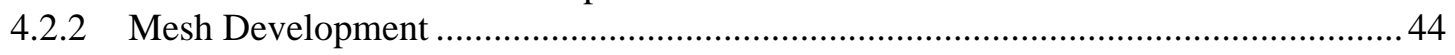

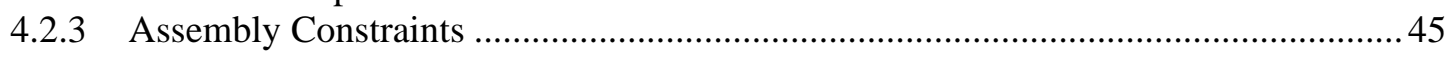

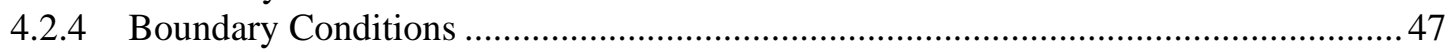

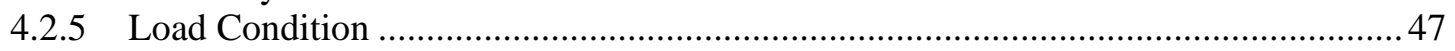

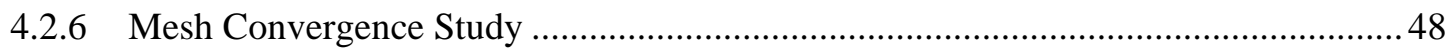

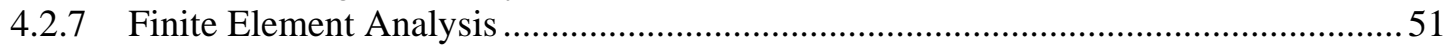

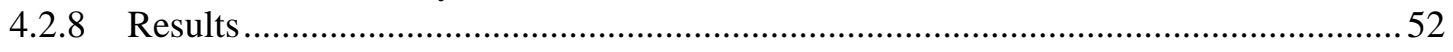

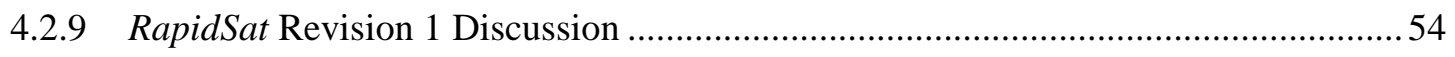

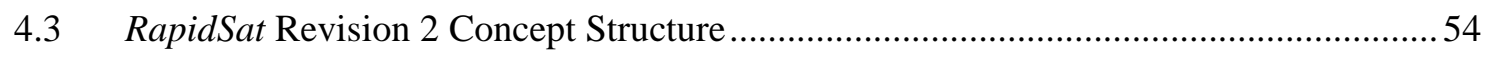

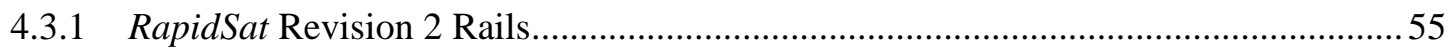

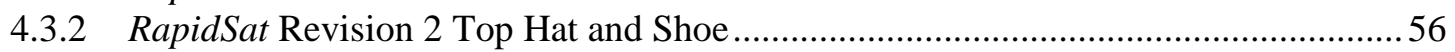

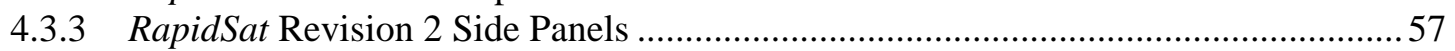

4.4 Finite Element Analysis of the RapidSat Revision 2 Structure .....................................57

4.4.1 Finite Element Model Development ……................................................................ 58

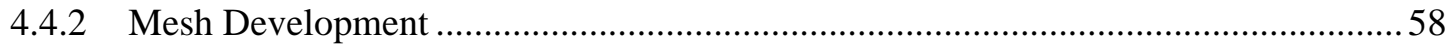

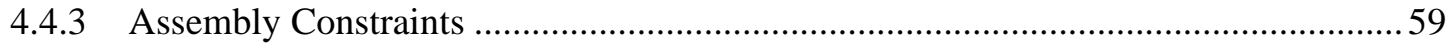

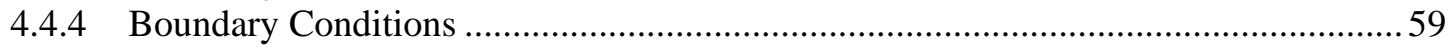

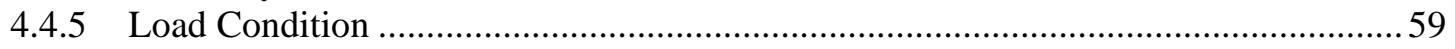

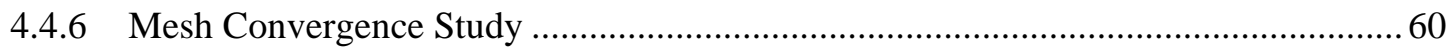

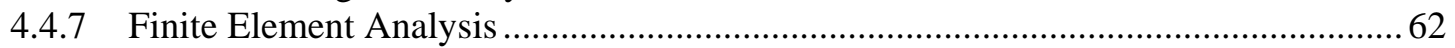

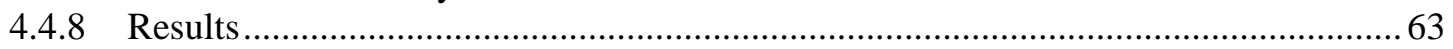

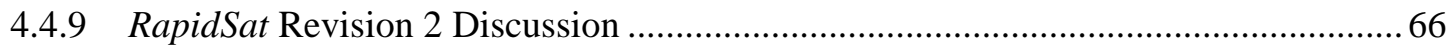

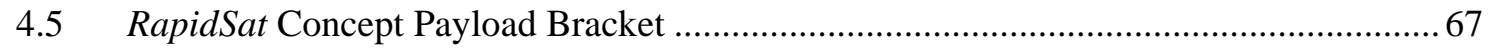

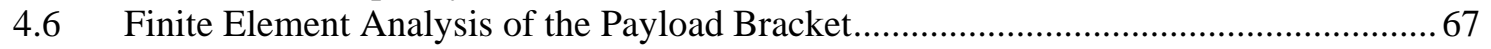

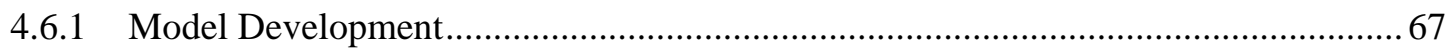

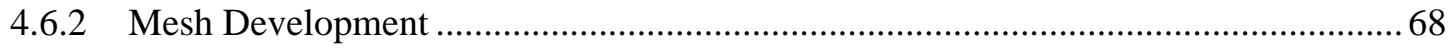

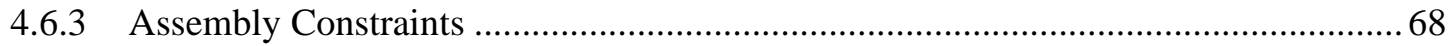

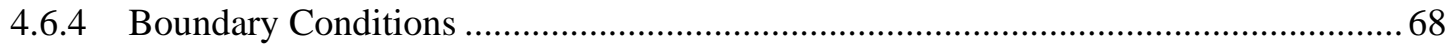

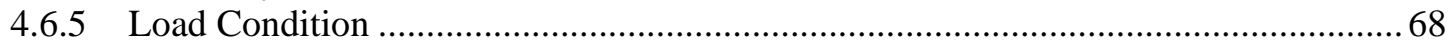

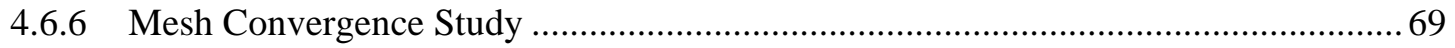

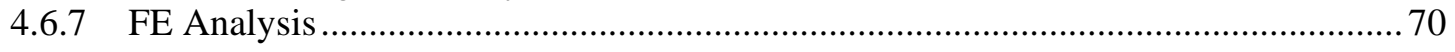

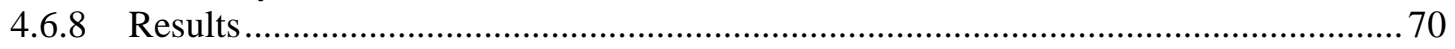

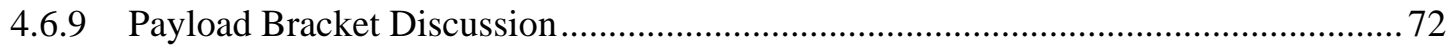

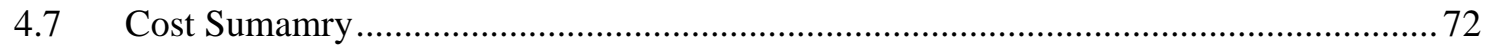

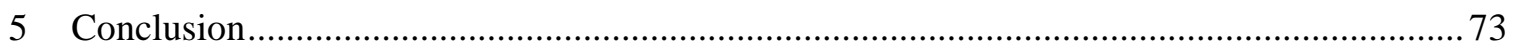

5.1 Feasibility of the Use of 3D Printed Parts in CubeSat Structural Applications .............. 73

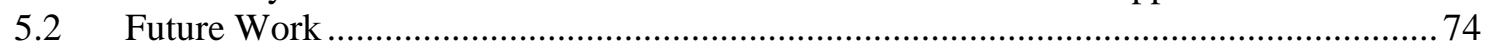

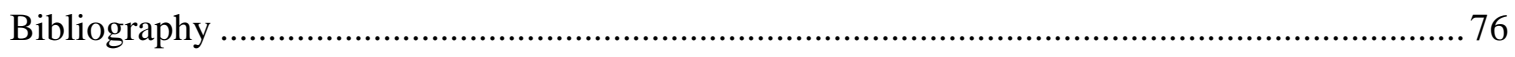

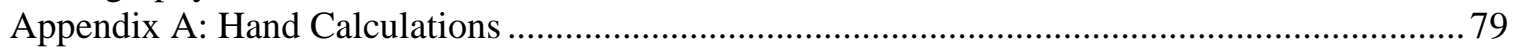

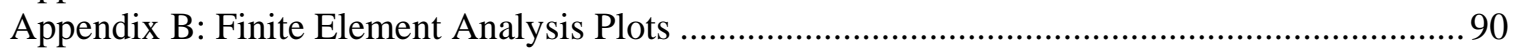

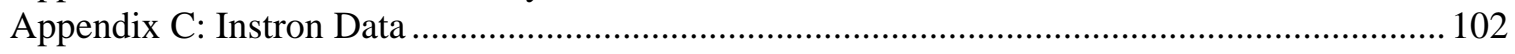

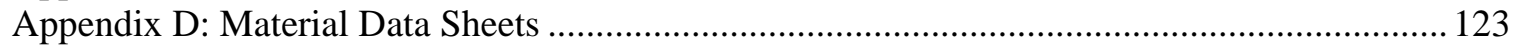




\section{List of Figures}

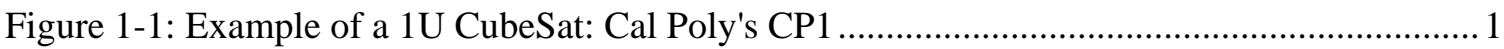

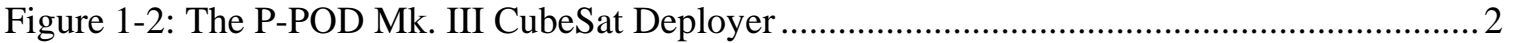

Figure 1-3: CubeSat Test Flow Procedures Necessary for Flight Integration ................................. 3

Figure 1-4: The HyperCube Structure of Cal Poly's Current System Bus ...................................... 5

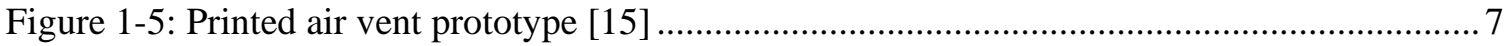

Figure 1-6: Comparison of a casted door hinge and 3D printed door hinge [13] ......................... 8

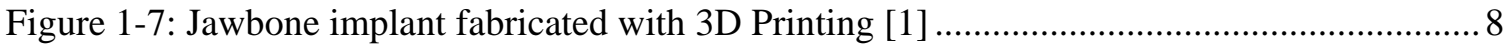

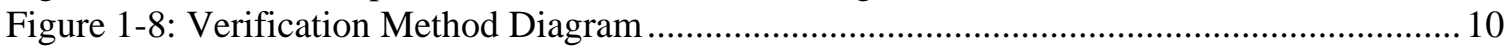

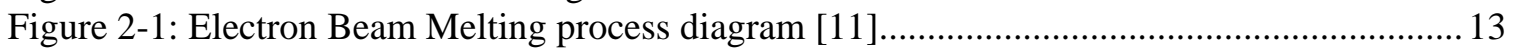

Figure 2-2: Fused Deposition Modeling process diagram [9] .................................................... 13

Figure 2-3: Laminated Object Manufacturing process diagram [12] ....................................... 14

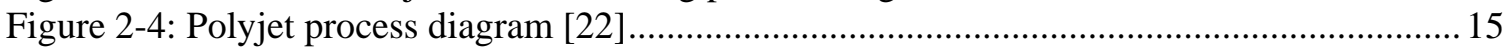

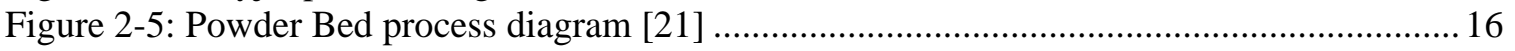

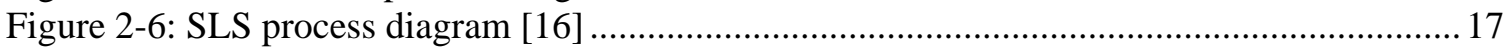

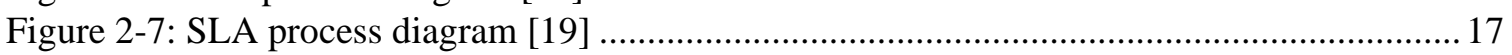

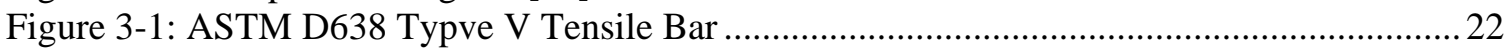

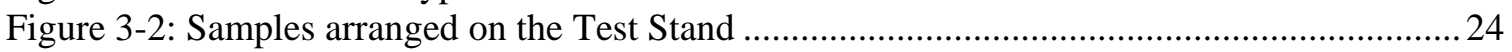

Figure 3-3: Temperature data recorded during the Prototherm bakeout......................................... 25

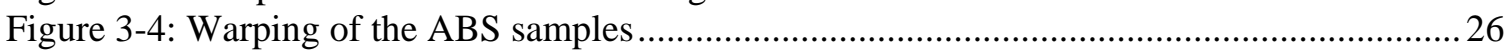

Figure 3-5: ASTM D638 Type V Tensile Bar dimensions [17] …......................................... 27

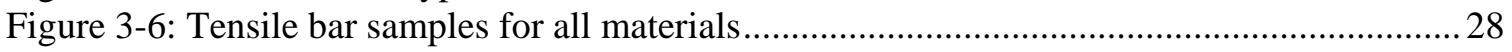

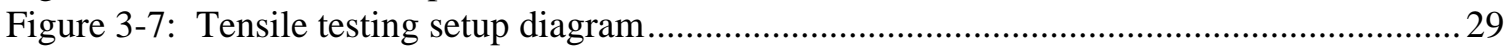

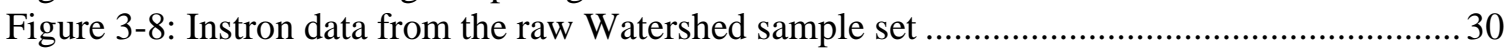

Figure 3-9: Yield Stress Calculation using the Third Derivative Method ...................................... 32

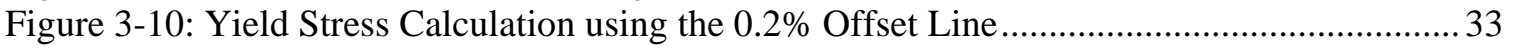

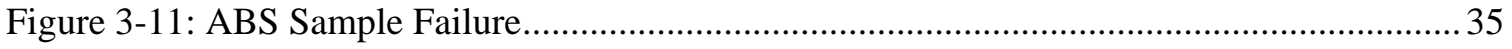

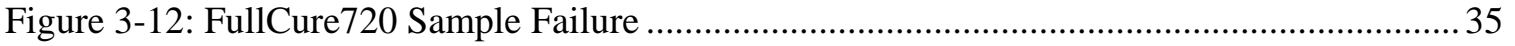

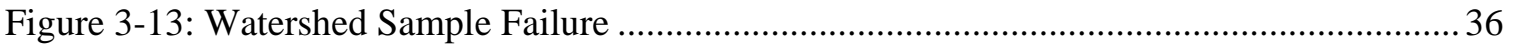

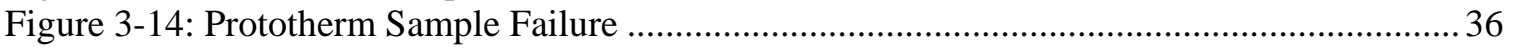

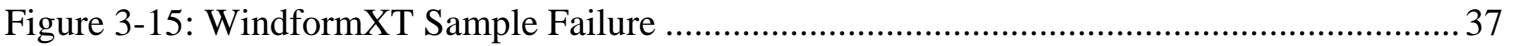

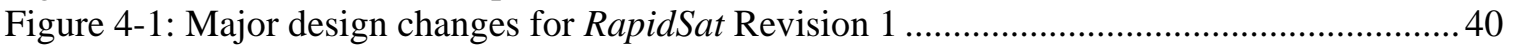

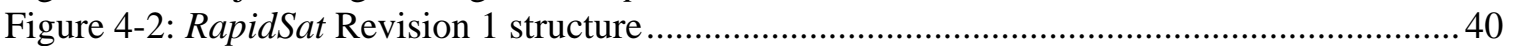

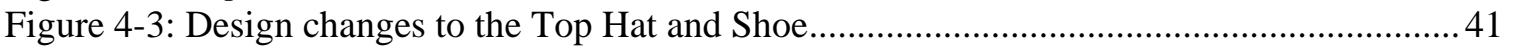

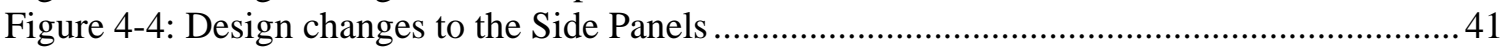

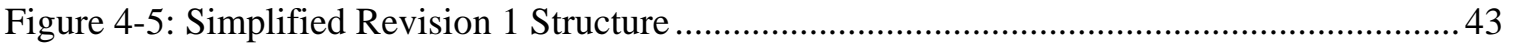

Figure 4-6: Comparison between unpartitioned, constant cross section partitioned, and even seeding partitioned sections showing element distortion caused by uneven seeding ................... 43

Figure 4-7: Comparison between Linear Elements and Quadratic Elements [6]............................ 44

Figure 4-8: Mesh of the Side Panel showing use of Hex and Wedge elements............................. 45

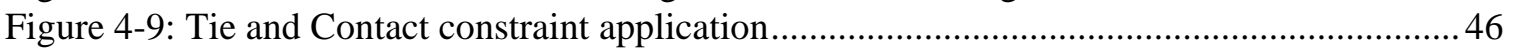

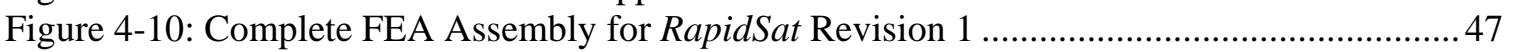

Figure 4-11: Boundary and Loading conditions for the Revision 1 structure................................ 48

Figure 4-12: Convergence Plots for all test points of the Revision 1 Structure.............................. 49

Figure 4-13: Converged mesh with test nodes used in convergence study ....................................51

viii 


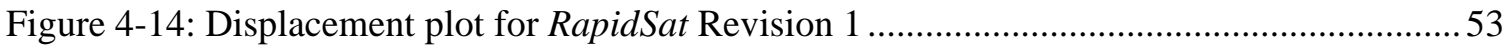

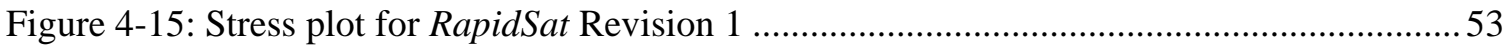

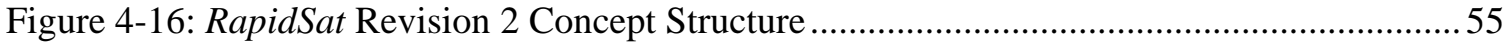

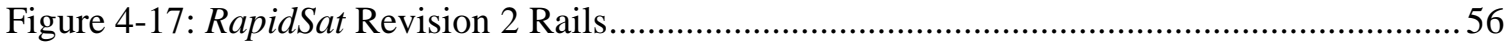

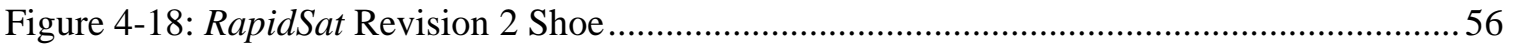

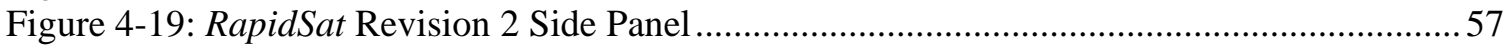

Figure 4-20: Simplified models of the Revision 2 Structure showing planes of symmetry ..........58

Figure 4-21: Boundary and Loading conditions for the Revision 2 FEA ....................................59

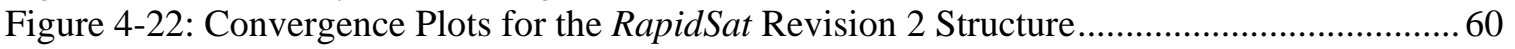

Figure 4-23: Converged mesh showing the test points used in the convergence study ..................62

Figure 4-24: Displacement plot of the X-axis loaded RapidSat Revision 2 structure ..................... 63

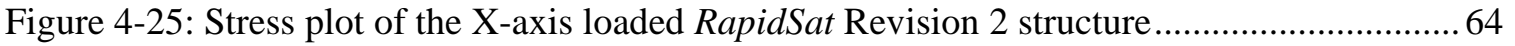

Figure 4-26: Displacement plot for the Z-axis loaded RapidSat Revision 2 structure ................... 65

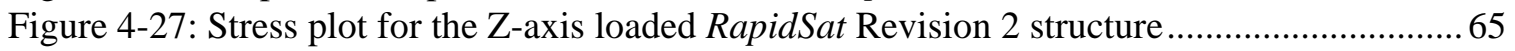

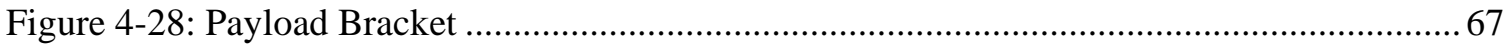

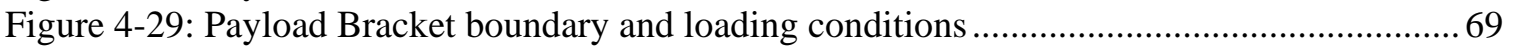

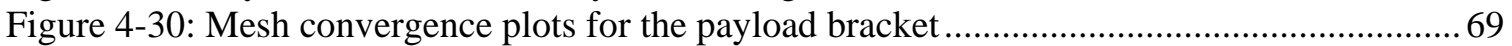

Figure 4-31: Displacment plot of the Payload Bracket.................................................................. 70

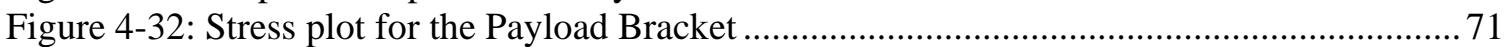

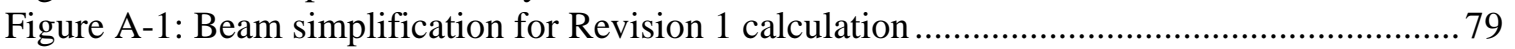

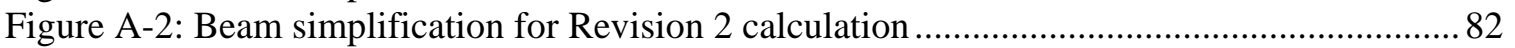

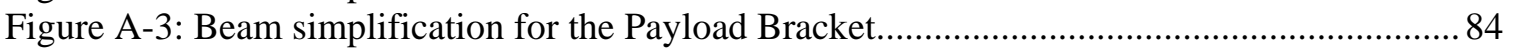

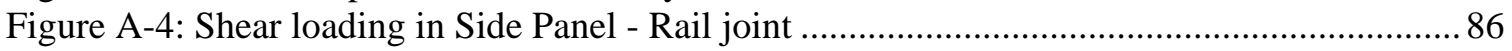

Figure B-1: Displacement plot for the Revision 1 structure ................................................ 90

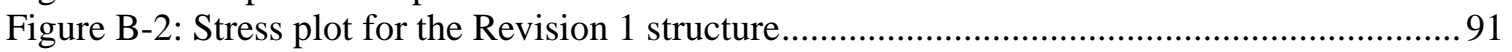

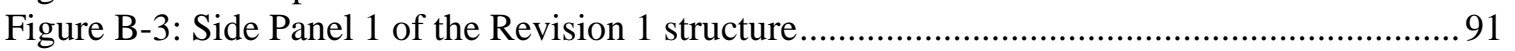

Figure B-4: Side Panel 3 of the Revision 1 structure (joint shear elements hidden) .................... 92

Figure B-5: Stress plot of the Revision 1 structure viewed from the $-\mathrm{X}$ side ............................... 92

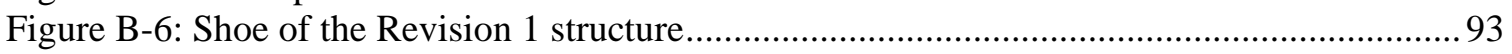

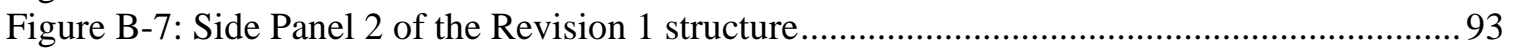

Figure B-8: Displacement plot of the X-loaded Revision 2 structure..........................................94

Figure B-9: Stress plot of the X-loaded Revision 2 structure .................................................. 94

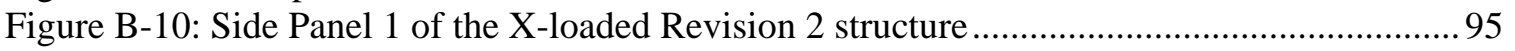

Figure B-11: Side Panel 3 of the X-loaded Revision 2 structure (joint shear elements hidden).... 95

Figure B-12: Highest stress point Side Panel 3 of the X-loaded Revision 2 structure (joint shear

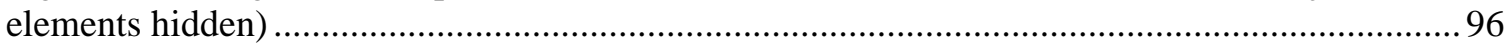

Figure B-13: Stress plot of the X-loaded Revision 2 structure viewed from the -X side .............96

Figure B-14: Side Panel 2 of the X-loaded Revision 2 structure (joint shear elements hidden).... 97

Figure B-15: Highest stress point on Side Panel 2 of the X-loaded Revision 2 structure (joint

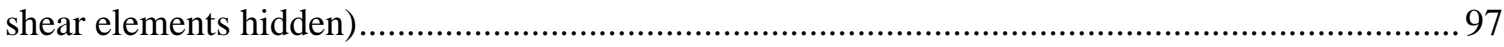

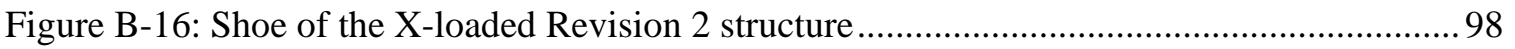

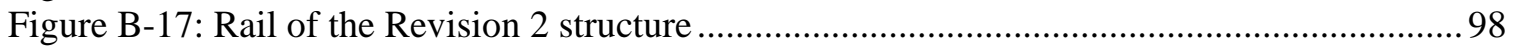

Figure B-18: Stress plot for the Z-loaded Revision 2 structure ................................................99

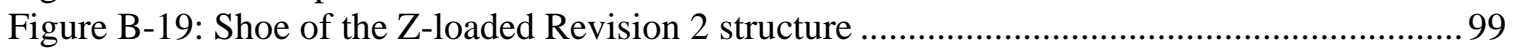

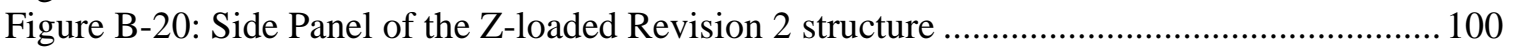

Figure B-21: Highest stress point on the Side Panel of the Z-loaded Revision 2 structure (joint

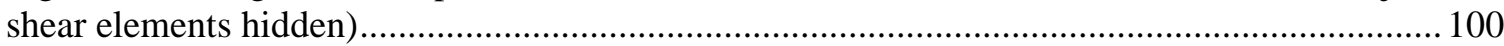

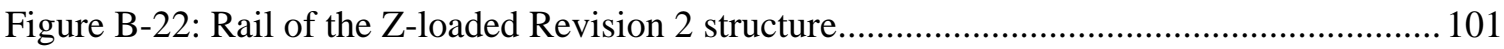

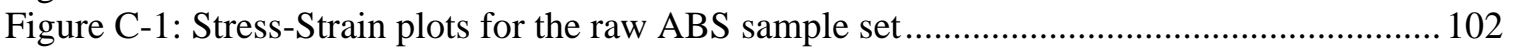

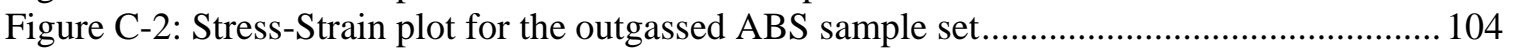

Figure C-3: Stress-Strain plots for the first half of the raw FullCure 720 sample set.................... 105

ix 
Figure C-4: Stress-Strain plots for the second half of the raw FullCure720 sample set.....

Figure C-5: Stress-Strain plots for the first half of the outgassed FullCure 720 sample set.....

Figure C-6: Stress-Strain plots for the second half of the outgassed FullCure720 sample set .... 109

Figure C-7: Stress-Strain plots for the raw Watershed sample set..

Figure C-8: Stress-Strain plots for the outgassed Watershed sample set................................... 113

Figure C-9: Stress-Strain plots for the raw Prototherm sample set.

Figure C-10: Stress-Strain plots for the outgassed Prototherm sample set ................................. 117

Figure C-11: Stress-Strain plots for the raw WindformXT sample set...................................... 119

Figure C-12: Stress-Strain plots for the outgassed WindformXT sample set ............................. 121 


\section{List of Tables}

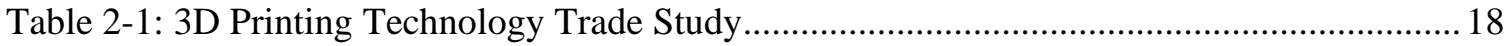

Table 2-2: Published Mechanical Data for the selected materials ............................................... 21

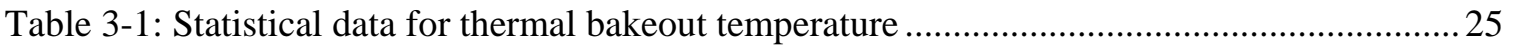

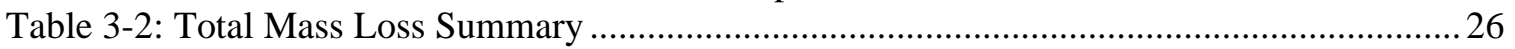

Table 3-3: ASTM D638 Tensile Bar dimenions and test parameters [17] .................................. 27

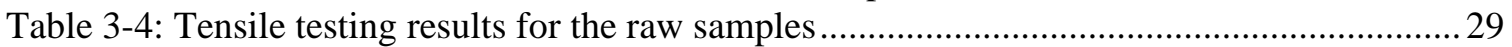

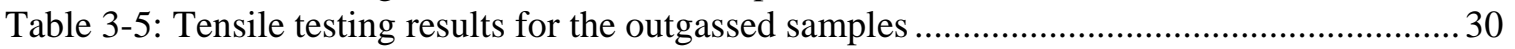

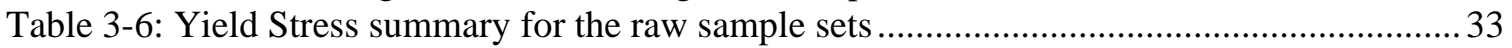

Table 3-7: Yield Stress summary for the outgassed sample sets ............................................... 34

Table 3-8: Percent change in material properties between the raw and outgassed sample sets..... 34

Table 3-9: Materials properties of post-bakeout samples used in the Design Iteration Phase........ 38

Table 4-1: Convergence Study results for the Revision 1 Structure .............................................50

Table 4-2: Details for the finalized mesh for the Revision 1 structure ......................................50

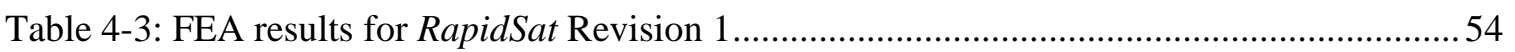

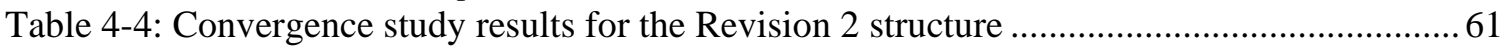

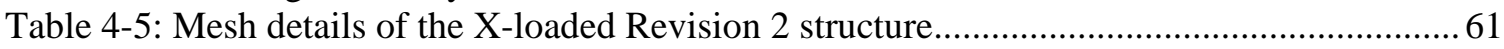

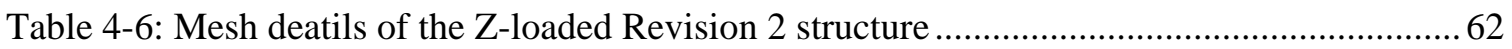

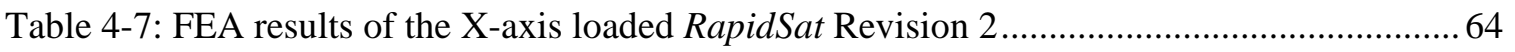

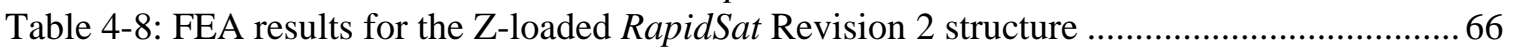

Table 4-9: Convergence study results for the Payload Bracket ....................................................69

Table 4-10: FEA result for the Payload Bracket showing Margin of Safety …............................ 71

Table 4-11: Cost Comparison of manufacturing methods ……...................................................... 72

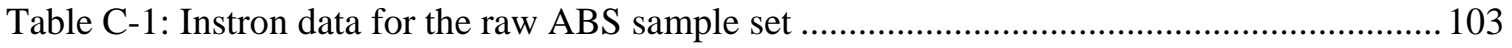

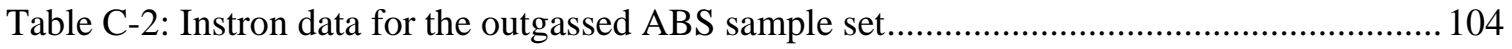

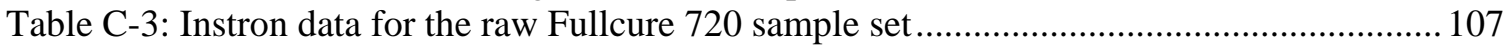

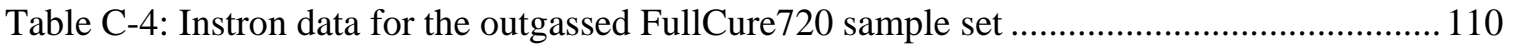

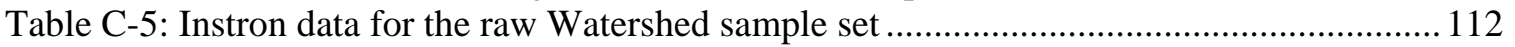

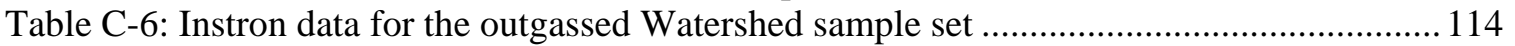

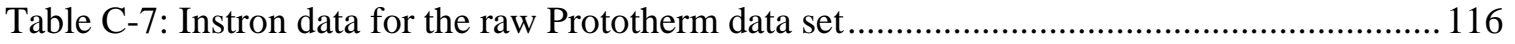

Table C-8: Instron data from the outgassed Prototherm sample set ......................................... 118

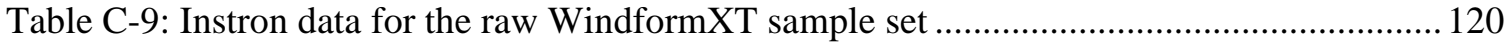

Table C-10: Instron data for the outgassed WindformXT sample set ....................................... 122 


\section{Introduction}

\subsection{The CubeSat Community and the P-POD}

The CubeSat Program started as a collaboration between California Polytechnic State University and Stanford University with the goal of providing inexpensive access to space for university students. The program accomplishes this by holding developers to standards that keep design costs low and by providing frequent launch opportunities for the CubeSats as secondary payloads. These standards, depicted in the CubeSat Design Specification (CDS) [5], define the satellite mass and volume, as well as other design requirements.

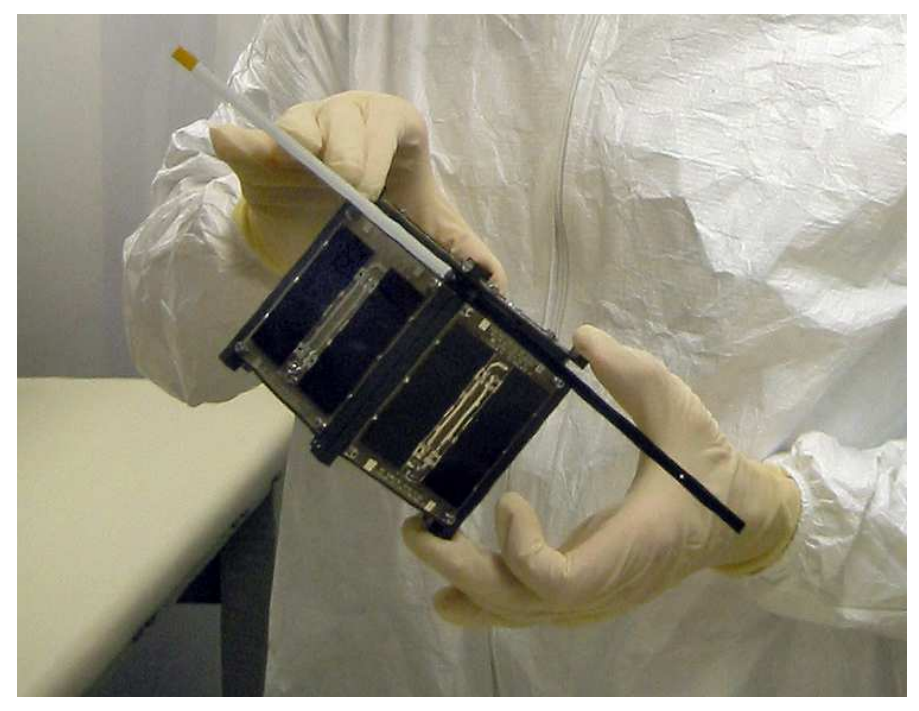

Figure 1-1: Example of a 1U CubeSat: Cal Poly's CP1

The total development cycle for a CubeSat is normally around two years. For university students, this short time period allows participants to experience every aspect of the life cycle of the satellite and gain crucial insight into the required disciplines and operations of the Aerospace industry before graduation. For government and private developers, the rapid development of 
CubeSats brings mission data to the ground in a much quicker time period and drastically reduces mission turnover when compared to commonly used larger satellites.

Since its creation, the CubeSat Community has grown to an international body of over 100 educational institutions, private companies, and government organizations from around the world. Through mission collaboration and technology sharing, 16 rockets have flown with CubeSat payloads, putting a total of 52 CubeSats in orbit.

The success of the community and the ability to launch CubeSats with virtually any launch provider relies on the use of the Poly Picosatellite Orbital Deployer (P-POD), a Cal Poly built CubeSat deployer. The P-POD houses up to three one unit (1U) CubeSats, and serves as their only interface to the launch vehicle. The P-POD's mission is to protect the primary payload and launch vehicle from any additional risks presented by the CubeSats. The CubeSats are securely held inside the P-POD during launch until the primary payload is safely away from the launch vehicle. Through design improvements and flight heritage, the P-POD has proven to be a safe and reliable deployment system for CubeSat payloads.
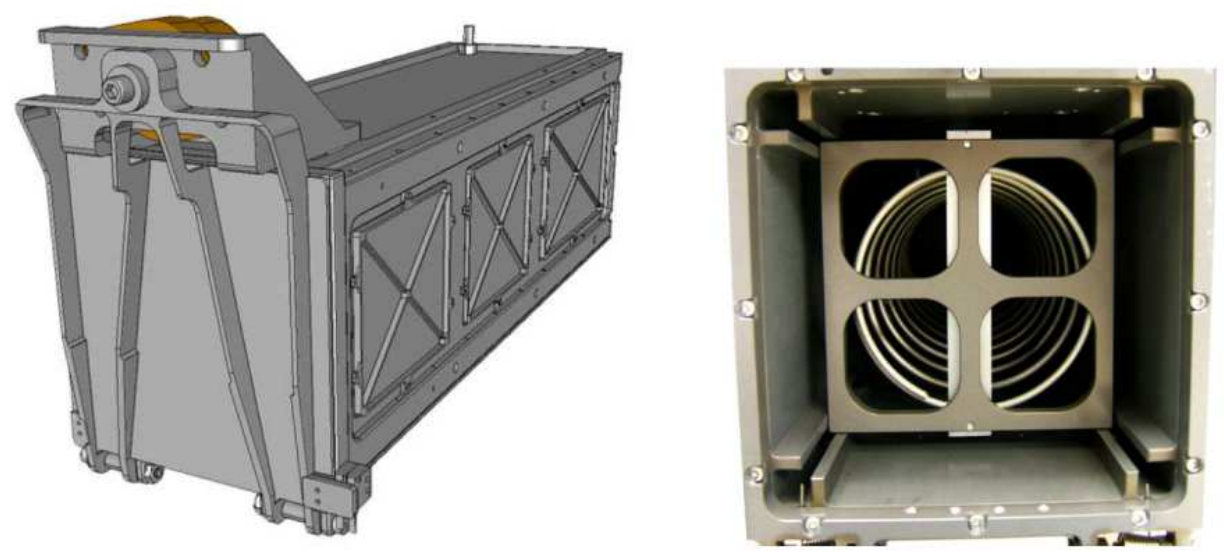

Figure 1-2: The P-POD Mk. III CubeSat Deployer 


\subsection{CubeSat Testing Requirements}

CubeSat developers must meet the design and testing requirements presented in the CDS in order to ensure the success of the P-POD and to mitigate risk to the launch vehicle, the primary payload, and other CubeSats. A flow diagram showing the tests that must be performed on the CubeSats before integration to the P-POD can be seen in Figure 1-3.

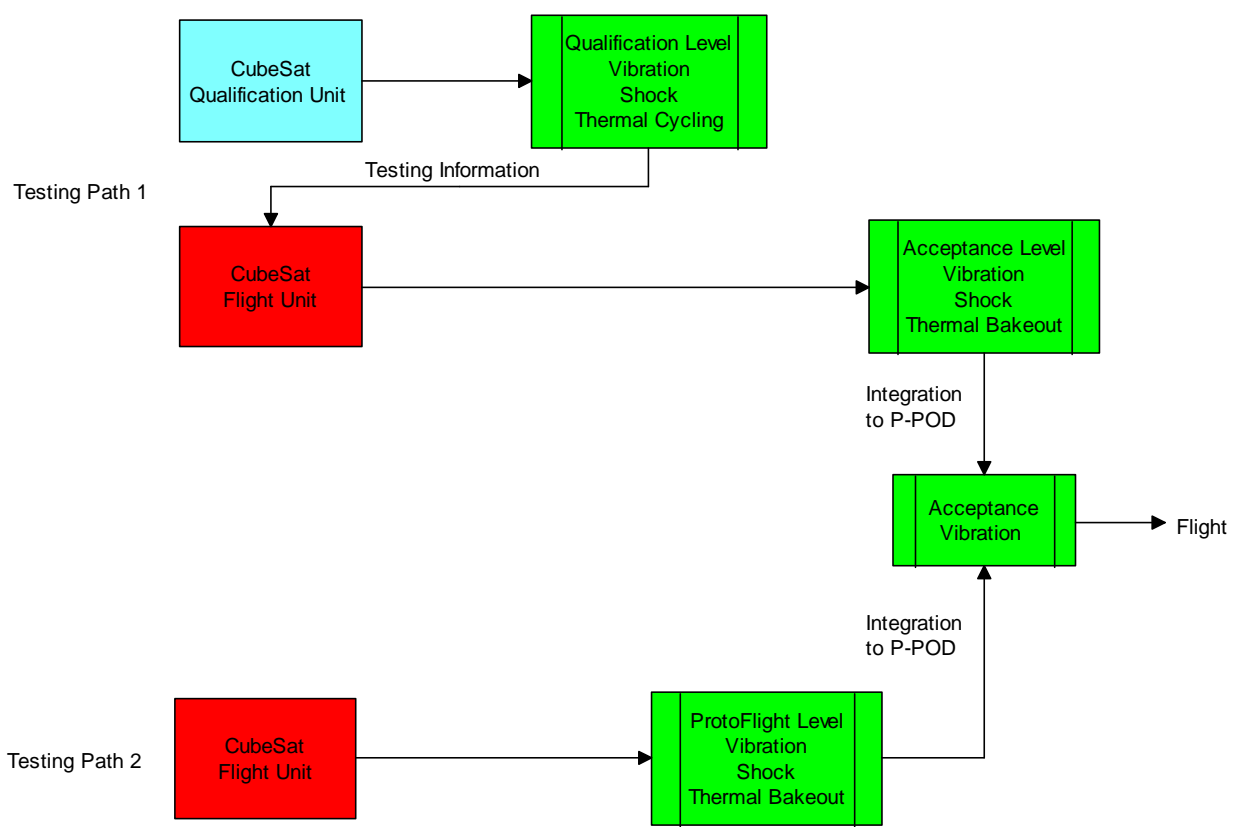

Figure 1-3: CubeSat Test Flow Procedures Necessary for Flight Integration

\subsubsection{Dynamic Loading}

All CubeSats must pass through a series of vibration and shock tests as shown above. Developers typically test vibration and shock loading with the use of a vibration slip table. Even though acoustic stimuli will be present during the launch, the loads are insignificant when compared to random vibration and shock and are generally ignored. The levels that developers are required use when performing these tests are typically supplied by the launch provider. In cases where a profile is not available, the NASA Goddard Environmental Verification Standard (GEVS) [5] is used. 


\subsubsection{Thermal Bakeout}

All CubeSats must pass through a thermal bakeout in a thermal vacuum chamber before integration to P-POD to ensure the proper outgassing of components. A CubeSat will be subjected to a hot soak at $70^{\circ} \mathrm{C}$ for a period of 3 hours, or $60^{\circ} \mathrm{C}$ for a period of 6 hours at a vacuum level of $10^{-5}$ torr during this thermal bakeout.

\subsection{Current Cal Poly CubeSat Design}

In late 2011, Cal Poly’s PolySat, in conjunction with Tyvak Nanosatellite Systems, finished development of a new $1 \mathrm{U}$ CubeSat design utilizing the Intrepid system board. This new bus design reduces the size of the avionics package to $10 \%$ of the total CubeSat volume [7], leaving the rest of the satellite's capacity free for payload use. This new design has already won Polysat several high profile contracts and will be used by Polysat and Tyvak for all future missions.

The structure of this bus, the HyperCube, was developed as a Senior Project for Cal Poly's Mechanical Engineering Department [7] and can be seen in Figure 1-4. It utilizes modular components to allow for easy production and assembly of the satellite. The structure consists of 3 parts: the Top Hat (1), the Shoe (1), and the Side Panels (4). All parts are constructed from Aluminum 6061 and fastened together with machine screws. 


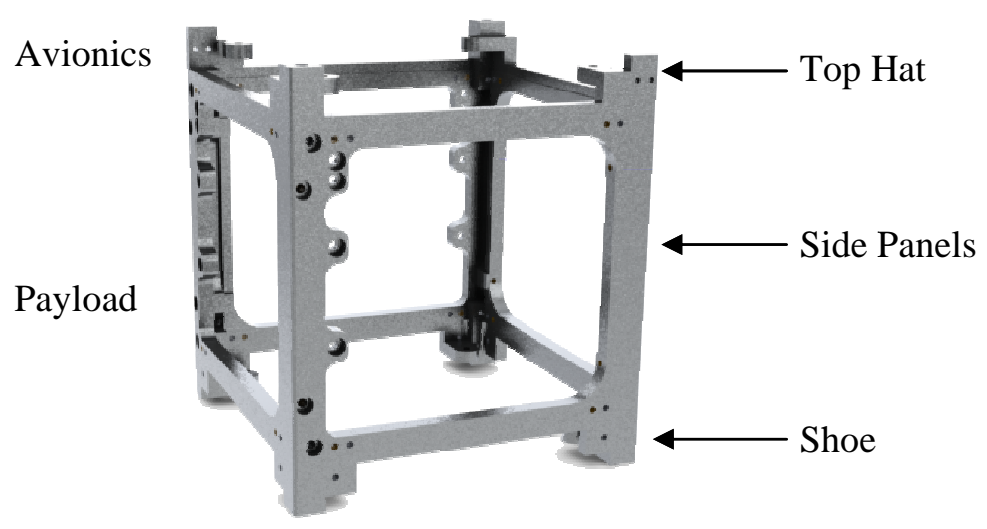

Figure 1-4: The HyperCube Structure of Cal Poly's Current System Bus

This design has several major improvements over Polysat's legacy bus hardware. The reduction in size of the avionics package allows for all the avionics hardware to be mounted to the Top Hat where it can be tested and integrated to the CubeSat separately from the payload hardware.

Further, the use of four identical Side Panels to build up the main body of the structure allows the machinist to fabricate a HyperCube with three CNC codes, lowering the total machining cost to $\$ 2000$ for a complete structure. This cost is typical for a CubeSat structure machined by a private machine shop.

\subsection{Conventional Machining Cost Reduction}

The structure and mechanical components of a CubeSat present one area in the satellite's development that could be improved to lower cost. These parts are typically machined out of 6061 or 7075 aluminum alloys by student or professional machinists. Due to the tight dimensional requirements presented in the CDS for the CubeSat to be able to interface into the PPOD, most of the machining work is generally performed with CNC mills. Many university and private sector CubeSat developers have direct access to CNC mills that can successfully machine CubeSat components. In these situations, all the machining for a CubeSat can be done for little or no cost. However, developers that do not have access to $\mathrm{CNC}$ mills are presented with the high 
price of having their parts manufactured at a third party machine shop. The high labor rates and overhead involved in third party machining can result in a production cost of thousands of dollars, even for geometrically simple components.

Conventional machining alternatives have been pursued to further lower the cost of manufacturing the HyperCube structure. First, attempts at creating a machining partnership with Cal Poly's Mustang 60 machine shop were made. Work was performed by student technicians at a rate of $\$ 15.00$ per hour with tooling and raw material provided by Polysat. This method reduced the total cost of machining components by cutting out the high labor rates of machine shops, but had several major flaws. Machining work done by the student technicians did not have a tolerance guarantee and many of the initial parts produced were unusable or had to be heavily modified by Polysat. This led to the conclusion that flight parts cannot be reliably produced by Mustang 60 .

Research into purchasing a CNC mill was also performed to determine the cost effectiveness of machining components in the Polysat lab. Table top CNC mills costing roughly $\$ 10,000$ were determined to be the only machines that would be usable in the current facilities available to Polysat. While these machines would be able to pay for themselves within the first six production runs of CubeSat parts, it was found that the torque output of the milling motors was insufficient. In order for these mills to machine an Aluminum 6061 CubeSat structure, the depth of cut for each pass would need to be very small. At this rate, a production run of a CubeSat would take weeks to machine and a qualified member of Polysat would be required to attend to the mill at all times and change out machining tools as necessary. As a result, it was determined that this process would not be sufficient to meet the rapid production requirements of future PolySat missions. 


\subsection{D Printing Use in Industry}

Recent developments in 3D printing processes have led to its use in several technological industries. These manufacturing methods are now being used to create parts for production fabrication in addition to their traditional use of printing prototype hardware.

3D printing has seen its widest use in the automotive industry. Jaguar and Landrover use the technology to create test models of various components that see use in many of their production vehicles, such as the air vent seen in Figure 1-5. These parts are used to characterize areas such as user interfaces, fatigue failure, and styling. Designers also see 3D printing as a way to create personalized cars in the near future [8]. This would be very expensive to achieve with conventional manufacturing. However, since 3D printing technology is not limited by tooling or low volume manufacturing cost increases, a personalized vehicle could be produced for a reasonable cost.

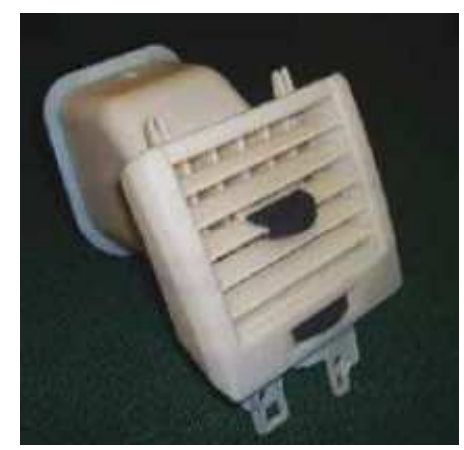

Figure 1-5: Printed air vent prototype [15]

Aerospace manufacturers General Electric (GE) and the European Aeronautic Defense and Space Company (EADS) have adopted 3D printing technology to manufacture airplane components that have significant weight savings. According to EADS, these weight savings could significantly reduce the operational cost of airplanes, since one kilogram of reduced weight can result in $\$ 3000$ 
per year in fuel savings [3]. Figure 1-6 shows a comparison between a door hinge created using conventional and 3D printing manufacturing methods.

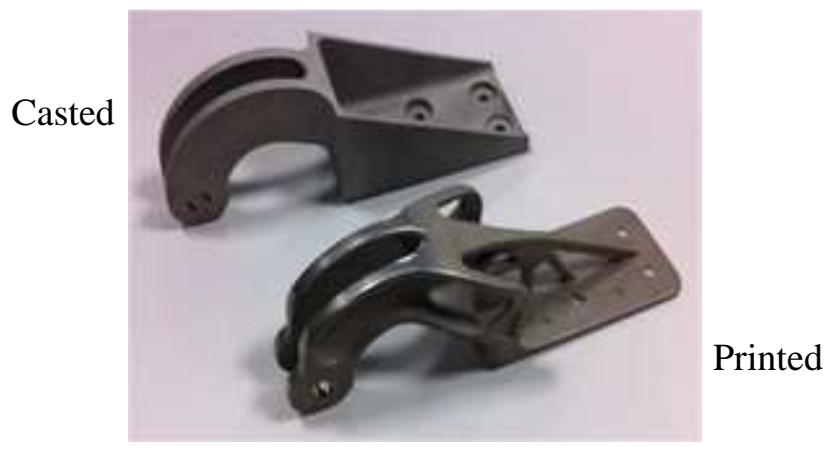

Figure 1-6: Comparison of a casted door hinge and 3D printed door hinge [13]

The biomedical industry has also benefited greatly from 3D printing. The technology's ability to create parts with complex contours and forms of curvature have revolutionized the production of medical implants [20]. Instead of using a "one size fits all" production mentality, implant components can be personalized for a patient for no additional cost. Further, the technology has been adapted by the medical industry to print fully functional organs derived from existing biological tissue [18]. Scientists see this revolutionary step in technology as a future replacement for organ donors and say that the technology is only a few years away.

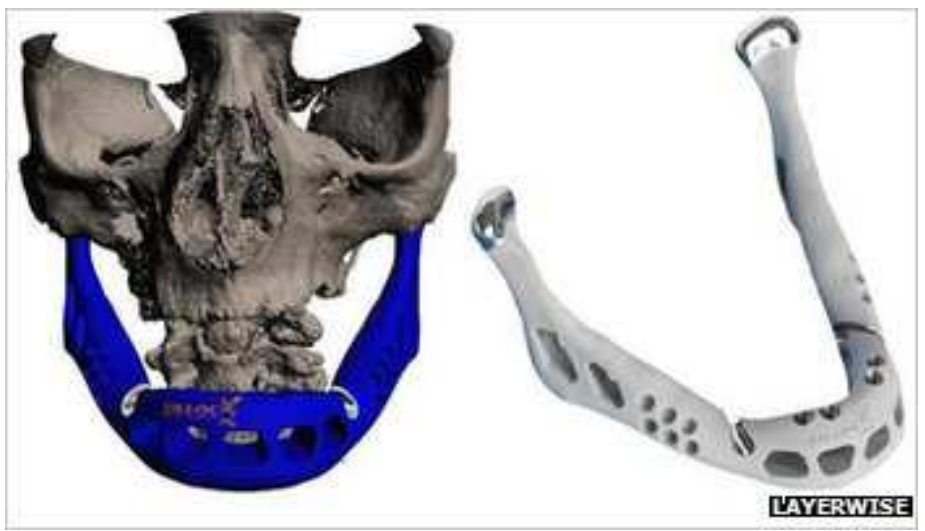

Figure 1-7: Jawbone implant fabricated with 3D Printing [1] 


\subsection{Purpose of Thesis}

Throughout the history of the CubeSat program, satellite development has been dominated by well funded universities and research institutions partnered with private companies. While these developers are on the forefront of the dramatic increase in the scientific capability of the CubeSat platform, they have overshadowed many developers who are still in the process of designing their first satellite. These institutions are building CubeSats with budgets that are orders of magnitude less than those of the more prominent missions. NASA's Educational Launch of Nano-Satellites initiative has provided free launch and integration services for selected CubeSats, which accounts for the largest cost in developing a CubeSat. However, hardware costs alone are still outside the budgetary constraints of many institutions and any savings gets them one step closer to launching their satellite. In order to expand the entrepreneurial and educational approach of the CubeSat program, including opening new doors for STEM education in university and non-university settings, further cost reducing measures must be taken to meet the needs of the next generation of low budget CubeSat developers.

The failure of conventional machining methods to provide a low cost production solution for institutions that do not have direct access to machining facilities has led to the need for research into non-conventional manufacturing techniques for use in CubeSat development to be performed. Three dimensional printing presents such a technology that has potential cost advantages over machining. This manufacturing method has been used successfully in a wide variety of industries, and the CubeSat community would serve as an ideal setting for its use in space. While few institutions have direct access to modern 3D printers, the cost of having parts printed by third party manufacturers is much lower than having parts machined. Typically, 3D printers are solely used to produce prototypes of hardware that will eventually be machined. However, recent developments in printing technology have led to the ability to produce functional parts using a variety of methods and materials. It is the goal of this thesis to study and characterize these 
different technologies to find acceptable 3D printing processes and materials for use in flight missions in order to lower the hardware cost of a CubeSat to $\$ 5000$.

\subsection{Candidate Verification Method}

Materials used in 3D printing have several disadvantages when compared to aluminum that need to be addressed before the technology can be used in CubeSat production. First, the majority of the materials used in 3D printing are polymers that have much weaker mechanical properties than aluminum. Further, these properties will change during thermal bakeout, causing the materials to perform differently in any subsequent structural testing. In order to determine the feasibility of using rapid prototype materials in CubeSat structures, it must be shown that the materials can withstand the testing requirements described in Section 1.2 and do not pose any additional risk to the success of the P-POD. A verification method consisting of Research, Testing, and Design Iteration phases was used to determine if the materials met these requirements.

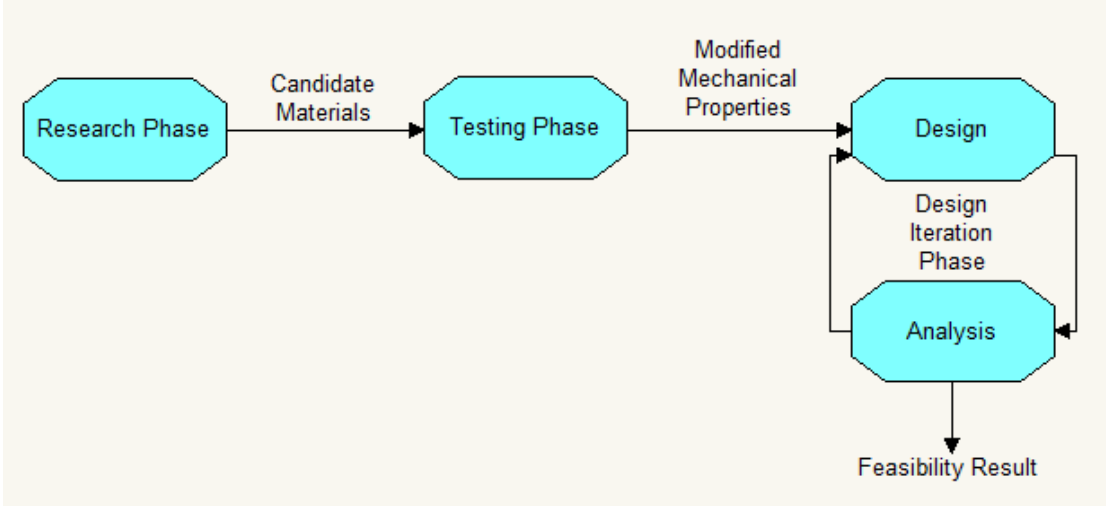

Figure 1-8: Verification Method Diagram

In the Research Phase, 3D printing technologies and materials were examined and candidate materials were chosen for use in the feasibility study. In the Testing Phase, the samples of the candidate materials were subjected to a combination of pre-bakeout and post-bakeout tensile tests to gain insight to the mechanical property changes caused by the outgassing and thermal 
treatment. The properties of the post-bakeout samples were used in the Design Iteration Phase to create a new CubeSat concept structure and sample components that were optimized for production with 3D printing. Finite Element Analysis (FEA) and hand calculations were then utilized to test the integrity of these designs when subjected to an expected worst case load condition defined in Section 4.2.5. Results from the FEA were used to iterate through the designs until the feasibility result for using 3D printed parts on CubeSats was reached. 


\section{Research Phase}

Research into different types of 3D printing technologies and materials was performed to find initial candidates worthy of further study. Chapter 2 describes and compares these technologies and materials, resulting in 5 selections for use in this thesis.

\subsection{3-D Printing Technologies}

There are 7 general types of 3D printing technologies that are currently used in various areas of industry. Aspects of these technologies were included in a trade study to determine which processes would have a high probability of providing an acceptable product for use in CubeSat development.

\subsubsection{Electron Beam Melting (EBM)}

Electron beam melting produces metal parts that are equal in strength to parts manufactured with conventional machining. This process successively melts pure powder layers of metal alloys in the shape of the part's cross section using a high powered electron beam inside a vacuum chamber. When a layer is complete, a powder dispenser deposits a fresh layer of metal on the existing part. The vacuum is able to draw out any voids in the material caused from reaction gasses, leaving full density parts that are extremely strong. For this reason, EBM is most commonly used as a manufacturing method to create production parts rather than prototypes. However, it is the most costly of the methods researched due to the complexity of the process. 


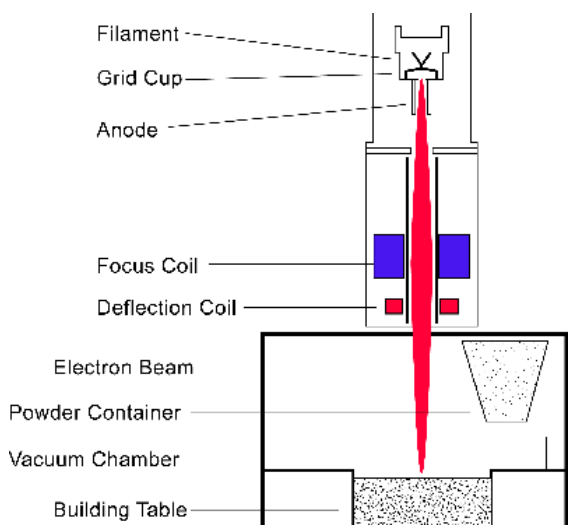

Figure 2-1: Electron Beam Melting process diagram [11]

\subsubsection{Fused Deposition Modeling (FDM)}

Fused Deposition Modeling uses thermoplastics and water-soluble support material to build up a part from a solid model. Initially, a tool path is created for each cross-sectional layer that the machine's printing head will follow. During printing, both the plastic and support material are heated to a molten state and extruded through the printing head in a continuous bead along the tool path. The material hardens immediately after exiting the printing head and fuses to the existing layers. When one layer of the model is completed, the print bed lowers and the next layer is deposited. The support material is removed when the part is completed with a long soak in hot soapy water.

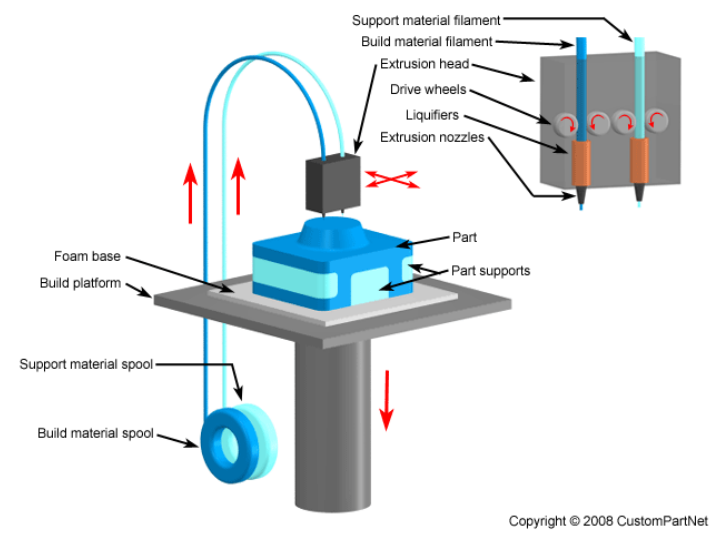

Figure 2-2: Fused Deposition Modeling process diagram [9] 
Since FDM uses less expensive engineering plastics such as ABS and Polycarbonate, it presents a low cost option for producing CubeSat parts. Cal Poly also has several Stratasys FDM prototyping machines on campus in the Mechanical Engineering and Biomedical Engineering Departments that are available for Polysat to use. In addition to allowing students to work directly with the machines, Polysat would only be charged for the material used and a $\$ 25.00$ flat fee for each print job.

\subsubsection{Laminated Object Manufacturing (LOM)}

Laminated Object Manufacturing involves using layers of adhesive coated paper, plastic, or metal sheets to build up the shape of a part. The adhesive material is initially adhered to the print bed or existing layers using a heated roller. Then, a laser or knife is used to cut out the shape of the cross section of the layer and the unused material is removed. When a layer is complete, the print surface is lowered by the layer height and a new sheet of material is placed on top of the part for the next layer.

LOM is a relatively low cost process due to the types of raw materials consumed. However, it does not have the dimensional accuracy of other processes, which limits its uses in many industries. As a result, LOM is no longer widely used and there are very few providers in the US.

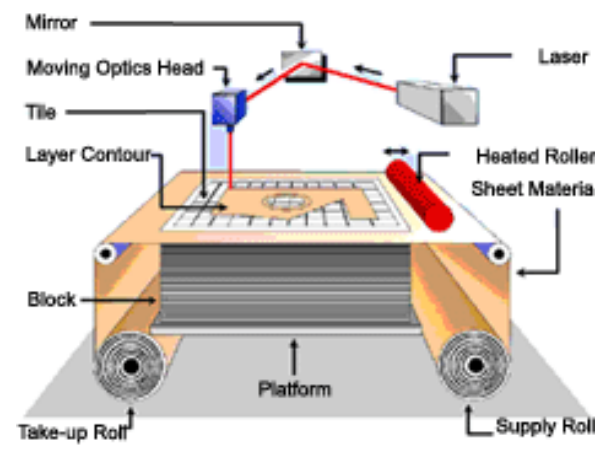

Figure 2-3: Laminated Object Manufacturing process diagram [12] 


\subsubsection{Polyjet Printing}

Polyjet printing is a relatively new technology patented by Objet that is very similar to a conventional inkjet printing. Polyjet 3D printers build up parts by spraying photopolymer model and support resins onto a print bed in cross sectional layers. Both resins are cured by a high intensity UV lamp that immediately follows the jetting heads. After each pass of the jetting heads, the print bed lowers for the next pass to be sprayed on top of the existing layers. When the job is complete, the wax-like support material is removed either by hand, or with a water jet.

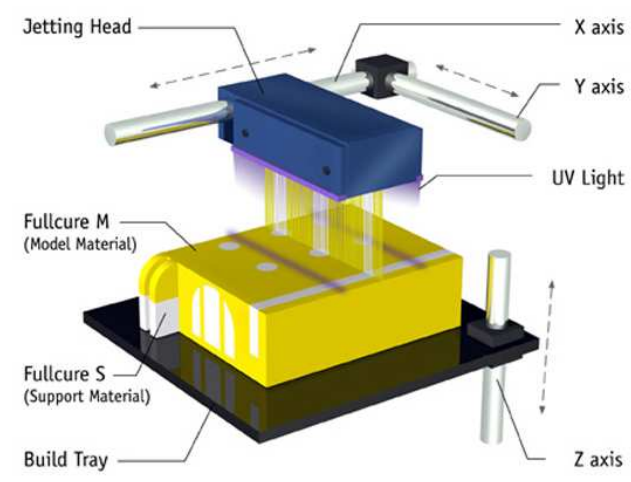

Figure 2-4: Polyjet process diagram [22]

Cal Poly's Mechanical Engineering department owns an Objet Eden 250 rapid prototyping system. This machine is able to print parts with a variety of materials in 16 micron layers with .1mm lateral tolerances. As with Cal Poly's FDM machines, Polysat would only be charged for the material cost and a $\$ 25.00$ flat fee for each print job with this system.

\subsubsection{Powder Bed and Inkjet Head Printing}

This process builds up the cross-sectional layers of a part using an inkjet head that dispenses a binding agent onto a bed of plaster powder. When layers are completed, a dispenser lays a fresh coat powder onto the surface of the part and the process is repeated. Areas of powder that are not 
coated with the binding agent are removed with the use of compressed air. The low cost of the raw materials used in this process is reflected in the total manufacturing cost of a part.

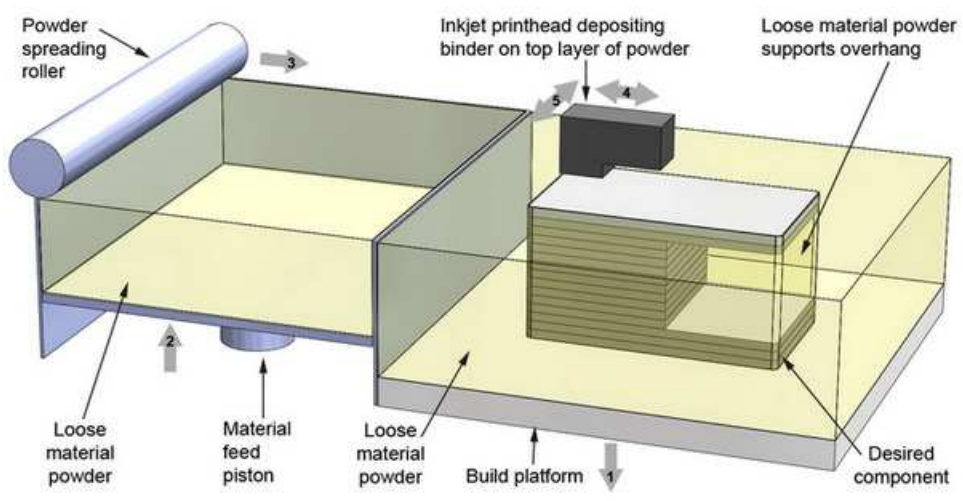

Figure 2-5: Powder Bed process diagram [21]

\subsubsection{Selective Laser Sintering (SLS)}

The Selective Laser Sintering process is often regarded as the future of low volume manufacturing. It uses a high powered laser to fuse particles of plastic, metal, ceramic, or glass powders along a cross sectional tool path created on a print bed. When one layer of the model is finished, the print bed is lowered by the layer height and additional powder is applied on the top of the existing layers. The process is then repeated until the model is completed. Depending on the power of the laser used to fuse the materials, mechanical properties of the finished part can be comparable to those of a part created with conventional machining methods. This technology also allows for the use of mixed material powders that form composites when fused by the laser. 


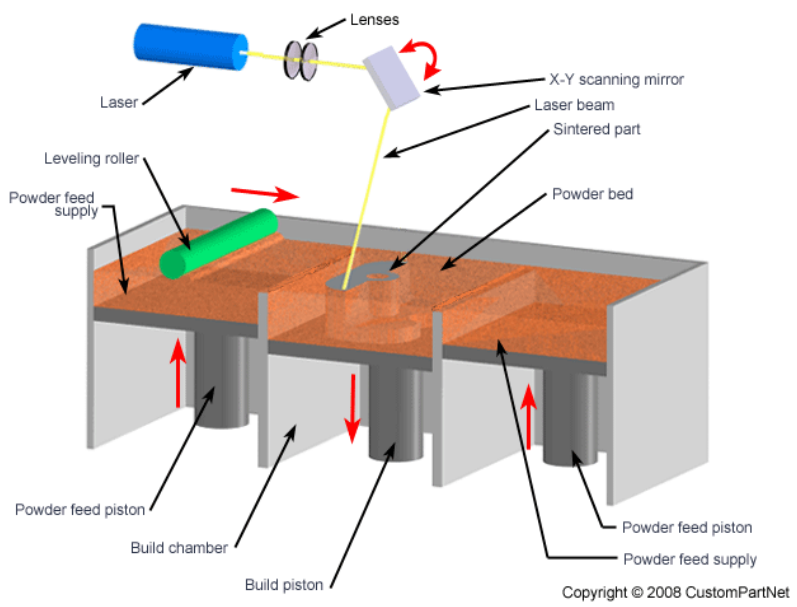

Figure 2-6: SLS process diagram [16]

\subsubsection{Stereolithography (SLA)}

Stereolithography is the oldest and most widely used method for rapid prototyping. SLA prints solid objects by successively solidifying thin layers photopolymer resins. Before printing, a tool path that is followed by an ultraviolet laser is created for each cross-sectional layer of the part. These tool paths are then projected onto a print bed that resides in a vat of the photopolymer resin. During printing, the laser follows the tool path and cures the cross sectional layers of the parts. When one layer is completed, the print bed lowers further into the vat, and the top surface of the model is covered with a new coating of liquid resin to be cured.

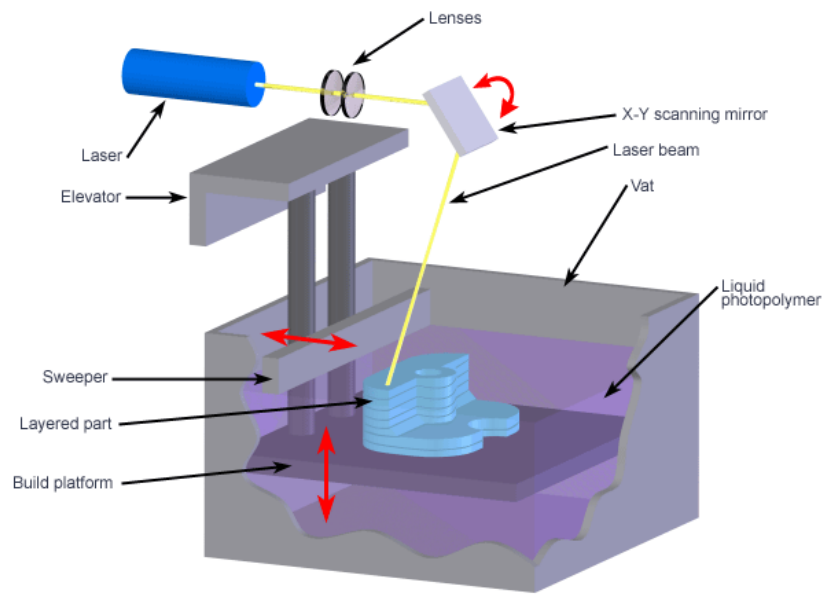

Copyright $\odot 2008$ CustomPartNet

Figure 2-7: SLA process diagram [19] 
Outgassing data for several SLA materials has been obtained by NASA Goddard. While this data does provide useful information into the expected mass loss of SLA resins, it does not include the post-outgassing mechanical properties.

Table 2-1 summarizes the research into the different 3D printing processes. Expected outgassing information was taken from researching similar materials on outgassing.nasa.gov. Cost information was derived from quotes of a simple CubeSat structure. Parameters that disqualified processes from further study are highlighted in red. This trade study showed that FDM, SLA, Polyjet, and SLS technologies were all eligible for further study.

Table 2-1: 3D Printing Technology Trade Study

\begin{tabular}{|c|c|c|c|c|c|c|c|}
\hline Parameter & EBM & FDM & LOM & SLA & Polyjet & $\begin{array}{l}\text { Powder } \\
\text { Inkjet }\end{array}$ & SLS \\
\hline Material & Metals & Plastic & $\begin{array}{l}\text { Paper, } \\
\text { Foils, } \\
\text { Plastics }\end{array}$ & Resin & Resin & Plaster & $\begin{array}{c}\text { Plastic, } \\
\text { metal, } \\
\text { ceramic, } \\
\text { composite }\end{array}$ \\
\hline $\begin{array}{l}\text { Published } \\
\text { Strength }\end{array}$ & Very High & Low & Very Low & Medium & Medium & Low & High \\
\hline $\begin{array}{l}\text { Expected } \\
\text { Outgassing } \\
\text { (\% Total } \\
\text { Mass Loss) }\end{array}$ & $0 \%$ & $0 \%-5 \%$ & $>5 \%$ & $0 \%-5 \%$ & $0 \%-5 \%$ & $>5 \%$ & $0 \%-5 \%$ \\
\hline $\begin{array}{c}\text { At Cal } \\
\text { Poly }\end{array}$ & No & Yes & No & No & Yes & No & No \\
\hline $\begin{array}{c}\text { Rough } \\
\text { Third Party } \\
\text { Cost }\end{array}$ & $\$ 2000+$ & $\$ 100-\$ 500$ & $\$ 100-\$ 500$ & $\begin{array}{l}\$ 500- \\
\$ 1000\end{array}$ & $\begin{array}{l}\$ 500- \\
\$ 1000\end{array}$ & $\begin{array}{l}\$ 500- \\
\$ 1000\end{array}$ & $\begin{array}{l}\$ 1000- \\
\$ 1500\end{array}$ \\
\hline $\begin{array}{l}\text { Est. Lead } \\
\text { Time }\end{array}$ & Weeks & Days & Weeks & Days & Days & Days & Weeks \\
\hline
\end{tabular}

\subsection{Researched Materials}

Candidate materials of each rapid prototype process were chosen for further study based on their published mechanical properties and availability. Table 2-2 contains a summary of the mechanical properties of these materials. 


\subsubsection{ABS Plastic/Cal Poly’s Stratasys Dimension 2000 Fused Deposition Modeler}

ABS has a long history of being used in engineering applications. It has an excellent balance of rigidity and toughness that makes it useful in creating functional parts. The Mechanical Engineering department has provided access to their Stratasys FDM machine, making the plastic the least expensive material studied in this thesis.

\subsubsection{Objet FullCure720 Resin/Cal Poly's Objet Eden 250 Polyjet Prototyper}

FullCure720 is Objet's most popular modeling resin due to its excellent strength properties and low cost. The material has the ability to withstand substantial abuse, making it a good candidate for use in functional parts. The Mechanical Engineering department has also provided access to their Eden 250 printer, making this the least expensive resin material studied.

\subsubsection{Prototherm 12120 Modeling Resin/Stereolithography from Harvest Technologies}

Prototherm is a resin produced by DSM Somos that has high strength and thermal resistant properties. This material presents the highest base strength properties out of the pure plastics what were chosen for this study. Prototherm is one of the few rapid prototyping plastics that has existing outgassing information available. The outgassing properties of this plastic have been tested by NASA Goddard, exhibiting Total Mass Loss (TML) of $0.92 \%$ and Collectable Volatile Condensable Material (CVCM) of $0.1 \%$. This material is far less common than other SLA plastics, making it one of the more expensive materials chosen for further study. 


\subsubsection{Watershed 11122 XC Modeling Resin/Stereolithography from ProtoCam}

Watershed is a photopolymer resin manufactured by DSM Somos that exhibits ABS-like mechanical properties when cured. It is widely used in SLA 3D printers and can be purchased from a large number of vendors. According to testing performed at NASA Goddard, this material exhibits $3.25 \%$ TML and $0.01 \%$ CVCM. This material is the least expensive plastic that Cal Poly does not have the ability to produce on campus.

\subsubsection{Windform XT / SLS from CRP Technologies}

Windform XT is a carbon filled nylon composite that exhibits very high strength and toughness. This material is currently being used by Planetary Systems Corporation for their PrintSat CubeSat. While this material presents a likely candidate for acceptable strength properties, it is more expensive than any of the other materials studied.

The published mechanical properties for the selected materials can be seen below. Datasheets for the materials can be found in Appendix D. 
Table 2-2: Published Mechanical Data for the selected materials

\begin{tabular}{|c|c|c|c|c|c|}
\hline \multirow{4}{*}{$\begin{array}{c}\text { Mechanical } \\
\text { Property }\end{array}$} & \multicolumn{2}{|c|}{ Cal Poly ME Department } & \multicolumn{3}{|c|}{ Outside Sources } \\
\hline & Polyjet & FDM & \multicolumn{2}{|c|}{ SLA } & SLS \\
\hline & Eden 250 & $\begin{array}{c}\text { Dimension } \\
2000\end{array}$ & ProtoCam & $\begin{array}{c}\text { Harvest } \\
\text { Technologies }\end{array}$ & $\begin{array}{c}\text { CRP } \\
\text { Technology }\end{array}$ \\
\hline & FullCure720 & ABS & $\begin{array}{l}\text { Watershed } \\
11122 \mathrm{XC}\end{array}$ & $\begin{array}{c}\text { ProtoTherm } \\
12120\end{array}$ & Windform XT \\
\hline $\begin{array}{l}\text { Tensile Strength } \\
\text { (MPa) }\end{array}$ & $50-65$ & 34.5 & $47.1-53.6$ & 77.2 & 77.85 \\
\hline Modulus (MPa) & $2000-3000$ & 2482 & $2650-2880$ & 3247 & 7320 \\
\hline $\begin{array}{c}\text { Tensile } \\
\text { Elongation }(\%)\end{array}$ & $15-25$ & 50 & $3.3-3.5$ & 4.5 & 2.6 \\
\hline $\begin{array}{c}\text { Felxural Strength } \\
(\mathrm{MPa})\end{array}$ & $80-110$ & 65.5 & $63.1-74.2$ & 103 & 131.52 \\
\hline $\begin{array}{c}\text { Flexural Modulus } \\
(\mathrm{MPa})\end{array}$ & $2700-3300$ & 2620 & $2040-2370$ & 3061 & 6248.5 \\
\hline IZOD $(\mathrm{J} / \mathrm{m})$ & $20-30$ & - & $0.2-0.3$ & 0.016 & - \\
\hline $\begin{array}{c}\text { Heat Deflection } \\
\left({ }^{\circ} \mathrm{C}\right)\end{array}$ & $45-50(.45 \mathrm{MPa})$ & - & $\begin{array}{l}45.9-54.5 \\
(.46 \mathrm{MPa})\end{array}$ & $\begin{array}{c}126.2 \\
(.46 \mathrm{MPa})\end{array}$ & $\begin{array}{c}175.4 \\
(1.82 \mathrm{MPa})\end{array}$ \\
\hline $\begin{array}{c}\text { Water Absorption } \\
(\%)\end{array}$ & $15-22$ & - & 0.35 & 0.24 & - \\
\hline $\operatorname{Tg}\left({ }^{\circ} \mathrm{C}\right)$ & $48-50$ & 104 & $39-46$ & 111 & - \\
\hline $\begin{array}{c}\text { Shore Hardness } \\
\text { (D) }\end{array}$ & $83-86$ & R105 & - & 86.7 & - \\
\hline $\begin{array}{c}\text { Rockwell } \\
\text { Hardness (M) }\end{array}$ & $73-76$ & - & - & - & - \\
\hline $\begin{array}{c}\text { Polymerized } \\
\text { Density }(\mathrm{g} / \mathrm{cm} 3)\end{array}$ & $1.18-1.19$ & 1.04 & 1.12 & 1.15 & 1.101 \\
\hline
\end{tabular}




\section{Testing Phase}

ASTM D638 Type V tensile bar samples of the materials selected in the Research Phase were printed in a flat orientation in batches of 40 for use in mechanical property testing. The samples were divided into three sets: one for testing of the raw material, another for testing of the material after a thermal bakeout, and a third for demonstration purposes. These samples were tested to gain raw and outgassed values of their elastic modulus and yield stress. The Poisson ratio was not published for any of the materials and it was not possible to measure this parameter with the testing method used for this study. Research was performed into the Poisson ratio of similar plastics, resulting in the decision to apply a constant value of 0.35 for this property to both the raw and outgassed sample sets for all of the materials.

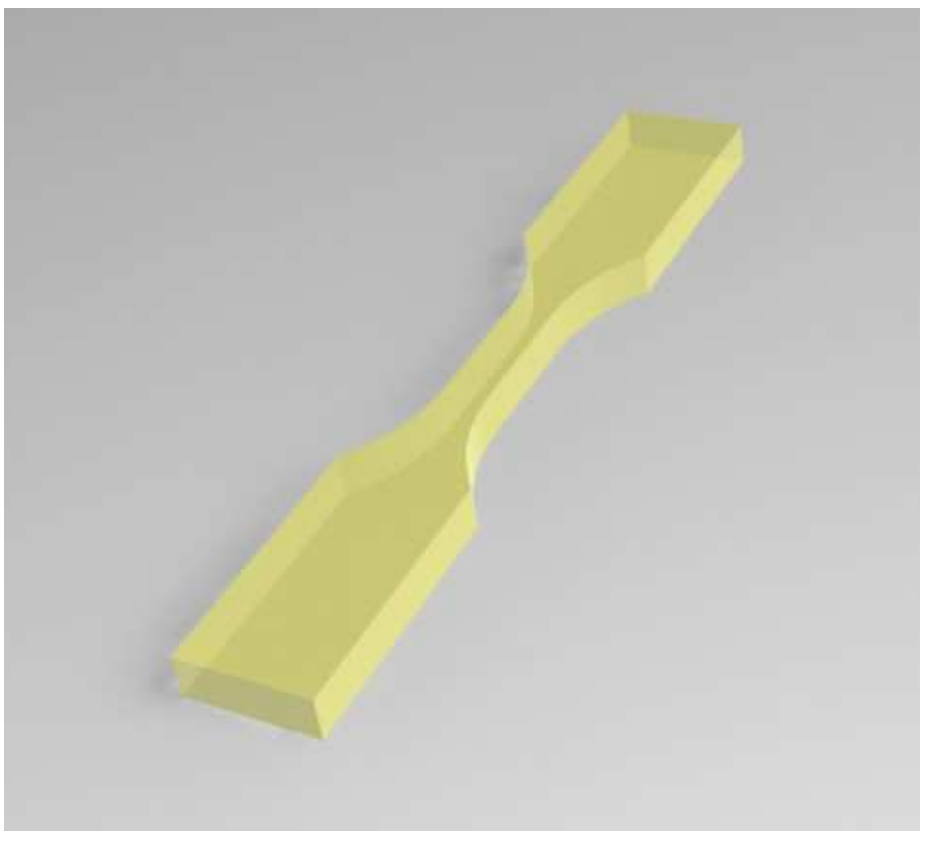

Figure 3-1: ASTM D638 Typve V Tensile Bar 


\subsection{Thermal Bakeout}

Samples of each material were subjected to a thermal bakeout in accordance with the CDS using the Cal Poly Aerospace Department's Space Environments Lab Hi-Tech Vacuum Chamber. The chamber used a Welch Duo Seal 1374 roughing pump and cryogenic cooling to lower the pressure inside the chamber to $10^{-5}$ torr. An electrical resistance heater, manually controlled with a variac voltage regulator, was used to heat the samples to $70^{\circ} \mathrm{C}$ for a period of three hours.

\subsubsection{Thermal Bakeout Test Stand}

A custom test stand was constructed from aluminum L-beam sections, plexiglass disks, and steel fasteners for use in the vacuum chamber. The L-beam sections were fastened together to form the uprights of the test stand and additional fasteners were secured to the beams to serve as rungs. Samples were arranged on end around the inside diameter of one of the plexiglass disks and held into place with kapton tape, as shown in Figure 3-2. This arrangement allowed for each of the samples to be heated as evenly as possible. A second disk was secured to the opposite end of the samples with more kapton tape. This assembly was then placed in the uprights with the plexiglass disks hanging from the fastener rungs. The test stand was then placed inside the vacuum chamber and the resistance heater was suspended in the middle of the sample arrangement as shown in Figure 3-2. Thermocouples were then secured to the resistance heater and at two different locations on the sample arrangement using kapton tape. These thermocouples were used to measure the temperature of the heater and samples during the thermal bakeout. A copper heat shield was then placed around the test stand to reflect radiation from the heater to the back side of the sample arrangement. 


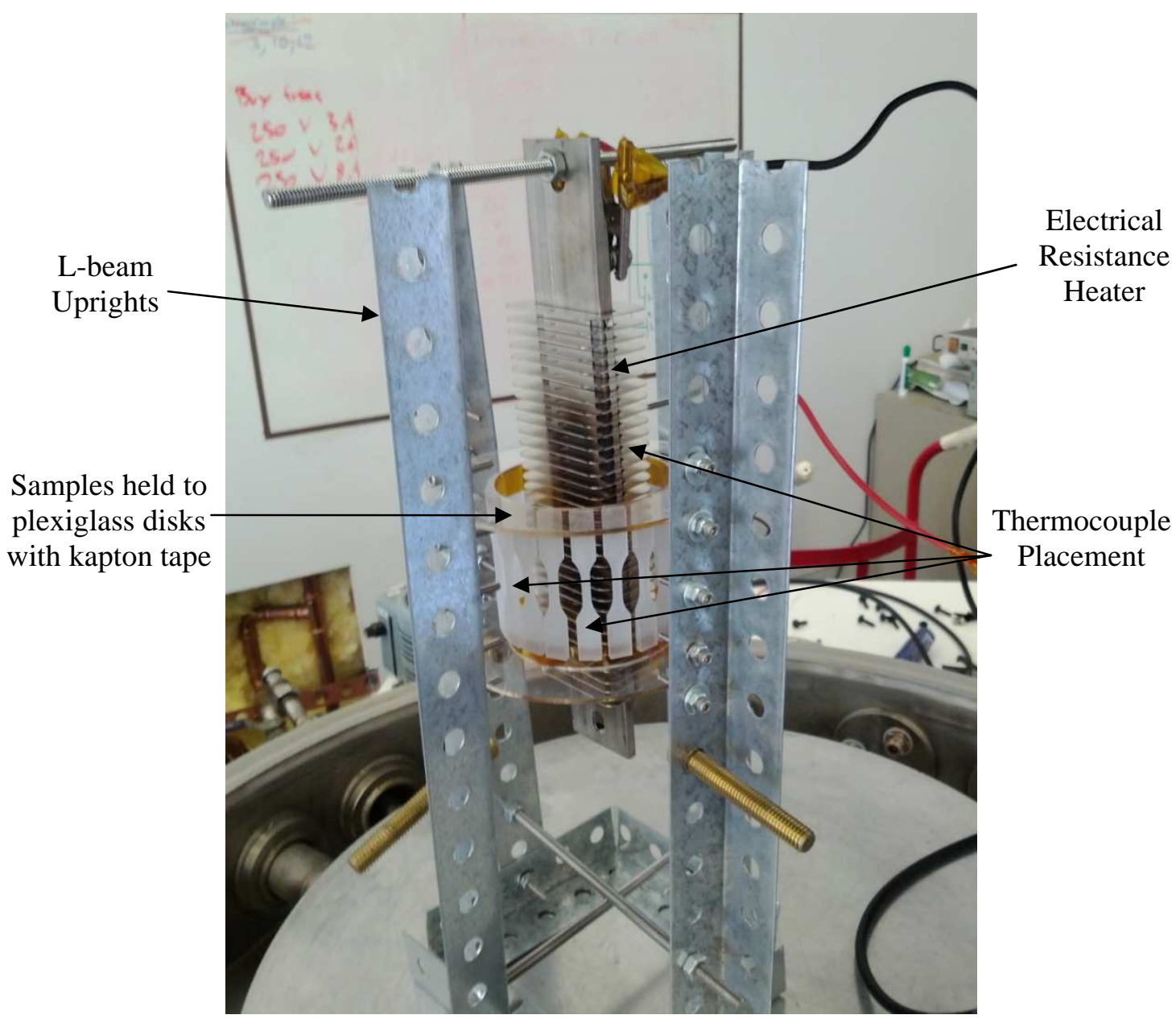

Figure 3-2: Samples arranged on the Test Stand

\subsubsection{Thermal Bakeout Procedure}

An initial mass of the sample sets was taken for use in the TML calculation before arranging the samples on the test stand. The test stand was then set up in the vacuum chamber as described in Section 3.1.1. The chamber was then sealed and pumped down to $10^{-5}$ torr. When this pressure was reached, power to the resistance heater was applied and the sample temperature was slowly raised to $70^{\circ} \mathrm{C}$. At this point, a three hour timer was started for the thermal bakeout. Oscillations around the nominal temperature were encountered since the variac was manually controlled and required frequent adjusting. Temperature information was recorded at ten minute intervals for the entirety of the bakeout and time was added to the 3 hour nominal amount for periods where these 
oscillations cause the sample temperature to drop below $70^{\circ} \mathrm{C}$. The temperature data for the bakeout of the Prototherm samples is shown in Figure 3-3, exhibiting the temperature oscillations encountered in the bakeout process. Table 3-1 shows the temperature data obtained for each thermal bakeout. The chamber was vented when the bakeout was complete and the final mass of the sample set was taken. The samples were then immediately subjected to tensile testing to prevent regassing of the plastic from effecting the modified material properties.

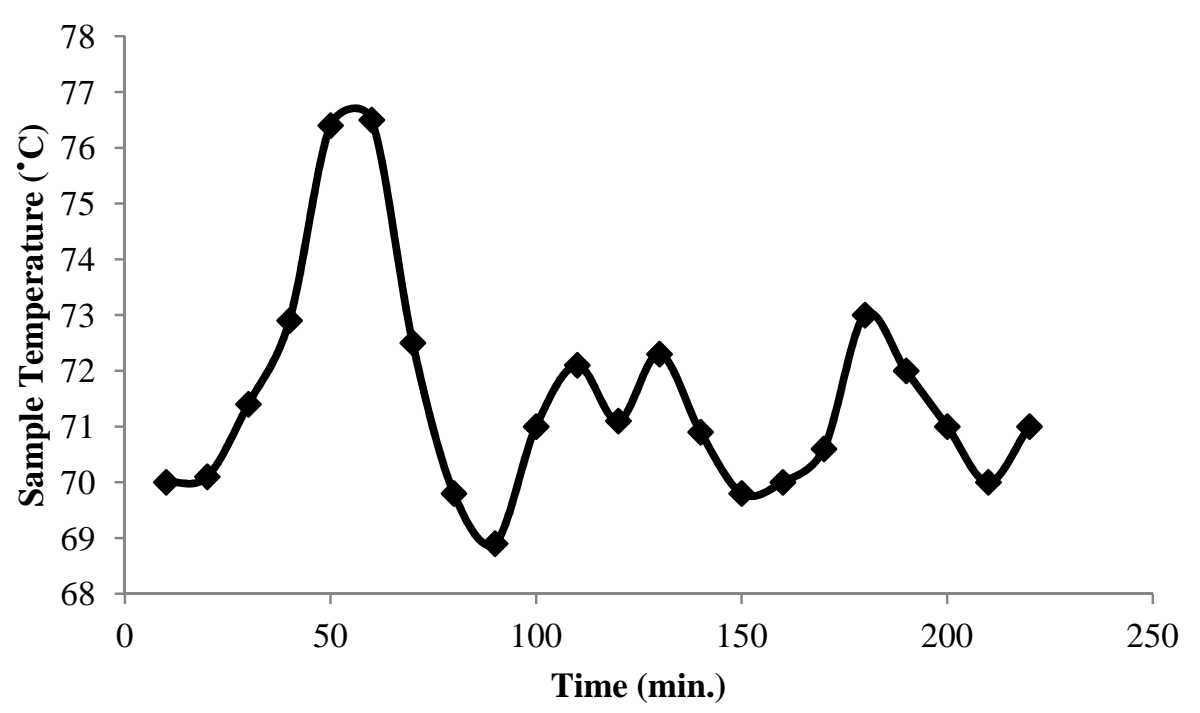

Figure 3-3: Temperature data recorded during the Prototherm bakeout

Table 3-1: Statistical data for thermal bakeout temperature

\begin{tabular}{|c|c|c|c|c|c|}
\hline Temperature Data & ABS & FullCure720 & Watershed & Prototherm & WindformXT \\
\hline Average $\left({ }^{\circ} \mathrm{C}\right)$ & 72.71 & 71.45 & 72.77 & 71.07 & 71.51 \\
\hline Standard Deviation $\left({ }^{\circ} \mathrm{C}\right)$ & 3.56 & 3.22 & 3.18 & 1.35 & 1.94 \\
\hline
\end{tabular}

\subsubsection{Thermal Bakeout Results}

All of the material sets exhibited a total mass loss value of less than $1 \%$. Even though this does not qualify the materials as low outgassing since the thermal bakeout was not performed to the ASTM standard of a 24 hour test at $125^{\circ} \mathrm{C}$, it shows that these plastics will not outgas 
significantly during the CubeSat thermal bakeout. Table 3-2 summarizes the outgassing information for all of the sample materials. Uncertainty in the measurement results from the resolution of the scales.

Table 3-2: Total Mass Loss Summary

\begin{tabular}{|c|c|c|c|c|c|}
\hline Mass Parameter & ABS & FullCure720 & Watershed & Prototherm & Windform XT \\
\hline & 29.70 & 35.29 & 33.653 & 35.633 & 36.107 \\
Initial Mass $(\mathrm{g})$ & \pm .005 & \pm .005 & \pm .0005 & \pm .0005 & \pm .0005 \\
\hline & 29.65 & 35.03 & 33.475 & 35.579 & 36.058 \\
Final Mass (g) & \pm .005 & \pm .005 & \pm .0005 & \pm .0005 & \pm .0005 \\
\hline & 0.17 & 0.74 & 0.529 & 0.152 & 0.136 \\
Total Mass Loss (\%) & \pm .051 & \pm 0.043 & \pm 0.00447 & \pm 0.00421 & \pm .00416 \\
\hline
\end{tabular}

The ABS specimens were the only parts that did not react well to being heated for an extended period of time. Twelve of the twenty samples warped significantly, as shown in Figure 3-4, and had to be discarded. This deformation was likely caused by uneven heating between the front and back sides of the samples. The FDM process results in parts that are not fully dense with significant voids between layers. These likely acted as insulation between the front and back of the samples, reducing the ability for heat to be conducted through the part. As a result, the front side experienced a higher temperature and had a higher rate of thermal expansion, warping the part. This effect would be seen in components of a 3D printed Cubesat during the required thermal bakeout and is considered a disqualifying factor for the FDM produced ABS in this feasibility study.

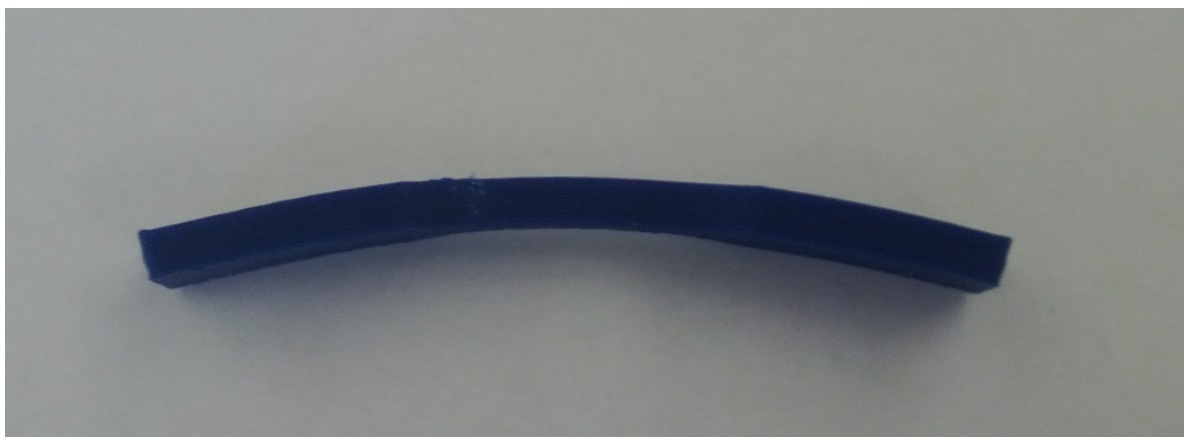

Figure 3-4: Warping of the ABS samples 


\subsection{Tensile Testing}

Destructive tensile testing according to the ASTM D638 standard was performed on all samples using the Cal Poly Aerospace Department's Instron machine. Test parameters for this standard are shown in Figure 3-5 and Table 3-3.

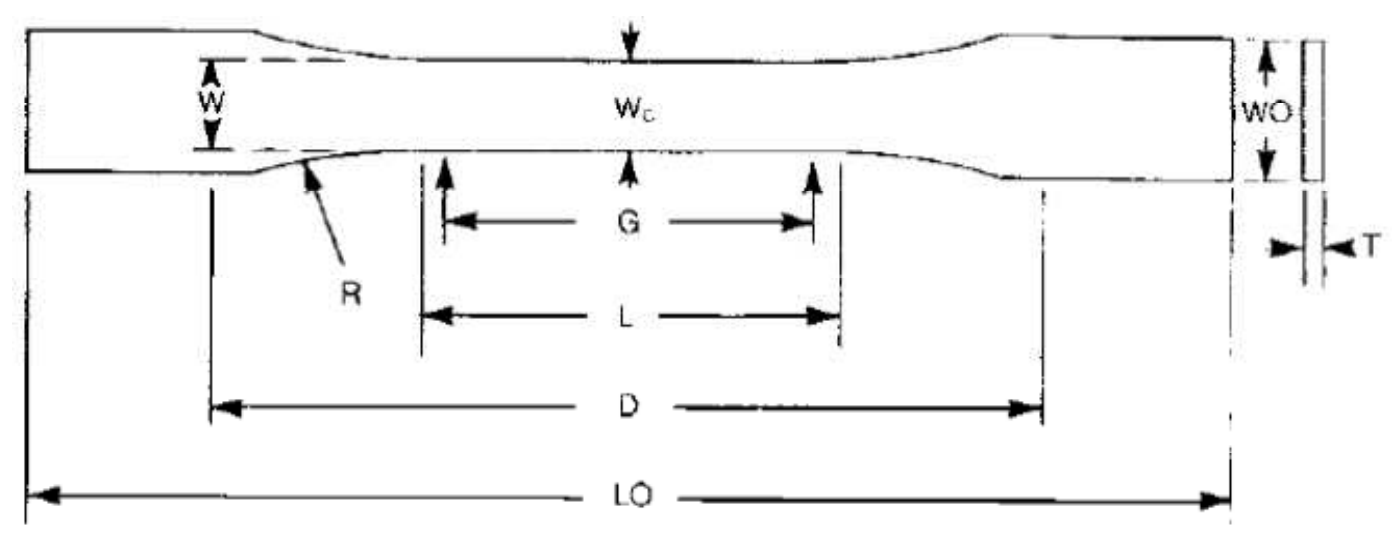

Figure 3-5: ASTM D638 Type V Tensile Bar dimensions [17]

Table 3-3: ASTM D638 Tensile Bar dimenions and test parameters [17]

\begin{tabular}{|c|c|}
\hline Parameter & Value \\
\hline Width of Narrow Section (W) & $0.125 \pm 0.02$ in. \\
\hline Length of Narrow Section (L) & $0.375 \pm 0.02$ in. \\
\hline Width Overall (WO) & $0.375+0.125$ in. \\
\hline Length Overall (LO) & 2.5 in. \\
\hline Gage Length (G) & $0.3 \pm 0.01$ in. \\
\hline Distance Between Grips (D) & $1.0 \pm 0.2$ in. \\
\hline Radius of Fillet (R) & $0.5 \pm 0.04$ in. \\
\hline Extension Rate & 0.05 in./min. \\
\hline Load Failure Criterion & $40 \%$ drop from max \\
\hline
\end{tabular}




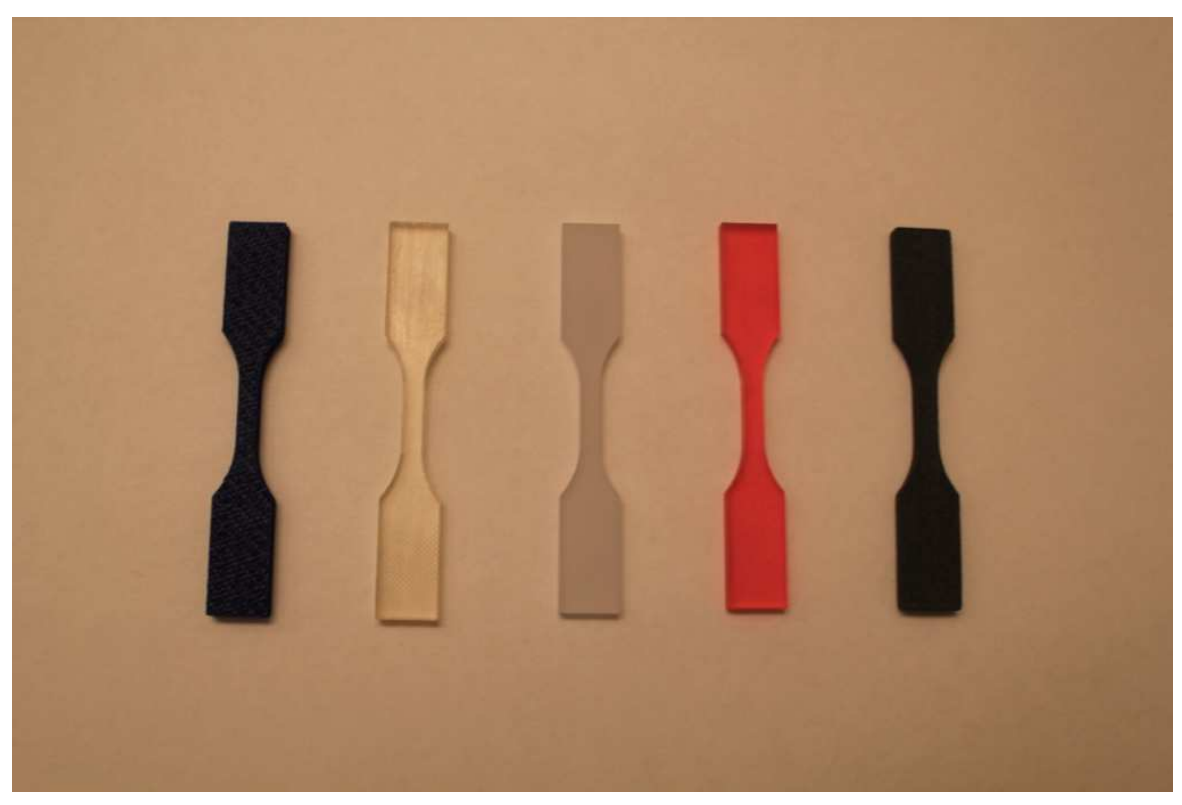

Figure 3-6: Tensile bar samples for all materials

\subsubsection{Tensile Testing Setup and Procedure}

As shown in Figure 3-7, specimens were loaded into the lower jaws of the Instron and gripped with a pressure of 20 psi. This pressure ensured that the jaws would not crush the specimens, and was sufficient to prevent slippage when the specimens were put under tension. A riser was fashioned from a strip of aluminum sheet metal and was used to align the edge of the lower grip with the bottom grip section of the tensile sample. The lower jaws of the Instron were then raised to align the edge of the upper grip with top grip section of the samples and the upper jaw was closed. The samples were then put under tensile loading until failure or extension greater than 0.1 inches was reached. 


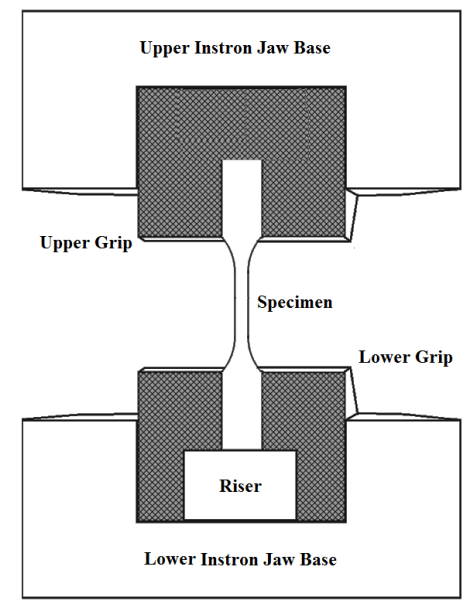

Figure 3-7: Tensile testing setup diagram

\subsubsection{Tensile Testing Results}

Table 3-4 and Table 3-5 contain the averaged tensile test results for the raw and outgassed materials. The stress-strain plot for the raw Watershed sample set is shown below in Figure 3-8. The full tensile test results and Instron data plots for all of the sample sets can be found in Appendix C. It can be seen that the samples performed consistently, with low standard deviations when compared to the mean values.

Table 3-4: Tensile testing results for the raw samples

\begin{tabular}{|c|c|c|c|c|c|}
\hline Material & $\begin{array}{l}\text { Statistical } \\
\text { Parameter }\end{array}$ & $\begin{array}{l}\text { Maximum } \\
\text { Load (lbf) }\end{array}$ & $\begin{array}{c}\text { Maximum Tensile } \\
\text { Stress (ksi) }\end{array}$ & $\begin{array}{c}\text { Strain at Maximum } \\
\text { Load (in/in) }\end{array}$ & $\begin{array}{c}\text { Elastic } \\
\text { Modulus (ksi) } \\
\end{array}$ \\
\hline \multirow{2}{*}{ ABS } & Mean & 123.05 & 7.52 & 0.0340 & 269.68 \\
\hline & $\begin{array}{c}\text { Standard } \\
\text { Deviation }\end{array}$ & 3.51 & 0.21 & 0.0014 & 10.53 \\
\hline \multirow[b]{2}{*}{ Fullcure720 } & Mean & 151.98 & 10.16 & 0.0409 & 384.41 \\
\hline & $\begin{array}{l}\text { Standard } \\
\text { Deviation }\end{array}$ & 9.52 & 0.49 & 0.0024 & 15.30 \\
\hline \multirow[b]{2}{*}{ Watershed } & Mean & 119.31 & 7.64 & 0.0337 & 355.09 \\
\hline & $\begin{array}{l}\text { Standard } \\
\text { Deviation }\end{array}$ & 2.84 & 0.18 & 0.0008 & 7.72 \\
\hline \multirow[b]{2}{*}{ Prototherm } & Mean & 180.04 & 11.52 & 0.0321 & 537.22 \\
\hline & $\begin{array}{l}\text { Standard } \\
\text { Deviation } \\
\end{array}$ & 13.04 & 0.83 & 0.0052 & 18.55 \\
\hline \multirow[b]{2}{*}{ WindformXT } & Mean & 256.19 & 16.40 & 0.0293 & 1131.17 \\
\hline & $\begin{array}{c}\text { Standard } \\
\text { Deviation }\end{array}$ & 14.00 & 0.90 & 0.0025 & 64.38 \\
\hline
\end{tabular}


Table 3-5: Tensile testing results for the outgassed samples

\begin{tabular}{|c|c|c|c|c|c|}
\hline \multirow{2}{*}{ Material } & $\begin{array}{c}\text { Statistical } \\
\text { Parameter }\end{array}$ & $\begin{array}{c}\text { Maximum } \\
\text { Load (lbf) }\end{array}$ & $\begin{array}{c}\text { Maximum } \\
\text { Tensile Stress } \\
(\mathrm{ksi})\end{array}$ & $\begin{array}{c}\text { Strain at Maximum } \\
\text { Load (in/in) }\end{array}$ & $\begin{array}{c}\text { Elastic } \\
\text { Modulus (ksi) }\end{array}$ \\
\hline & Mean & 123.35 & 7.54 & 0.0344 & 271.43 \\
\hline \multirow{3}{*}{ Fullcure720 } & $\begin{array}{c}\text { Standard } \\
\text { Deviation }\end{array}$ & 2.88 & 0.18 & 0.0013 & 11.43 \\
\cline { 2 - 6 } & Mean & 164.56 & 10.53 & 0.0399 & 421.80 \\
\hline \multirow{3}{*}{ Watershed } & $\begin{array}{c}\text { Standard } \\
\text { Deviation }\end{array}$ & 8.50 & 0.54 & 0.0013 & 14.43 \\
\cline { 2 - 6 } & $\begin{array}{c}\text { Mean } \\
\text { Ptandard }\end{array}$ & 123.56 & 7.91 & 0.0376 & 352.92 \\
\hline \multirow{3}{*}{ Deviation } & Mean & 224.99 & 0.29 & 0.0020 & 18.02 \\
\cline { 2 - 6 } & $\begin{array}{c}\text { Standard } \\
\text { Deviation }\end{array}$ & 8.20 & 14.40 & 0.0427 & 519.88 \\
\hline & Mean & 241.78 & 15.47 & 0.0052 & 12.11 \\
\cline { 2 - 6 } & $\begin{array}{c}\text { Standard } \\
\text { Deviation }\end{array}$ & 8.72 & 0.56 & 0.0298 & 1120.64 \\
\hline
\end{tabular}

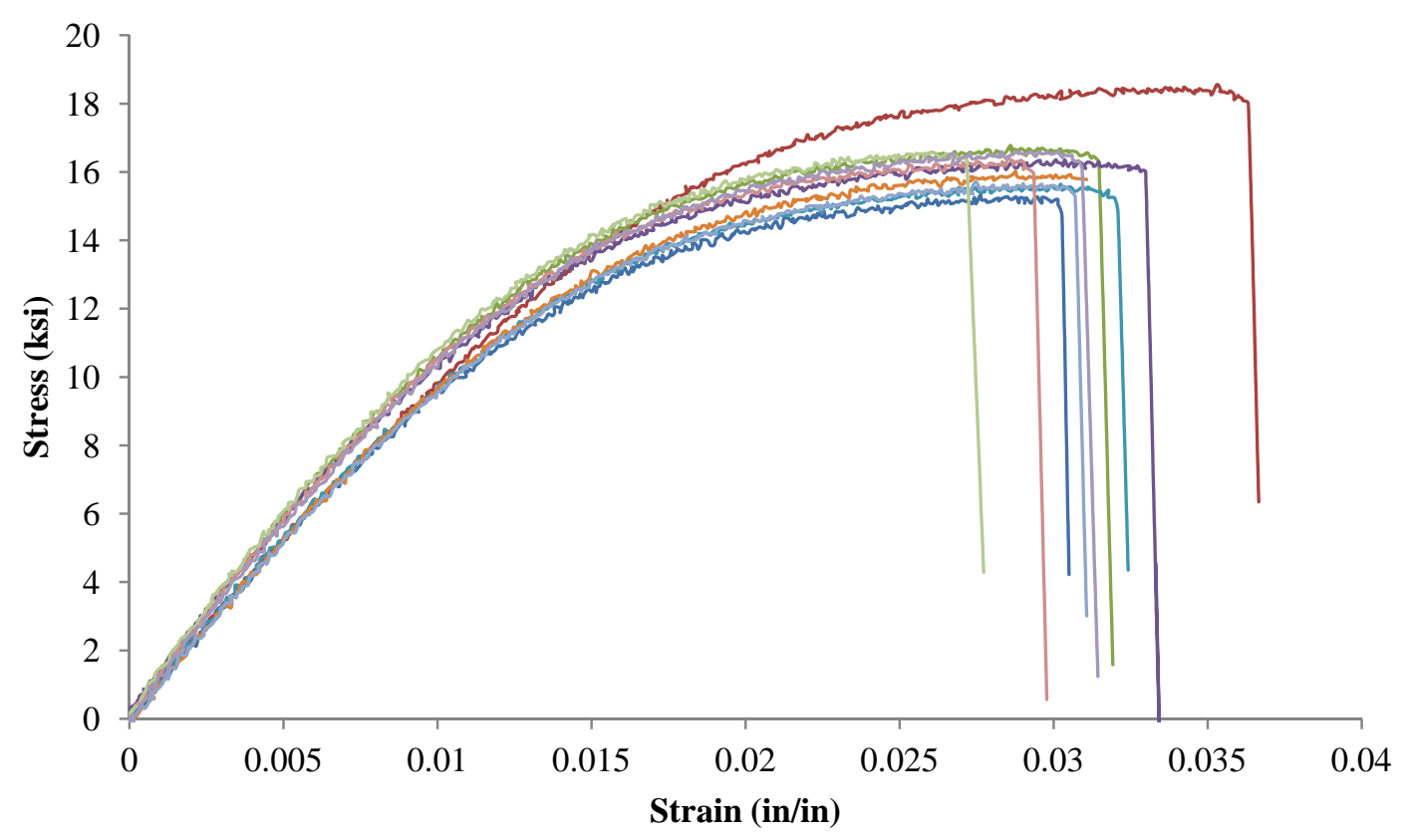

Figure 3-8: Instron data from the raw Watershed sample set 


\subsubsection{Yield Stress Calculation}

The industry standard for the calculation of the yield stress in linear elastic materials is the $0.2 \%$ strain offset method. This method creates a line with the initial slope of the material's stress-strain curve that crosses the strain axis at a value of $0.002 \mathrm{in} / \mathrm{in}$. The material yield stress is then estimated to be where the offset line intersects the stress-strain curve. However, there is no industry standard method for determining the yield stress for ductile or partially ductile materials studied in this thesis.

According to Christensen [4] the yield stress for ductile materials can be estimated by examining the derivatives of the stress-strain plot. He states that the strain at which the yield stress occurs lies at the point where the rate of change of the curvature of the plot is at its greatest. This point is associated with the highest molecular rearrangement and damage in the material. Analytically, this strain value is found by setting the third derivative of the stress strain curve equal to zero.

$$
\sigma=\sigma_{y} \text { where } \frac{d^{3} \sigma}{d \varepsilon^{3}}=0
$$

In order to calculate this value from the tensile data obtained with the Instron machine, a function was needed to describe the shape of every stress-strain curve. This function was obtained by fitting a fourth order polynomial to the data using the line estimation function in Excel as shown below. This method produced a polynomial function with the necessary significant figures to accurately find the third derivative of the stress strain curve.

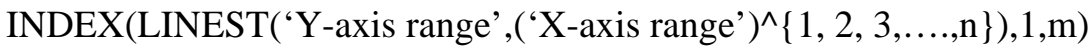

$$
\begin{aligned}
& \mathrm{n}=\text { polynomial order } \\
& \mathrm{m}=\text { desire coefficient }
\end{aligned}
$$

The yield strain was then solved for by setting the third derivative of this polynomial equal to zero. This strain was plugged back into the original function to find the estimated yield stress. An 
example graph with data from a specimen of the outgassed Watershed set can be seen in

Figure 3-8, showing the raw data, the polynomial approximation, and the calculated yield stress.

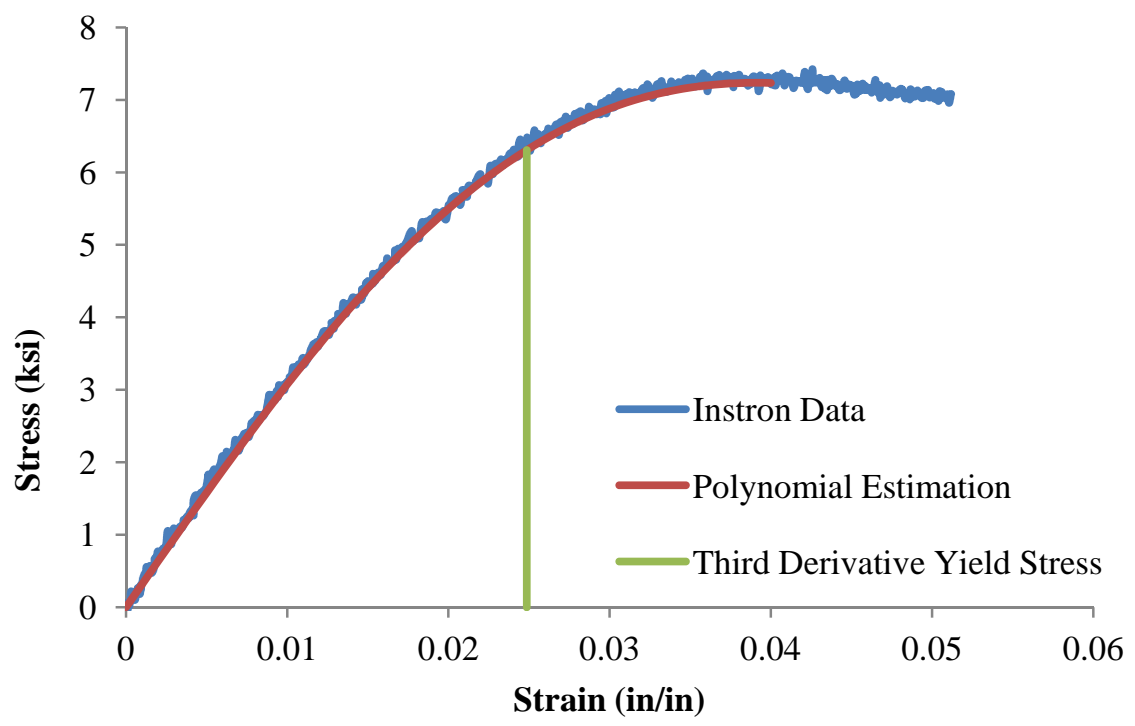

Figure 3-9: Yield Stress Calculation using the Third Derivative Method

This method of calculating the yield stress worked well for the ABS, Fullcure720, and Watershed sample sets. However, a fourth order polynomial was not able to be fitted to the data for the Prototherm and WindformXT samples sets since they exhibited linear elastic and brittle tensile properties. For these materials, the yield stress was estimated using a standard $0.2 \%$ offset line. An example graph with data from a specimen of the outgassed WindformXT set can be in Figure 3-10, showing the raw data and the offset line. 


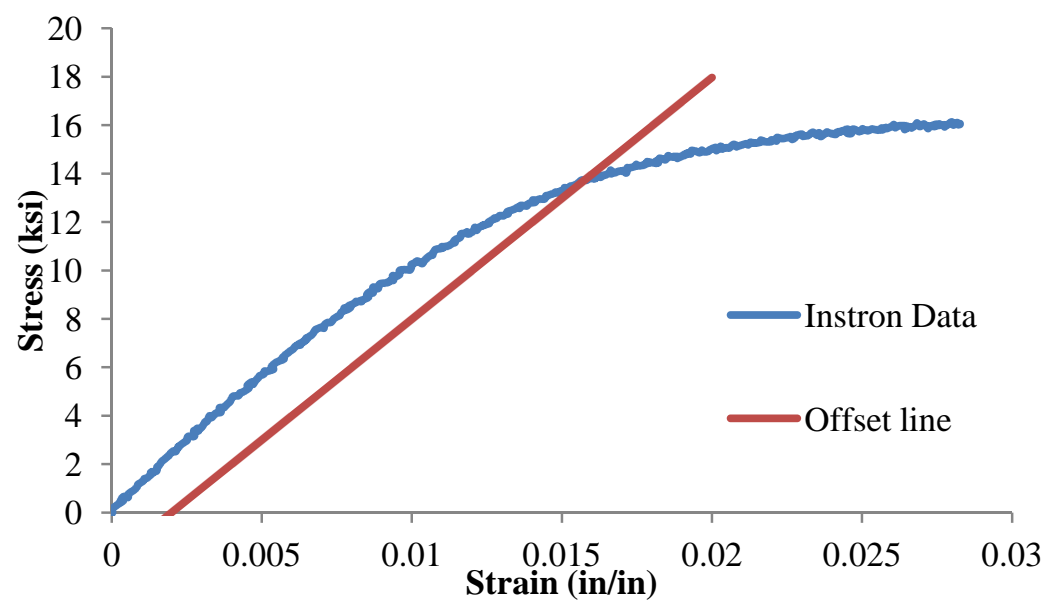

Figure 3-10: Yield Stress Calculation using the 0.2\% Offset Line

Table 3-6 and Table 3-7 summarize the yield stress calculations for the raw and outgassed sample sets. The calculated values of the yield location on the plot match well with the predicted locations derived from comparison with published data of ductile and brittle materials.

Table 3-6: Yield Stress summary for the raw sample sets

\begin{tabular}{|c|c|c|c|}
\hline Material & Statistical Parameter & Yield Strain (in/in) & Yield Stress (ksi) \\
\hline \multirow{2}{*}{ ABS } & Mean & 0.0309 & 6.76 \\
\cline { 2 - 4 } & Standard Deviation & 0.0037 & 0.37 \\
\hline \multirow{2}{*}{ Fullcure720 } & Mean & 0.0406 & 9.59 \\
\cline { 2 - 4 } & Standard Deviation & 0.0049 & 0.45 \\
\hline \multirow{2}{*}{ Watershed } & Mean & 0.0289 & 7.11 \\
\cline { 2 - 4 } & Standard Deviation & 0.0009 & 0.15 \\
\hline \multirow{2}{*}{ Prototherm } & Mean & 0.0237 & 9.87 \\
\cline { 2 - 4 } & Standard Deviation & 0.0010 & 0.54 \\
\hline \multirow{2}{*}{ WindformXT } & Mean & 0.0150 & 13.41 \\
\cline { 2 - 4 } & Standard Deviation & 0.0011 & 1.05 \\
\hline
\end{tabular}


Table 3-7: Yield Stress summary for the outgassed sample sets

\begin{tabular}{|c|c|c|c|}
\hline Material & Statistical Parameter & Yield Strain (in/in) & Yield Stress (ksi) \\
\hline \multirow{2}{*}{ ABS } & Mean & 0.0337 & 6.84 \\
\cline { 2 - 4 } & Standard Deviation & 0.00634 & 0.22 \\
\cline { 2 - 4 } Fullcure720 & Mean & 0.0312 & 9.50 \\
\cline { 2 - 4 } & Standard Deviation & 0.664 & 0.66 \\
\hline \multirow{2}{*}{ Watershed } & Mean & 0.0249 & 6.60 \\
\cline { 2 - 4 } & Standard Deviation & 0.000195 & 0.24 \\
\hline \multirow{2}{*}{ Prototherm } & Mean & 0.0561 & 14.00 \\
\cline { 2 - 4 } & Standard Deviation & 0.00137 & 0.073 \\
\hline \multirow{2}{*}{ WindformXT } & Mean & 0.0144 & 12.28 \\
\cline { 2 - 4 } & Standard Deviation & 0.000937 & 0.97 \\
\hline
\end{tabular}

\subsection{Summary of Mechanical Property Changes}

The percent differences of the mechanical properties between the pre and post-bakeout samples are shown in Table 3-8. It can be seen that the process did not have a large effect on the mechanical properties of the majority of the materials. However, the Prototherm sample sets exhibited a drastic increase in the material's load bearing capabilities as a result of the bakeout.

Table 3-8: Percent change in material properties between the raw and outgassed sample sets

\begin{tabular}{|c|c|c|c|c|c|c|}
\hline Material & $\begin{array}{c}\text { Maximum } \\
\text { Load (lbf) }\end{array}$ & $\begin{array}{c}\text { Maximum } \\
\text { Tensile Stress } \\
(\mathrm{ksi})\end{array}$ & $\begin{array}{c}\text { Strain at } \\
\text { Maximum Load } \\
(\mathrm{in} / \mathrm{in})\end{array}$ & $\begin{array}{c}\text { Elastic } \\
\text { Modulus } \\
(\mathrm{ksi})\end{array}$ & $\begin{array}{c}\text { Yield } \\
\text { Strain } \\
(\mathrm{ksi})\end{array}$ & $\begin{array}{c}\text { Yield } \\
\text { Stress } \\
(\mathrm{in} / \mathrm{in})\end{array}$ \\
\hline ABS & 0.24 & 0.24 & 1.09 & 0.65 & 9.21 & 1.11 \\
\hline Fullcure720 & 8.28 & 3.64 & -2.56 & 9.73 & -23.04 & -0.95 \\
\hline Watershed & 0.036 & 0.036 & 0.12 & -0.0061 & -13.82 & -7.12 \\
\hline Prototherm & 24.97 & 24.97 & 33.07 & -3.23 & 136.32 & 41.79 \\
\hline WindformXT & -5.62 & -5.62 & 1.57 & -0.93 & -3.93 & -8.41 \\
\hline
\end{tabular}




\subsection{Failure Characteristics}

The highly anisotropic nature of the ABS samples caused by the FDM process caused a gradual failure in plastic fibers of the part rather than a clean break. This signifies that the layers of the part do not uniformly support loading and will likely cause unpredictable stress concentrations in any functional parts manufactured with this technology.
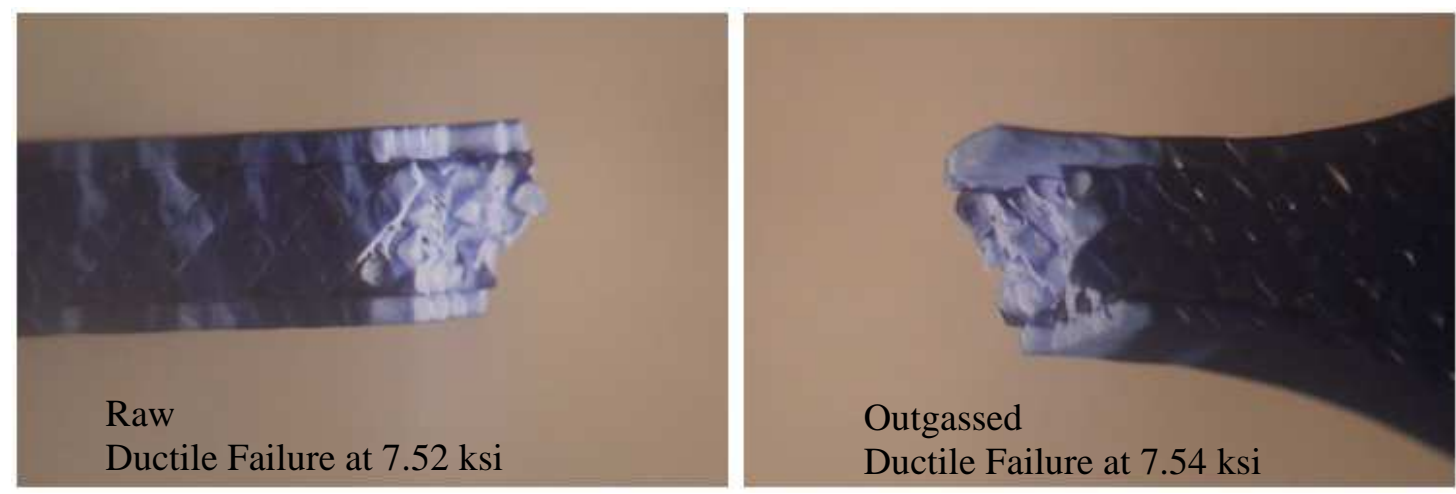

Figure 3-11: ABS Sample Failure

The raw FullCure720 and Watershed samples sets exhibited the same failure type characterized by slight necking followed by a clean break. However, the thermal bakeout effected these materials in different magnitudes. The FullCure 720 became more brittle after the bakeout. This can be seen by a reduction in the yield and ultimate strains with an increase in elastic modulus. The Watershed samples also exhibited this behavior, but on a more mild scale.
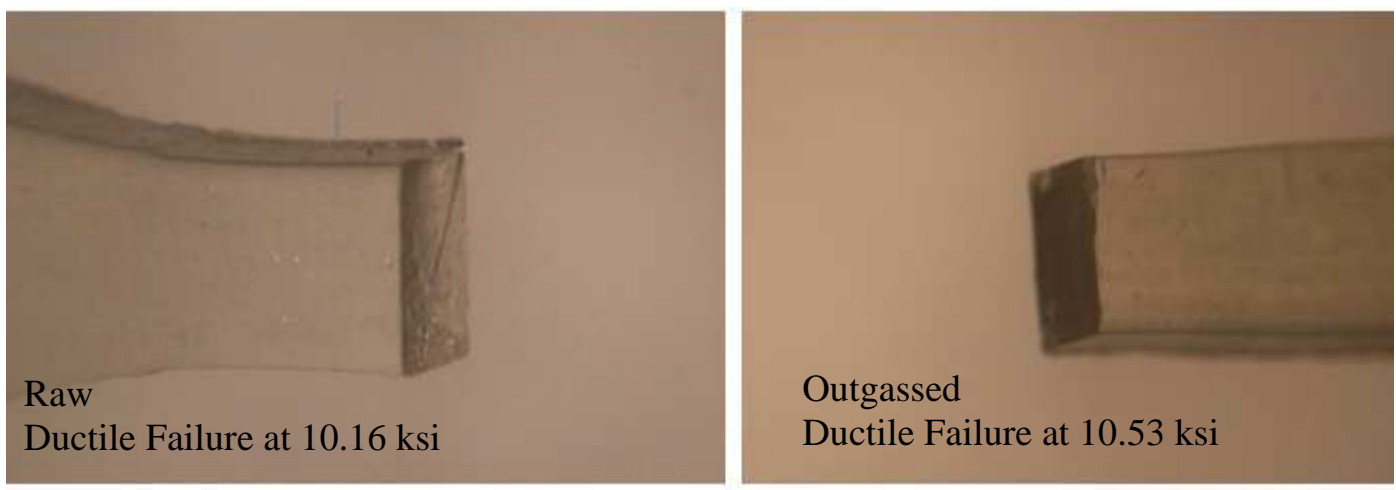

Figure 3-12: FullCure720 Sample Failure 

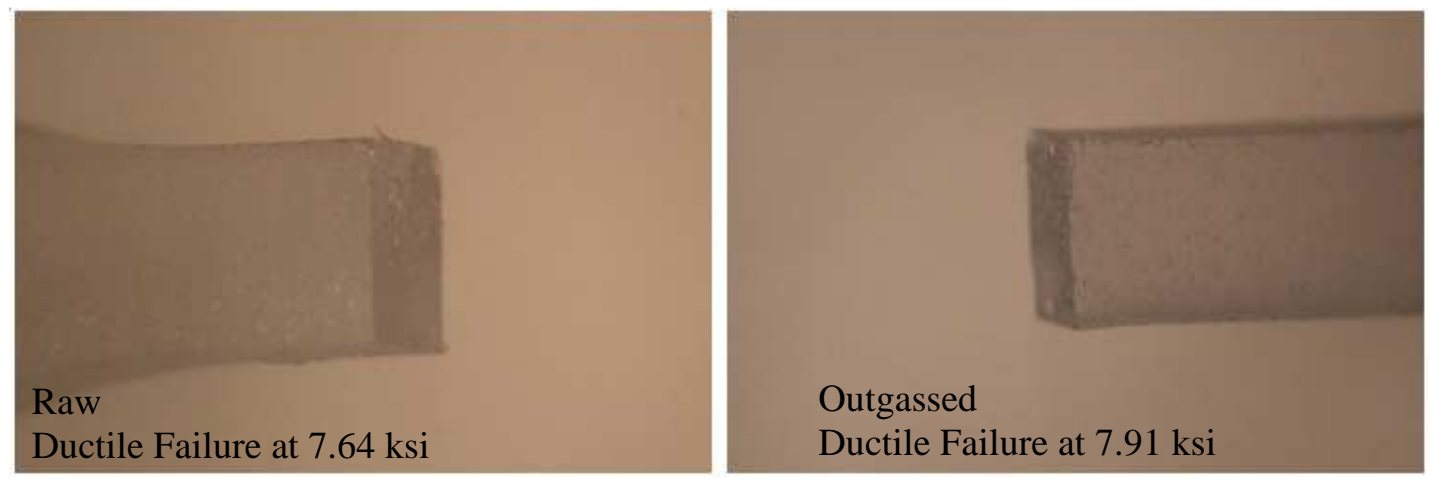

Figure 3-13: Watershed Sample Failure

The thermal bakeout effected the Prototherm sample set in the opposite manner. In this case, the raw samples experienced almost purely brittle failure, shattering at a low strain value. The post bakeout sample failed in a more linear-elastic manner, with a clean break at a higher strain value. This mode of failure allowed the samples to hold a much larger load before failing, resulting in the largest increase in yield stress, and ultimate stress when compared to the raw samples.
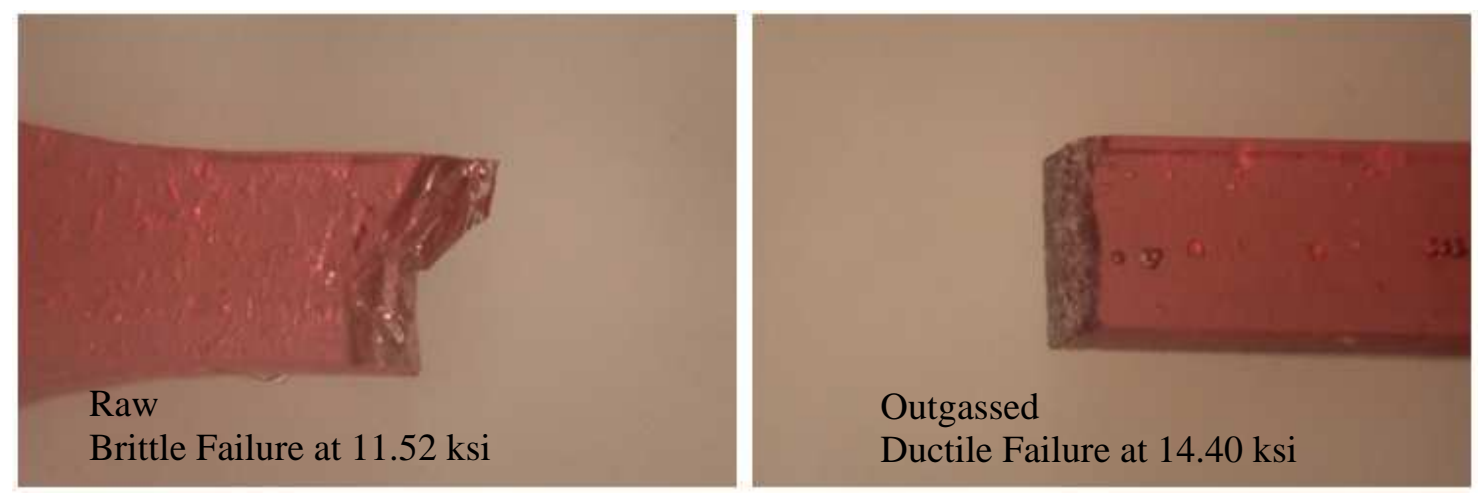

Figure 3-14: Prototherm Sample Failure 
Both sample sets of WindformXT experienced brittle failures, breaking at low strain values.
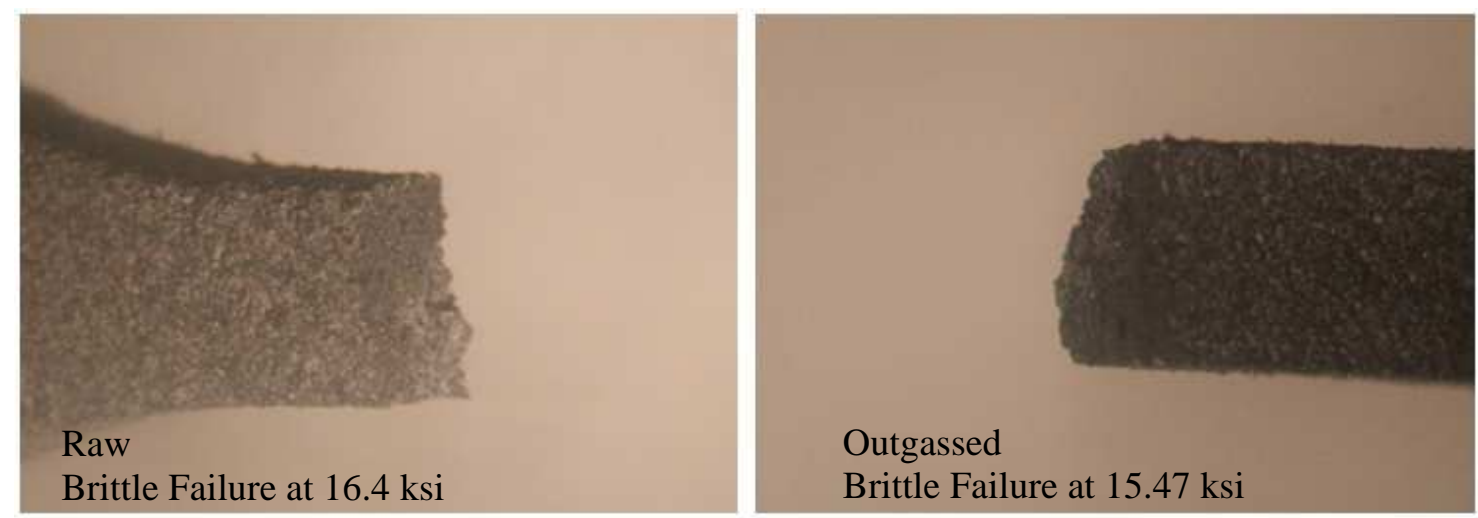

Figure 3-15: WindformXT Sample Failure

\subsection{Discussion of Testing Results}

The tensile testing results from the raw and outgassed samples show that the thermal bakeout had different effects on each type of 3D printed material. Unfortunately, this prevents an overall statement on the effects of a thermal bakeout from being made and requires the effects to be studied for each specific material.

The process had an insignificant effect on the mechanical properties of the ABS samples. However, the warping of the samples during bakeout and the stress concentrations between the printed layers of the parts are a major area of concern. These properties are a result of the FDM process itself rather than the material properties of the ABS, leading to the conclusion that all parts produced with this technology will exhibit the same characteristics. These inherent anisotropic properties of FDM make failure less predictable than the current aluminum parts. This in turn adds additional risk to the P-POD, resulting in the disqualification of the FDM process from the feasibility study. 
The rest of the samples did not have any adverse reactions to the thermal bakeout that were a cause concern. The process acted as a post cure heat treatment for the FullCure720 and Watershed sample sets. The bonds between the polymers strengthened as gasses were allowed to escape during the outgassing process. Conversely, the thermal bakeout seems to have removed a portion of the cure applied to the Prototherm samples during manufacturing. While this process would have had a negative effect on the other photopolymer samples, this greatly increased the usability of this plastic. The Prototherm failed more predictably and carried a much larger load after the bakeout as shown in Table 3-8 and Figure 3-14. WindformXT was the only material to exhibit a reduction in strength as a result of the bakeout process. However, this change was small for all the studied parameters and likely wouldn't have a large effect on the performance of the material. The values obtained during the Testing Phase what were used in the Design Iteration Phase are shown in Table 3-9.

Table 3-9: Materials properties of post-bakeout samples used in the Design Iteration Phase

\begin{tabular}{|c|c|c|}
\hline Material & Yield Stress (MPa) & Elastic Modulus (MPa) \\
\hline Fullcure720 & 65.50 & 2908.21 \\
\hline Watershed & 45.50 & 2433.30 \\
\hline Prototherm & 96.53 & 3584.45 \\
\hline WindformXT & 84.67 & 7726.75 \\
\hline
\end{tabular}




\section{Design Iteration Phase}

Two revisions of a concept CubeSat structure and accompanying payload bracket were designed to be used in a low-budget 3D printed system bus. There were two criteria placed on the design to ensure its functionality. First, compatibility with Cal Poly's electronics hardware revisions was required. Second, the payload volume was not allowed to decrease by more than $20 \%$ from the $675 \mathrm{~cm}^{3}$ of volume available in the HyperCube structure [7]. Finite Element Analysis was performed in Abaqus/Standard with the material properties found during the Testing Phase, shown in Table 3-9. Information from the analysis was used to iterate through the design until a feasible concept was reached that had a yield stress Margin of Safety of 7.

\subsection{RapidSat Revision 1 Concept Structure}

The first revision for the RapidSat structure was heavily based off of the HyperCube. It followed the same modular format, using four identical Side Panels, a Top Hat, and a Shoe. As a result, it maintained compatibility with the electronics hardware and had no decrease in the available payload volume. Further, the lower density of the 3D Printed materials lead to a mass savings of 73 grams when compared to the aluminum HyperCube. Modifications to the structure were made to lower stress concentrations, since the material used in the RapidSat structure will be more susceptible to failure in these regions. A revision common to all parts was the addition of mating Extrusions and Slots along part interfaces that spread shear loading over a large surface area instead of localizing it to the fasteners. Also, all hole diameters were widened for the use of HeliCoils that would be secured to the plastic using Loctite. Examples of these modifications can be seen below in Figure 4-1. Further modifications made to the individual parts are described in Sections 4.1.1 and 4.1.2. 


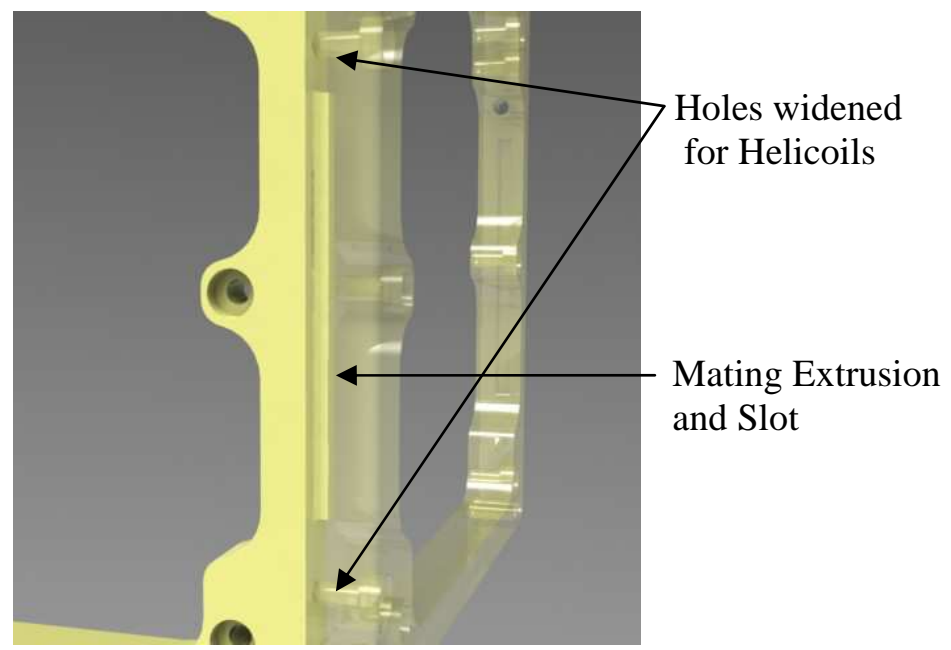

Figure 4-1: Major design changes for RapidSat Revision 1

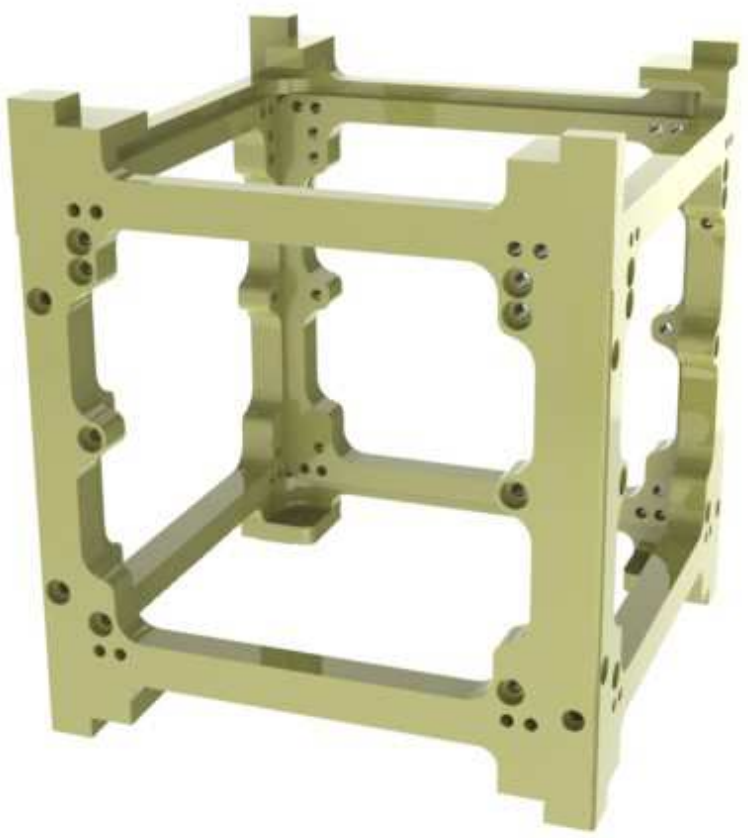

Figure 4-2: RapidSat Revision 1 structure

\subsubsection{RapidSat Revision 1 Top Hat and Shoe}

The Top Hat and Shoe were modified to strengthen the mounting tabs and circuit board mounting points. The mounting tabs, which are used to secure the Top Hat and Shoe to the rest of the structure, were enlarged, filleted and moved to the corners of the part. In addition to lowering the 
stress concentrations at these joints, this prevents the tabs from intruding on the internal payload space of the structure. Large fillets were also added in the corners of the part. Design changes from the HyperCube Top Hat can be seen in Figure 4-3.

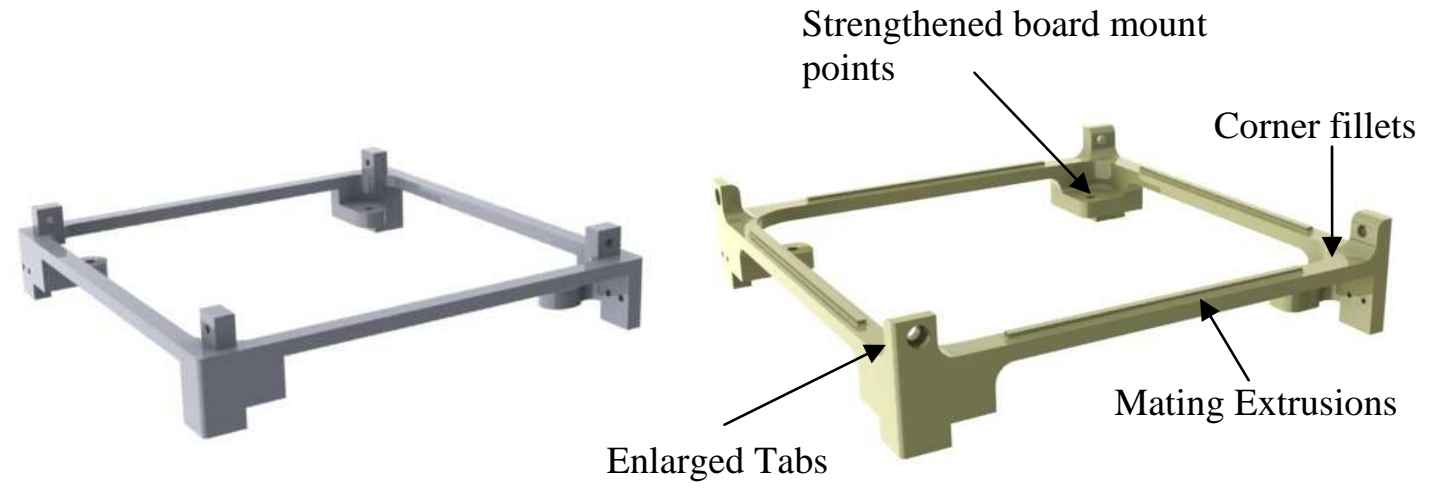

Figure 4-3: Design changes to the Top Hat and Shoe

\subsubsection{RapidSat Revision 1 Side Panels}

The Side Panels used in the RapidSat design retained many of the same features as the HyperCube Side Panels. There were few modifications apart from the general additions made to all of the parts. Additional payload mounting holes were added by mirroring the existing mounting holes on the HyperCube Side Panel. Also, the interfaces for the Top Hat and Shoe were modified to accommodate the change in mounting method.

Top Hat \& Shoe Mounts

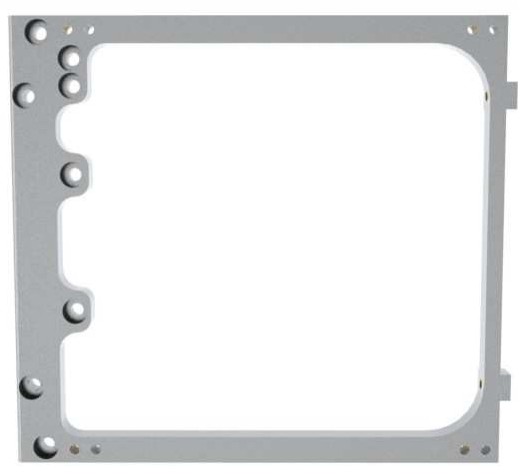

Added Mounting Holes

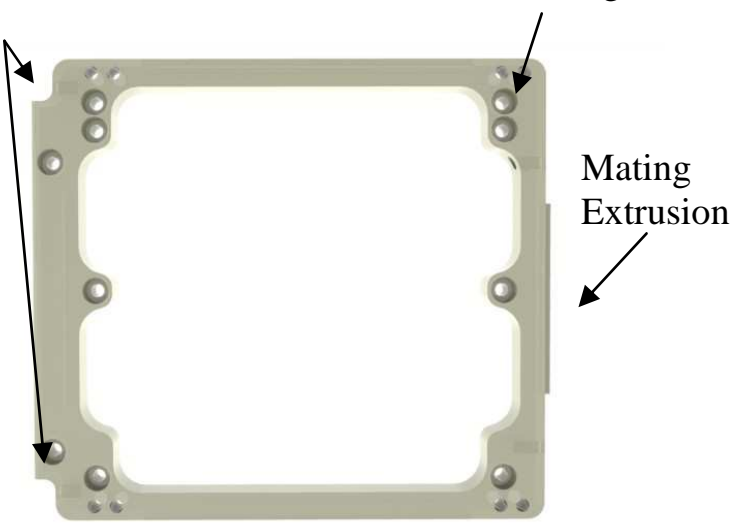

Figure 4-4: Design changes to the Side Panels 


\subsection{Finite Element Analysis of the RapidSat Revision 1 Structure}

A Finite Element Model of the RapidSat Revision 1 Structure was constructed with Abaqus/Standard using the material properties found in the Testing Phase. A worst case loading condition derived in Section 4.2.5 was applied along the $\mathrm{X}$-axis of the structure to gain insight to the survivability of the materials during random vibration. The validity of the FEA results was determined by comparison to simplified hand calculations shown in Appendix A. They were then used to make additional modifications to the structure components for the next revision of the part designs.

\subsubsection{Finite Element Model Development}

Two planes of symmetry were utilized in this structure to reduce the complexity and computation time of the analysis. This required using Solidworks to cut out sections of the parts that could be mirrored about a symmetry plane. Solidworks was also used to simplify the geometry of the parts be removing or altering features that would have led to poor mesh quality. This included all holes and non-vital structural fillets. These defeatured parts were then saved as .STEP files and imported into Abaqus as 3D deformable solids. The part assembly imported to Abaqus with the planes of symmetry is shown in Figure 4-5. In order to accurately model a flight CubeSat, 3D deformable solids were created to symbolize a Printed Circuit Board and Payload. A mass of 121 grams was assigned to the PCB represent an avionics package that had been cut along the same axes of symmetry as the structure. The mass of the Payload was assigned such that the total mass of the CubeSat would equal $1.33 \mathrm{~kg}$, the maximum mass allowed for a $1 \mathrm{U}$ CubeSat [5]. 


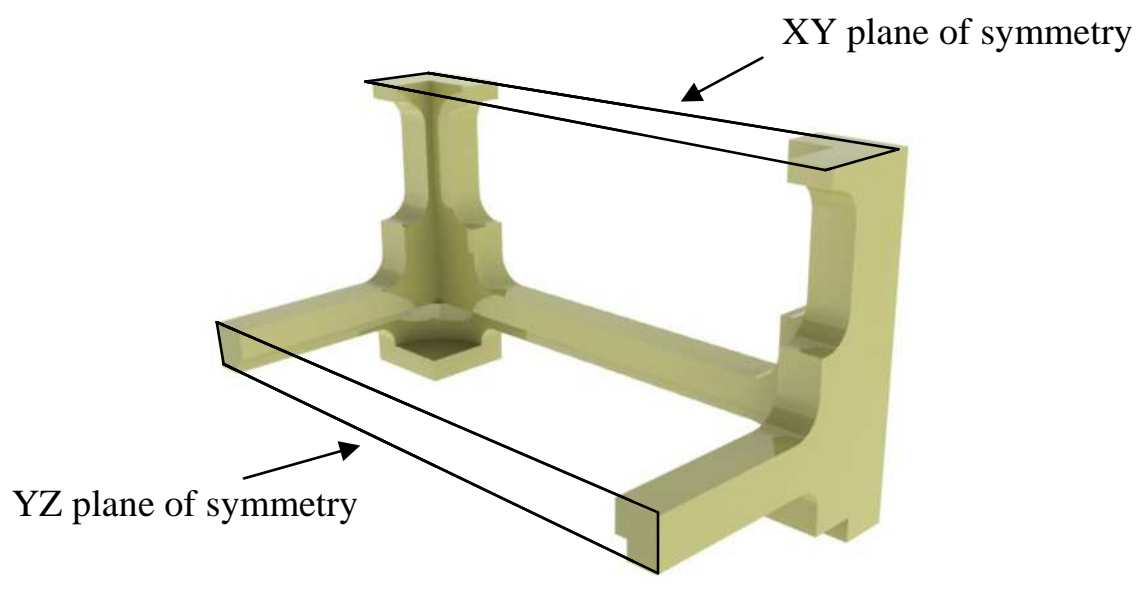

Figure 4-5: Simplified Revision 1 Structure

The complex features that were not removed required that many partitions be made in the parts to ensure good mesh quality. These partitions were created to maximize the regions of constant cross sectional area. Additional partitions were created to extend edge intersections through the parts to ensure even element seeding. The partitioning strategy is shown in Figure 4-6.
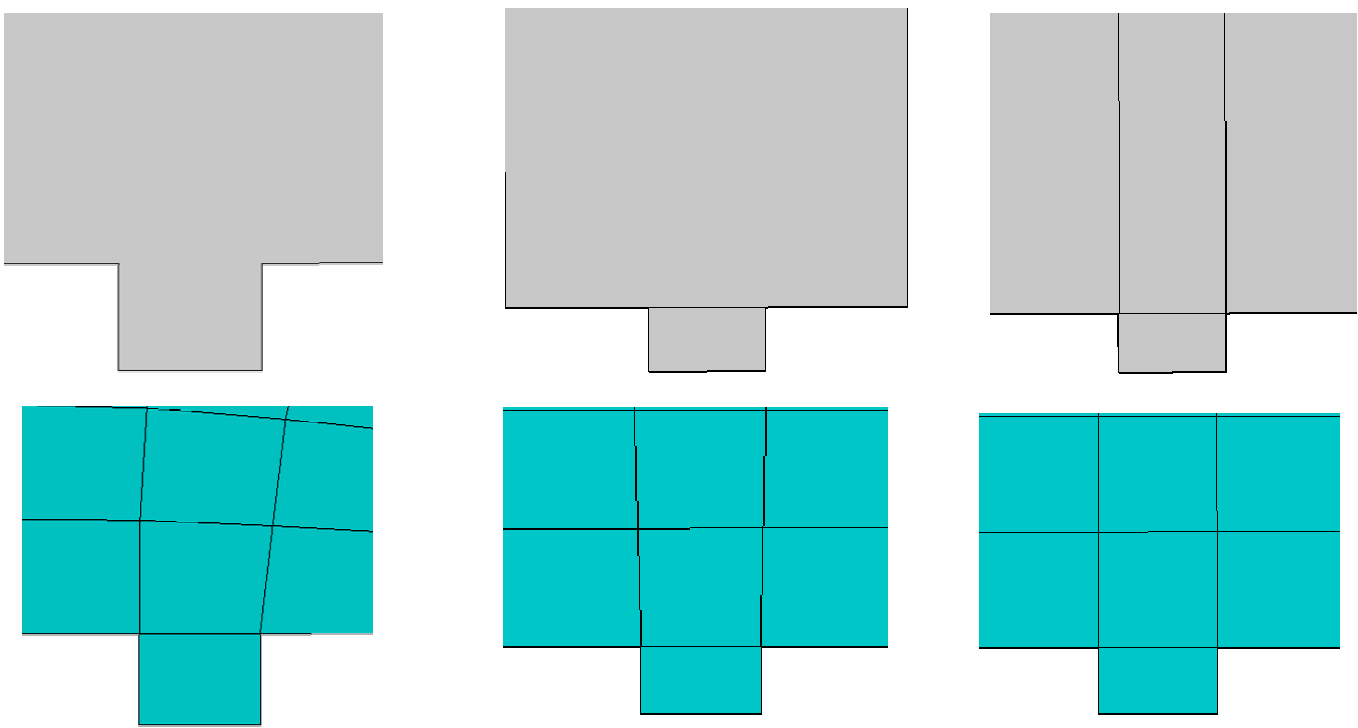

Figure 4-6: Comparison between unpartitioned, constant cross section partitioned, and even seeding partitioned sections showing element distortion caused by uneven seeding 


\subsubsection{Mesh Development}

There are two general element types that are available in Abaqus to build the mesh of a part: linear, and quadratic. Linear elements have straight edges and nodes at each vertex. The nodes are able to translate under load, but the edges will always remain straight. The inability of the edges to bend causes artificial stiffness in the element known as shear locking. In order to accurately portray curvature in a part, the size of linear elements needs to be very small. Quadratic elements contain nodes at each vertex as well as nodes along their edges. When these elements deform, the presence of the additional nodes along the edges allows curvature. The differences between linear and quadratic element deformation can be seen in Figure 4-7. All of the components of the RapidSat structure will deform with some level of curvature during random vibration. This dictated the decision to use quadratic elements in the part meshes.

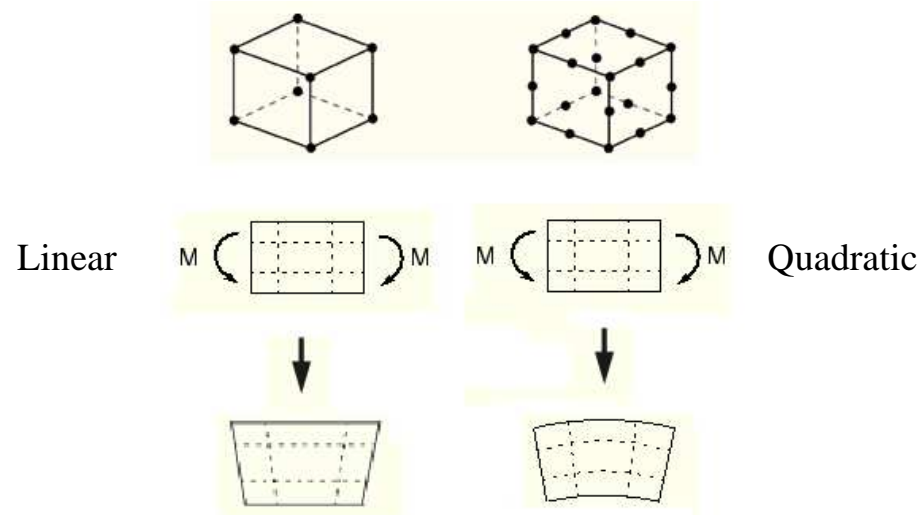

Figure 4-7: Comparison between Linear Elements and Quadratic Elements [6]

Abaqus contains three types of element shapes for use in 3D stress analyses: Hexahedral, Wedge, and Tetrahedral. Discussion with Dr. Peter Schuster from the Cal Poly Mechanical Engineering Department during his undergraduate course in Applied Finite Element Analysis led to the conclusion that the use of tetrahedral elements adds inaccurate stiffness to parts when used in this type of application. Because of this, a combination of Hexahedral and Wedge elements were used 
to construct the mesh of the RapidSat. Partitioned regions that exhibited a constant rectangular cross section were meshed using structured hexahedral elements. Filleted regions were meshed using swept wedges since the tapered edge of the element is well suited for modeling the ends of the fillets. The meshes produced with this development method were very high in quality as shown in Table 4-2. The circuit board and payload mass parts had very simple geometry, warranting the use of quadratic hexahedral, reduced integration elements. These types of elements are much less complex than the full integration elements since there are less points where computation takes place. Figure 4-8 shows the layout of the elements types and details of the final mesh are discussed in Section 4.2.6.

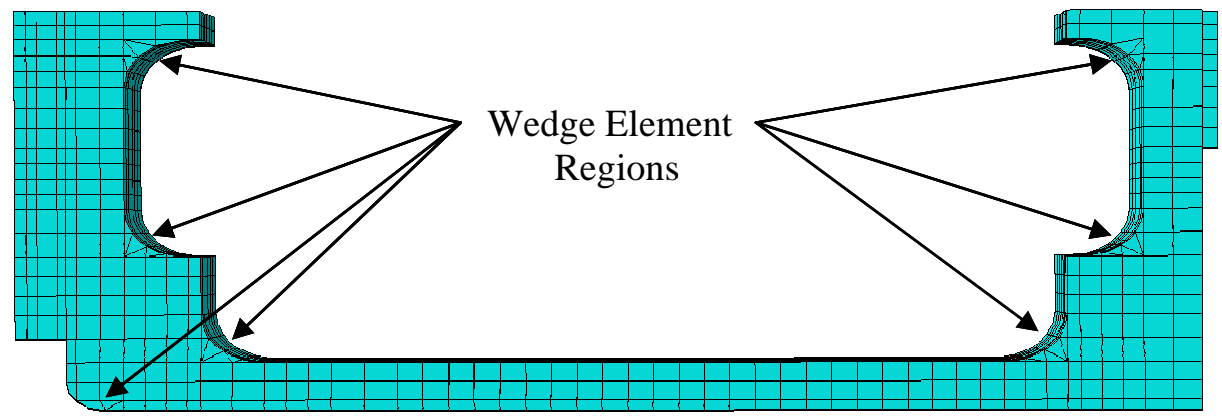

Figure 4-8: Mesh of the Side Panel showing use of Hex and Wedge elements

\subsubsection{Assembly Constraints}

Fastener interfaces between the parts in the structure were modeled with surface to surface tie constraints. In these types of constraints, the nodes of a slave surface are forced to have the same displacement as the nodes on a master surface. While this constraining method will physically join the parts at the fastener location, it is not truly representative of how the real joints will behave. The tie constraints will localize all of the shear stress in the joint to the surface elements, while the stress in the physical joint stress will be more evenly distributed. As a result, analysis of 
the joints with hand calculations performed in Appendix A will be used to determine the structural characteristics at these points.

The remaining adjoining surfaces between the parts were constrained using surface to surface contacts with frictionless, hard property definitions. These constraints prevented parts from penetrating each other when the load was applied. The contact constraints added non-linearity to the analysis, which greatly increased the computing time necessary to solve the model. However, this accurately approximated the interaction between the real behavior of the parts.

In order for the constraints to be accurately enforced, the mesh size of the slave surfaces was required to be finer than the master surfaces. This prevented multiple master nodes from being assigned to the same slave node. After experiencing difficulties with enforcing the ties and contacts, it was discovered that nodes shared between constraints along their edges caused inaccuracies in their applications. Additional partitions were added to the parts to provide separation between the constraint borders. This separation can be seen in Figure 4-9 and the complete FEA assembly can be seen in Figure 4-10.

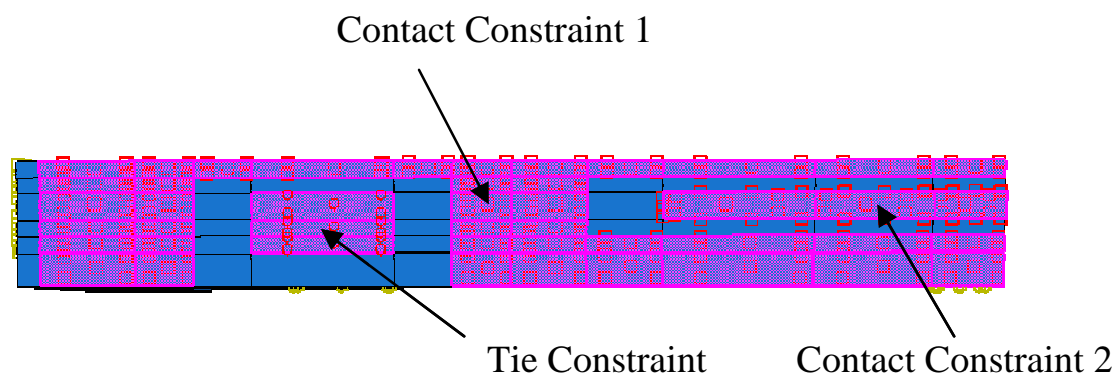

Figure 4-9: Tie and Contact constraint application 


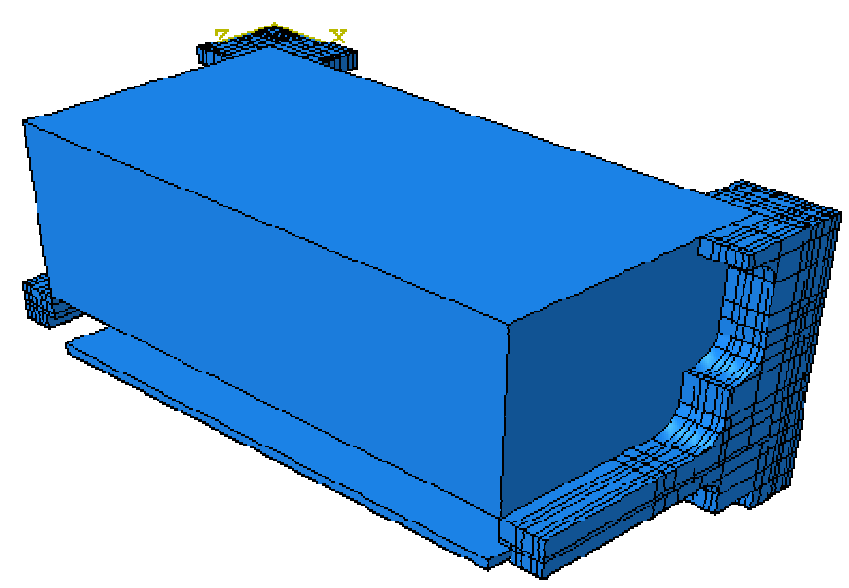

Figure 4-10: Complete FEA Assembly for RapidSat Revision 1

\subsubsection{Boundary Conditions}

The CubeSat will be constrained at the corners by the rails of the P-POD during the vibration tests and rocket launch. This was approximated in the FE model by applying a pinned boundary condition on the $+\mathrm{X}$ face of the CubeSat rail. This type of condition fixes the translational degrees of freedom of the selected nodes, but still allows them to rotate. Symmetric boundary conditions were also applied along the symmetry planes described in Section 4.2.1. All of the boundary conditions were applied in the initial step of the analysis. Figure 4-10 shows the application of the boundary conditions as well as the loading discussed in the Section 4.2.5.

\subsubsection{Load Condition}

The ELaNa 6 mission had the harshest vibration conditions that developers have been required to test their CubeSats. The random vibration profile provided by United Launch Alliance exhibited a peak of $23 \mathrm{G}_{\mathrm{rms}}$. A static load approximation of this vibration peak was used in the analysis of the RapidSat structure. This approximation was calculated using the "three sigma" load of the Miles' Equation [10]. This conservative estimate of the peak loading simply involves multiplying the peak RMS acceleration by 3 . 


$$
\begin{gathered}
3 \times G_{r m s \text { peak }}=G_{\text {static }} \\
3 \times 23 G_{r m s}=69 G
\end{gathered}
$$

This static approximation was applied to the whole model in the form of a gravity load along the $+\mathrm{X}$-axis of the assembly, compressing the satellite against the boundary condition applied in Section 4.2.4. Convergence issues were encountered in the analysis when this load was applied all at once in a single step. This was a result of the inability of the solver to prevent penetration between surfaces in the contact constraints with the sudden application of such a large load. The $69 \mathrm{G}$ load was split up into two analysis steps and gradually applied to the model to solve this issue. The first step applied a $5 \mathrm{G}$ load to the structure, allowing the solver to set the contact surfaces under a low loading condition. Once this was complete, the remaining $64 \mathrm{G}$ load was applied in the second step.

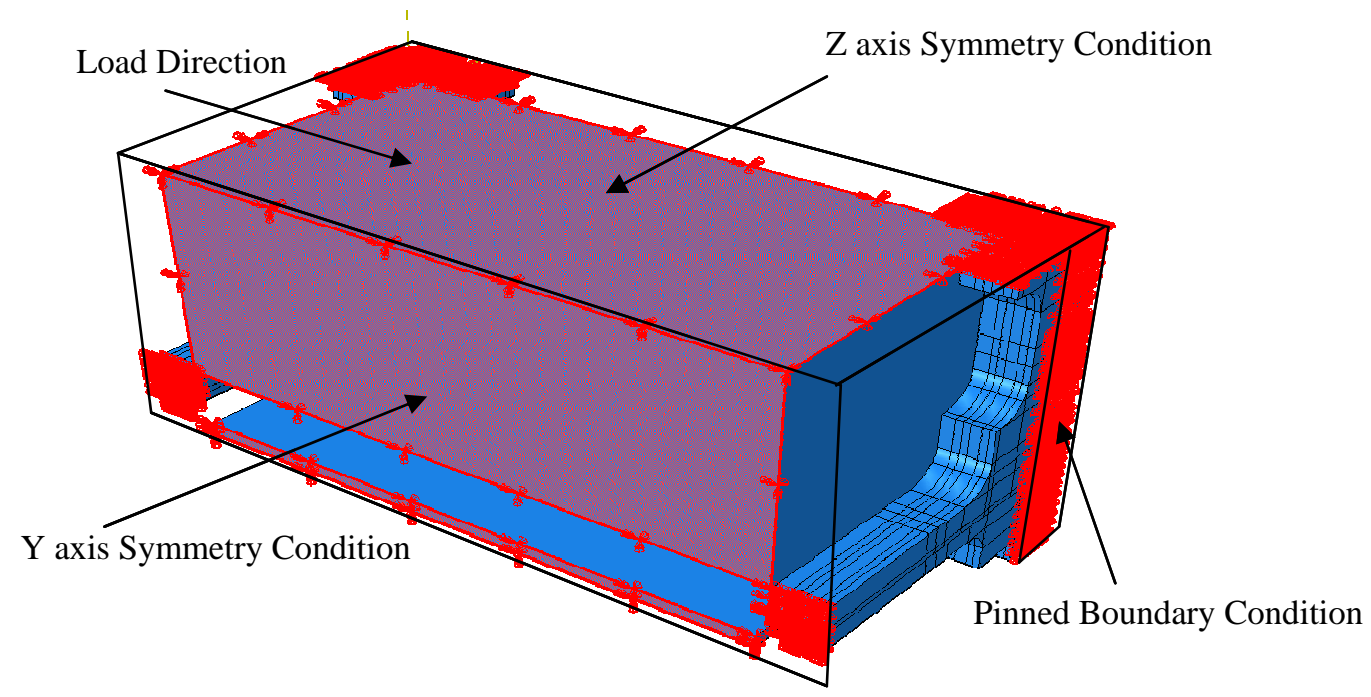

Figure 4-11: Boundary and Loading conditions for the Revision 1 structure

\subsubsection{Mesh Convergence Study}

A convergence study was performed on the assembly mesh to determine the required element size needed to accurately solve the model. A global seed size of $3 \mathrm{~mm}$ was applied to the Side Panels that were cut along two planes of symmetry in the first step of this study. Since these parts 
contained the slave surfaces for all the constraints, a slightly larger seed size was required for the other parts in the assembly for accurate enforcement of the assembly constraints as described in Section 4.2.3. Thus, global seed sizes of $3.25 \mathrm{~mm}$ and $3.5 \mathrm{~mm}$ were assigned to the other Side Panels and Shoe respectively. As the study progressed, the seed size for each part was reduced in $0.5 \mathrm{~mm}$ increments. The Mises stress and displacement magnitude of a test point on each part in the assembly were studied. These test points were located away from any stress concentrations to prevent irregularities in the results. A percent difference of less than 5\% in the test parameters for two consecutive reductions in seed size was used as the criterion for convergence. The test points studied are shown on the converged mesh model in Figure 4-13. Plots showing the number of elements in each step against the normalized stress and displacement values are shown in Figure 4-12 and a summary of the results is shown in Table 4-1. The final mesh exhibited a very low amount of element warnings caused by elements having an aspect ratio greater than 10 . These elements were located at the ends of the fillets and did not impact the accuracy of analysis results.
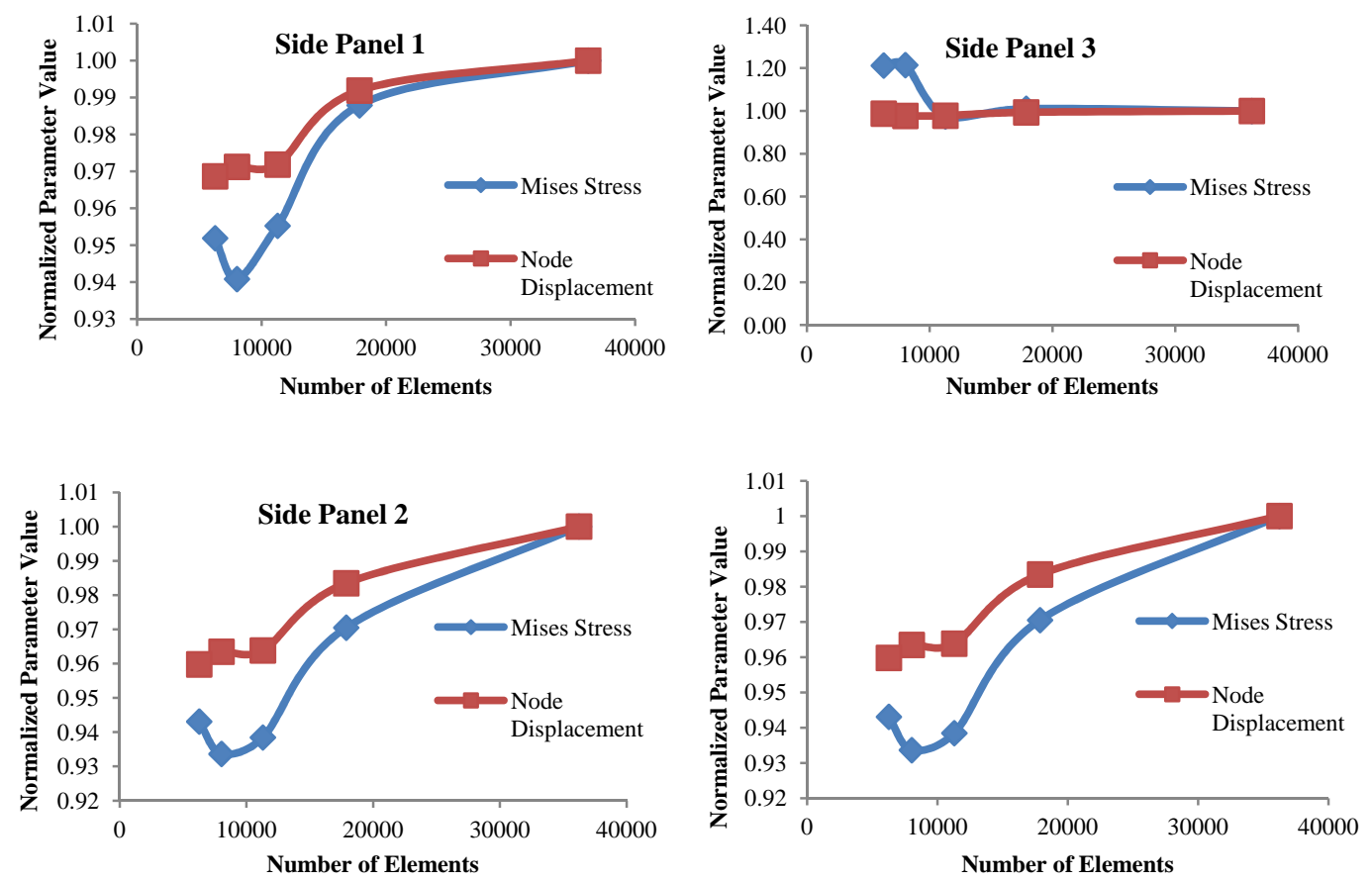

Figure 4-12: Convergence Plots for all test points of the Revision 1 Structure 
Table 4-1: Convergence Study results for the Revision 1 Structure

\begin{tabular}{|c|c|c|c|c|c|c|c|c|}
\hline \multirow{2}{*}{$\begin{array}{l}\text { Number of } \\
\text { Elements }\end{array}$} & \multicolumn{4}{|c|}{ Shoe } & \multicolumn{4}{|c|}{ Side Panel 1} \\
\hline & $\begin{array}{c}\text { Mises } \\
\text { Stress }(\mathrm{Pa})\end{array}$ & $\begin{array}{c}\text { Mises \% } \\
\text { Difference }\end{array}$ & $\begin{array}{l}\text { Displacement } \\
(\mathrm{m})\end{array}$ & $\begin{array}{l}\text { Disp. \% } \\
\text { Diff }\end{array}$ & $\begin{array}{c}\text { Mises } \\
\text { Stress }(\mathrm{Pa})\end{array}$ & $\begin{array}{c}\text { Mises \% } \\
\text { Difference }\end{array}$ & $\begin{array}{c}\text { Displacement } \\
(\mathrm{m})\end{array}$ & $\begin{array}{c}\text { Disp. \% } \\
\text { Diff }\end{array}$ \\
\hline 36231 & 325781 & 1.21 & $1.46 \mathrm{E}-05$ & 0.81 & 80630.3 & 1.06 & $1.15 \mathrm{E}-06$ & 0.61 \\
\hline 17864 & 321834 & 3.31 & $1.45 \mathrm{E}-05$ & 2.02 & 81483 & 3.52 & $1.14 \mathrm{E}-06$ & 1.58 \\
\hline 11286 & 311193 & 1.51 & $1.42 \mathrm{E}-05$ & 0.07 & 78613.9 & 24.58 & $1.12 \mathrm{E}-06$ & 0.08 \\
\hline 8019 & 306495 & 1.18 & $1.42 \mathrm{E}-05$ & 0.26 & 97937.8 & 0.17 & $1.12 \mathrm{E}-06$ & 1.06 \\
\hline 6261 & 310103 & - & $1.41 \mathrm{E}-05$ & - & 97774 & - & $1.14 \mathrm{E}-06$ & - \\
\hline \multirow{2}{*}{$\begin{array}{l}\text { Number of } \\
\text { Elements }\end{array}$} & \multicolumn{4}{|c|}{ Side Panel 2} & \multicolumn{4}{|c|}{ Side Panel 3} \\
\hline & $\begin{array}{c}\text { Mises } \\
\text { Stress }(\mathrm{Pa})\end{array}$ & $\begin{array}{c}\text { Mises \% } \\
\text { Difference }\end{array}$ & $\begin{array}{c}\text { Displacement } \\
(\mathrm{m})\end{array}$ & $\begin{array}{l}\text { Disp. \% } \\
\text { Diff }\end{array}$ & $\begin{array}{c}\text { Mises } \\
\text { Stress }(\mathrm{Pa})\end{array}$ & $\begin{array}{c}\text { Mises \% } \\
\text { Difference }\end{array}$ & $\begin{array}{c}\text { Displacement } \\
(\mathrm{m})\end{array}$ & $\begin{array}{c}\text { Disp. } \% \\
\text { Diff }\end{array}$ \\
\hline 36231 & 299870 & 2.95 & $8.05 \mathrm{E}-06$ & 1.66 & 169823 & 0.19 & 8.92E-06 & 1.36 \\
\hline 17864 & 291020 & 3.30 & $7.92 \mathrm{E}-06$ & 1.99 & 169493 & 1.64 & $8.80 \mathrm{E}-06$ & 1.47 \\
\hline 11286 & 281411 & 0.51 & $7.76 \mathrm{E}-06$ & 0.04 & 166713 & 0.42 & $8.67 \mathrm{E}-06$ & 0.04 \\
\hline 8019 & 279968 & 1.01 & $7.76 \mathrm{E}-06$ & 0.38 & 166005 & 0.25 & 8.67E-06 & 0.38 \\
\hline 6261 & 282804 & - & 7.73E-06 & - & 165596 & - & 8.63E-06 & - \\
\hline
\end{tabular}

Table 4-2: Details for the finalized mesh for the Revision 1 structure

\begin{tabular}{|c|c|c|c|c|c|c|}
\hline \multirow[b]{2}{*}{ Part } & \multicolumn{3}{|c|}{ Hex } & \multicolumn{3}{|c|}{ Wedge } \\
\hline & $\begin{array}{l}\text { Number of } \\
\text { Elements }\end{array}$ & $\begin{array}{c}\text { Average } \\
\text { Aspect Ratio } \\
\text { (1 nominal) }\end{array}$ & $\begin{array}{c}\text { Worst Aspect } \\
\text { Ratio } \\
(1 \text { nominal })\end{array}$ & $\begin{array}{l}\text { Number of } \\
\text { Elements }\end{array}$ & $\begin{array}{c}\text { Average } \\
\text { Aspect Ratio } \\
\text { (1 nominal) }\end{array}$ & $\begin{array}{c}\text { Worst Aspect } \\
\text { Ratio } \\
\text { (1 nominal) }\end{array}$ \\
\hline Side Panel 1 & 3928 & 1.18 & 1.67 & 424 & 3.35 & 11.21 \\
\hline Side Panel 2 & 4644 & 1.36 & 2 & 456 & 3.7 & 13.46 \\
\hline Side Panel 3 & 4786 & 1.4 & 2.14 & 480 & 3.57 & 8.52 \\
\hline Shoe & 3371 & 1.66 & 2.67 & 232 & 2.79 & 5.27 \\
\hline PCB & $\begin{array}{c}882 \text { (reduced } \\
\text { integration) }\end{array}$ & 1.01 & 1.01 & - & - & - \\
\hline Payload & $\begin{array}{c}17028 \text { (reduced } \\
\text { integration) }\end{array}$ & 1.04 & 1.04 & - & - & - \\
\hline
\end{tabular}




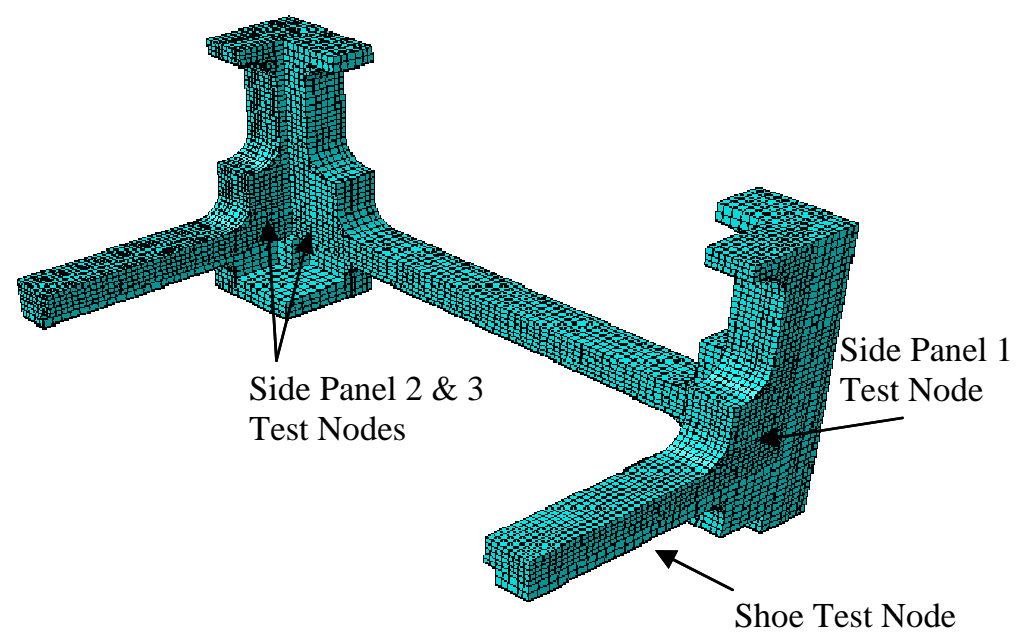

Figure 4-13: Converged mesh with test nodes used in convergence study

\subsubsection{Finite Element Analysis}

Once all part meshes were converged, analyses were performed using each of the material properties obtained in the Testing Phase. These were used to gain insight to how a structure composed of each material would react to the applied loading. Results from these analyses can be seen in Section 4.2.8.

Several warnings were encountered during the analysis of this model. The majority of these were standard warnings printed when using the tie constraint and were ignored. The other warnings were cause by the intersection of the pinned and symmetric boundary constraints which can be seen in Figure 4-11. Shared nodes along this intersection experienced over constrained degrees of freedom, causing Abaqus to report the warnings. However, the displacement of the nodes along this edge still behaved as expected, leading to the conclusion that these issues did not affect the accuracy of the model.

There were several factors that gave credence to the validity of the FEA. First, the behavior of the assembly was what one would expect and no areas in the model that had unusual displacements. Also, stresses and displacements of studied points in the model compared favorably to values 
obtained from simple hand calculations in Appendix A. Lastly, the largest force residual present at the end of the analyses was of the order of $10^{-12} \mathrm{~N}$. This shows that the solver was able to accurately solve the force-stiffness-displacement relationship of the model.

\subsubsection{Results}

The following section details the results of the Finite Element Analyses performed on the RapidSat Revision 1 structure using the properties of each 3D printed material. The displacement behavior of the structure was similar for each material, therefore, all the images shown are taken from the FullCure720 analysis. The highest stress in each of the parts in the assembly was located and used as the point of study for the comparison of the different material behaviors. It was found that the peak stress in several parts occurred where the tie constraints between the parts were put in shear. It was known that these constraints did not accurately model shear at the part joint, so stress at these points were ignored in favor of the next highest stress location. Instead, hand calculations shown in Appendix A were used to estimate the joint shear stress. The stress values of the study points along with plots showing the general behavior of the loaded structure are shown below in Figure 4-14, Figure 4-15, and Table 4-3. Detailed pictures of the locations of the study points are located in Appendix B. Assembly components were mirrored along the symmetry planes to provide a view of the full CubeSat structure. 


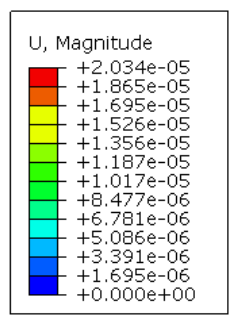

Step: Step-2

Time $=1.000$

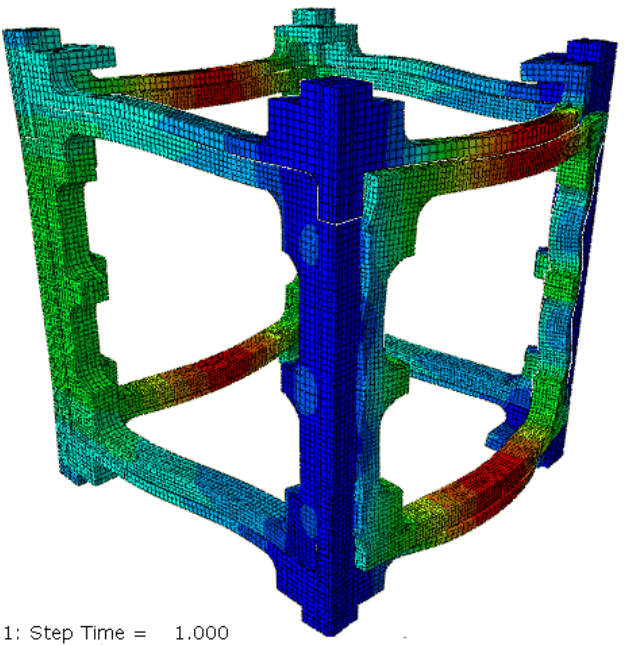

Var: U Deformation Scale Factor: $+4.933 e+02$

Figure 4-14: Displacement plot for RapidSat Revision 1

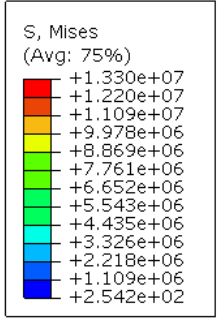

Step: Step-2

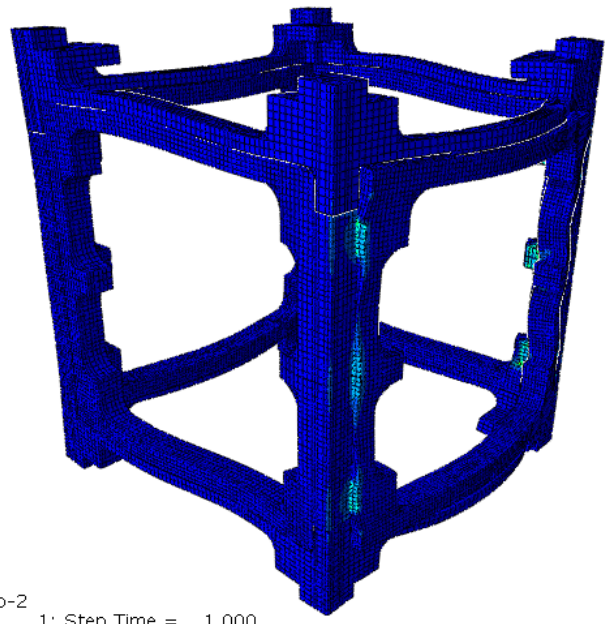

Primary Var: $S$. Mises

Deformed Var: U Deformation Scale Factor: $+4.933 \mathrm{e}+02$

Figure 4-15: Stress plot for RapidSat Revision 1 
Table 4-3: FEA results for RapidSat Revision 1

\begin{tabular}{|c|c|c|c|c|c|c|c|}
\hline \multirow{2}{*}{$\begin{array}{l}\text { Material } \\
\text { Analysis }\end{array}$} & \multirow{2}{*}{ Stress Type } & \multicolumn{4}{|c|}{ Study Points } & \multirow{2}{*}{$\begin{array}{c}\text { Margin } \\
\text { of Safety }\end{array}$} & \multirow{2}{*}{$\begin{array}{c}\text { Max Assembly } \\
\text { Displacement (m) }\end{array}$} \\
\hline & & Shoe & Side Panel 1 & Side Panel 2 & Side Panel 3 & & \\
\hline \multirow[b]{2}{*}{ FullCure720 } & Mises (Pa) & $3.77 \mathrm{E}+06$ & $1.07 \mathrm{E}+07$ & $1.73 \mathrm{E}+06$ & $6.54 \mathrm{E}+06$ & \multirow[b]{2}{*}{5.12} & \multirow[b]{2}{*}{$2.03 \mathrm{E}-05$} \\
\hline & $\begin{array}{l}\text { Max Principal } \\
(\mathrm{Pa})\end{array}$ & $1.16 \mathrm{E}+06$ & $4.92 \mathrm{E}+06$ & $2.73 \mathrm{E}+06$ & $2.20 \mathrm{E}+06$ & & \\
\hline \multirow[b]{2}{*}{ Watershed } & Mises (Pa) & $3.75 \mathrm{E}+06$ & $1.06 \mathrm{E}+07$ & $1.75 \mathrm{E}+06$ & $6.38 \mathrm{E}+06$ & \multirow[b]{2}{*}{3.29} & \multirow[b]{2}{*}{$2.35 \mathrm{E}-05$} \\
\hline & $\begin{array}{c}\text { Max Principal } \\
(\mathrm{Pa})\end{array}$ & $1.11 \mathrm{E}+06$ & $4.49 \mathrm{E}+06$ & $2.76 \mathrm{E}+06$ & $2.16 \mathrm{E}+06$ & & \\
\hline \multirow{2}{*}{ Prototherm } & Mises (Pa) & $3.77 \mathrm{E}+06$ & $1.08 \mathrm{E}+07$ & $1.76 \mathrm{E}+06$ & $1.76 \mathrm{E}+06$ & \multirow{2}{*}{7.93} & \multirow{2}{*}{$1.64 \mathrm{E}-05$} \\
\hline & $\begin{array}{c}\text { Max Principal } \\
(\mathrm{Pa})\end{array}$ & $1.25 \mathrm{E}+06$ & $4.91 \mathrm{E}+06$ & $2.77 \mathrm{E}+06$ & $2.77 \mathrm{E}+06$ & & \\
\hline \multirow[b]{2}{*}{ WindformXT } & Mises (Pa) & $3.79 \mathrm{E}+06$ & $1.13 \mathrm{E}+07$ & $1.96 \mathrm{E}+06$ & $6.82 \mathrm{E}+06$ & \multirow[b]{2}{*}{6.50} & \multirow[b]{2}{*}{$8.11 \mathrm{E}-06$} \\
\hline & $\begin{array}{l}\text { Max Principal } \\
(\mathrm{Pa})\end{array}$ & $1.71 \mathrm{E}+06$ & $5.17 \mathrm{E}+06$ & $3.10 \mathrm{E}+06$ & $2.30 \mathrm{E}+06$ & & \\
\hline
\end{tabular}

\subsubsection{RapidSat Revision 1 Discussion}

Analysis results for the RapidSat Revision 1 structure showed that additional strengthening would be required for the margin of safety criterion to be achieved for the majority of the materials. Also, the contact areas between the CubeSat rails and the P-POD were raised as an area of concern when reviewing the design with members of Polysat and the CubeSat community during the 2012 CubeSat Workshop. It was determined that the contact stress between the 3D printed structure, the P-POD, and the other CubeSats would likely cause abrasion on the surface of the plastics. This would leave deposits of the material on the rails of the P-POD and cause irregularities in the deployment characteristics of the CubeSats during launch. These factors led to the decision to develop a second revision of the design.

\subsection{RapidSat Revision 2 Concept Structure}

A second revision of the RapidSat structure was developed to address the design concerns mentioned in Section 4.2.9. Aluminum rails were created to replace the $3 \mathrm{D}$ printed rails in the Revision 1 design. The introduction of these rails required several design changes to be made to the other parts in the assembly. These changes are outlined in Sections 4.3.1 - 4.3.3. The method 
for joining the parts together was also revised in this design. It was determined that the integrity of the joints of the Revision 1 design would heavily rely on the strength of the Loctite used to secure the HeliCoils rather than the HeliCoils themselves. Pockets were added to the Side Panels of the Revision 2 structure to accommodate the use of hex nuts to remove the need for HeliCoils. These pockets are described further in Section 4.3.3. Lastly, the thickness of the printed parts was increased to lower the overall stress seen with the Revision 1 Structure. This resulted in a $13 \%$ loss in payload volume and a mass increase of 83 grams when compared to the aluminum HyperCube structure.

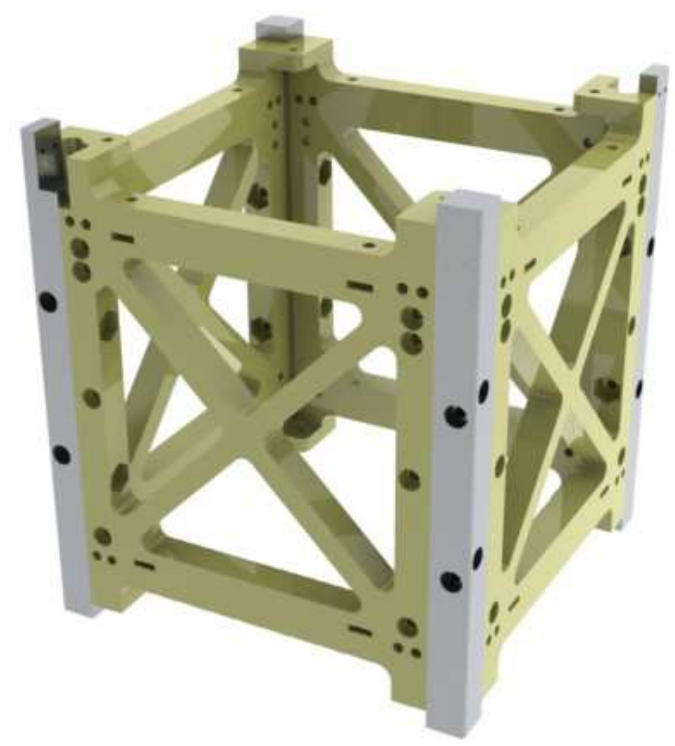

Figure 4-16: RapidSat Revision 2 Concept Structure

\subsubsection{RapidSat Revision 2 Rails}

The Rails of the second revision structure were designed to provide an aluminum contact for the P-POD and other CubeSats at all four corners along the entire length of the CubeSat. The only relatively complex features the Rails possess are the mating Extrusion and Slot features of the 
first revision parts, shown in Figure 4-17. As a result, these parts could easily be machined by student technicians on a CNC or hand mill.

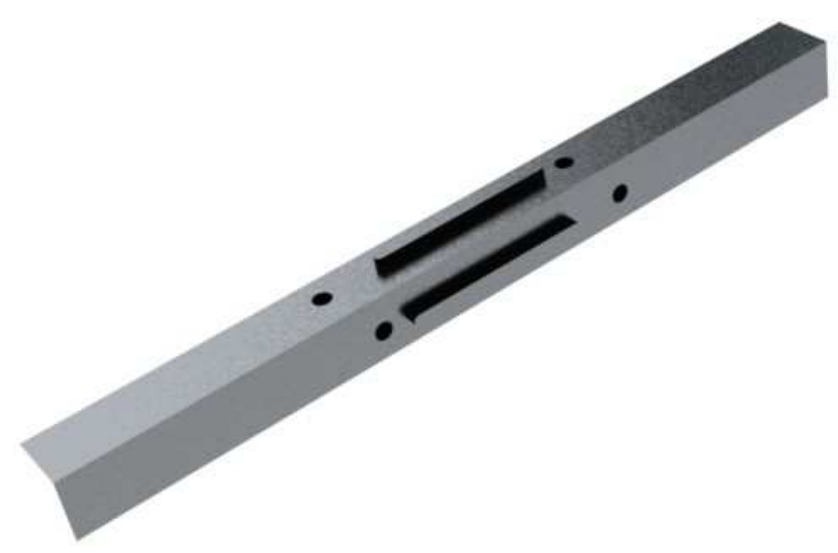

Figure 4-17: RapidSat Revision 2 Rails

\subsubsection{RapidSat Revision 2 Top Hat and Shoe}

The Top Hat and Shoe required modification for them fit around the new Rails. This involved eliminating the mounting tabs. In this revision of the structure, the Top Hat and Shoe mount to the Side Panels along their bottom face with a 8 screws, seen in Figure 4-18.

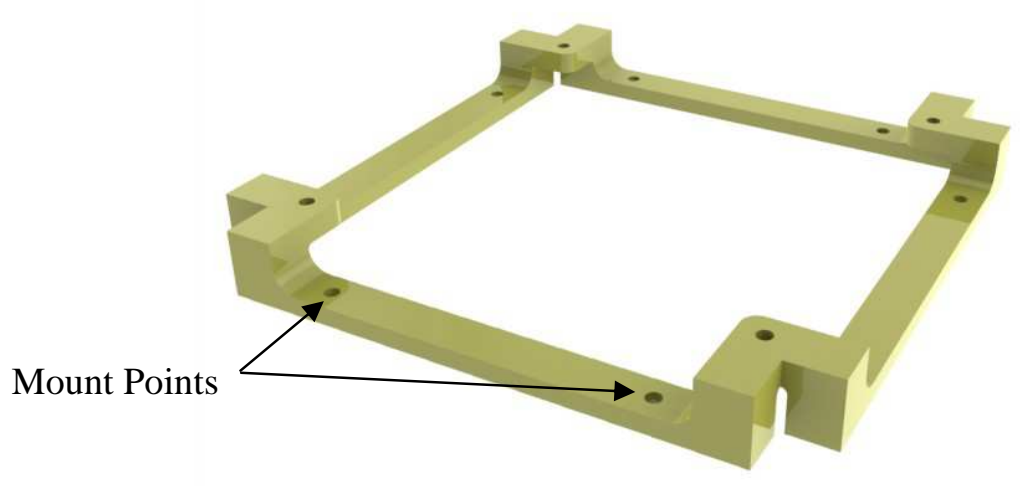

Figure 4-18: RapidSat Revision 2 Shoe 


\subsubsection{RapidSat Revision 2 Side Panels}

Major modifications to Side Panels include the addition of diagonal braces and the pockets for hex nuts initially described in Section 4.3 and shown in Figure 4-19. The braces will prevent the side panels from flexing significantly during vibration and add additional support for sensitive payloads. The pockets are contoured to the shape of the hex nuts, allowing them to fit snugly in the structure. This places the joint loads on the fasteners and structure rather than Loctite used in the previous revision.

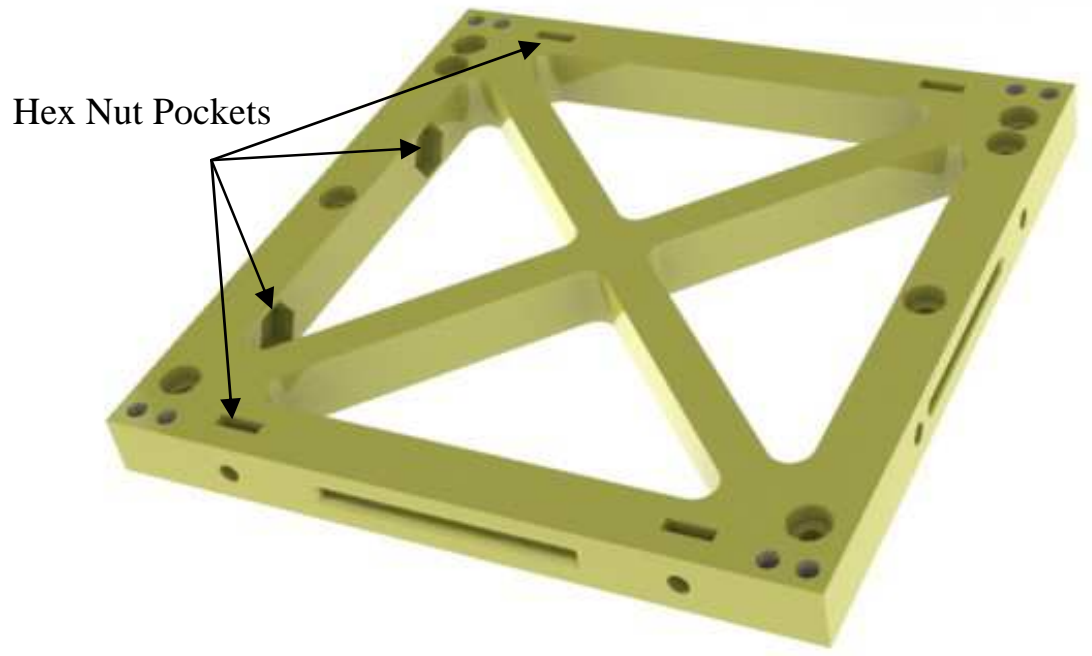

Figure 4-19: RapidSat Revision 2 Side Panel

\subsection{Finite Element Analysis of the RapidSat Revision 2 Structure}

Two Finite Element Models of the RapidSat Revision 2 Structure were constructed with Abaqus/Standard using the same methods described in Section 4.3 to study vibration loading along the $\mathrm{X}$ and $\mathrm{Z}$ axes. Results from the Finite Element Analysis were again compared to simplified hand calculations shown in Appendix A to determine their validity. 


\subsubsection{Finite Element Model Development}

Two planes of symmetry were utilized for each model to reduce the complexity and computation time of the analyses. Parts were simplified using the same methods described in Section 4.2.1and imported as 3D deformable solids, with Payload and PCB mass representations being created in Abaqus. The part assemblies for the Revision 2 structure with the utilized planes of symmetry are shown in Figure 4-20. The partitioning strategy used in the Revision 1 structure was also used in these models.

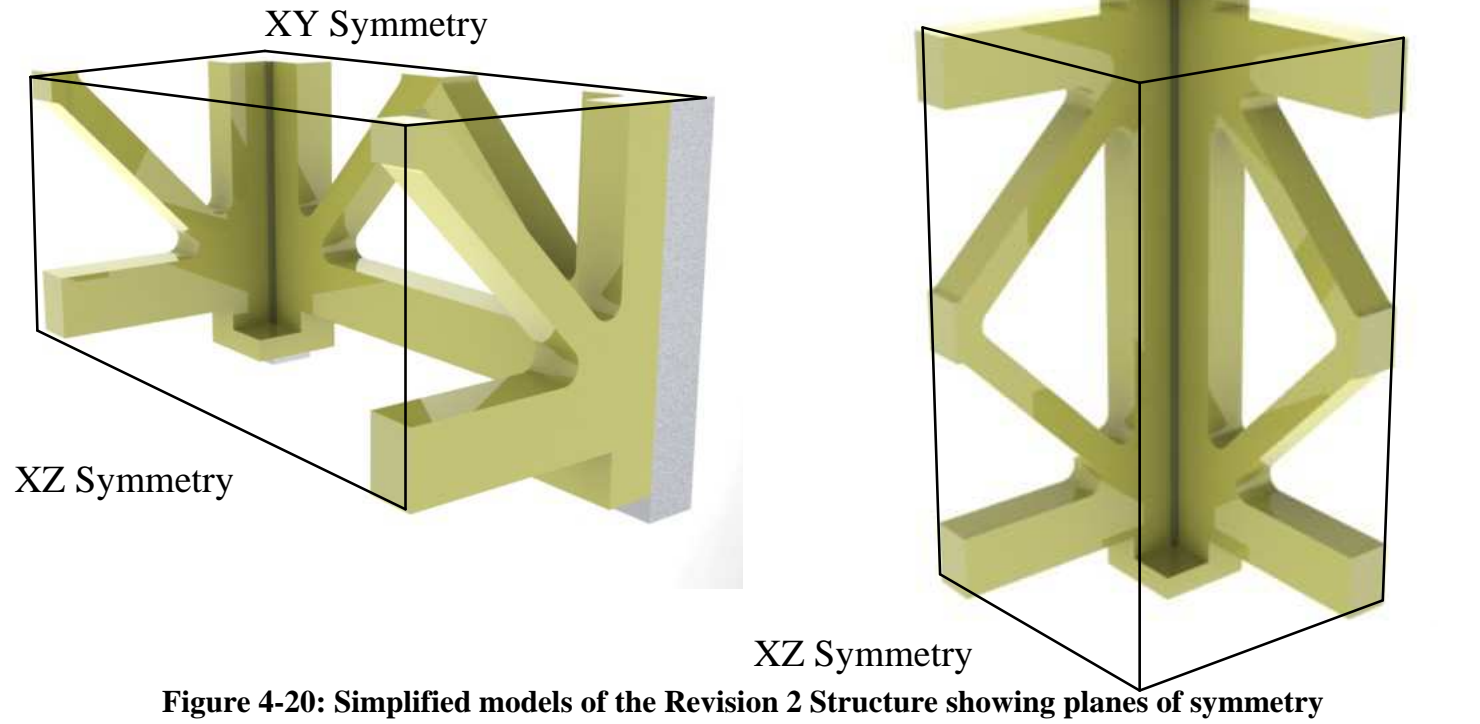

\subsubsection{Mesh Development}

Straight sections of constant rectangular cross section in the models were represented by quadratic hex elements and curved sections of the structures were represented by quadratic wedge elements. Justification for these decisions are made in Section 4.2.2. The final assembly mesh can be seen in Figure 4-23. 


\subsubsection{Assembly Constraints}

There were no changes in the types of constraints used in the Revision 2 structure. A detailed description of these constraints can be found in Section 4.2.3

\subsubsection{Boundary Conditions}

The pinned boundary condition on the $+\mathrm{X}$ face of the CubeSat rail along with $\mathrm{Y}$ and $\mathrm{Z}$ symmetry conditions present in the Revision 1 model were applied to the X-axis loaded Revision 2 model. A pinned boundary condition on the top of the Rail was applied to the Z- axis loaded Revision 2 model in addition to $\mathrm{X}$ and $\mathrm{Y}$ symmetry. Figure 4-21 shows the application of the boundary conditions as well as the loading discussed in Section 4.4.5.

\subsubsection{Load Condition}

A 69 G Gravity load was applied in the $+X$ direction for the first Revision 2 model. The same load was applied in the $+\mathrm{Z}$ direction for the second model. The load was split up into two analysis steps and gradually applied to the model to prevent convergence problems from occurring. The derivation of this load and its application method can be found in Section 4.2.5.
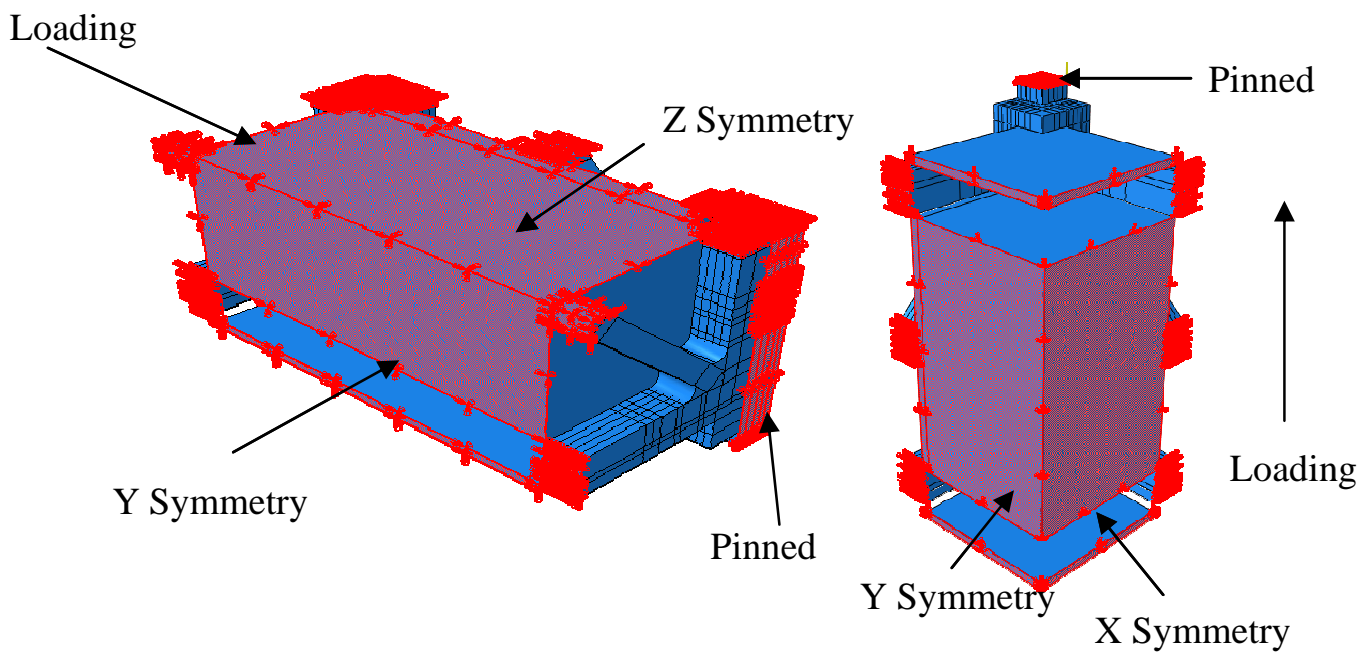

Figure 4-21: Boundary and Loading conditions for the Revision 2 FEA 


\subsubsection{Mesh Convergence Study}

A convergence study was performed on the assembly mesh for the X-axis loaded model using the same methods describe in Section 4.2.6. Similarities between the parts in each model allowed for the use of a single study to justify mesh convergence for both assemblies. The test points studied are shown in Figure 4-23. Plots showing the results normalized against the converged stress and displacement values are shown in Figure 4-22 and a summary of the results is shown in Table 4-4.
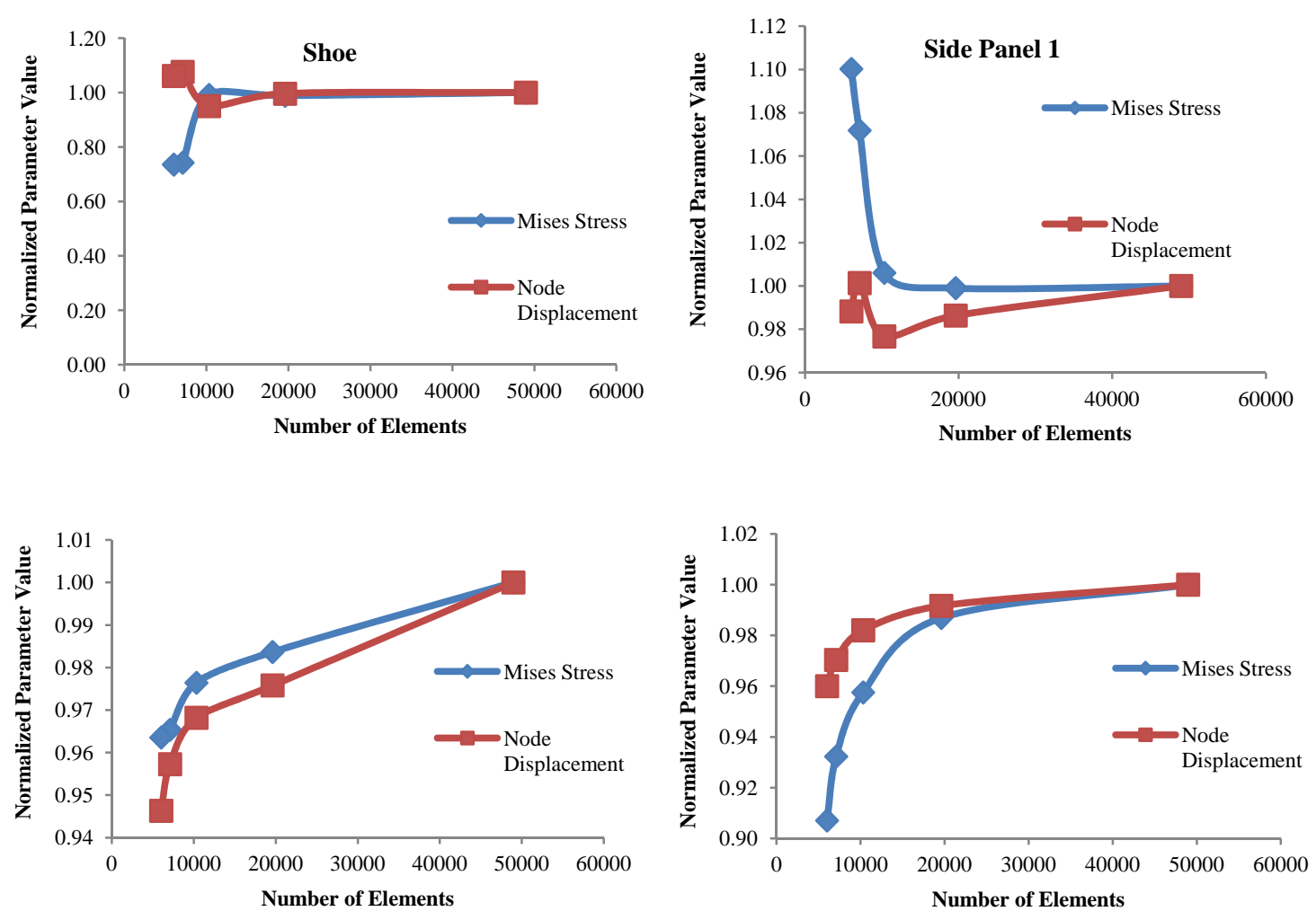

Figure 4-22: Convergence Plots for the RapidSat Revision 2 Structure 
Table 4-4: Convergence study results for the Revision 2 structure

\begin{tabular}{|c|c|c|c|c|c|c|c|c|}
\hline \multirow{2}{*}{$\begin{array}{l}\text { Number of } \\
\text { Elements }\end{array}$} & \multicolumn{4}{|c|}{ Side Panel 1} & \multicolumn{4}{|c|}{ Side Panel 2} \\
\hline & $\begin{array}{c}\text { Mises } \\
\text { Stress }(\mathrm{Pa})\end{array}$ & $\begin{array}{c}\text { Mises \% } \\
\text { Difference }\end{array}$ & $\begin{array}{c}\text { Displacement } \\
(\mathrm{m})\end{array}$ & $\begin{array}{l}\text { Disp. \% } \\
\text { Diff }\end{array}$ & $\begin{array}{c}\text { Mises } \\
\text { Stress }(\mathrm{Pa})\end{array}$ & $\begin{array}{c}\text { Mises \% } \\
\text { Difference }\end{array}$ & $\begin{array}{c}\text { Displacement } \\
(\mathrm{m})\end{array}$ & $\begin{array}{c}\text { Disp. \% } \\
\text { Diff }\end{array}$ \\
\hline 48961 & 449941 & 1.17 & $7.78 \mathrm{E}-06$ & 0.39 & 279239 & 0.10 & $2.00 \mathrm{E}-06$ & 1.40 \\
\hline 19598 & 444721 & 0.34 & $7.75 \mathrm{E}-06$ & 4.78 & 278956 & 0.70 & $1.98 \mathrm{E}-06$ & 0.99 \\
\hline 10315 & 446256 & 33.52 & 7.39E-06 & 11.70 & 280915 & 6.13 & $1.96 \mathrm{E}-06$ & 2.46 \\
\hline 7095 & 334219 & 0.94 & 8.37E-06 & 1.42 & 299288 & 2.58 & $2.01 \mathrm{E}-06$ & 1.32 \\
\hline 6018 & 331106 & - & $8.26 \mathrm{E}-06$ & - & 307224 & - & $1.98 \mathrm{E}-06$ & - \\
\hline \multirow{2}{*}{$\begin{array}{l}\text { Number of } \\
\text { Elements }\end{array}$} & \multicolumn{4}{|c|}{ Shoe } & \multicolumn{4}{|c|}{ Rail } \\
\hline & $\begin{array}{c}\text { Mises } \\
\text { Stress }(\mathrm{Pa})\end{array}$ & $\begin{array}{c}\text { Mises \% } \\
\text { Difference }\end{array}$ & $\begin{array}{c}\text { Displacement } \\
(\mathrm{m})\end{array}$ & $\begin{array}{l}\text { Disp. \% } \\
\text { Diff }\end{array}$ & $\begin{array}{c}\text { Mises } \\
\text { Stress }(\mathrm{Pa})\end{array}$ & $\begin{array}{c}\text { Mises \% } \\
\text { Difference }\end{array}$ & $\begin{array}{c}\text { Displacement } \\
(\mathrm{m})\end{array}$ & $\begin{array}{c}\text { Disp. \% } \\
\text { Diff }\end{array}$ \\
\hline 48961 & 139630 & 1.66 & $6.89 \mathrm{E}-06$ & 2.48 & 135070 & 4.42 & $9.03 \mathrm{E}-06$ & 3.12 \\
\hline 19598 & 137347 & 0.74 & $6.72 \mathrm{E}-06$ & 0.79 & 129356 & 3.07 & $8.76 \mathrm{E}-06$ & 0.98 \\
\hline 10315 & 136337 & 1.14 & $6.67 \mathrm{E}-06$ & 1.14 & 125507 & 2.71 & $8.68 \mathrm{E}-06$ & 1.20 \\
\hline 7095 & 134794 & 0.19 & $6.59 \mathrm{E}-06$ & 1.16 & 122194 & 2.78 & 8.57E-06 & 1.08 \\
\hline 6018 & 134539 & - & $6.52 \mathrm{E}-06$ & - & 118892 & - & $8.48 \mathrm{E}-06$ & - \\
\hline
\end{tabular}

Table 4-5: Mesh details of the X-loaded Revision 2 structure

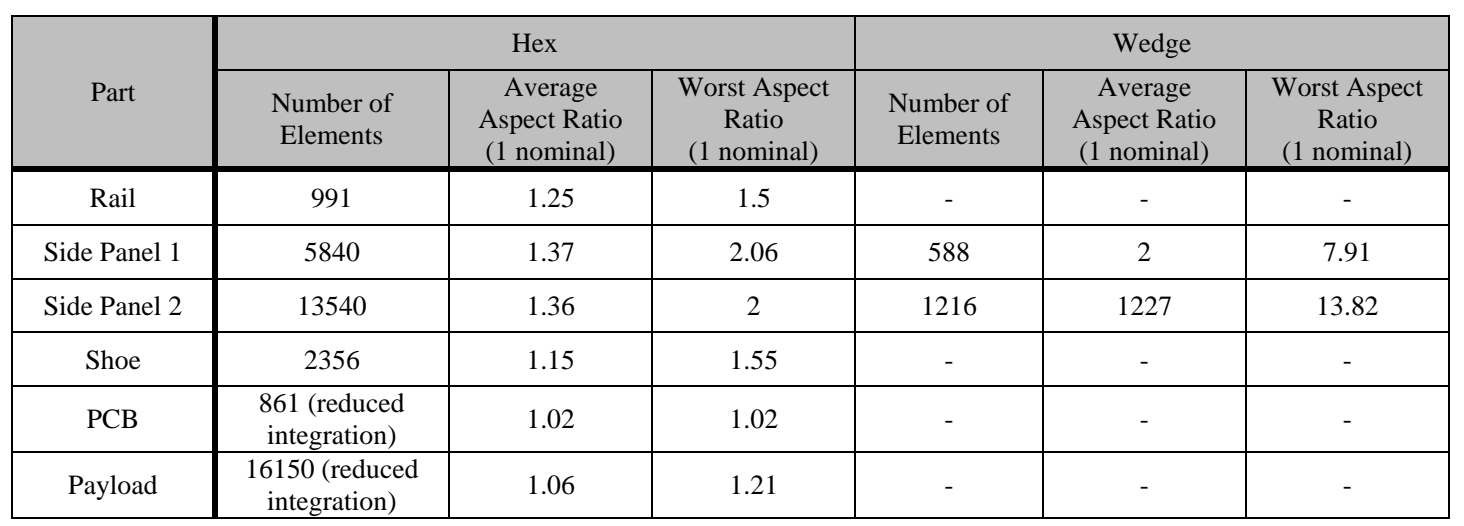


Table 4-6: Mesh deatils of the Z-loaded Revision 2 structure

\begin{tabular}{|c|c|c|c|c|c|c|}
\hline \multirow{2}{*}{ Part } & \multicolumn{3}{|c|}{ Hex } & \multicolumn{3}{|c|}{ Wedge } \\
\cline { 2 - 6 } & $\begin{array}{c}\text { Number of } \\
\text { Elements }\end{array}$ & $\begin{array}{c}\text { Average } \\
\text { Aspect Ratio } \\
(1 \text { nominal })\end{array}$ & $\begin{array}{c}\text { Worst Aspect } \\
\text { Ratio } \\
(1 \text { nominal })\end{array}$ & $\begin{array}{c}\text { Number of } \\
\text { Elements }\end{array}$ & $\begin{array}{c}\text { Average } \\
\text { Aspect Ratio } \\
(1 \text { nominal })\end{array}$ & $\begin{array}{c}\text { Worst Aspect } \\
\text { Ratio } \\
(1 \text { nominal })\end{array}$ \\
\hline Rail & 1932 & 1.25 & 1.42 & - & - & -2.37 \\
\hline Side Panel & 9660 & 1.54 & 2 & 1032 & - & - \\
\hline Shoe & 1333 & 1.29 & 1.5 & - & - \\
\hline PCB & $\begin{array}{c}440 \text { (reduced } \\
\text { integration) }\end{array}$ & 1.01 & 1.01 & - & - \\
\hline
\end{tabular}
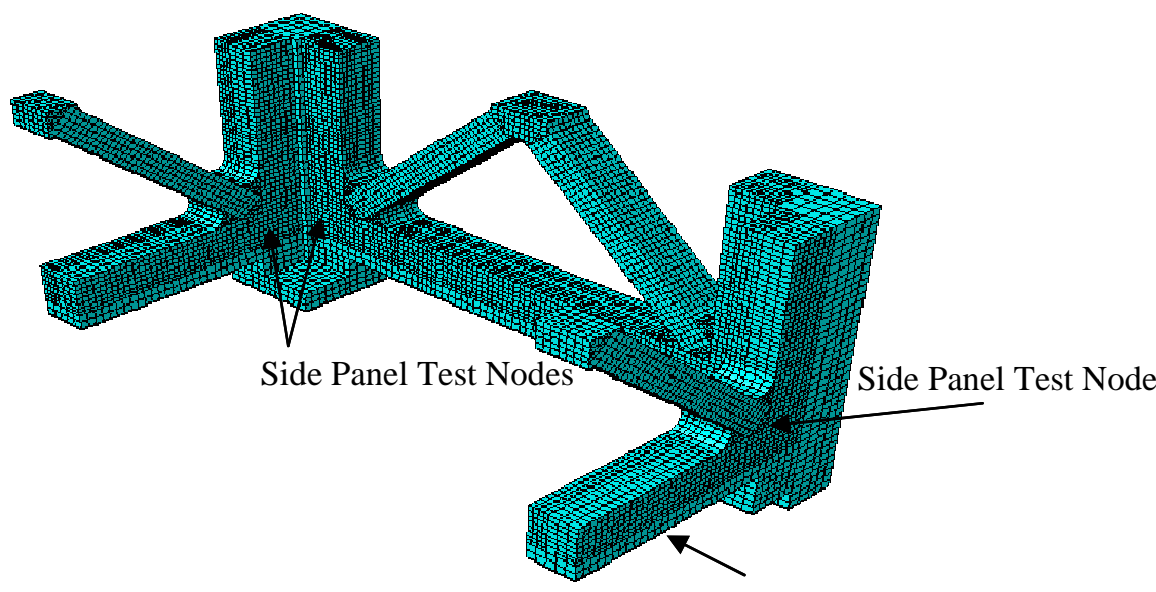

Shoe Test Node

Figure 4-23: Converged mesh showing the test points used in the convergence study

\subsubsection{Finite Element Analysis}

The same types of warnings described in Section 4.2.7 were encountered when running this model and it was determined that they did not impacted the model's accuracy. These models also exhibited the same types of validity properties described in Section 4.2.7 as well. 


\subsubsection{Results}

The following section details the results of the Finite Element Analyses performed on the RapidSat Revision 2 structure under both loading conditions using the properties of each 3D printed material. As was found with the first revision, the displacement behavior of the structure was similar for each material and all the images shown are taken from the FullCure720 analysis. Study points were chosen at the values of highest stress in each part, continuing to ignore joint shear stress. The stress values of the study points along with figures showing the general behavior of the loaded structure are shown in Figure 4-24, Figure 4-25, Figure 4-26, Figure 4-27. Table 4-7, and Table 4-8. Detailed pictures of the locations of the study points are located in Appendix B. Assembly components were mirrored along the symmetry planes to provide a view of the full CubeSat structure.

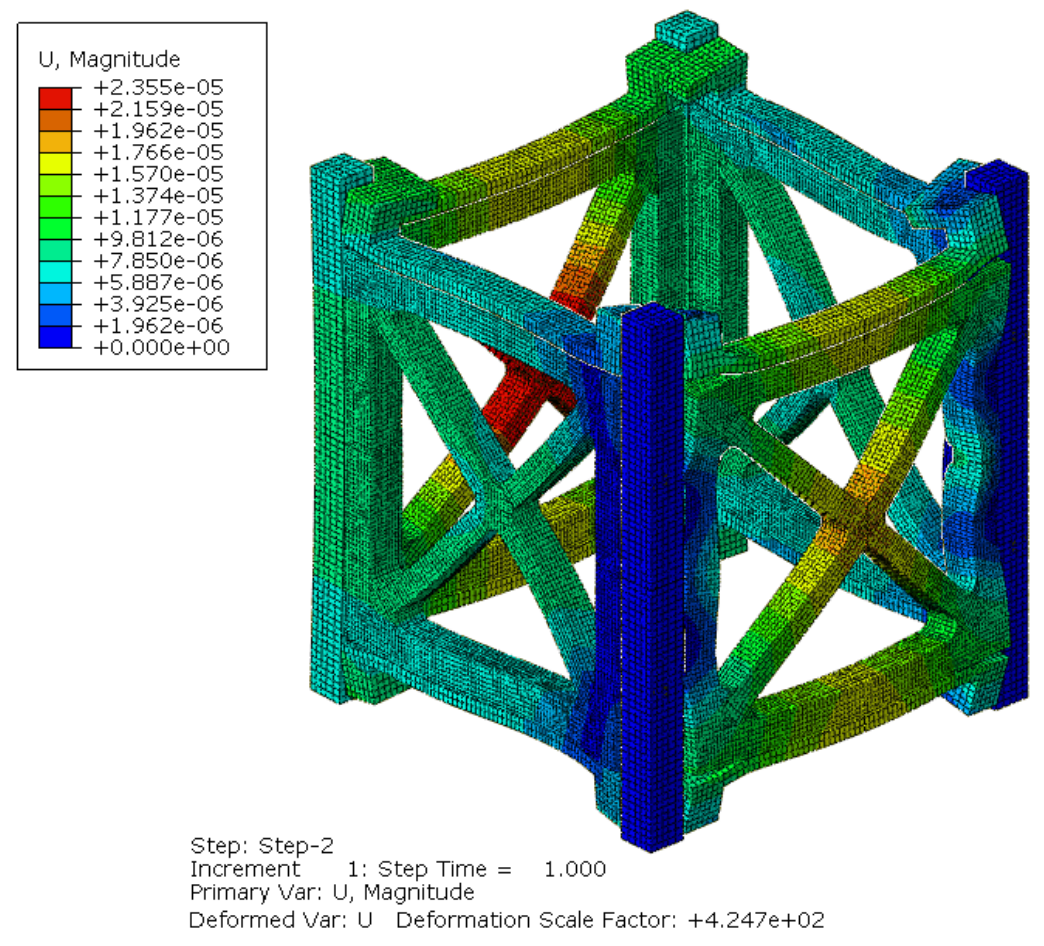

Figure 4-24: Displacement plot of the X-axis loaded RapidSat Revision 2 structure 


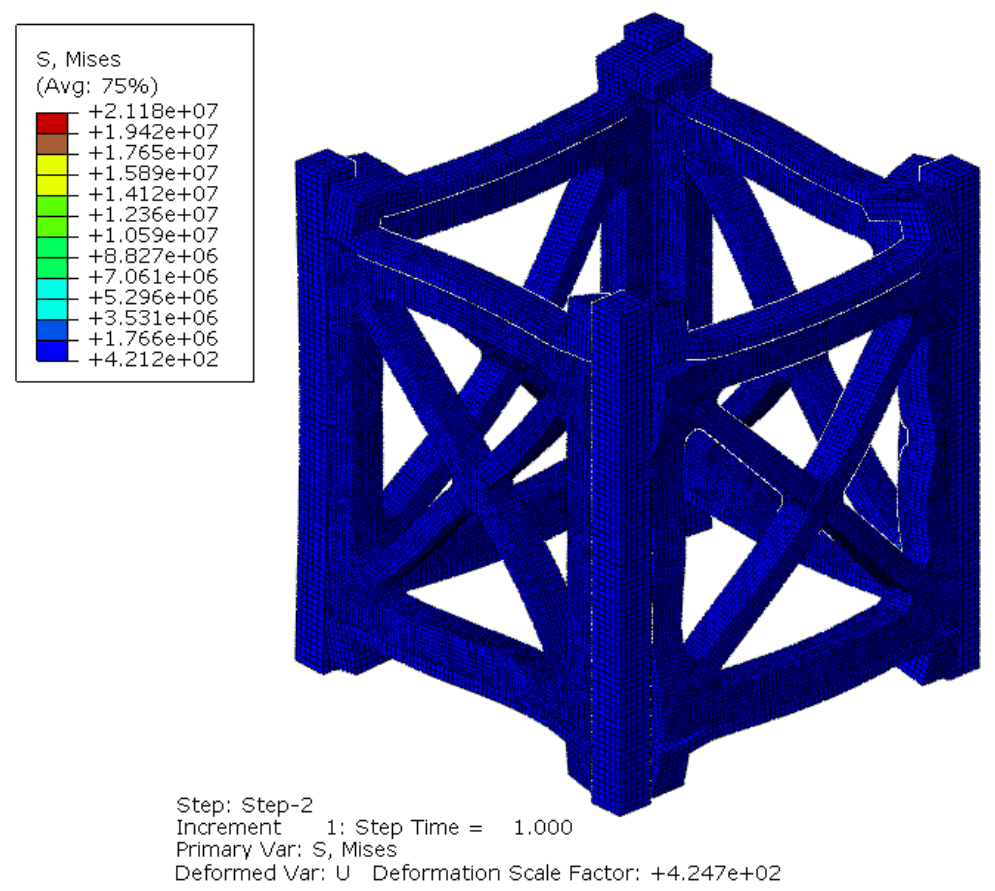

Figure 4-25: Stress plot of the X-axis loaded RapidSat Revision 2 structure

Table 4-7: FEA results of the X-axis loaded RapidSat Revision 2

\begin{tabular}{|c|c|c|c|c|c|c|c|c|c|}
\hline $\begin{array}{l}\text { Material } \\
\text { Analysis }\end{array}$ & $\begin{array}{l}\text { Stress } \\
\text { Type }\end{array}$ & \multicolumn{6}{|c|}{ Study Points } & $\begin{array}{l}\text { Margin } \\
\text { of } \\
\text { Safety }\end{array}$ & $\begin{array}{l}\text { Maximum } \\
\text { Displacement } \\
\text { (m) }\end{array}$ \\
\hline FullCure720 & $\begin{array}{c}\text { Max } \\
\text { Principal } \\
(\mathrm{MPa})\end{array}$ & $\begin{array}{c}2.78 \\
E+06\end{array}$ & $\begin{array}{c}1.47 \\
\mathrm{E}+06\end{array}$ & $\begin{array}{l}5.21 \\
E+06\end{array}$ & $\begin{array}{c}3.49 \\
\mathrm{E}+06\end{array}$ & $\begin{array}{c}1.11 \\
\mathrm{E}+06\end{array}$ & $\begin{array}{c}6.19 \\
E+06\end{array}$ & 7.79 & $2.36 \mathrm{E}-05$ \\
\hline Watershed & $\begin{array}{c}\text { Max } \\
\text { Principal } \\
(\mathrm{MPa})\end{array}$ & $\begin{array}{c}2.74 \\
E+06\end{array}$ & $\begin{array}{c}1.46 \\
\mathrm{E}+06\end{array}$ & $\begin{array}{c}4.99 \\
E+06\end{array}$ & $\begin{array}{c}3.32 \\
\mathrm{E}+06\end{array}$ & $\begin{array}{c}1.19 \\
\mathrm{E}+06\end{array}$ & $\begin{array}{c}6.20 \\
E+06\end{array}$ & 5.12 & $2.71 \mathrm{E}-05$ \\
\hline Prototherm & $\begin{array}{l}\text { Mises } \\
(\mathrm{MPa}) \\
\end{array}$ & $\begin{array}{c}4.18 \\
\mathrm{E}+06 \\
\end{array}$ & $\begin{array}{c}2.01 \\
E+06 \\
\end{array}$ & $\begin{array}{c}7.45 \\
E+06 \\
\end{array}$ & $\begin{array}{c}4.67 \\
E+06\end{array}$ & $\begin{array}{c}8.46 \\
\mathrm{E}+05 \\
\end{array}$ & $\begin{array}{c}1.24 \\
\mathrm{E}+07 \\
\end{array}$ & 11.96 & $1.87 \mathrm{E}-05$ \\
\hline WindformXT & $\begin{array}{c}\text { Max } \\
\text { Principal } \\
(\mathrm{MPa})\end{array}$ & $\begin{array}{c}2.99 \\
E+06\end{array}$ & $\begin{array}{c}1.38 \\
\mathrm{E}+06\end{array}$ & $\begin{array}{c}5.23 \\
E+06\end{array}$ & $\begin{array}{c}3.29 \\
E+06\end{array}$ & $\begin{array}{c}9.69 \\
\mathrm{E}+05\end{array}$ & $\begin{array}{c}5.87 \\
\mathrm{E}+06\end{array}$ & 10.55 & $1.01 \mathrm{E}-05$ \\
\hline
\end{tabular}




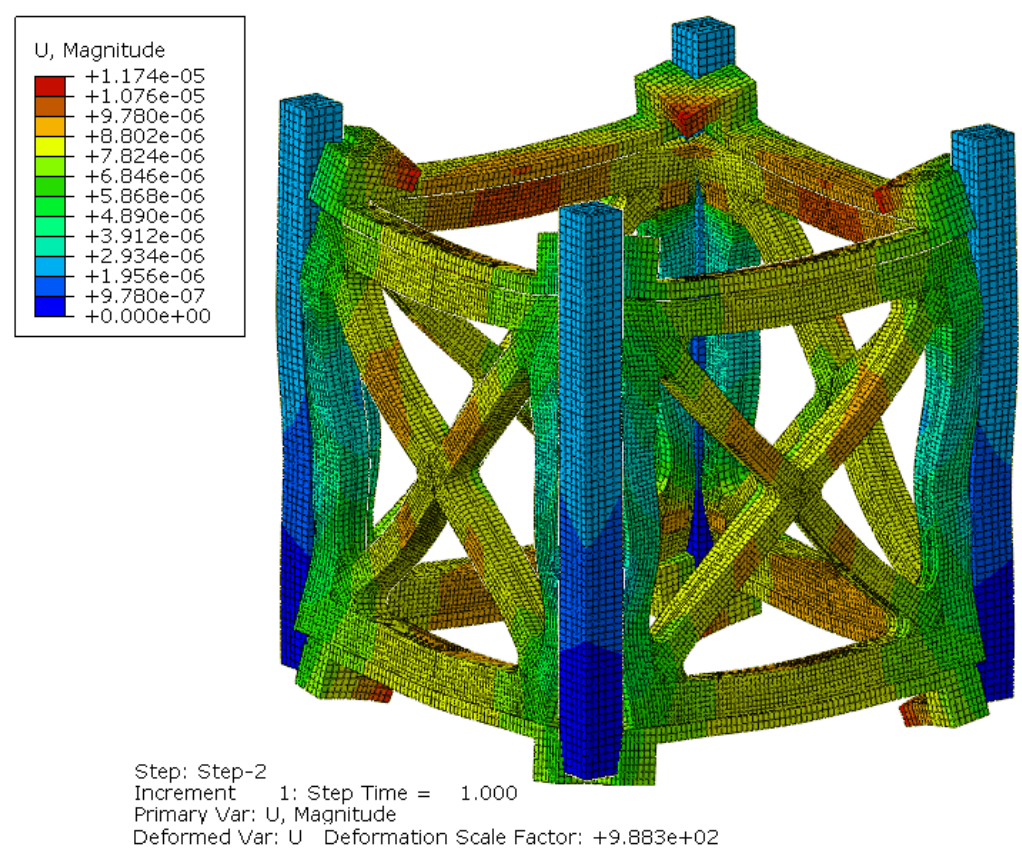

Figure 4-26: Displacement plot for the Z-axis loaded RapidSat Revision 2 structure

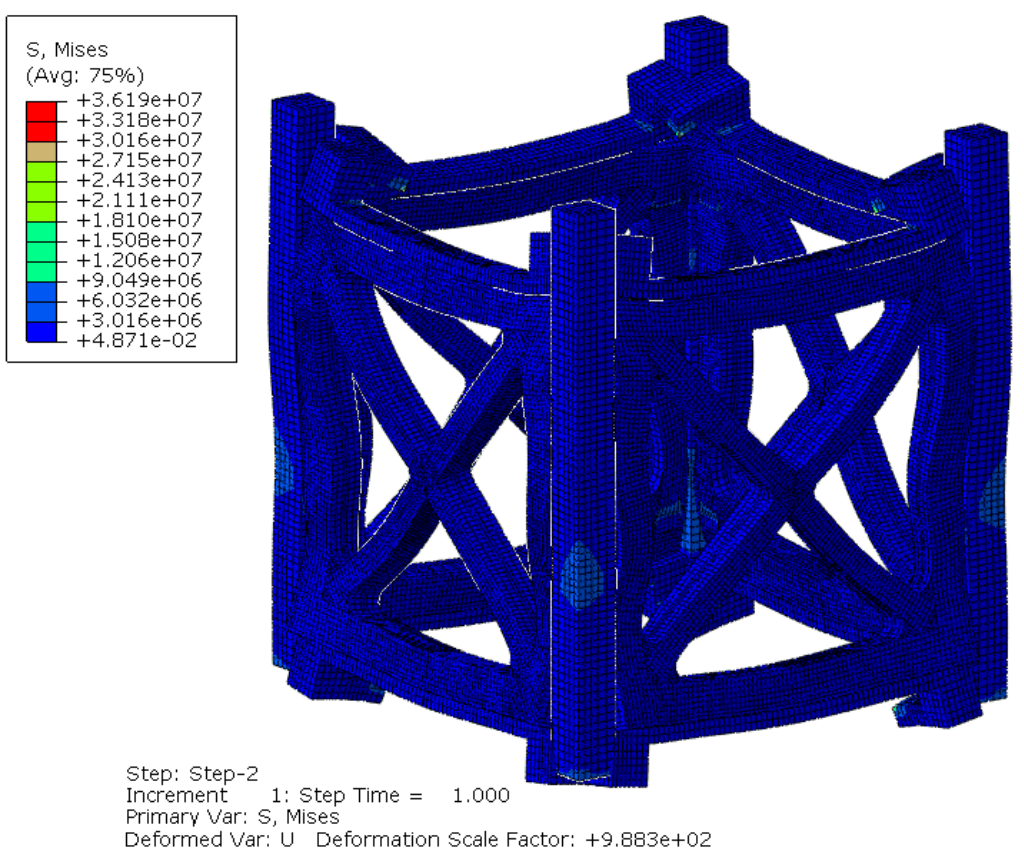

Figure 4-27: Stress plot for the Z-axis loaded RapidSat Revision 2 structure 
Table 4-8: FEA results for the Z-loaded RapidSat Revision 2 structure

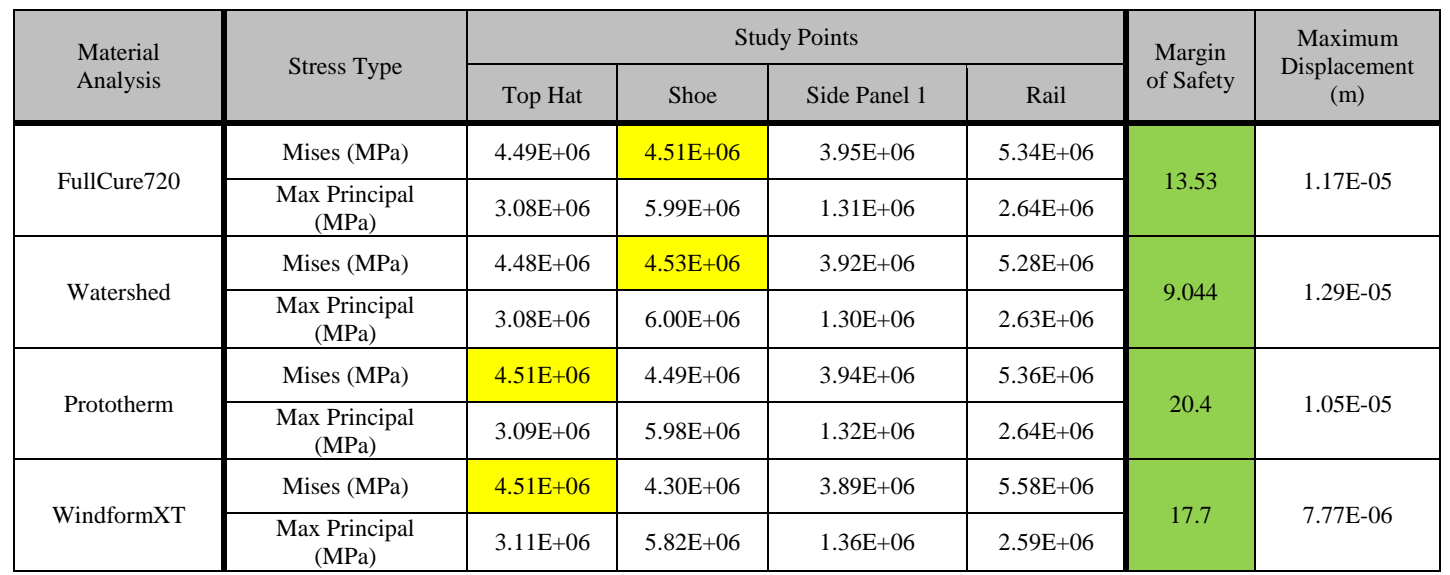

\subsubsection{RapidSat Revision 2 Discussion}

The FullCure720, Prototherm, and WindformXT Revision 2 structures all met the success criterion set for this analysis. All realistic stress values found in the FEA meet a margin of safety of at least 7 and the payload volume only decreased by $13 \%$. It is also important to note that the margin of safety criterion would have been met using the yield properties of the raw samples as well. This shows that the materials would be able to survive the conditions presented in either of the acceptable CubeSat test flows shown in Figure 1-3.

The analysis performed with the material properties of the Watershed sample set failed to meet the yield stress success criterion and could not be used in this structure. This was expected due to its low performance level during the Testing Phase. However, its elastic properties could provide useful damping in some non-load bearing applications.

While this structure has not been optimized for a for specific mission use, the results from this set of analyses show that a generic CubeSat concept structure manufactured from 3D printing material is capable of surviving a launch environment. 


\subsection{RapidSat Concept Payload Bracket}

The Payload Bracket from the HyperCube structure was slightly modified for use in the 3D printed concept. The only changes in this part were the widening of all the threaded holes to accommodate the use of HeliCoils. The Payload Bracket can be seen in Figure 4-28.

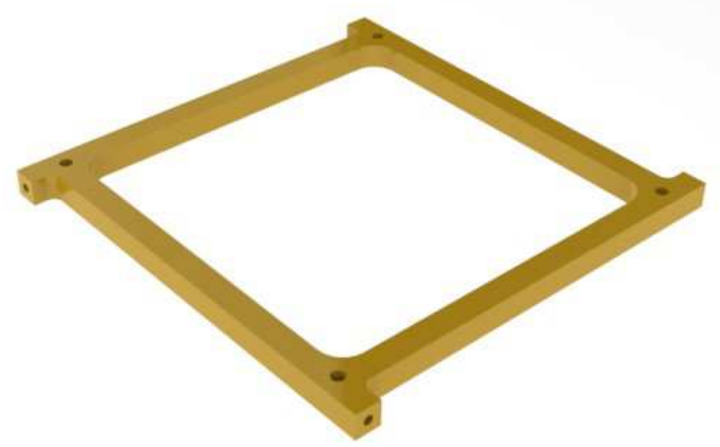

Figure 4-28: Payload Bracket

\subsection{Finite Element Analysis of the Payload Bracket}

Finite Element Analysis of the Payload Bracket was performed to study vibration loading along the Z-axis using the material properties found in the Testing Phase. Results from the Finite Element Analysis were again compared to simplified hand calculations shown in Appendix A to determine their validity.

\subsubsection{Model Development}

There were no planes of symmetry that could be utilized in the analysis of this part. The only simplification made was the removal of all holes and fillets. Partitions were added to the corners of the Bracket to aide in meshing the part. A PCB mass representation was also created in Abaqus with a 3D deformable shell for use in this assembly. 


\subsubsection{Mesh Development}

The Bracket did not have any complex features and could easily be meshed using quadratic hex elements. Quadratic shell, reduced integration elements were used to mesh the PCB. Justifications for these decisions can be seen in Section 4.2.2.

\subsubsection{Assembly Constraints}

The PCB was fixed to the bracket along its edges using a single tie constraint. The PCB was designated as the master surface in this constraint since the Bracket contained more nodes along this interface.

\subsubsection{Boundary Conditions}

The Payload Bracket will be fixed to the CubeSat structure using fasteners at each corner. This justified the use of Encastre boundary conditions along the mounting faces. An Encastre condition completely fixes the motion of constrained surface and can be seen in Figure 4-29.

\subsubsection{Load Condition}

A 69 G Gravity load was applied $+Z$ direction for this model. The load was split up into two analysis steps and gradually applied to the model to prevent convergence problems from occurring. The derivation of this load and its application method can be found in Section 4.2.5. 


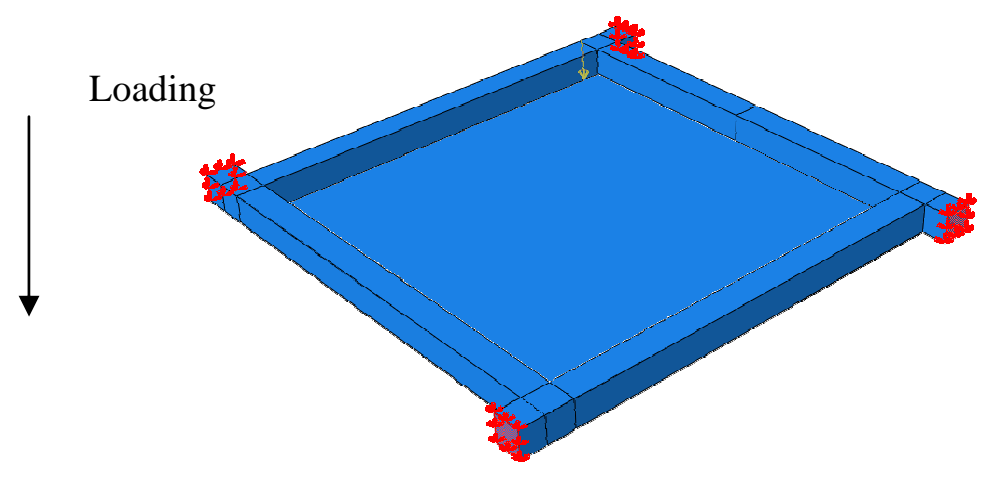

Figure 4-29: Payload Bracket boundary and loading conditions

\subsubsection{Mesh Convergence Study}

A convergence study was performed on the assembly mesh using the same methods describe in Section 4.2.6. The test points studied are shown in Figure 4-31. Plots showing the number of elements against the normalized stress and displacement values are shown in Figure 4-30 and a summary of the results is shown in Table 4-9.
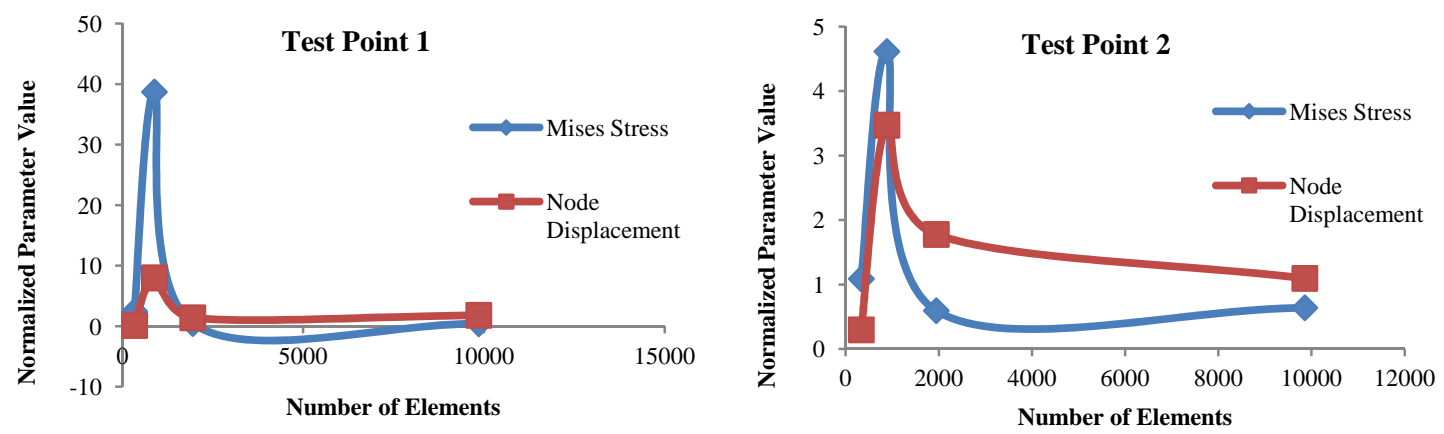

Figure 4-30: Mesh convergence plots for the payload bracket

Table 4-9: Convergence study results for the Payload Bracket

\begin{tabular}{|c|c|c|c|c|c|c|c|c|}
\hline \multirow{2}{*}{$\begin{array}{c}\text { Number of } \\
\text { Elements }\end{array}$} & \multicolumn{4}{|c|}{ Test Point 1 } & \multicolumn{4}{c|}{ Test Point 2 } \\
\cline { 2 - 10 } & $\begin{array}{c}\text { Mises Stress } \\
(\mathrm{MPa})\end{array}$ & $\%$ Diff & $\begin{array}{c}\text { Displacement } \\
(\mathrm{m})\end{array}$ & $\%$ Diff & $\begin{array}{c}\text { Mises Stress } \\
(\mathrm{MPa})\end{array}$ & $\%$ Diff & $\begin{array}{c}\text { Displacement } \\
(\mathrm{m})\end{array}$ & $\%$ Diff \\
\hline 260 & 1301370 & - & $2.31 \mathrm{E}-05$ & - & 745154 & - & $1.12 \mathrm{E}-04$ & - \\
\hline 336 & 1333790 & 2.49 & $2.32 \mathrm{E}-05$ & 0.16 & 737054 & 1.09 & $1.13 \mathrm{E}-04$ & 0.30 \\
\hline 885 & 817250 & 38.73 & $2.50 \mathrm{E}-05$ & 8.00 & 771067 & 4.61 & $1.17 \mathrm{E}-04$ & 3.47 \\
\hline 1944 & 821143 & 0.48 & $2.54 \mathrm{E}-05$ & 1.41 & 795986 & 3.23 & $1.19 \mathrm{E}-04$ & 1.78 \\
\hline 9856 & 824684 & 0.43 & $2.58 \mathrm{E}-05$ & 1.82 & 770684 & 3.18 & $1.20 \mathrm{E}-04$ & 1.09 \\
\hline
\end{tabular}




\subsubsection{FE Analysis}

There were no warnings or errors encountered when performing this analysis. Displacement results from the analysis were significantly lower than the results obtained with hand calculations in Appendix A. However, the assumptions made in the hand calculation would result in a higher displacement value, and the discrepancy was not a cause of concern.

\subsubsection{Results}

The highest stress occurred in areas where fillets had been removed, and was ignored since these fillets will be present in the flight part. Study points were chosen at values of high stress and deflection that would realistically be present in the physical part. The stress values of the study points along with figures showing the general behavior of the loaded assembly are in Figure 4-31, Figure 4-32 and Table 4-10.

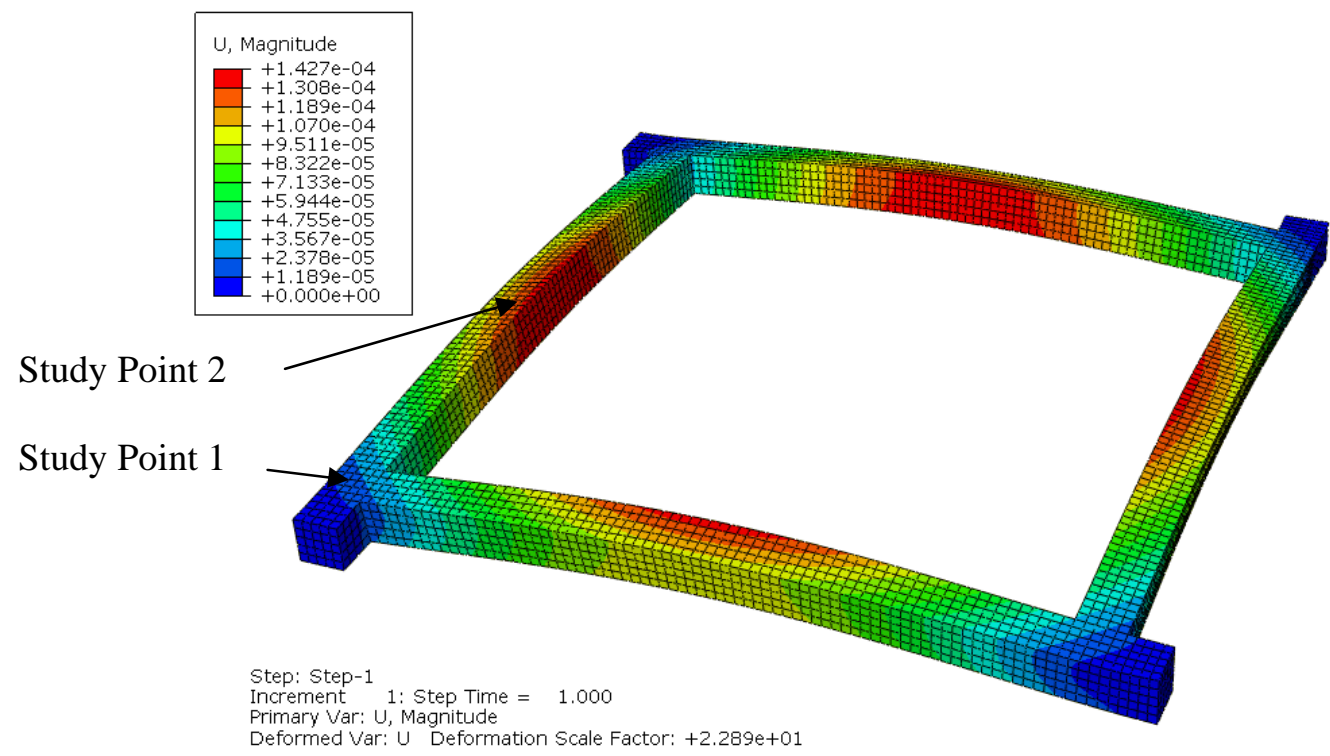

Figure 4-31: Displacment plot of the Payload Bracket 


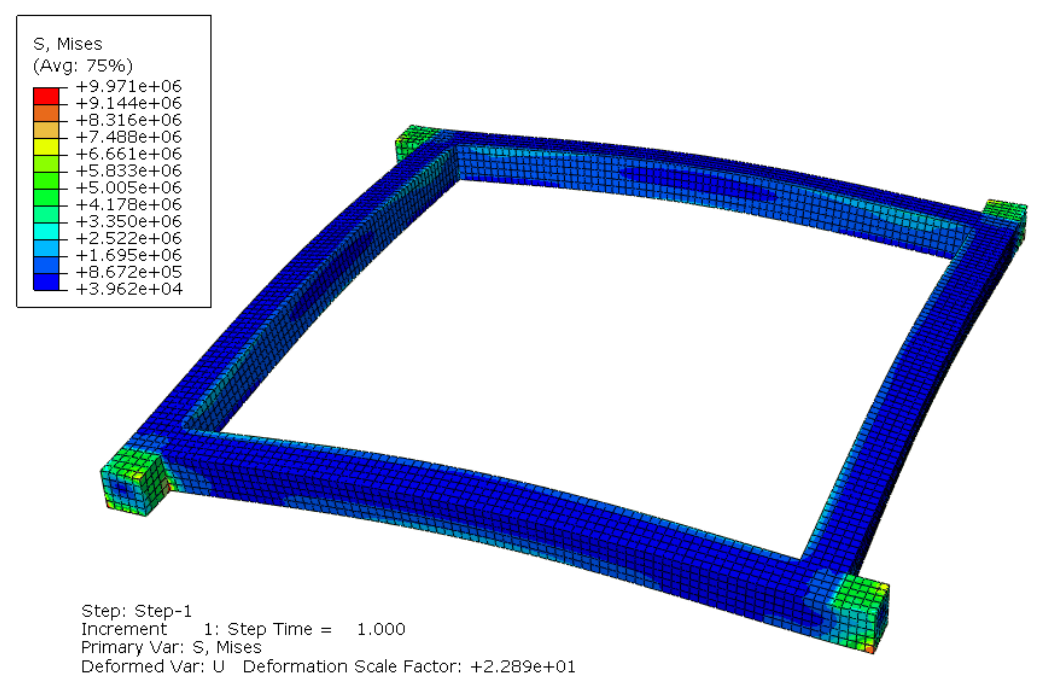

Figure 4-32: Stress plot for the Payload Bracket

Table 4-10: FEA result for the Payload Bracket showing Margin of Safety

\begin{tabular}{|c|c|c|}
\hline Material Analysis & Stress Type & Stress Value \\
\hline \multirow{4}{*}{ FullCure } & Mises & $4.26 \mathrm{E}+06$ \\
\cline { 2 - 3 } & Max Principal & $4.25 \mathrm{E}+06$ \\
\cline { 2 - 3 } & Margin of Safety & 14.38 \\
\hline \multirow{4}{*}{ Watershed } & Mises & $4.44 \mathrm{E}+06$ \\
\cline { 2 - 3 } & Max Principal & $4.36 \mathrm{E}+06$ \\
\cline { 2 - 3 } & Margin of Safety & 9.25 \\
\hline \multirow{4}{*}{ Prototherm } & Mises & $4.78 \mathrm{E}+06$ \\
\cline { 2 - 3 } & Max Principal & $4.71 \mathrm{E}+06$ \\
\cline { 2 - 3 } & Margin of Safety & 19.19 \\
\hline \multirow{4}{*}{ WindformXT } & Mises & $5.43 \mathrm{E}+06$ \\
\cline { 2 - 3 } & Max Principal & $5.37 \mathrm{E}+06$ \\
\cline { 2 - 3 } & Margin of Safety & 14.60 \\
\hline
\end{tabular}




\subsubsection{Payload Bracket Discussion}

All of the materials met the success criterion set for this analysis. It is possible for these materials to see a wide range of use for this type of application. As the types of science instruments flown on CubeSat missions become more complex, it can be inferred that complicated bracketry with non-machinable features may be required to secure them to the main structure of the CubeSat. Further, the ductility of these materials may provide damping characteristics that could protect sensitive instruments form shock and vibration stimuli. This analysis shows that these materials can be used successfully house these types of payloads and survive the launch environment.

\subsection{Cost Sumamry}

Quotes for the RapidSat Revision 2 structure were obtained and compared to the cost of the HyperCube. The FullCure 720 presented a price that was orders of magnitude less expensive than the HyperCube, since Polysat has the ability print parts using the Mechanical Engineering Department's Objet printer. Further, purchasing a Prototherm Structure would be almost 4x less expensive than machining an aluminum structure. A quote for WindformXT was not able to be obtained. As a result, similar materials produced with SLS technology were quoted and their average cost is presented. The costs can be seen in Table 4-11.

Table 4-11: Cost Comparison of manufacturing methods

\begin{tabular}{|c|c|c|c|c|c|c|}
\hline $\begin{array}{c}\text { \# of } \\
\text { Structures }\end{array}$ & Aluminum & $\begin{array}{c}\text { FullCure720 } \\
\text { from } \\
\text { Cal Poly }\end{array}$ & $\begin{array}{c}\text { FullCure720 } \\
\text { from } 3^{\text {rd }} \\
\text { party }\end{array}$ & Watershed & Prototherm & SLS Material \\
\hline 1 Unit & $\$ 1960$ & $\$ 60$ & $\$ 432$ & $\$ 323$ & $\$ 584$ & $\$ 740$ \\
\hline 3 Units & $\$ 5100$ & $\$ 180$ & $\$ 906$ & $\$ 972$ & $\$ 1476.30$ & $\$ 1689.10$ \\
\hline 5 Units & $\$ 7850$ & $\$ 300$ & $\$ 1531$ & $\$ 1252$ & $\$ 2073$ & $\$ 2468.80$ \\
\hline
\end{tabular}




\section{Conclusion}

\subsection{Feasibility of the Use of 3D Printed Parts in CubeSat Structural Applications}

This study has found that a CubeSat can be developed to successfully incorporate the use of 3D printing manufacturing techniques into its design. This technology provides a potential cost savings of thousands of dollars, even for structures that would be simple to machine. Additional cost savings would be seen for very complex structures that would require advanced machining technology such as Electrical Discharge Machining to produce with aluminum. Using a Tyvak Nanosatellite Systems Intrepid system board at a cost of \$3195 [24] for the satellite avionics, it is conceivable that all the flight hardware for a CubeSat with a 3D printed structure could be procured for less than $\$ 5000$.

Not only do these materials provide the necessary strength to survive the rigorous testing and launch environments at a lower cost than machined aluminum, but they allow developers to be more creative with their satellites. Without any limitations from machinability, parts can be produced as they are imagined and new levels of optimization and functionality can be achieved. Further, extremely complex shapes, and even working mechanisms can be produced with 3D printing processes that cannot be manufactured with conventional machining. This allows designers create parts that require no post processing or assembly, streamlining the entire production process.

The CubeSat community's ability to use various technologies in innovative applications is key to its success. It has allowed these satellites to evolve from simple university projects to multinational collaborations with significant worth to the science community. The results of this thesis 
show that 3D printing is an ideal technology for the CubeSat community to adopt, as all of its advantages are perfectly suited for CubeSat development. It could be the next technology to revolutionize the community, much like it has with other technological industries.

\subsection{Future Work}

There are hundreds of different $3 \mathrm{D}$ printing materials that could be viable candidates for use in CubeSat production. Since only a small number of materials were tested in this thesis and a general statement towards the mechanical property changes due to the thermal bakeout could not be made, additional research must be performed if a developer desires to use a different material than what was studied here. Further, there are many post treatments that can be performed on these materials that will change their behaviors. As seen with the Prototherm samples, heat treatments can drastically change the load bearing capabilities of 3D printed plastics.

Characterization of this will aid developers in the material selection process. Also, metal coatings can be applied to the materials that could prevent outgassing and high contact stress from limiting their use. Further, the orientation in which parts are printed may have an effect on the materials' load bearing capabilities due to the anisotropic properties between the printed layers of the parts. This effect should be studied by doing comparative strength testing between identical parts printed in different orientations.

Also, a full ASTM compliant outgassing study of the materials needs to be performed on these materials to find if any of them meet NASA's low outgassing standards. This information is necessary for a CubeSat to be considered for the ELaNa missions and is another key aspect of these materials that will determine their feasibility. Further, outgassing would need to be considered when integrating the CubeSats into the P-POD. If a CubeSat has sensitive instruments that could be contaminated by the outgassing of 3D-Printed components, measures must be taken to provide separation. 
While the results of this thesis show that 3D Printed materials could theoretically withstand the loading applied during a rocket launch, functional testing is the only way to show their true performance. Random vibration and shock testing should be performed on any $3 \mathrm{D}$ printed CubeSat components both before and after thermal bakeout. Also, the fear of material abrasion against the P-POD rails described in Section 4.2.9 should be fully characterized to determine if it would truly hinder the CubeSat's deployment from the P-POD.

Lastly, the RapidSat structure was designed as a generic concept and the analysis performed in this thesis does not provide a full characterization of its behavior under mission specific conditions. Payload hardware would need to be modeled within the structure to gain insight to its performance if it is to be used for a flight mission. 


\section{Bibliography}

[1] [3D Printed Jaw Bone]. (2012). BBC News Technology. Retrieved from

<http://www.bbc.co.uk/news/technology-16907104>

[2] Budynas, Richard G. Nisbett, J. Keith. (2008). Shigley's Mechanical Engineering Design, $8^{\text {th }}$

Edition (pp. 435-439). New York, NY: McGraw-Hill.

[3] Bullis, Kevin. (2011). GE and EADS to Print Parts for Airplanes. Technology Review.

Retrieved from <http://www.technologyreview.com/energy/37540/page2/>

[4] Christensen, R.M. (2008). Observations of the Definition of Yield Stress. Acta Mechanica, 196, 239-244. DOI: 10.1007/s00707-007-0478-0

[5] CubeSat Design Specification Rev. 12. (2012). The CubeSat Program.

[6] Deformation of fully integrated linear and quadratic elements. (2007). Dassault Systems.

Retrieved from < http://abaqus.civil.uwa.edu.au/docs/abaqus/v6.7/books/gsa/default.htm>

[7] Dolengewics, James. Whipple, Lucas. Wong, Stephanie. (2010). “ The Next Generation

CubeSat: A Modular and Adaptable CubeSat Frame Design.” Senior Project Report, California Polytechnic State University.

[8] Filton. (2011). The Printed World. The Economist. Retrieved from

<http://www.economist.com/node/18114221>

[9] Fused Deposition Modeling. (2008). CustomPartNet. Retrieved from

<http://www.custompartnet.com/wu/fused-deposition-modeling >

[10] Gordon, Scott. Simmons, Ryan. (2001). Miles' Equation. NASA GSFC. Retrieved from < http://femci.gsfc.nasa.gov/workshop/2001/posters/simmons/Simmons_MilesEquation.pdf> 
[11] Hiemenz, Joe. (2007). Electron Beam Melting process diagram. Stratasys, Inc. Retrieved from <http://www.eetimes.com/design/industrial-control/4013703/Rapid-prototypes-move-tometal-components>

[12] [Laminated Object Manufacturing process diagram]. (2012). Rapid Prototyping Center. Retrieved from <http://www.rpc.msoe.edu/machines_lom.php>

[13] Lighter Load. (2011). Technology Review. Retrieved from <http://www.technologyreview.com/energy/37540/>

[14] Plastic Properties. (2012). Engineer's Edge. Retrieved from <http://www.engineersedge.com/plastic/materials_common_plastic.htm> [15] [Printed Air Vent Prototype]. (2010). Objet. Retrieved from <http://www.objet.com/Portals/0/docs2/Auto_Jaguar_CS_Letter_low.pdf> [16] Selective Laser Sintering. (2008). CustomPartNet. Retrieved from <http://www.custompartnet.com/wu/selective-laser-sintering>

[17] Specimen Dimensions for Thickness. n.d.. ASTM. Retrieved from Standard Test Method for Tensile Properties of Plastics.

[18] Spielgel, Rob. (2012). 3D Printer Joins Organ Replacement Revolution. TechNewsWorld. Retrieved from <http://www.technewsworld.com/rsstory/74365.html>

[19] Stereolithography. (2008). CustomPartNet. Retrieved from $<$ http://www.custompartnet.com/wu/stereolithography> [20] Transplant Jaw made by 3D printer claimed as first. (2012). BBC News Technology. Retrieved from <http://www.bbc.co.uk/news/technology-16907104> 
[21] Three Dimensional Printing. (2008). CustomPartNet. Retrieved from <http://www.custompartnet.com/wu/3d-printing>

[22] The Objet Polyjet Process. (2012). Objet. Retrieved from

<http://www.objet.com/products/polyjet_technology/>

[23] The Power of Two. (2010). Objet. Retrieved from

<http://www.objet.com/Portals/0/docs2/Auto_Jaguar_CS_Letter_low.pdf>

[24] Tyvak Nano-Satellite Systems Price List. (2012) Tyvak Nano-Satellite Systems. Retrieved from < http://www.tyvak.com/products/Pico/TyvakPriceList_v103_.pdf> 


\section{Appendix A: Hand Calculations}

A series of hand calculations were performed and compared to the FEA results to determine their validity. Hand calculations were performed using the material properties of the WindformXT sample set. All equations were taken from Shigley's [2].

\section{RapidSat Revision 1 Calculation}

The deflection of the cross beam of the side panel was analyzed with this calculation. It was treated independently from the rest of the model with the simplified boundary conditions shown in Figure A-1.

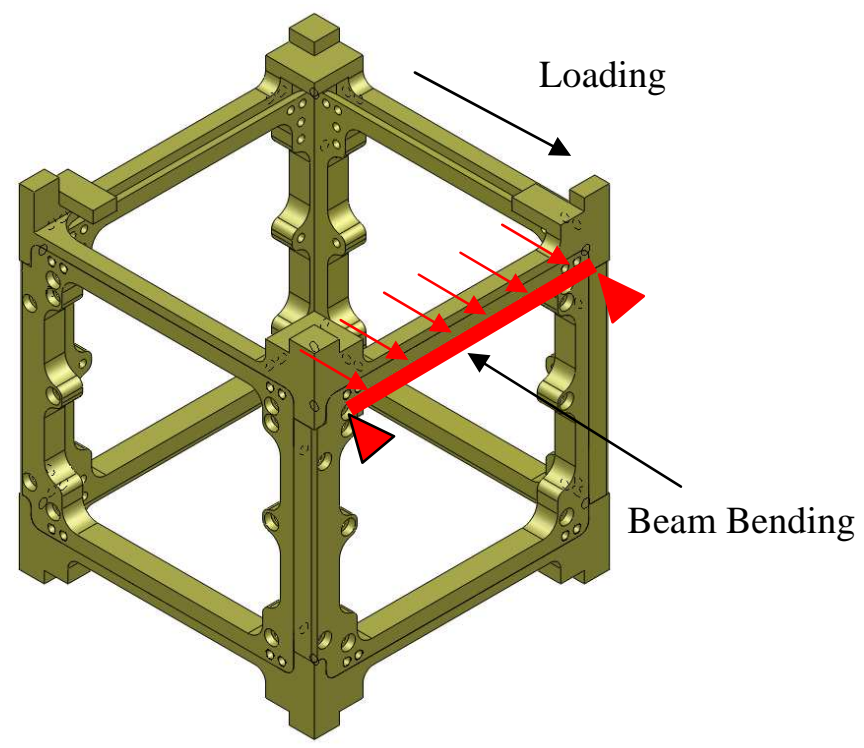

Figure A-1: Beam simplification for Revision 1 calculation 


\section{Beam Bending - Deflection}

Assumptions:

- Pinned boundary conditions at ends of member

- Uniform loading

- Uniform cross section

- No interactions with other parts

- Constant cross section of $3 \mathrm{~mm} \times 7 \mathrm{~mm}$

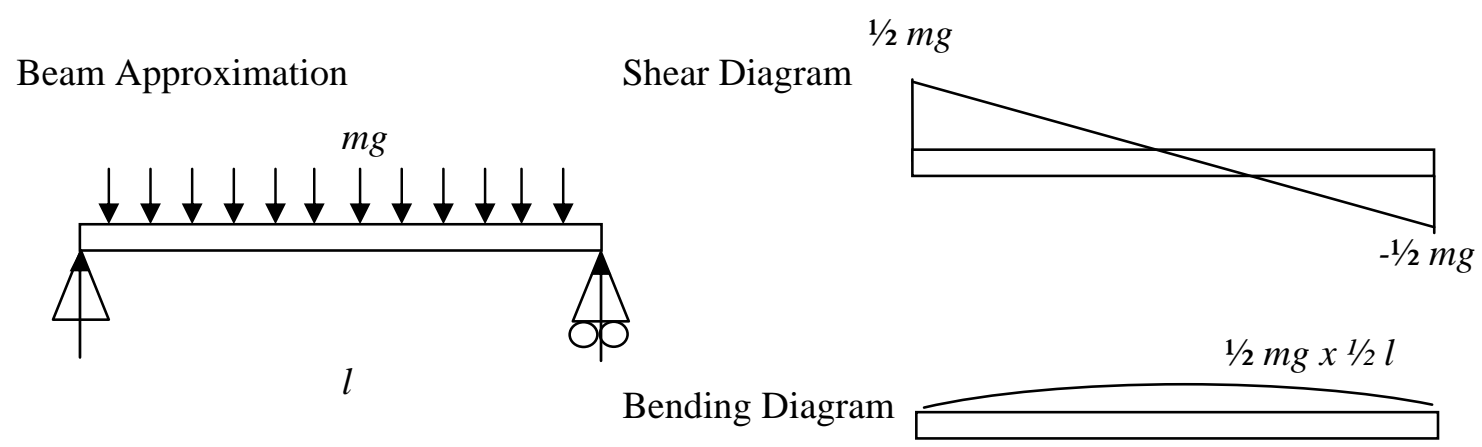

Constants:

$l=.086 \mathrm{~m}$

$I=1 / 12 \times \mathrm{bh}^{3}=8.575^{*} 10^{-11} \mathrm{~m}^{4}$

$m_{\text {load }}=.0025 \mathrm{~kg}$

$E=7725 \mathrm{MPa}$

$g_{\text {load }}=69 \times 9.8 \mathrm{~m} / \mathrm{s}^{2}=676.2 \mathrm{~m} / \mathrm{s}^{2}$

Deflection Calculation

$$
\begin{gathered}
\delta_{\text {max }}=\frac{5 m_{\text {load }} g_{\text {load }} l^{4}}{384 E I} \\
\delta_{\max }=\frac{5 * .0025 \mathrm{~kg} * 676.2 \mathrm{~m} / \mathrm{s} *(0.086 \mathrm{~m})^{4}}{384 * 7725 * 10^{6} \mathrm{~Pa} * 8.575 E-11 \mathrm{~m}^{4}}=1.818 * 10^{-6} \mathrm{~m}
\end{gathered}
$$




\section{Comparison to FEA Results}

The FEA results show a displacement of 5.15E- $6 \mathrm{~m}$ at the center of this beam. The assumptions made in the hand calculation account for the discrepancy between the two analysis methods. The pinned condition is not truly representative of the boundary condition as the part is able to translate as well as bend at these points as the part deforms. When this translational component is removed by subtracting the displacement value at the end of the beam from the total, the resulting bending component of the FEA is $2.54 \mathrm{E}-6 \mathrm{~m}$. This value compares much more favorably with the hand calculation result, with only $28 \%$ difference. The low percent difference between the two analysis results indicate that the FEA is an accurate approximation of the structure's behavior. 


\section{RapidSat Revision 2 Calculation}

The deflection of the cross beam formed by the side panel and shoe was analyzed with this

calculation. It was treated independently from the rest of the model with the simplified boundary conditions shown in Figure A-2.

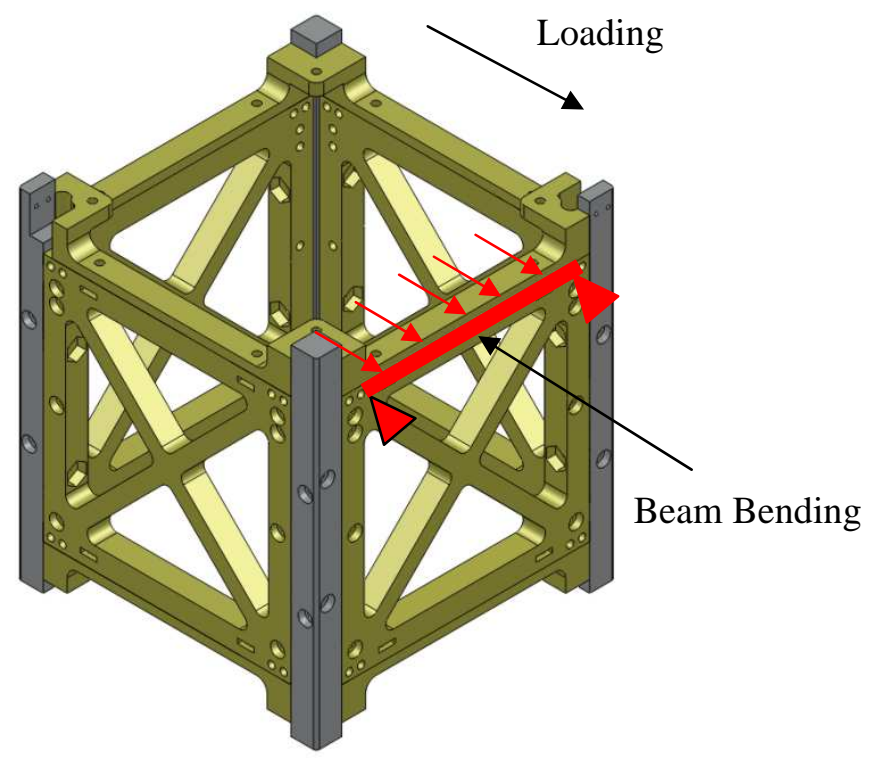

Figure A-2: Beam simplification for Revision 2 calculation

\section{Beam Bending - Deflection}

Assumptions:

- Pinned boundary conditions at ends of member

- Uniform loading

- Uniform cross section

- No interactions with other parts

- Constant cross section of $10.5 \mathrm{~mm} \times 7.5 \mathrm{~mm}$ 


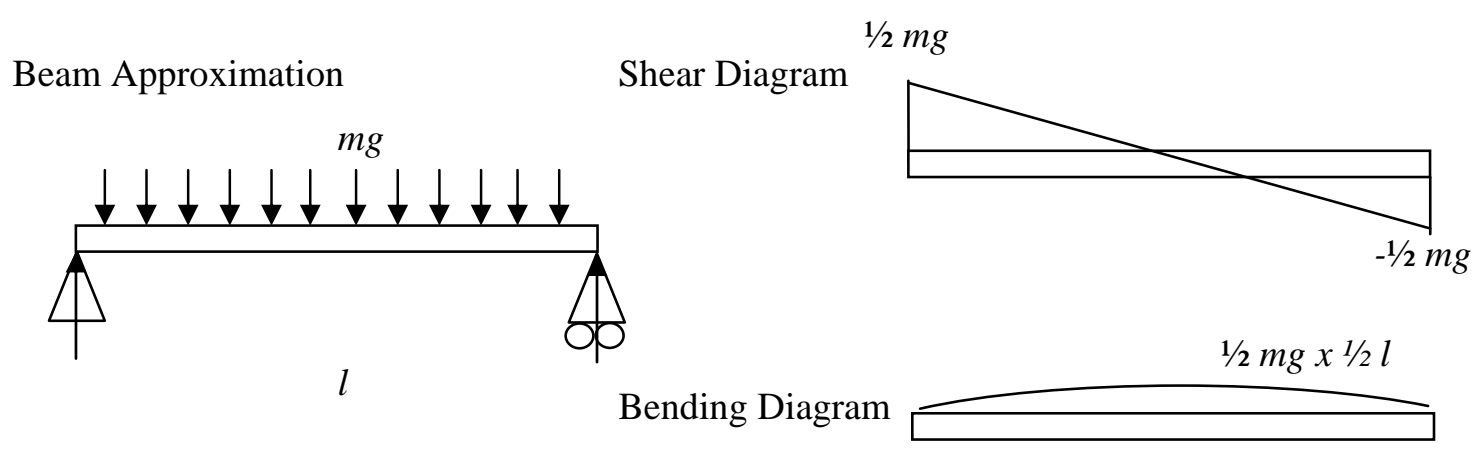

Constants:

$l=.083 \mathrm{~m}$

$I=1 / 12 \times \mathrm{bh}^{3}=3.69 * 10^{-10} \mathrm{~m}^{4}$

$m_{\text {laod }}=.0075 \mathrm{~kg}$

$E=7725 \mathrm{MPa}$

$g_{\text {load }}=69 \times 9.8 \mathrm{~m} / \mathrm{s}^{2}=676.2 \mathrm{~m} / \mathrm{s}^{2}$

Deflection Calculation

$$
\begin{gathered}
\delta_{\max }=\frac{5 m_{\text {load }} g_{\text {load }} l^{4}}{384 E I} \\
\delta_{\max }=\frac{5 * .0075 \mathrm{~kg} * 676.2 \mathrm{~m} / \mathrm{s} *(0.083 \mathrm{~m})^{4}}{384 * 7725 * 10^{6} \mathrm{~Pa} * 3.69 \mathrm{E}-10 \mathrm{~m}^{4}}=1.099 * 10^{-6} \mathrm{~m}
\end{gathered}
$$

\section{Comparison to FEA Results}

The FEA results show a displacement of $1.41 \mathrm{E}-6 \mathrm{~m}$ at the center of this beam using the same method as the calculation for the Revision 1 structure. This value differs from the hand calculation by $22 \%$. The low percent difference provides confidence in the results of the FEA. 


\section{Payload Bracket Calculation}

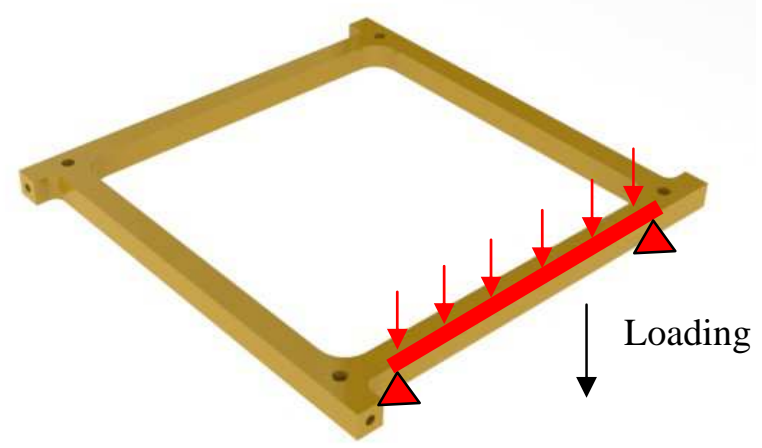

Figure A-3: Beam simplification for the Payload Bracket

\section{Beam Bending - Deflection}

Results from these calculations will be compared to the deflection of the model.

Assumptions:

- Pinned boundary conditions at ends of member

- Uniform loading

- Uniform cross section

- No interactions with other parts

- Constant cross section of $5 \mathrm{~mm} \times 5 \mathrm{~mm}$

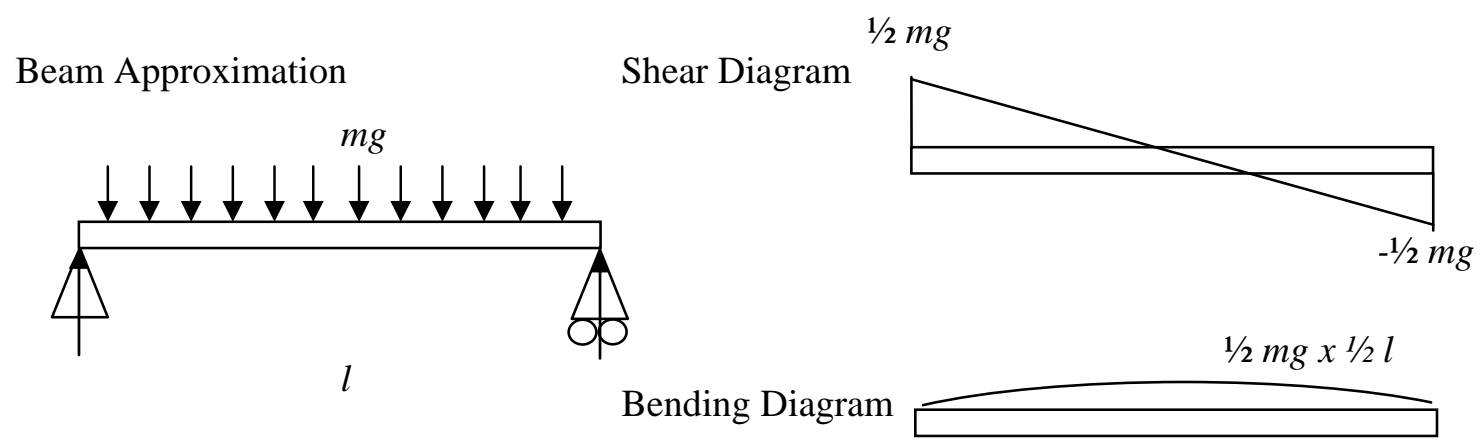




\section{Constants:}

$l=.0865 \mathrm{~m}$

$$
I=1 / 12 \times \mathrm{bh}^{3}=5.208 * 10^{-11} \mathrm{~m}^{4}
$$

$m_{\text {laod }}=.050 \mathrm{~kg}$

$$
E=7725 \mathrm{MPa}
$$

$g_{\text {load }}=69 \times 9.8 \mathrm{~m} / \mathrm{s}^{2}=676.2 \mathrm{~m} / \mathrm{s}^{2}$

Deflection Calculation

$$
\begin{gathered}
\delta_{\max }=\frac{5 m_{\text {load }} g_{\text {load }} l^{4}}{384 E I} \\
\delta_{\max }=\frac{5 * .0075 \mathrm{~kg} * 676.2 \mathrm{~m} / \mathrm{s} *(0.083 \mathrm{~m})^{4}}{384 * 7725 * 10^{6} \mathrm{~Pa} * 3.69 E-10 \mathrm{~m}^{4}}=6.126 * 10^{-5} \mathrm{~m}
\end{gathered}
$$

\section{Comparison to FEA Results}

The FEA results show a displacement of $1.256 \mathrm{E}-5 \mathrm{~m}$ at the center of this beam using the same method as the calculation for the revision 1 structure. This value differs from the hand calculation by $79.49 \%$. This percent difference may be the result of the assumption of treating this member as a single beam. The actual model is a frame coupled with a plate, which would lead to a higher stiffness structure that would deform less. Both results show deflections of less than a tenth of a millimeter and are not a cause for concern. 


\section{RapidSat Revision 2 Joint Shear Calculations}

A probable mode of failure in a 3D printed structure lies in the bolted joints. These joints will be put into a large amount of shear as they support the payload mass, which could cause the 3D printed material to fail from rupture, crush, or shear. It will be assumed that the 4 fasteners securing the Side Panel to the Rail in the load bearing direction will each support an equal portion of the payload. This is a conservative assumption, since the Extrusions and Slots added to the structure and the payload mounting points in the other Side Panels will support this load as well. Figure A-4 shows the shear loading at this joint.

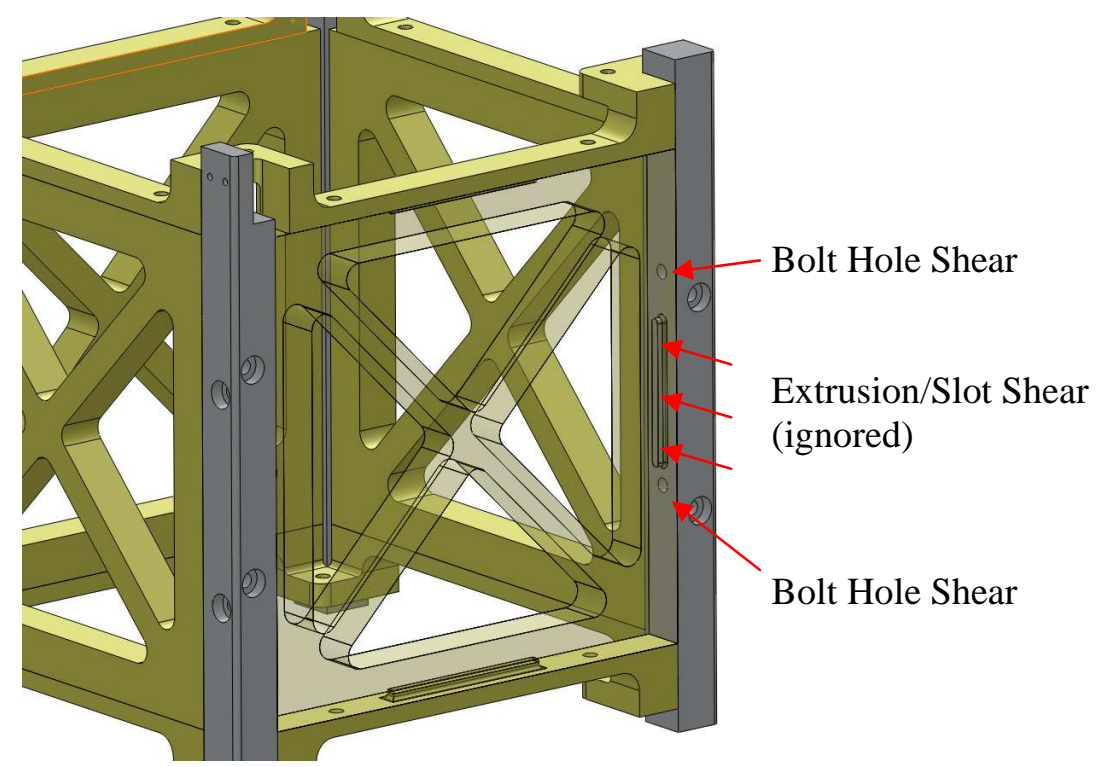

Figure A-4: Shear loading in Side Panel - Rail joint 


\section{Shear Loading - Failure from rupture}

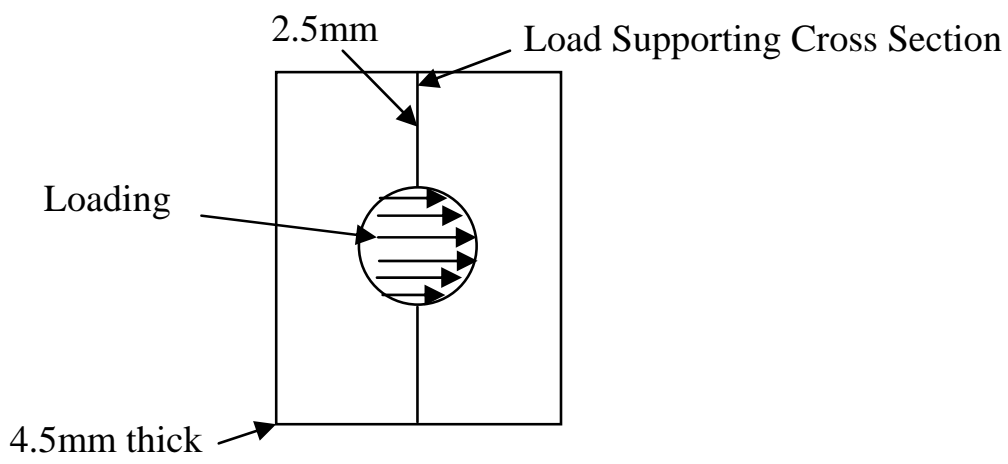

Assumptions: It will be assumed that the load will be supported by cross section that is $2.5 \mathrm{~mm}$ in width along the edge of the bolt. Again, this is a conservative assumption as the load will be supported by the length of the member.

Constants:

$$
\begin{array}{ll}
m_{\text {load }}=.225 \mathrm{~kg} & t=.0045 \mathrm{~m} \\
g_{\text {load }}=69 \times 9.8 \mathrm{~m} / \mathrm{s}^{2}=676.2 \mathrm{~m} / \mathrm{s}^{2} & w=.0025 \mathrm{~m} \\
A=2 * t * w=2 * .0025 m * .0045 m=2.25 E-5 m^{2}
\end{array}
$$

\section{Calculation:}

$$
\begin{gathered}
\sigma_{\text {max }}=\frac{m * g_{\text {load }}}{A} \\
\sigma_{\text {max }}=\frac{.225 \mathrm{~kg} * 676.2 \mathrm{~m} / \mathrm{s}^{2}}{2.25 \mathrm{E}-5 \mathrm{~m}^{2}}=4.06 \mathrm{MPa}
\end{gathered}
$$

This calculated value for the maximum stress along the cross section that would rupture is an order of magnitude lower than the yield stress for the weakest material studied. This gives confidence that these joints will not fail in this manner. 


\section{Shear Loading - Failure from crushing}

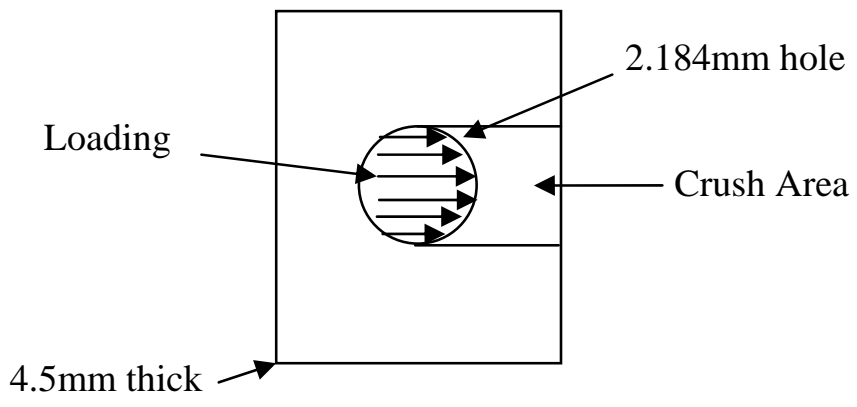

Assumptions: It will be assumed that the entire load will be supported by the crush area

Constants:

$m_{\text {load }}=.225 \mathrm{~kg}$

$d=.002184 \mathrm{~m}$

$\mathrm{g}_{\text {load }}=69 \times 9.8 \mathrm{~m} / \mathrm{s}^{2}=676.2 \mathrm{~m} / \mathrm{s}^{2}$

$t=.0045 \mathrm{~m}$

$A=t * d=.002184 * .0045=9.828 E-6 m$

Calculation:

$$
\begin{gathered}
\sigma_{\text {max }}=\frac{m_{\text {load }} g_{\text {load }}}{A} \\
\sigma_{\text {max }}=\frac{.225 \mathrm{~kg} * 676.2 \mathrm{~m} / \mathrm{s}^{2}}{9.828 \mathrm{E}-6 \mathrm{~m}}=15.48 \mathrm{MPa}
\end{gathered}
$$

This value does not meet the goal of exhibiting a margin of safety of 7 for any of the materials. However, the assumptions made in this calculation make it very conservative. As a result, it will not be considered a disqualifying factor in the feasibility study, but will be noted as an area of concern that should be closely watched during functional testing. 


\section{Shear loading - Failure from shear}

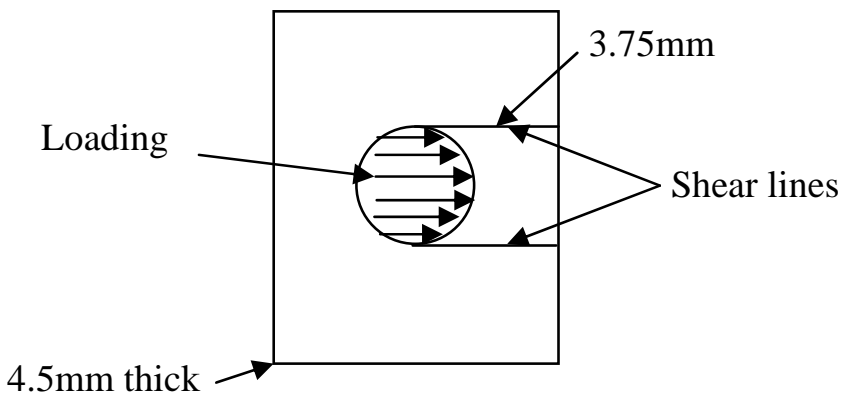

Assumptions: It will be assumed that the entire load will be supported along the shear lines.

Constants:

$m_{\text {load }}=.225 \mathrm{~kg}$

$a=.00375 \mathrm{~m}$

$\mathrm{g}_{\text {load }}=69 \times 9.8 \mathrm{~m} / \mathrm{s}^{2}=676.2 \mathrm{~m} / \mathrm{s}^{2}$

$t=.0045 \mathrm{~m}$

$A=2 * a * d=2 * .00375 * .0045=3.375 E-5 m$

Calculation :

$$
\begin{gathered}
\tau_{\text {max }}=\frac{m_{\text {load }} * g_{\text {load }}}{A} \\
\tau_{\text {max }}=\frac{.225 \mathrm{~kg} * 676.2 \mathrm{~m} / \mathrm{s}^{2}}{3.375 \mathrm{E}-5 \mathrm{~m}}=4.5 \mathrm{MPa}
\end{gathered}
$$

This calculated value for the maximum shear stress along the shear lines that would cause shear in the joint is an order of magnitude lower than the yield stress for the weakest material studied. This gives confidence that these joints will not fail in this manner. 


\section{Appendix B: Finite Element Analysis Plots}

The following plots detail the behavior of all of the components from both revisions of the

RapidSat structure. Study points used to determine the Margin of Safety are labeled along with the loading direction.

Plots for the RapidSat Revision 1 structure

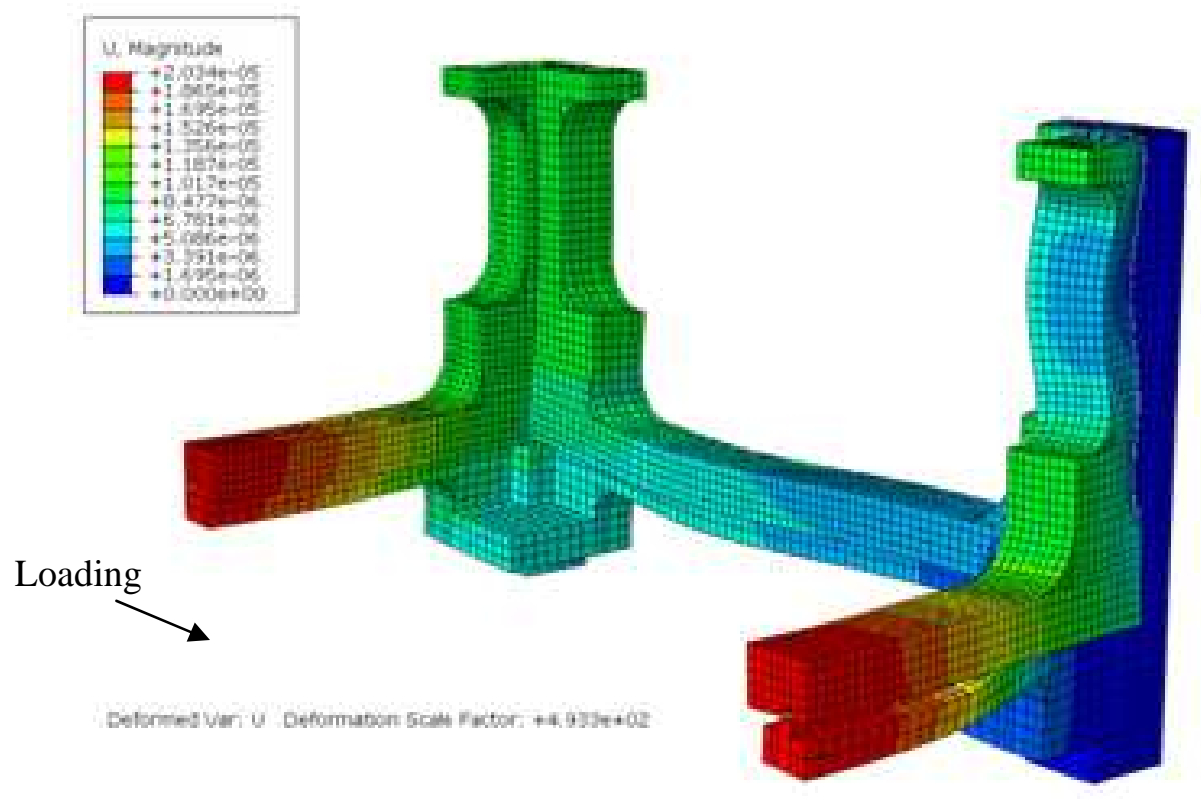

Figure B-1: Displacement plot for the Revision 1 structure 


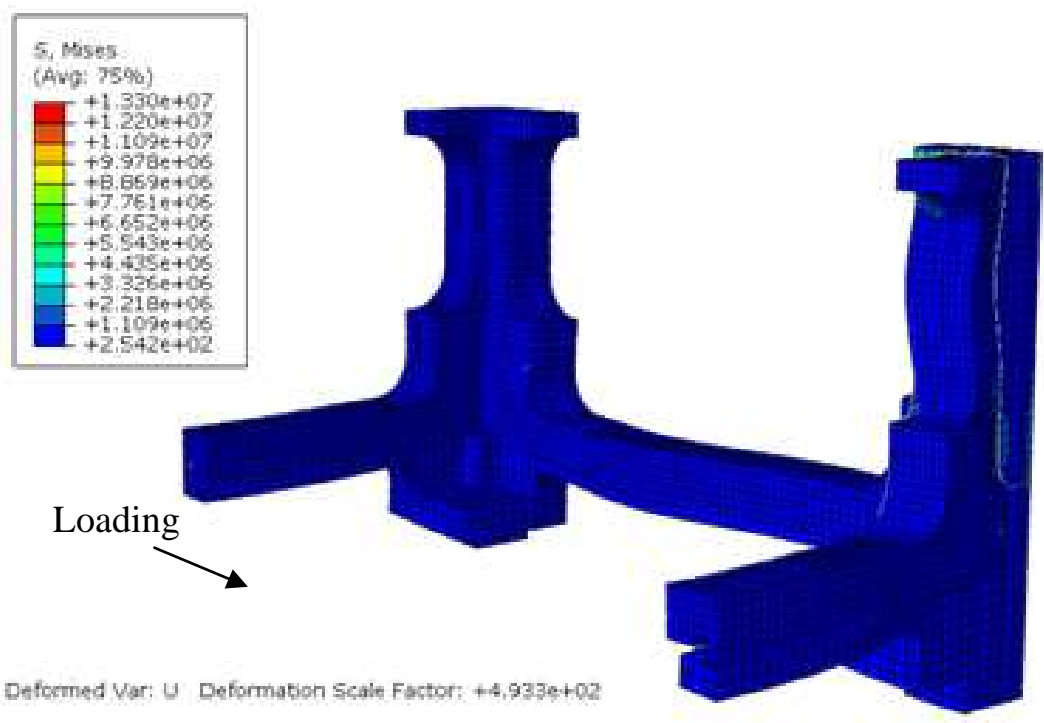

Figure B-2: Stress plot for the Revision 1 structure

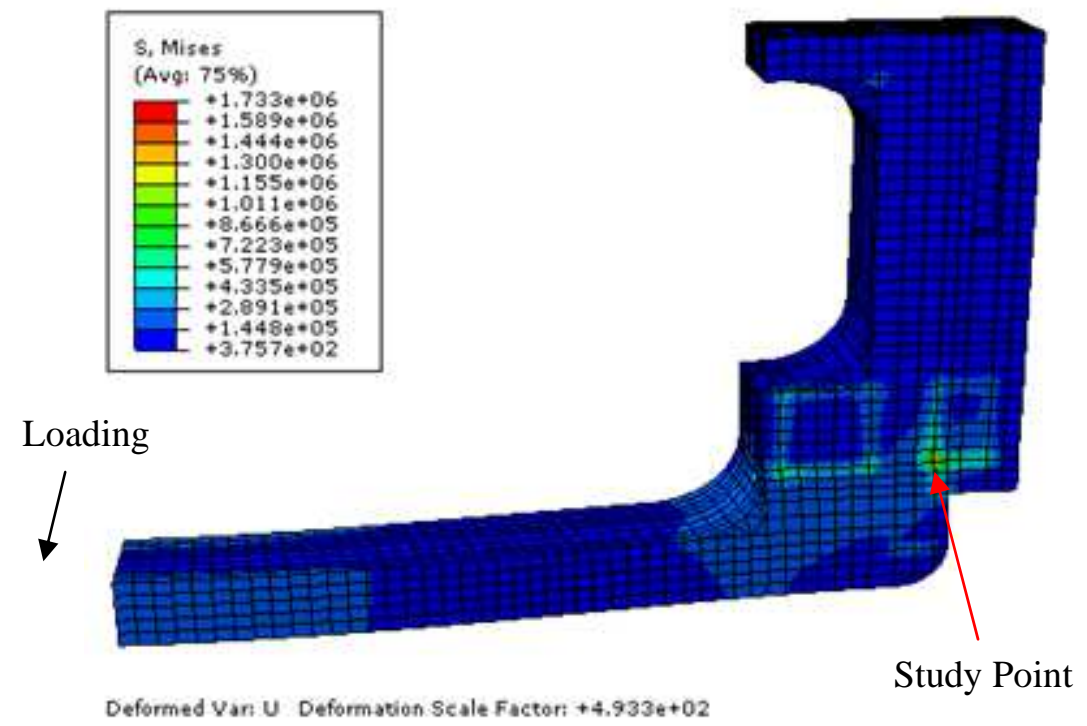

Figure B-3: Side Panel 1 of the Revision 1 structure 


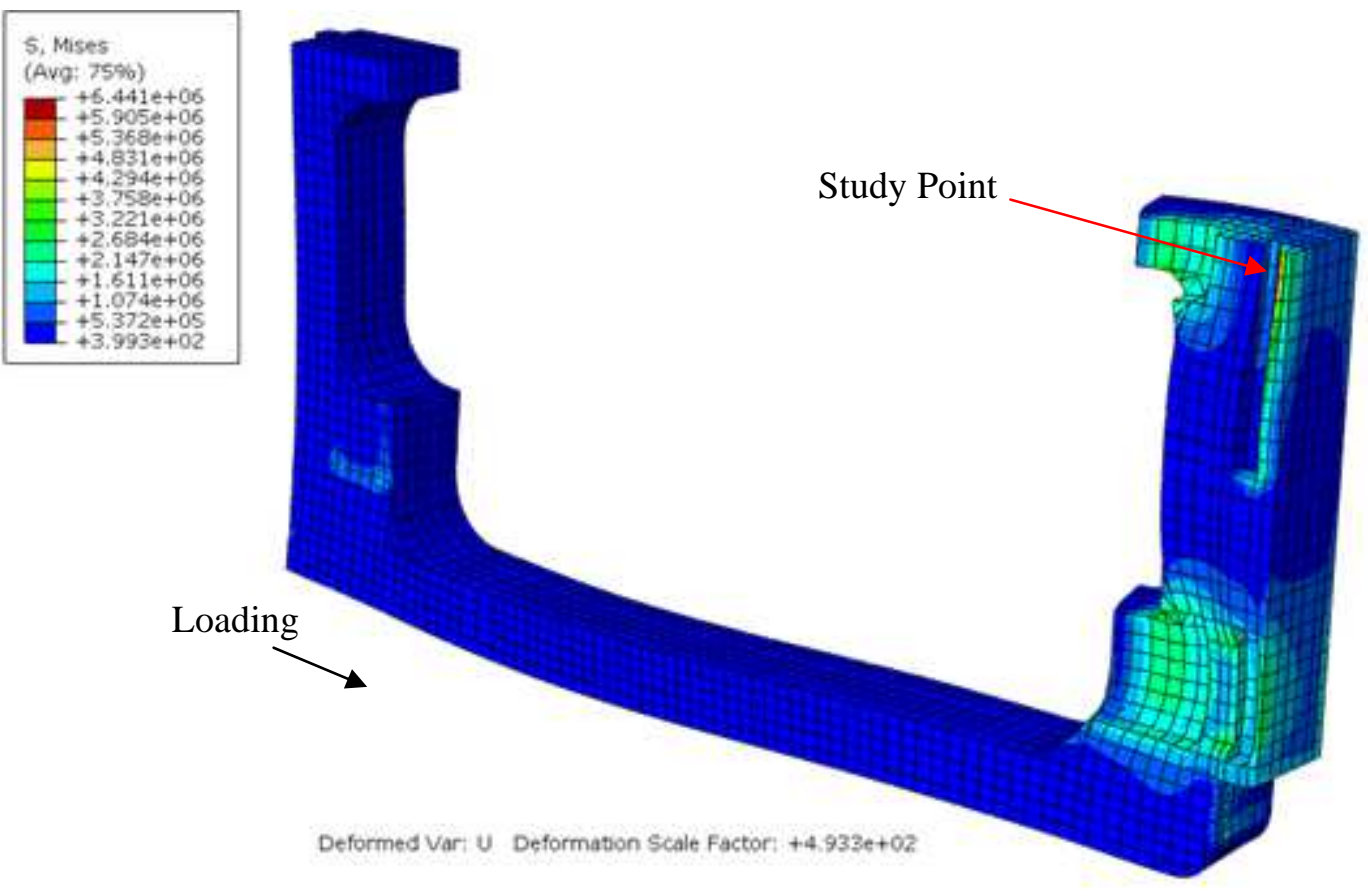

Figure B-4: Side Panel 3 of the Revision 1 structure (joint shear elements hidden)
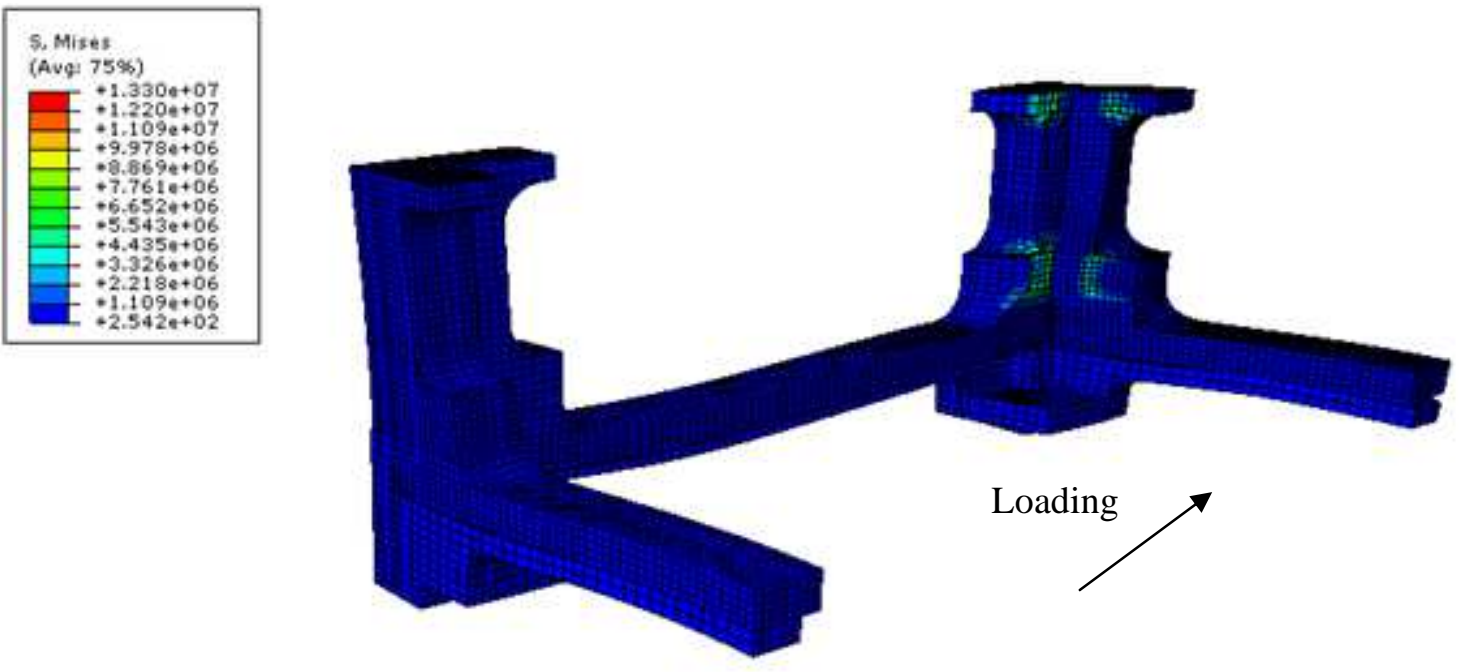

Deformed Van U Deformation Scale Facton $+4.933 e+02$

Figure B-5: Stress plot of the Revision 1 structure viewed from the -X side 


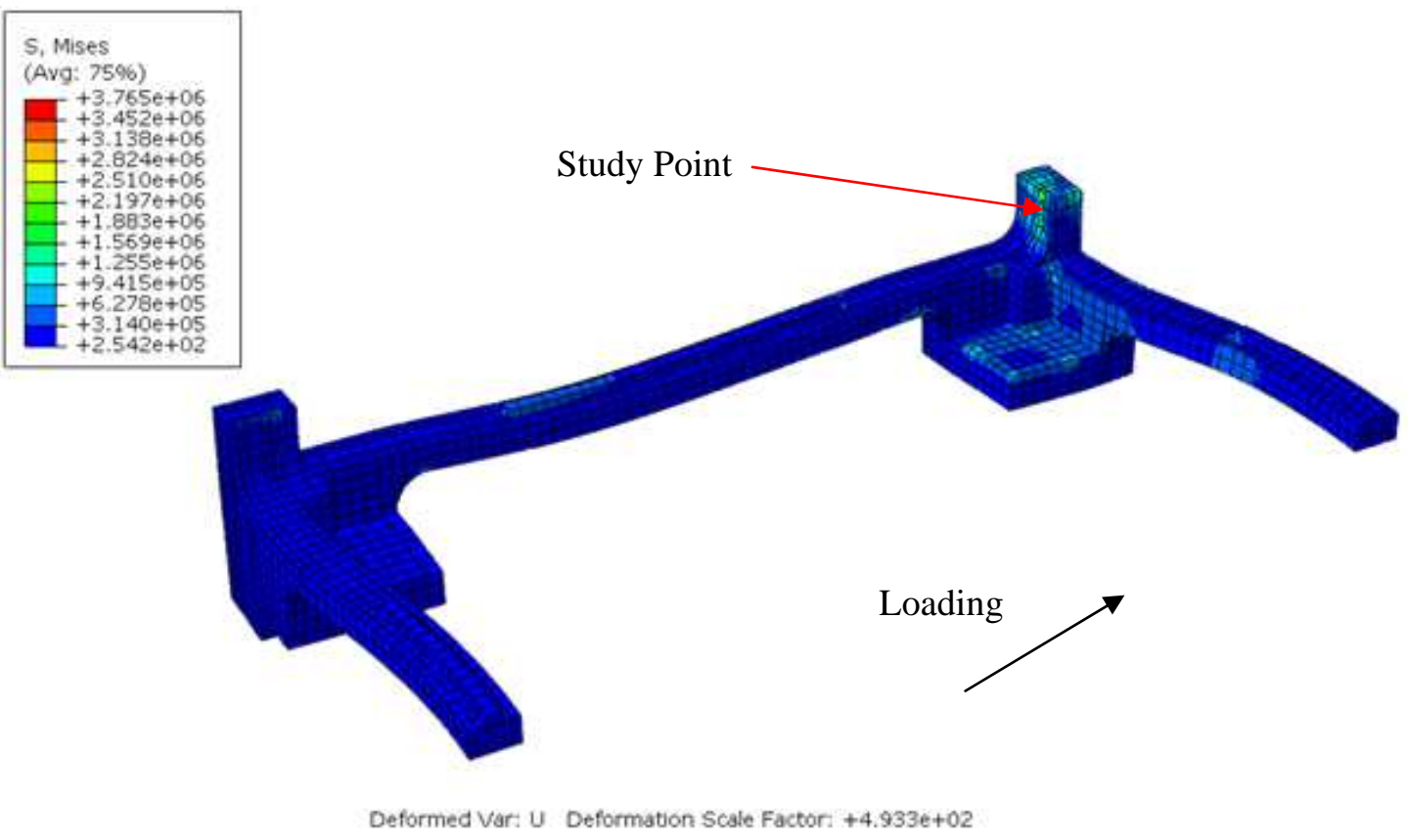

Figure B-6: Shoe of the Revision 1 structure

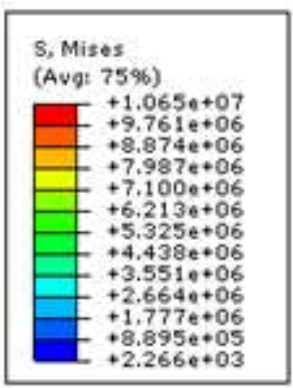

Study Point

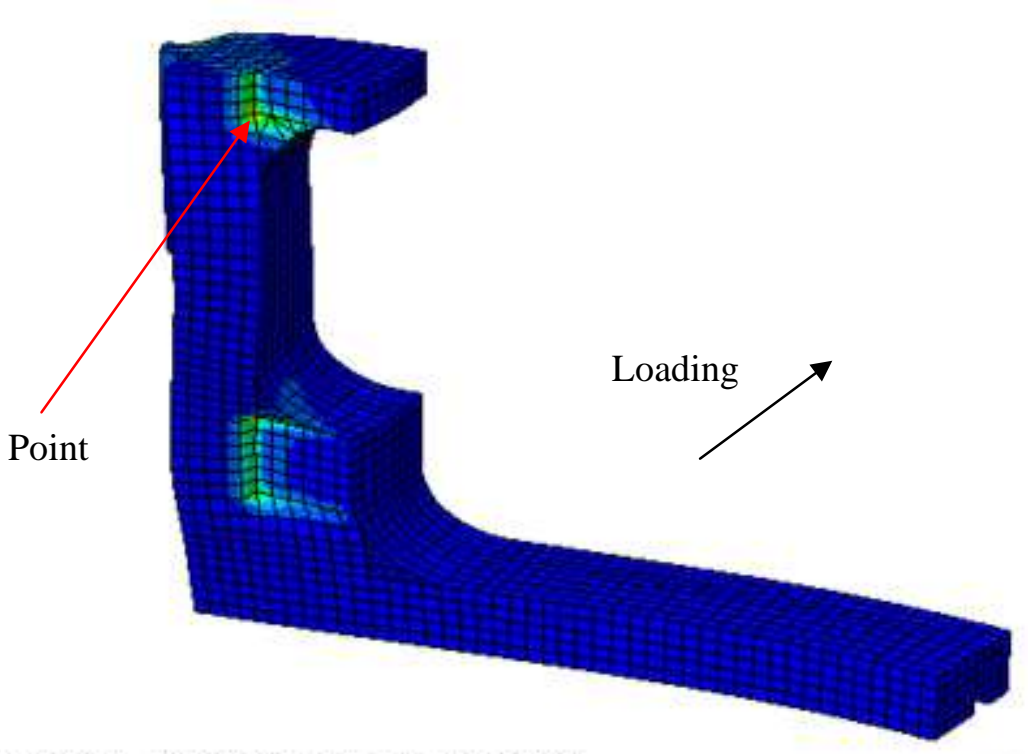

Deformed Van U Deformation Scale Facton $+4.933 e+02$

Figure B-7: Side Panel 2 of the Revision 1 structure 
Plots for the RapidSat Revision 2 structure, X-axis loaded

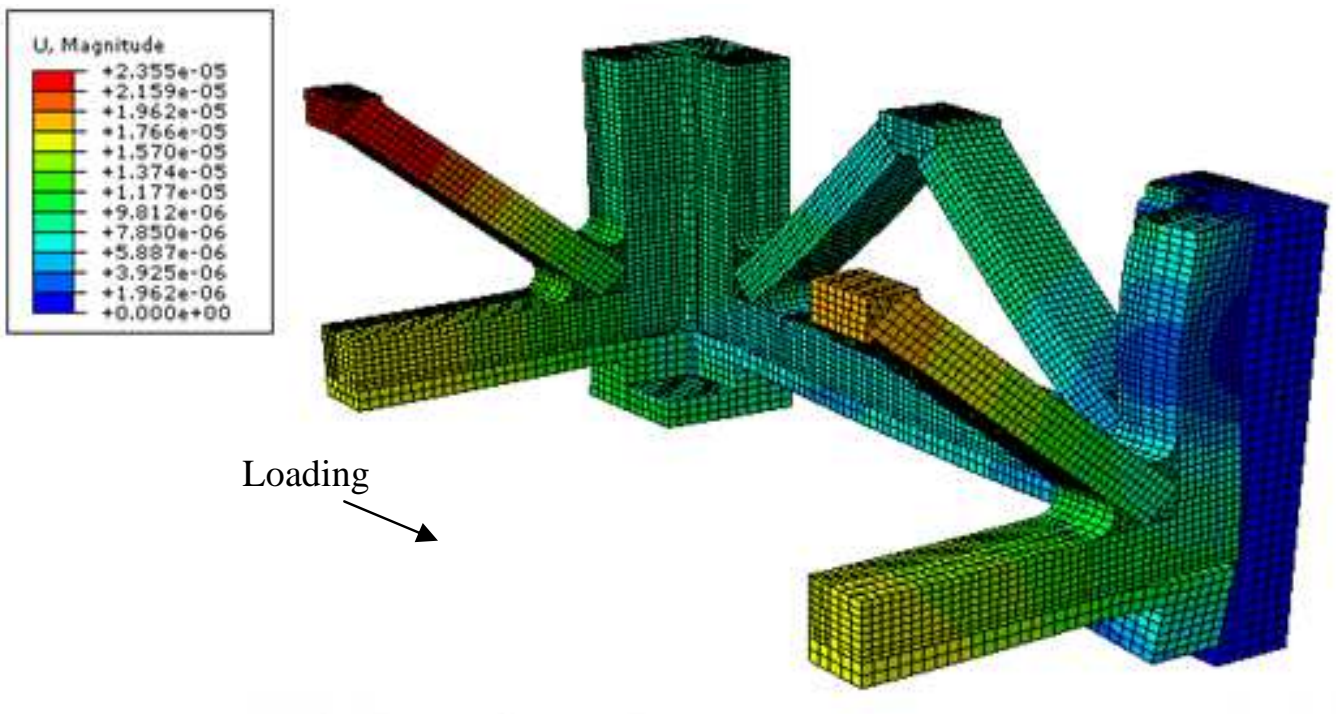

Deformed Van U Deformation Scale Facton $+1.773 e+02$

Figure B-8: Displacement plot of the X-loaded Revision 2 structure
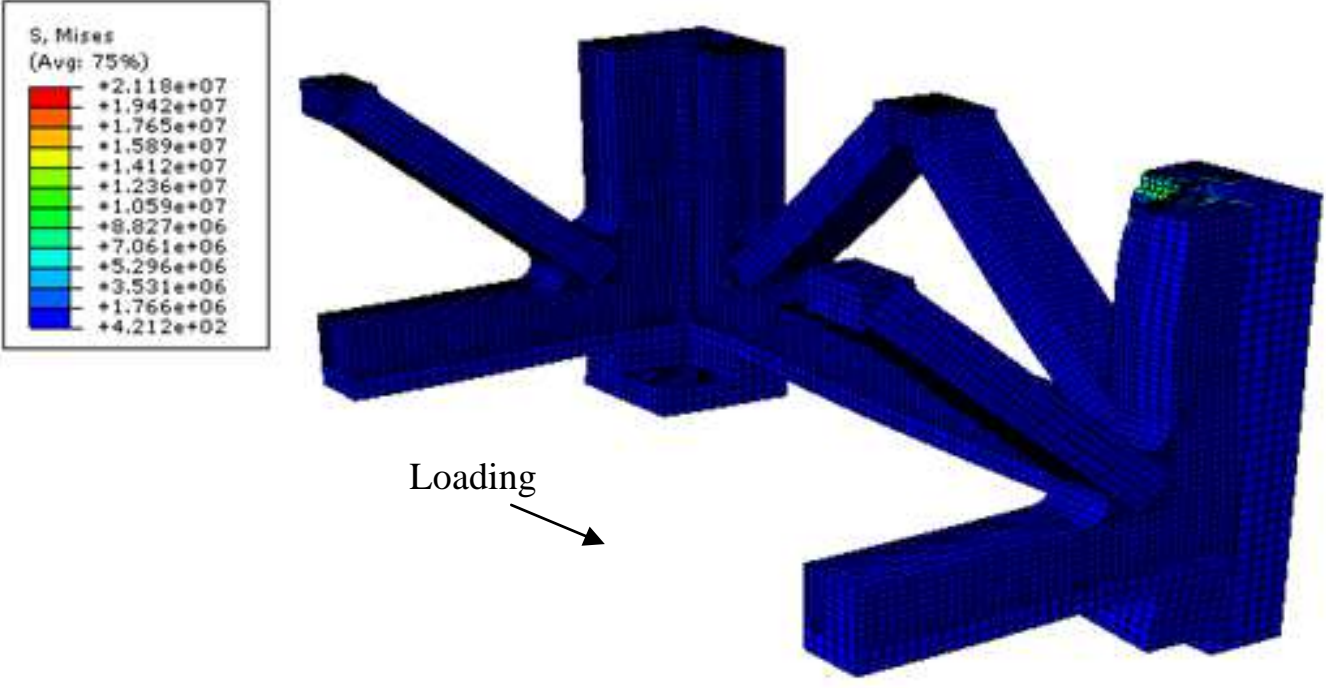

Deformed Van U Deformation Scale Facton $\bullet 1.773 e+02$

Figure B-9: Stress plot of the X-loaded Revision 2 structure 


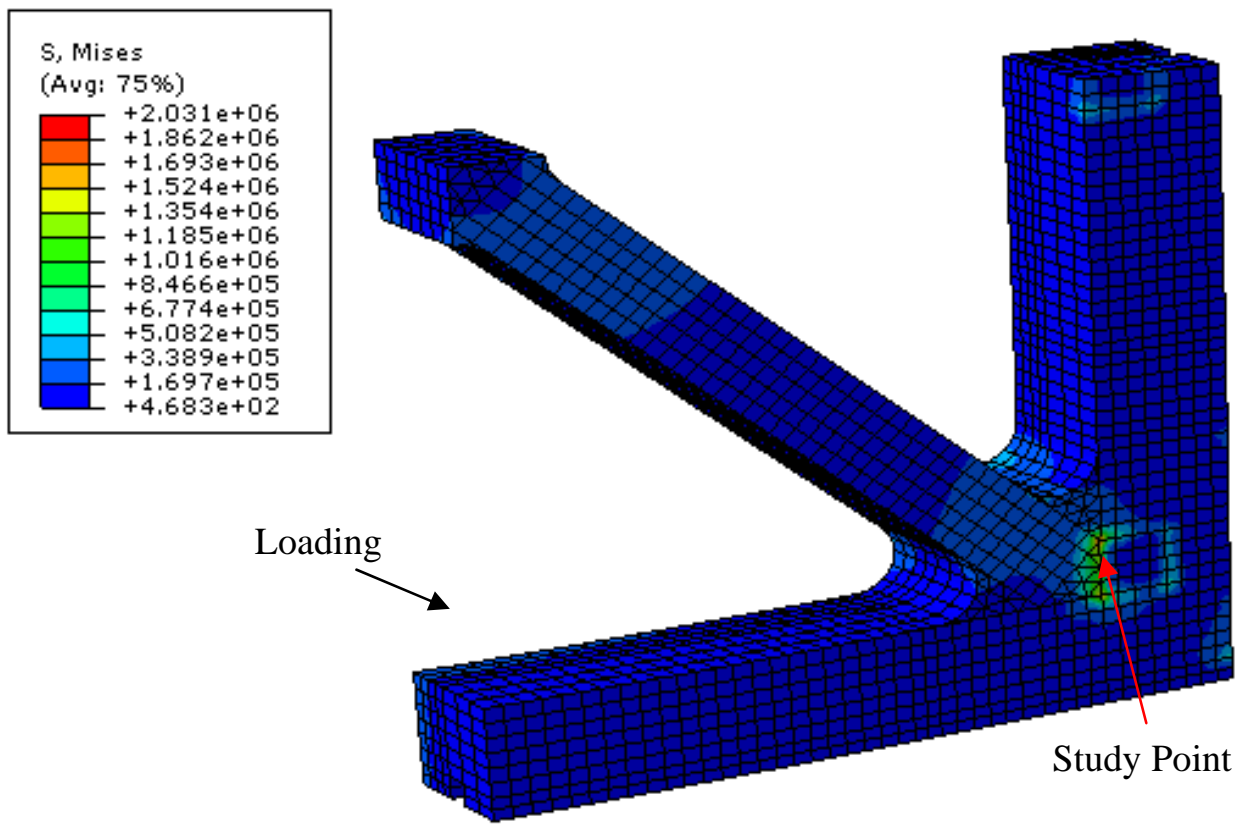

Deformed Var: U Deformation Scale Factor: $+1.773 e+02$

Figure B-10: Side Panel 1 of the X-loaded Revision 2 structure

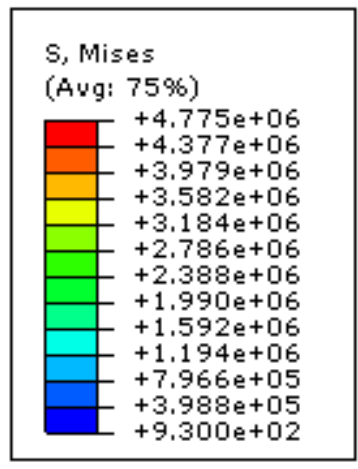

Loading

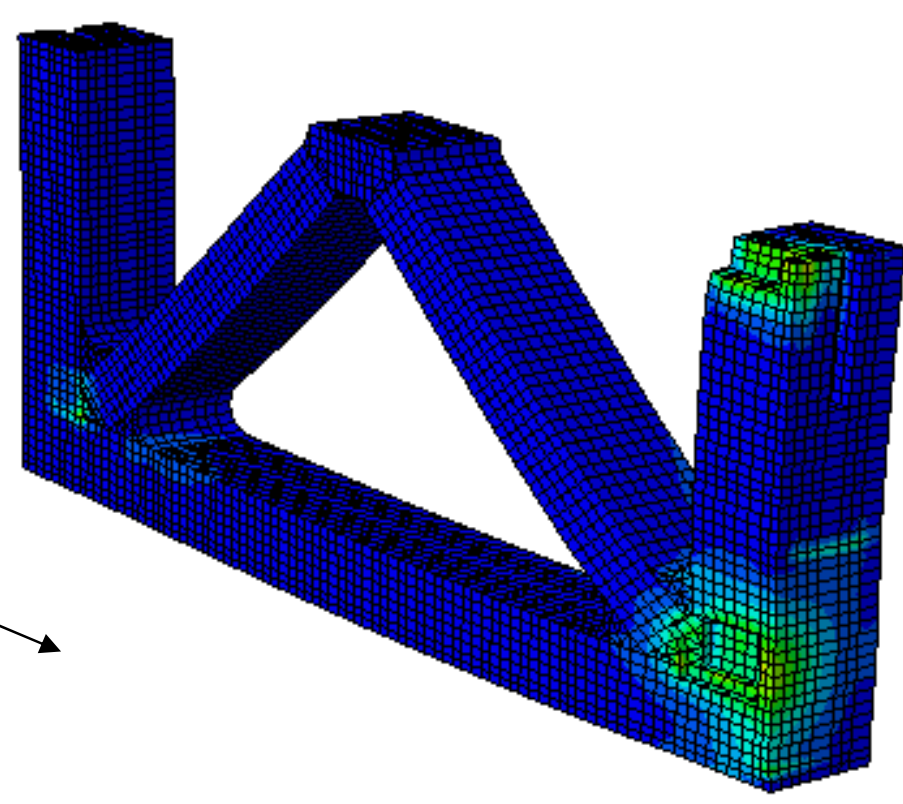

Deformed Var: U Deformation Scale Factor: $+1.773 e+02$

Figure B-11: Side Panel 3 of the X-loaded Revision 2 structure (joint shear elements hidden) 


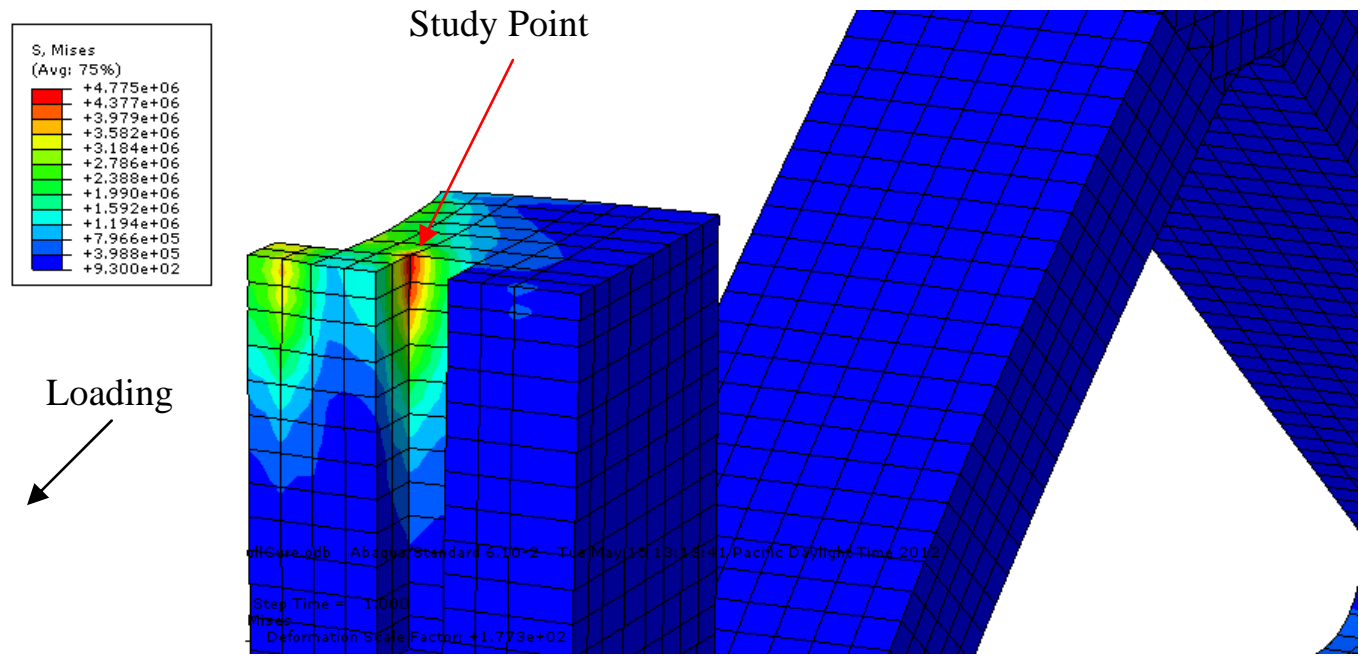

Figure B-12: Highest stress point Side Panel 3 of the X-loaded Revision 2 structure (joint shear elements hidden)

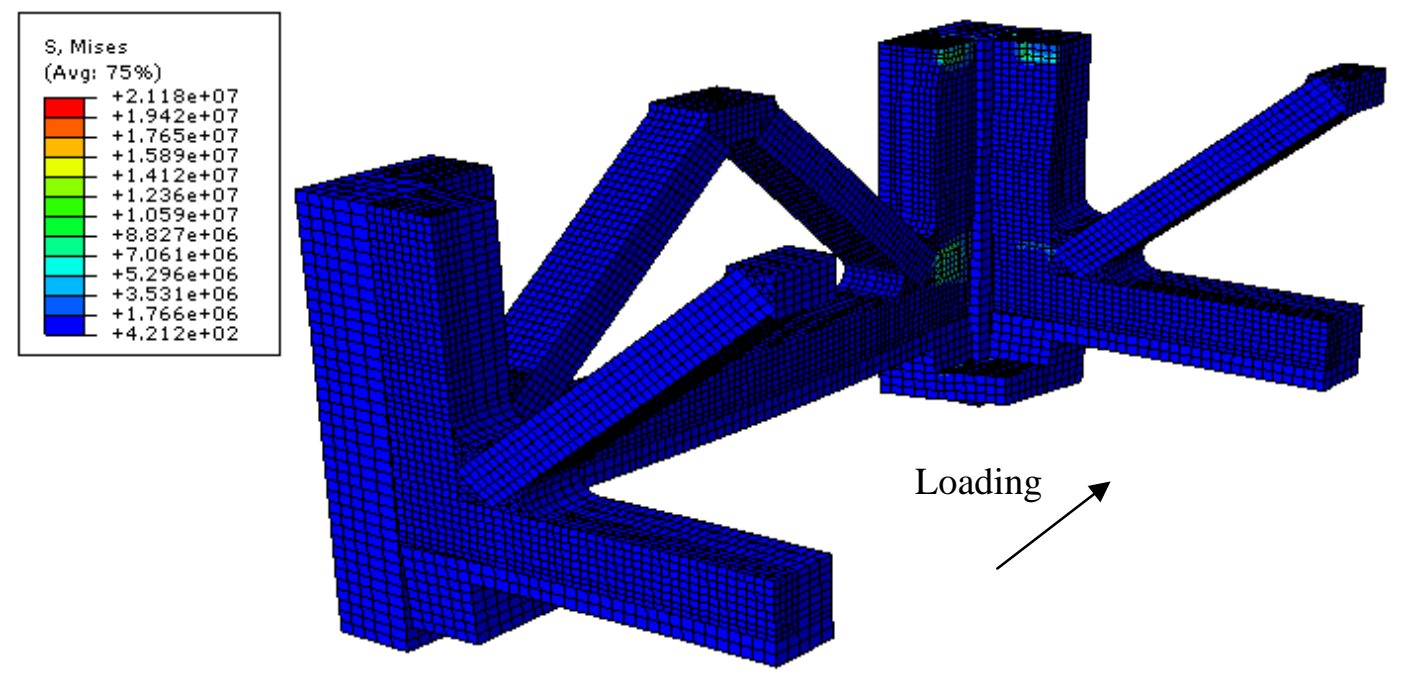

Deformed Var: U Deformation Scale Factor: $+1.773 \mathrm{e}+02$

Figure B-13: Stress plot of the X-loaded Revision 2 structure viewed from the $-\mathrm{X}$ side 


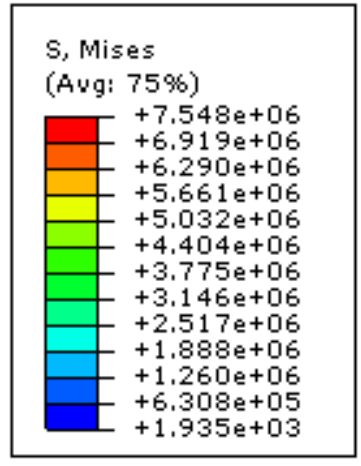

Loading
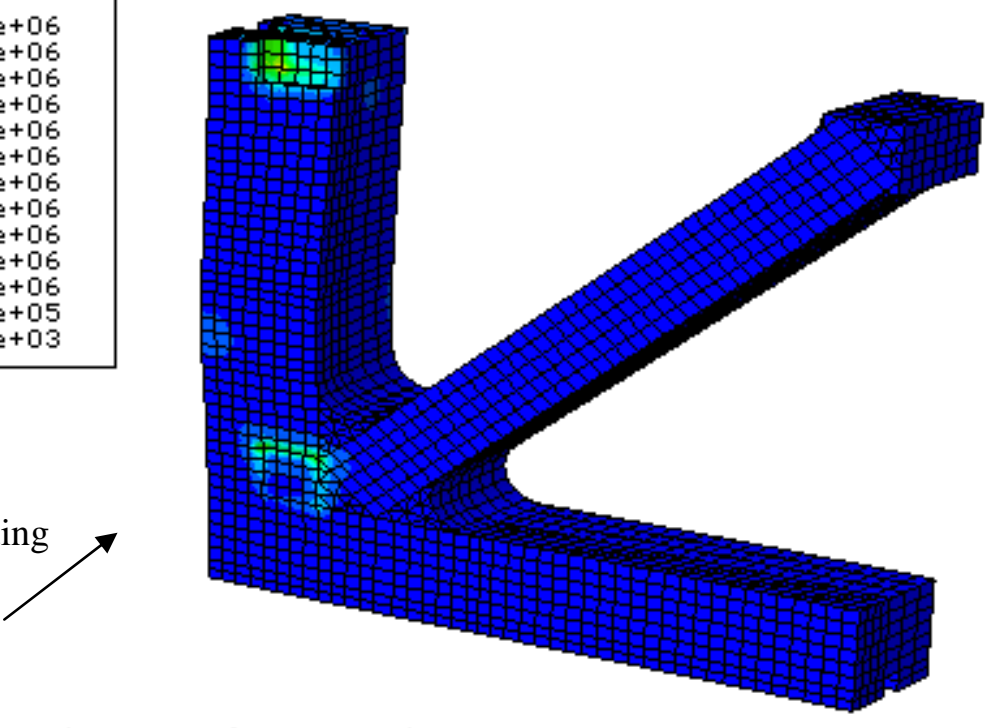

Deformed Var: U Deformation Scale Factor: $+1.773 \mathrm{e}+02$

Figure B-14: Side Panel 2 of the X-loaded Revision 2 structure (joint shear elements hidden)
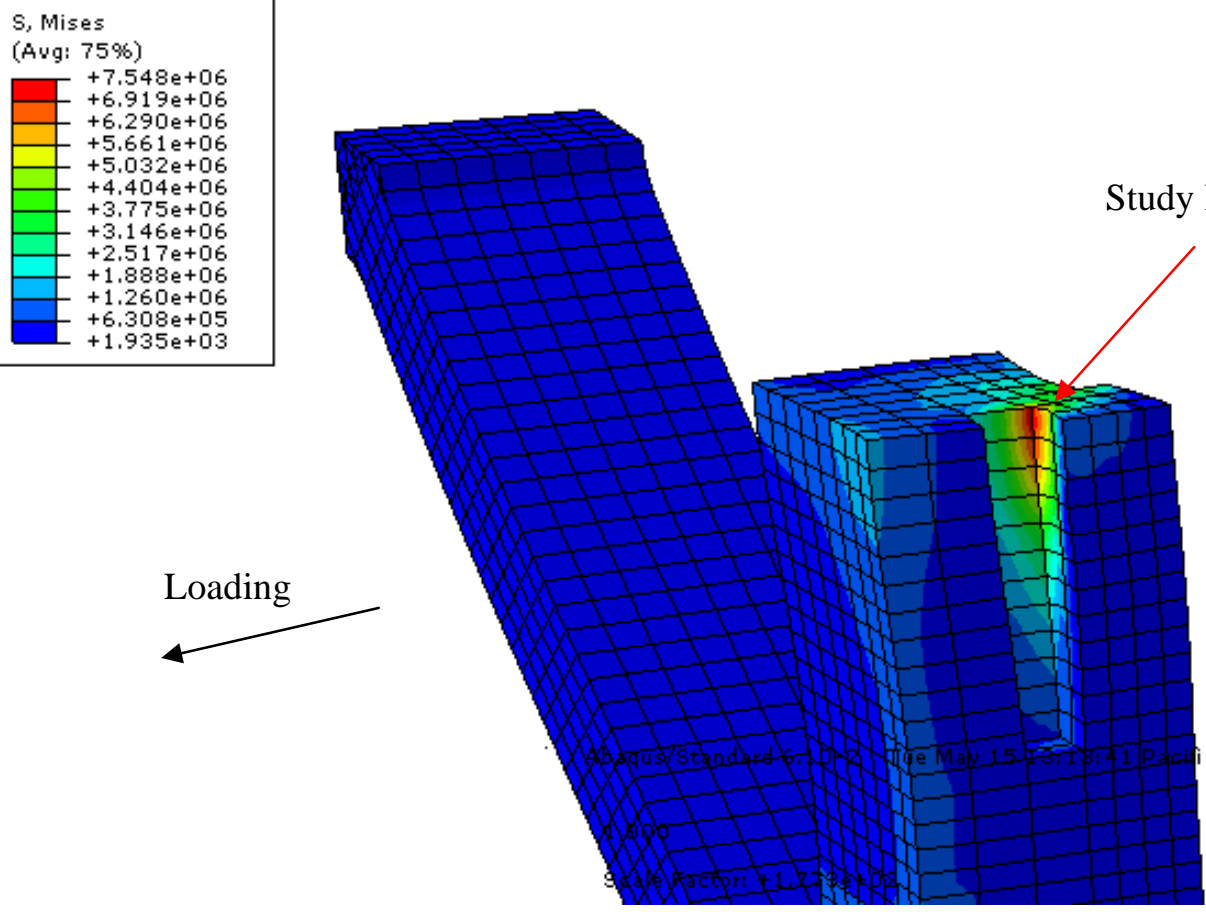

Figure B-15: Highest stress point on Side Panel 2 of the X-loaded Revision 2 structure (joint shear elements hidden) 


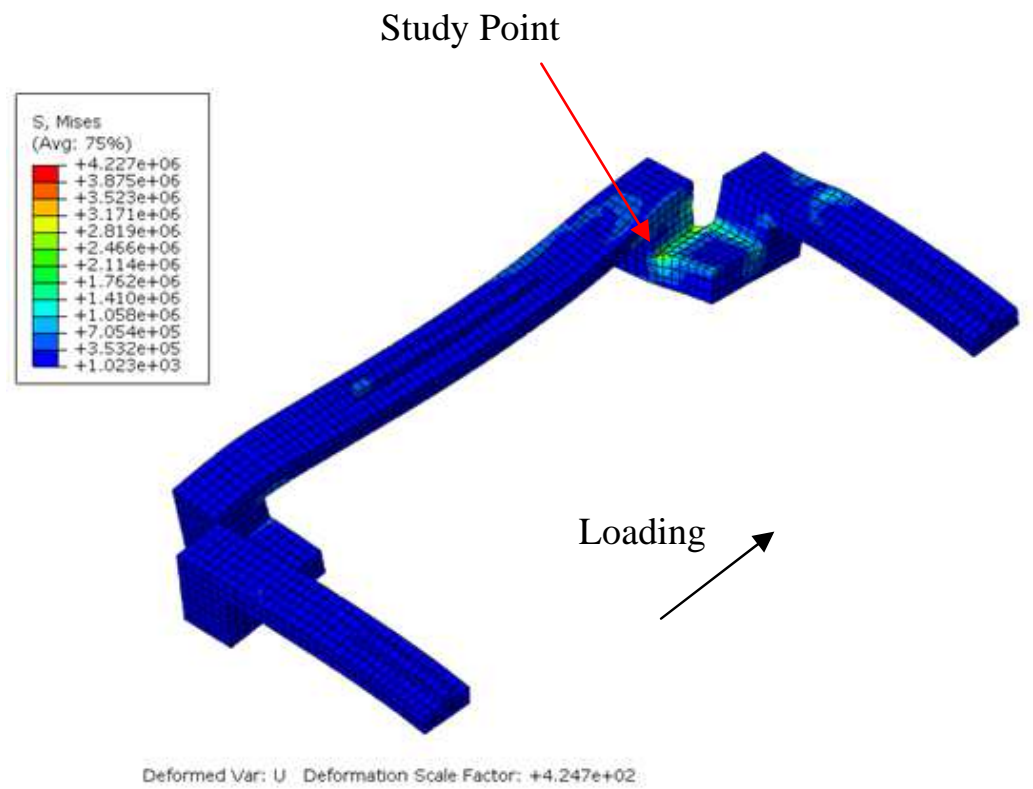

Figure B-16: Shoe of the X-loaded Revision 2 structure

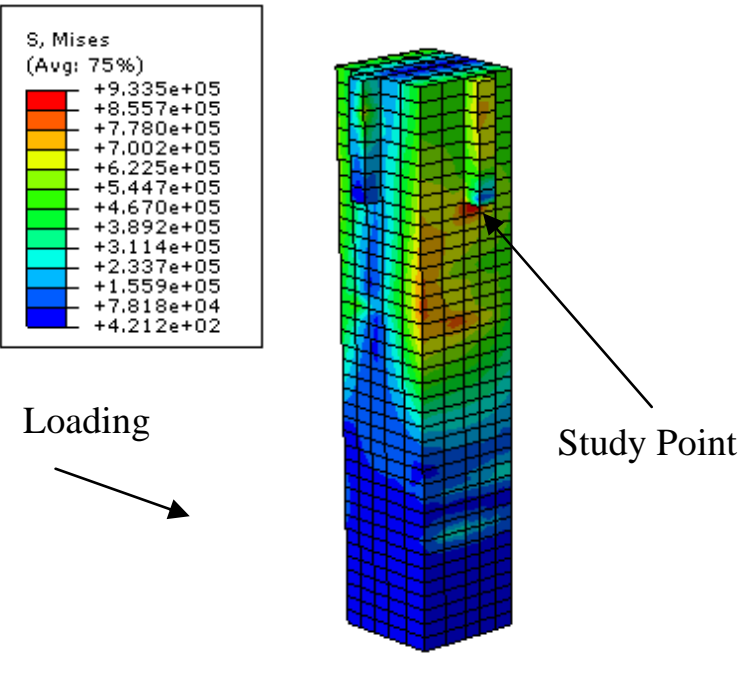

Deformed Var: U Deformation Scale Factor: $+1.000 e+00$

Figure B-17: Rail of the Revision 2 structure 
Plots for the RapidSat Revision 2 structure, Z-axis loaded

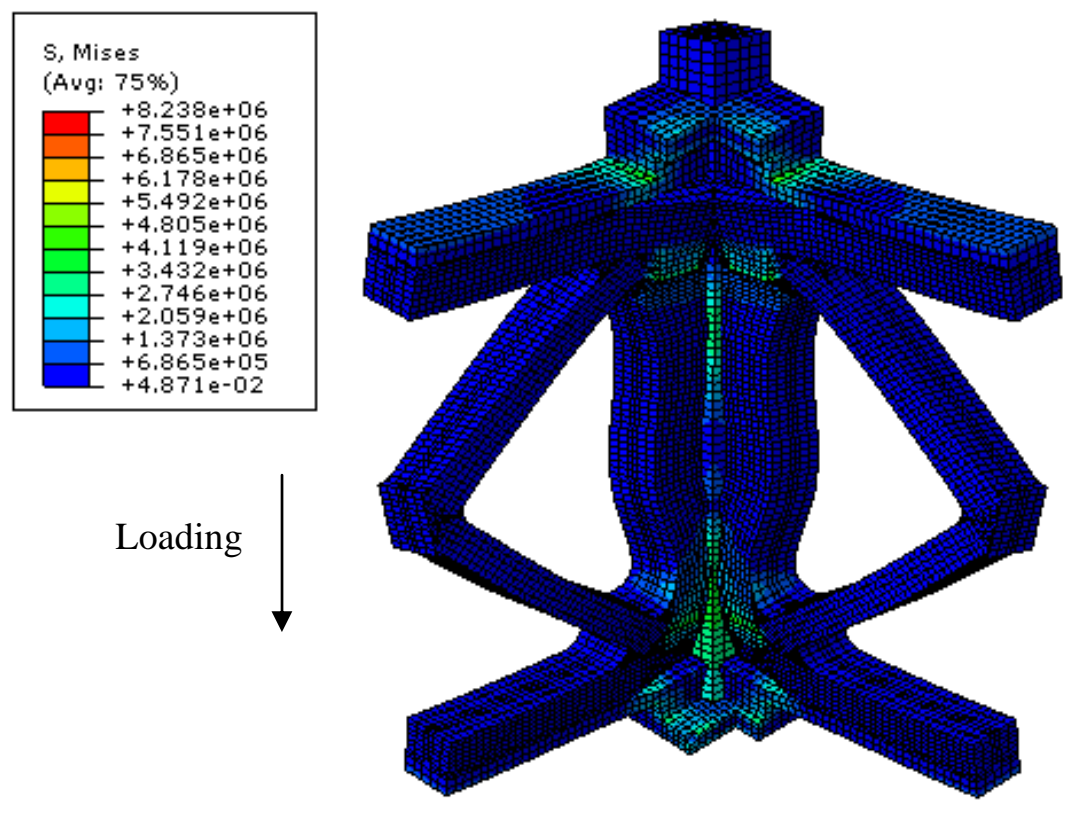

Deformed Var: U Deformation Scale Factor: $+1.120 e+03$

Figure B-18: Stress plot for the Z-loaded Revision 2 structure

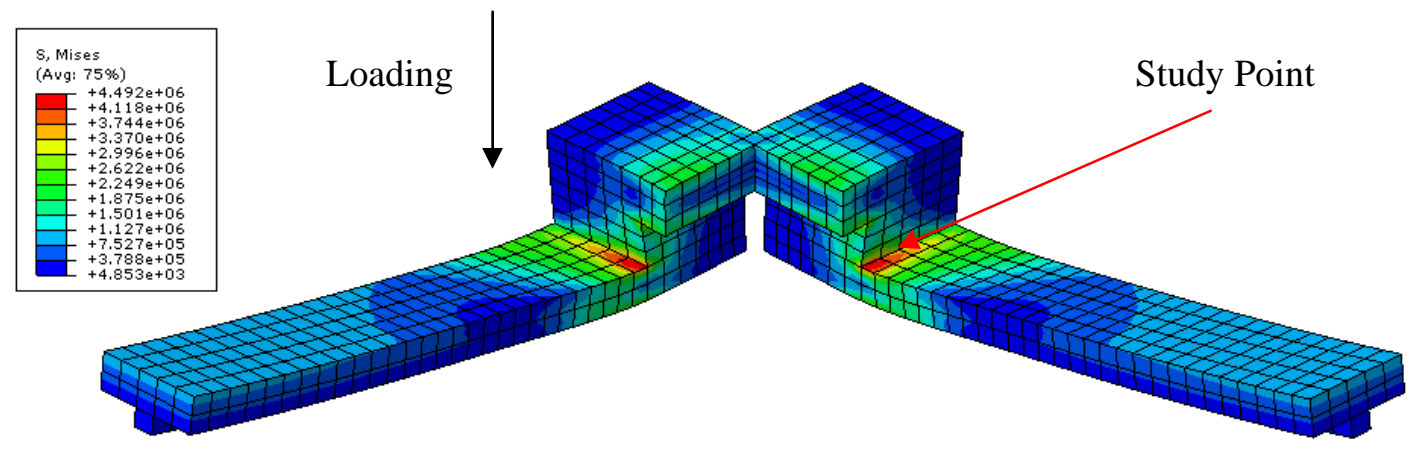

Deformed Var: U Deformation Scale Factor: $+1,120 \mathrm{e}+03$

Figure B-19: Shoe of the Z-loaded Revision 2 structure 

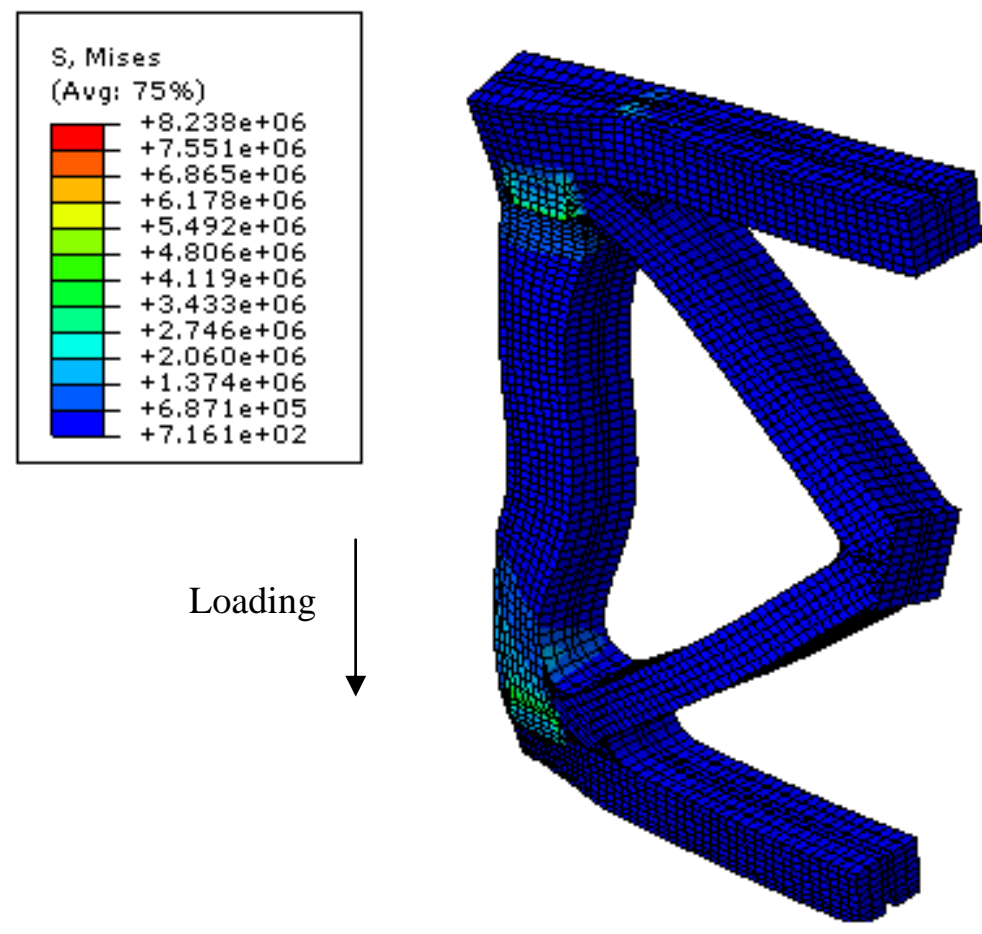

Deformed Var: U Deformation Scale Factor: $+1.120 e+03$

Figure B-20: Side Panel of the Z-loaded Revision 2 structure

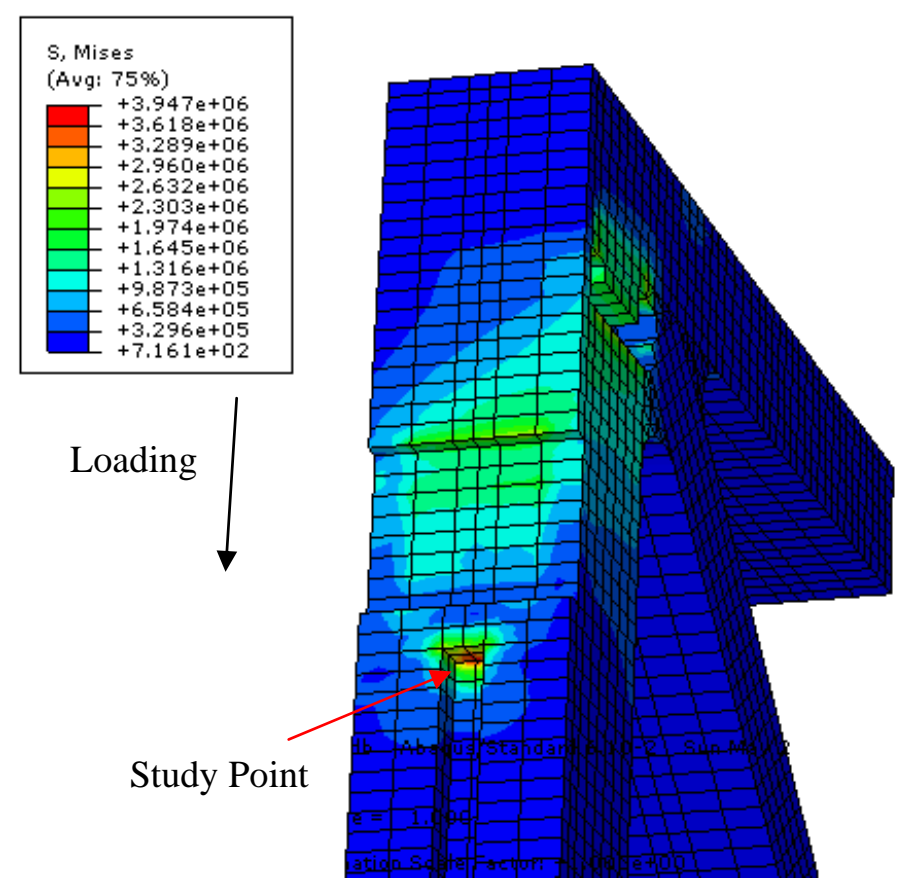

Figure B-21: Highest stress point on the Side Panel of the Z-loaded Revision 2 structure (joint shear elements hidden) 


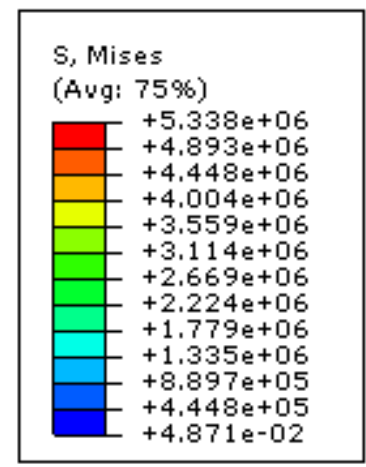

Study Point

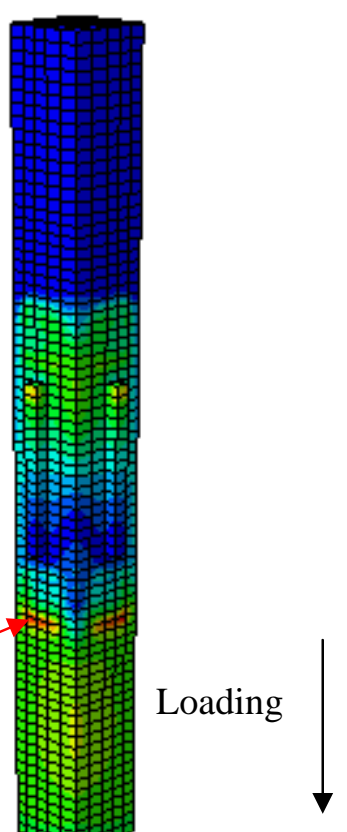

Deformed Var: U Deformation Scale Factor: $+1,000 e+00$

Figure B-22: Rail of the Z-loaded Revision 2 structure 


\section{Appendix C: Instron Data}

Specimen 1 to 8
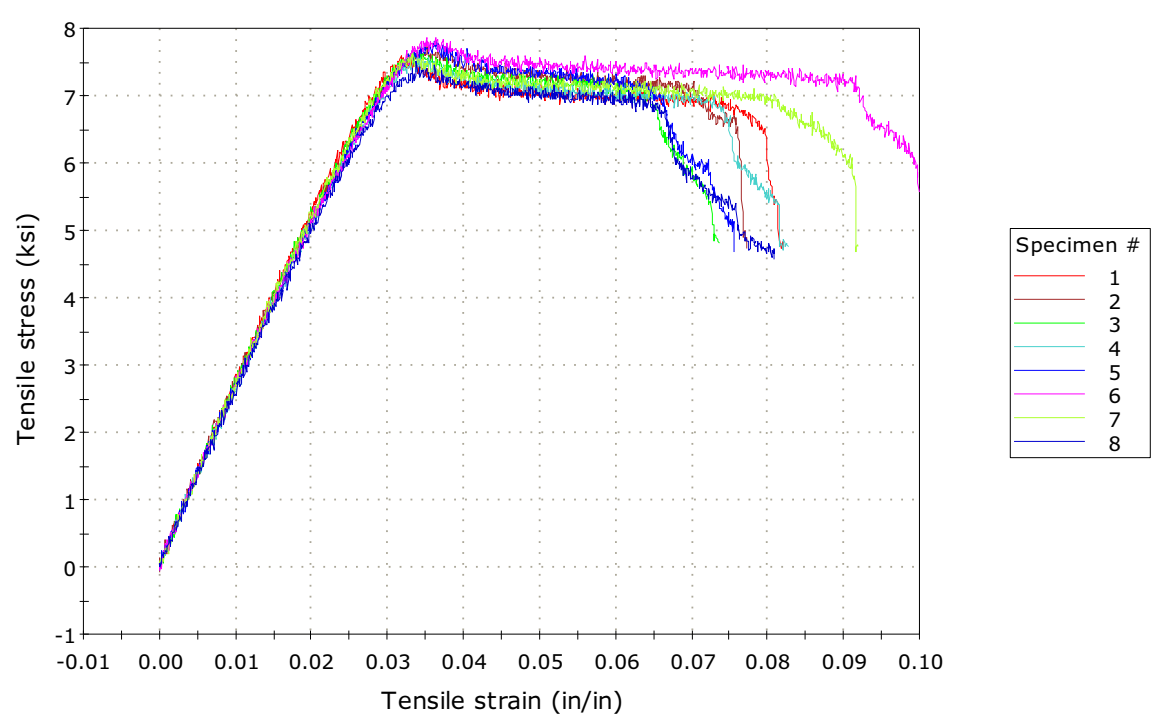

Specimen 9 to 15

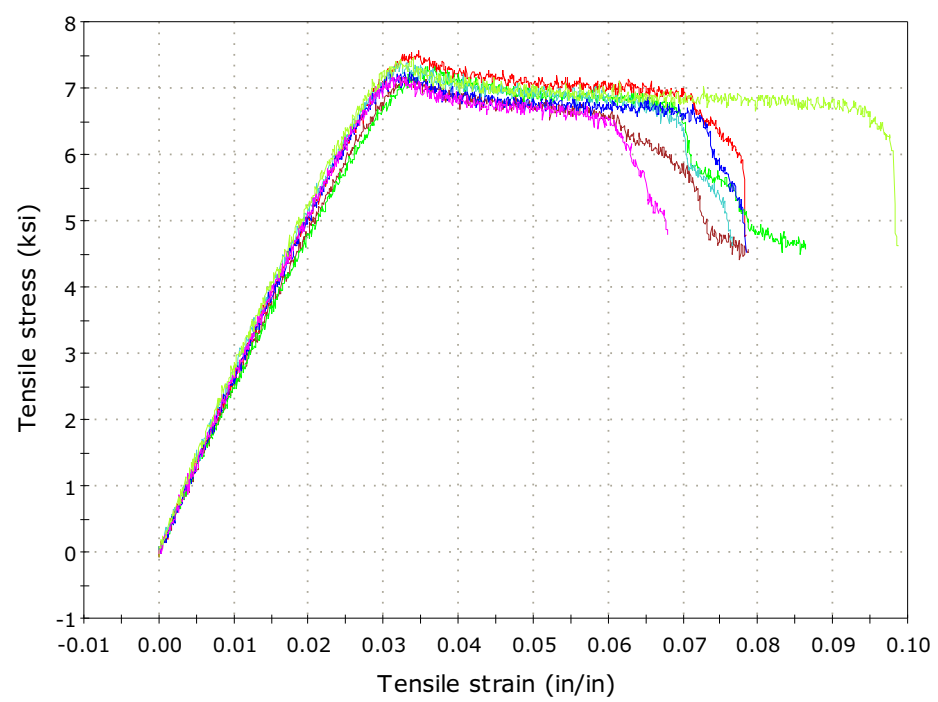

Figure C-1: Stress-Strain plots for the raw ABS sample set 
Table C-1: Instron data for the raw ABS sample set

\begin{tabular}{|c|c|c|c|c|}
\hline \multirow{2}{*}{ Specimen } & $\begin{array}{l}\text { Maximum } \\
\text { Load }\end{array}$ & $\begin{array}{c}\text { Maximum } \\
\text { Tensile stress }\end{array}$ & $\begin{array}{l}\text { Strain at Maximum } \\
\text { Load }\end{array}$ & $\begin{array}{c}\text { Modulus (Automatic } \\
\text { Young's) }\end{array}$ \\
\hline & (lbf) & (ksi) & (in/in) & (ksi) \\
\hline 1 & 124.09421 & 7.58568 & 0.03172 & 279.82761 \\
\hline 2 & 126.32392 & 7.72198 & 0.03534 & 270.49438 \\
\hline 3 & 125.31358 & 7.66022 & 0.03436 & 284.64156 \\
\hline 4 & 125.4449 & 7.66825 & 0.0338 & 267.4147 \\
\hline 5 & 127.84344 & 7.81487 & 0.03622 & 271.46039 \\
\hline 6 & 128.51342 & 7.85582 & 0.03626 & 271.62176 \\
\hline 7 & 124.62752 & 7.61828 & 0.03322 & 270.43474 \\
\hline 8 & 122.86949 & 7.51082 & 0.03384 & 265.30401 \\
\hline 9 & 123.88786 & 7.57307 & 0.03474 & 266.98755 \\
\hline 10 & 117.71062 & 7.19547 & 0.03381 & 251.75605 \\
\hline 11 & 119.98856 & 7.33471 & 0.03569 & 253.76727 \\
\hline 12 & 120.89438 & 7.39008 & 0.0323 & 277.32274 \\
\hline 13 & 118.46368 & 7.2415 & 0.03346 & 261.93289 \\
\hline 14 & 117.56858 & 7.18678 & 0.03195 & 261.80384 \\
\hline 15 & 122.24774 & 7.47281 & 0.03393 & 290.46222 \\
\hline Mean & 123.05279 & 7.52202 & 0.03404 & 269.68211 \\
\hline Standard Deviation & 3.51496 & 0.21486 & 0.00143 & 10.53353 \\
\hline $\begin{array}{c}\text { Coefficient of } \\
\text { Variation }\end{array}$ & 2.85647 & 2.85647 & 4.2025 & 3.9059 \\
\hline Mean + 1 SD & 126.56775 & 7.73689 & 0.03547 & 280.21564 \\
\hline Mean - 1 SD & 119.53783 & 7.30716 & 0.03261 & 259.14859 \\
\hline
\end{tabular}




\section{Specimen 1 to 8}
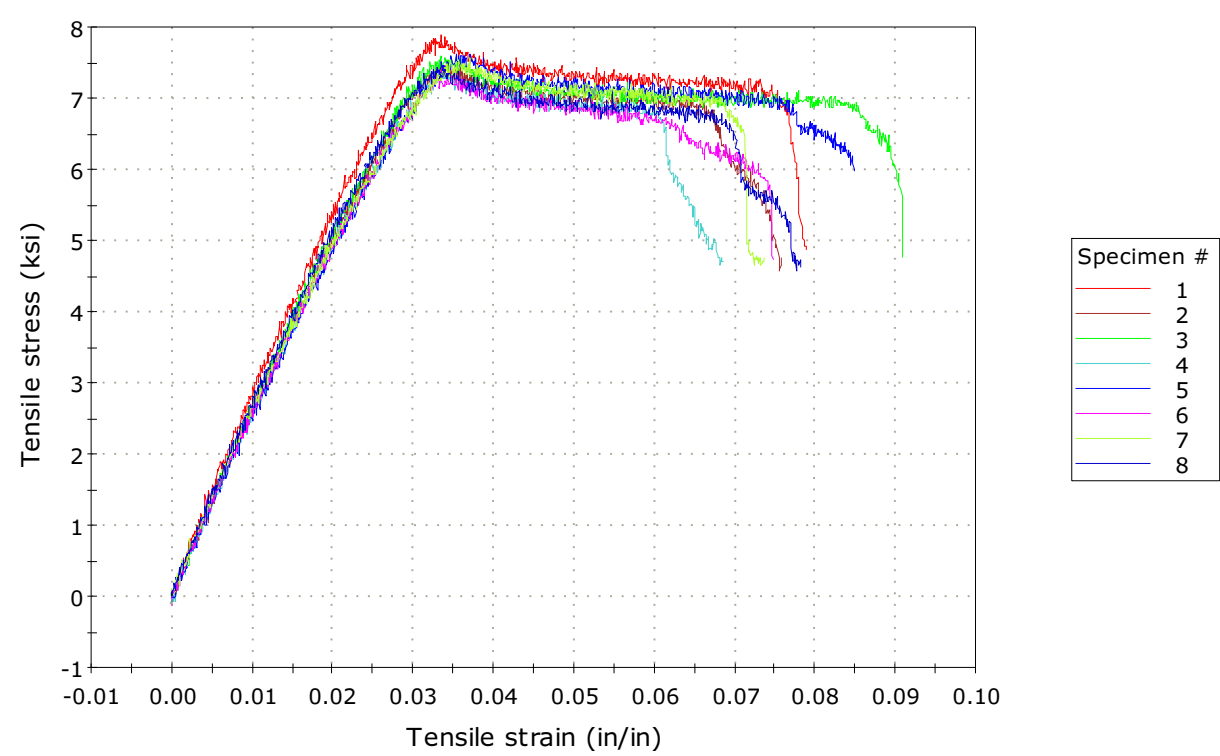

Figure C-2: Stress-Strain plot for the outgassed ABS sample set

Table C-2: Instron data for the outgassed ABS sample set

\begin{tabular}{|c|c|c|c|c|}
\hline \multirow{2}{*}{ Specimen } & $\begin{array}{c}\text { Maximum } \\
\text { Load }\end{array}$ & $\begin{array}{c}\text { Maximum } \\
\text { Tensile stress }\end{array}$ & $\begin{array}{c}\text { Strain at Maximum } \\
\text { Load }\end{array}$ & $\begin{array}{c}\text { Modulus (Automatic } \\
\text { Young's) }\end{array}$ \\
\cline { 2 - 5 }$(\mathrm{l})$ & $(\mathrm{kss})$ & $0.03353)$ & 292.85962 \\
\hline 1 & 129.05477 & 7.88892 & 0.03451 & 265.6571 \\
\hline 2 & 122.91236 & 7.51344 & 0.03345 & 273.77592 \\
\hline 3 & 124.36757 & 7.60239 & 0.03379 & 256.10886 \\
\hline 4 & 120.077 & 7.34012 & 0.03539 & 264.3909 \\
\hline 5 & 124.79368 & 7.62844 & 0.03352 & 268.69558 \\
\hline 6 & 120.61834 & 7.37321 & 0.03714 & 267.94122 \\
\hline 7 & 123.64667 & 7.55833 & 0.03394 & 282.03938 \\
\hline 8 & 121.32585 & 7.41646 & 0.03441 & 271.43357 \\
\hline Mean & 123.34953 & 7.54016 & 0.00128 & 11.43024 \\
\hline Standard Deviation & 2.88383 & 0.17628 & 3.72597 & 4.21106 \\
\hline Coefficient of Variation & 2.33793 & 2.33793 & 0.03569 & 282.86381 \\
\hline Mean + 1 SD & 126.23336 & 7.71645 & 0.03313 & 260.00334 \\
\hline Mean - 1 SD & 120.4657 & 7.36388 & & \\
\hline
\end{tabular}


Specimen 1 to 8
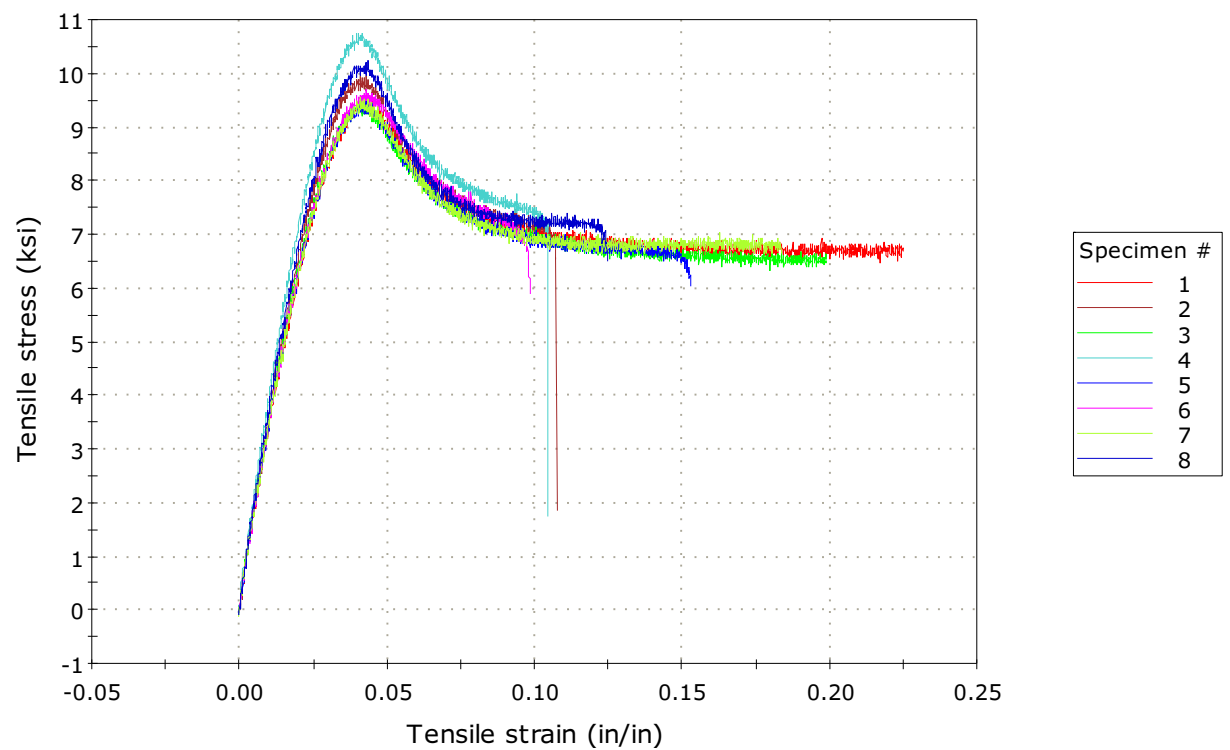

Specimen 9 to 10

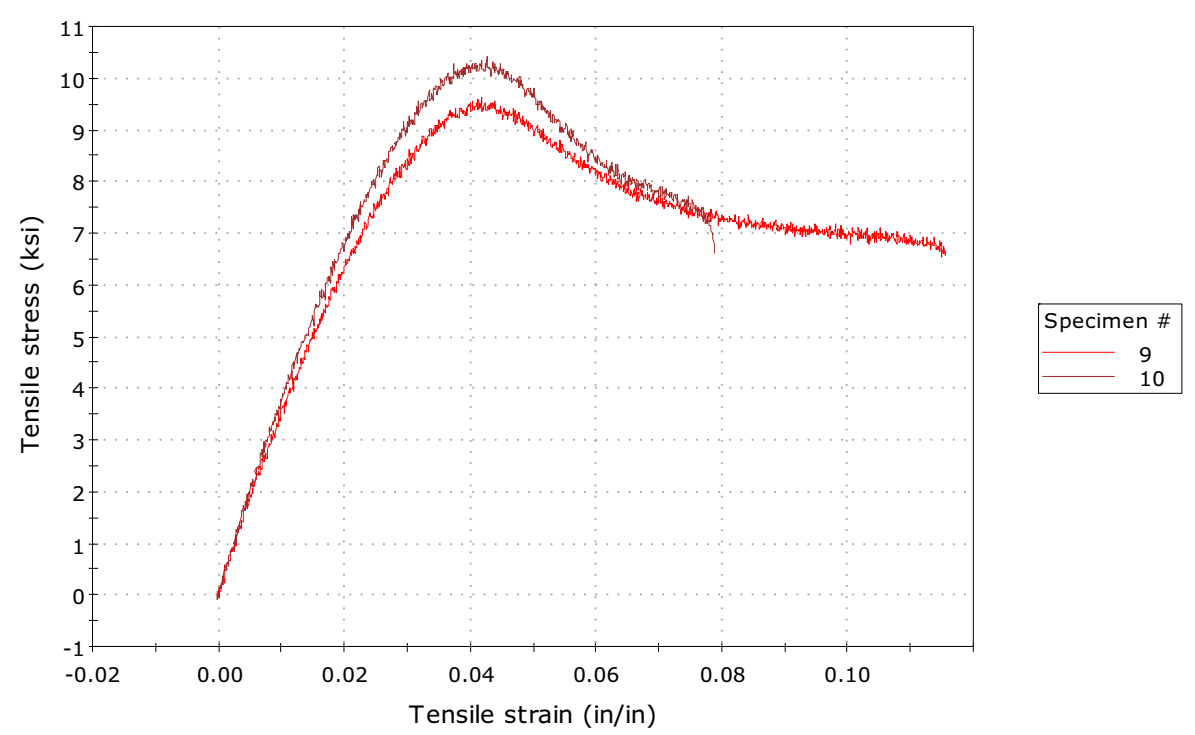

Figure C-3: Stress-Strain plots for the first half of the raw FullCure720 sample set 
Specimen 1 to 8
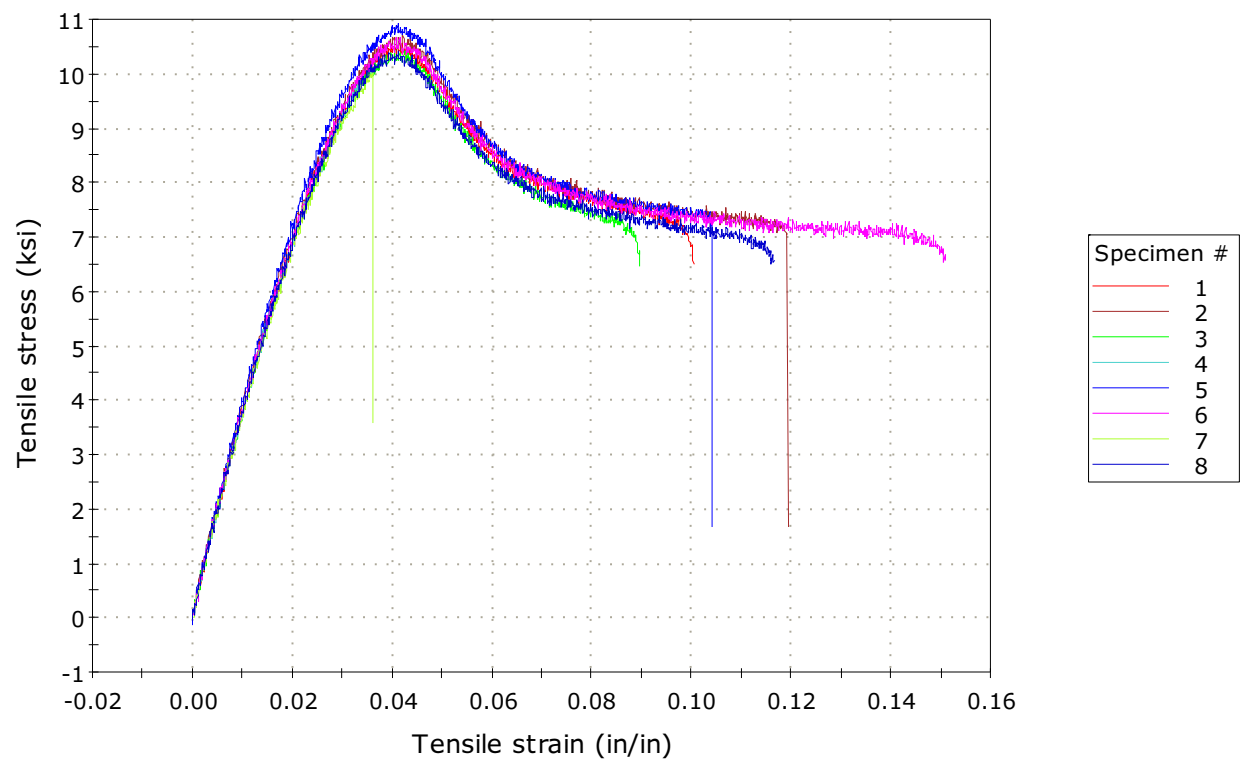

Specimen 9 to 10

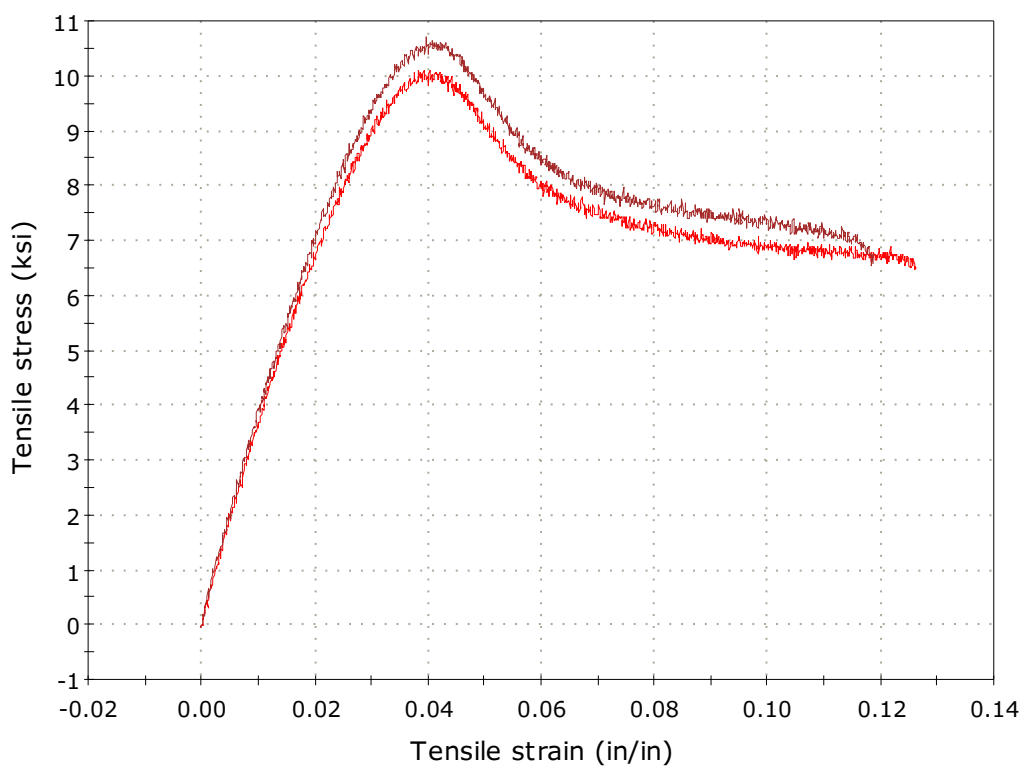

Figure C-4: Stress-Strain plots for the second half of the raw FullCure720 sample set 
Table C-3: Instron data for the raw Fullcure 720 sample set

\begin{tabular}{|c|c|c|c|c|}
\hline \multirow{2}{*}{ Specimen } & Maximum Load & $\begin{array}{c}\text { Maximum } \\
\text { Tensile stress }\end{array}$ & $\begin{array}{l}\text { Strain at Maximum } \\
\text { Load }\end{array}$ & $\begin{array}{c}\text { Modulus (Automatic } \\
\text { Young's) }\end{array}$ \\
\hline & (lbf) & (ksi) & (in/in) & (ksi) \\
\hline 1 & 139.17151 & 9.5056 & 0.04315 & 356.19051 \\
\hline 2 & 145.98657 & 9.97108 & 0.04087 & 378.94414 \\
\hline 3 & 138.90887 & 9.48766 & 0.04122 & 377.92099 \\
\hline 4 & 157.50492 & 10.7578 & 0.04031 & 395.82851 \\
\hline 5 & 139.82541 & 9.55026 & 0.04184 & 362.97782 \\
\hline 6 & 142.02831 & 9.70072 & 0.04296 & 361.25631 \\
\hline 7 & 139.91385 & 9.5563 & 0.04126 & 360.01208 \\
\hline 8 & 149.85907 & 10.23558 & 0.04371 & 393.51138 \\
\hline 9 & 141.01262 & 9.63135 & 0.04196 & 371.13927 \\
\hline 10 & 152.54704 & 10.41917 & 0.04264 & 393.54692 \\
\hline 11 & 160.91915 & 10.55069 & 0.04214 & 388.08577 \\
\hline 12 & 163.44096 & 10.71604 & 0.04215 & 398.98842 \\
\hline 13 & 159.97849 & 10.48902 & 0.04074 & 383.05294 \\
\hline 14 & 149.47316 & 9.80023 & 0.03318 & 395.15249 \\
\hline 15 & 166.60596 & 10.92355 & 0.04115 & 408.2736 \\
\hline 16 & 163.01754 & 10.68827 & 0.04134 & 399.64151 \\
\hline 17 & 152.99459 & 10.03112 & 0.03611 & 397.14501 \\
\hline 18 & 159.19595 & 10.43771 & 0.04129 & 398.25996 \\
\hline 19 & 153.94865 & 10.09367 & 0.04045 & 381.36287 \\
\hline 20 & 163.31233 & 10.7076 & 0.03979 & 386.9337 \\
\hline Mean & 151.9822475 & 10.162671 & 0.040913 & 384.41121 \\
\hline Standard Deviation & 9.51864617 & 0.488407949 & 0.002409691 & 15.29746503 \\
\hline Coefficient of Variation & 4.52261 & 4.52261 & 2.61823 & 4.0439 \\
\hline Mean + 1 SD & 151.21894 & 10.32846 & 0.04309 & 390.30279 \\
\hline Mean - 1 SD & 138.13269 & 9.43465 & 0.04089 & 359.96279 \\
\hline
\end{tabular}


Specimen 1 to 8

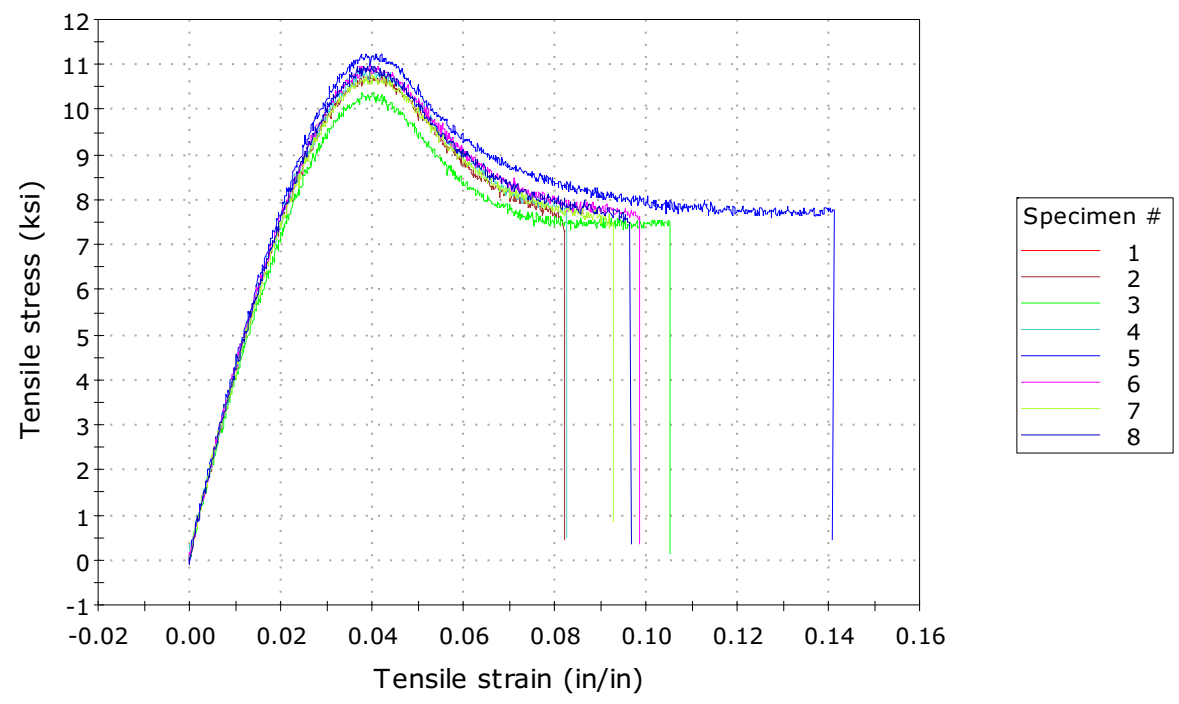

Specimen 9 to 11

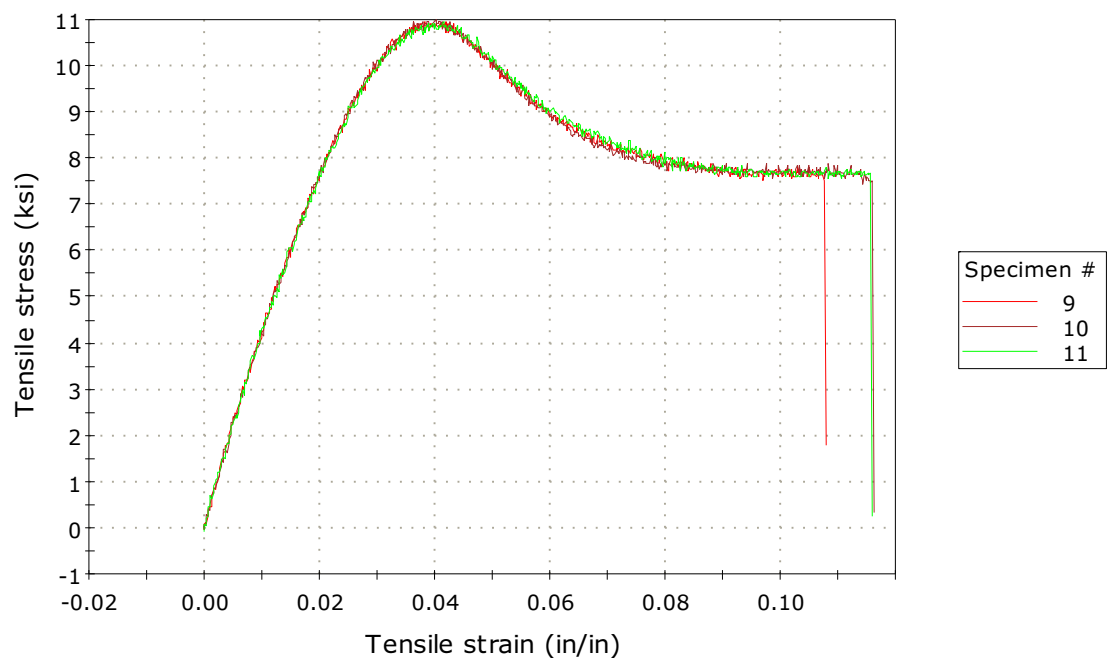

Figure C-5: Stress-Strain plots for the first half of the outgassed FullCure720 sample set 
Specimen 1 to 8
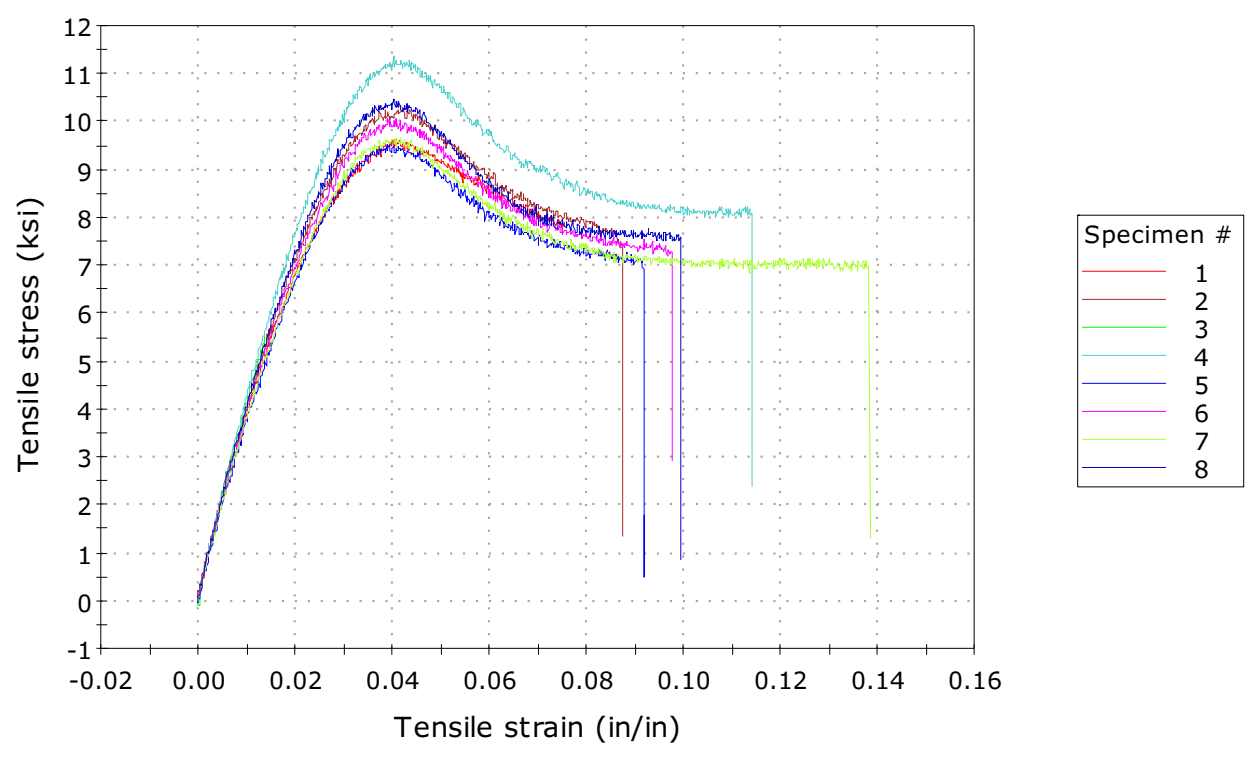

Specimen 9 to 11
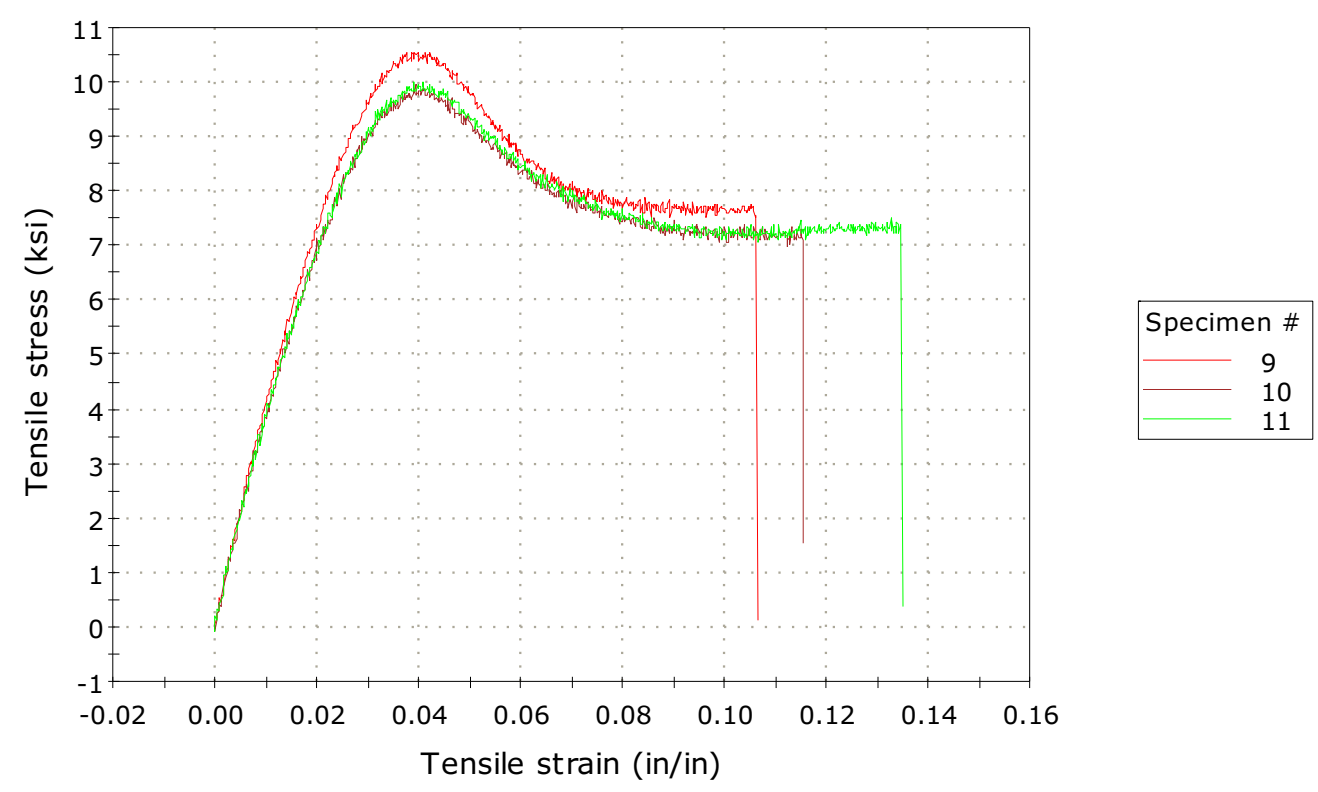

Figure C-6: Stress-Strain plots for the second half of the outgassed FullCure720 sample set 
Table C-4: Instron data for the outgassed FullCure720 sample set

\begin{tabular}{|c|c|c|c|c|}
\hline \multirow{2}{*}{ Specimen } & $\begin{array}{l}\text { Maximum } \\
\text { Load }\end{array}$ & $\begin{array}{c}\text { Maximum } \\
\text { Tensile stress } \\
\end{array}$ & $\begin{array}{c}\text { Strain at } \\
\text { Maximum Load } \\
\end{array}$ & $\begin{array}{c}\text { Modulus (Automatic } \\
\text { Young's) }\end{array}$ \\
\hline & (lbf) & (ksi) & (in/in) & (ksi) \\
\hline 1 & 150.31734 & 9.62031 & 0.04052 & 420.05679 \\
\hline 2 & 161.13622 & 10.31272 & 0.04236 & 411.17272 \\
\hline 4 & 177.32301 & 11.34867 & 0.04032 & 420.24921 \\
\hline 5 & 148.98274 & 9.53489 & 0.03951 & 389.26772 \\
\hline 6 & 157.42988 & 10.07551 & 0.03915 & 414.45057 \\
\hline 7 & 151.26336 & 9.68085 & 0.0409 & 421.98495 \\
\hline 8 & 163.54816 & 10.46708 & 0.04032 & 413.91319 \\
\hline 9 & 164.92029 & 10.5549 & 0.04006 & 421.77733 \\
\hline 10 & 155.46817 & 9.94996 & 0.03935 & 397.68022 \\
\hline 11 & 156.46778 & 10.01394 & 0.03913 & 409.57123 \\
\hline 12 & 169.58337 & 10.85334 & 0.03981 & 429.01635 \\
\hline 13 & 162.49495 & 10.39968 & 0.03798 & 413.6964 \\
\hline 14 & 171.45396 & 10.97305 & 0.04033 & 422.2487 \\
\hline 15 & 175.65073 & 11.24165 & 0.03882 & 441.73372 \\
\hline 16 & 171.3146 & 10.96413 & 0.03963 & 440.49142 \\
\hline 17 & 168.42028 & 10.7789 & 0.0401 & 439.70595 \\
\hline 18 & 171.56652 & 10.98026 & 0.04067 & 426.05895 \\
\hline 19 & 171.13237 & 10.95247 & 0.03633 & 451.0274 \\
\hline 20 & 171.70587 & 10.98918 & 0.04035 & 430.73117 \\
\hline 21 & 171.10021 & 10.95041 & 0.0417 & 421.21819 \\
\hline Mean & 164.5639905 & 10.532095 & 0.039867 & 421.802609 \\
\hline Standard Deviation & 8.717013772 & 0.557889835 & 0.001284352 & 14.80054016 \\
\hline Coefficient of Variation & 5.297035971 & 5.297045225 & 3.221590706 & 3.508878287 \\
\hline Mean + 1 SD & 173.2810043 & 11.08998484 & 0.041151352 & 436.6031492 \\
\hline Mean - 1 SD & 155.8469767 & 9.61116 & 0.03917 & 401.12756 \\
\hline
\end{tabular}


Specimen 1 to 8
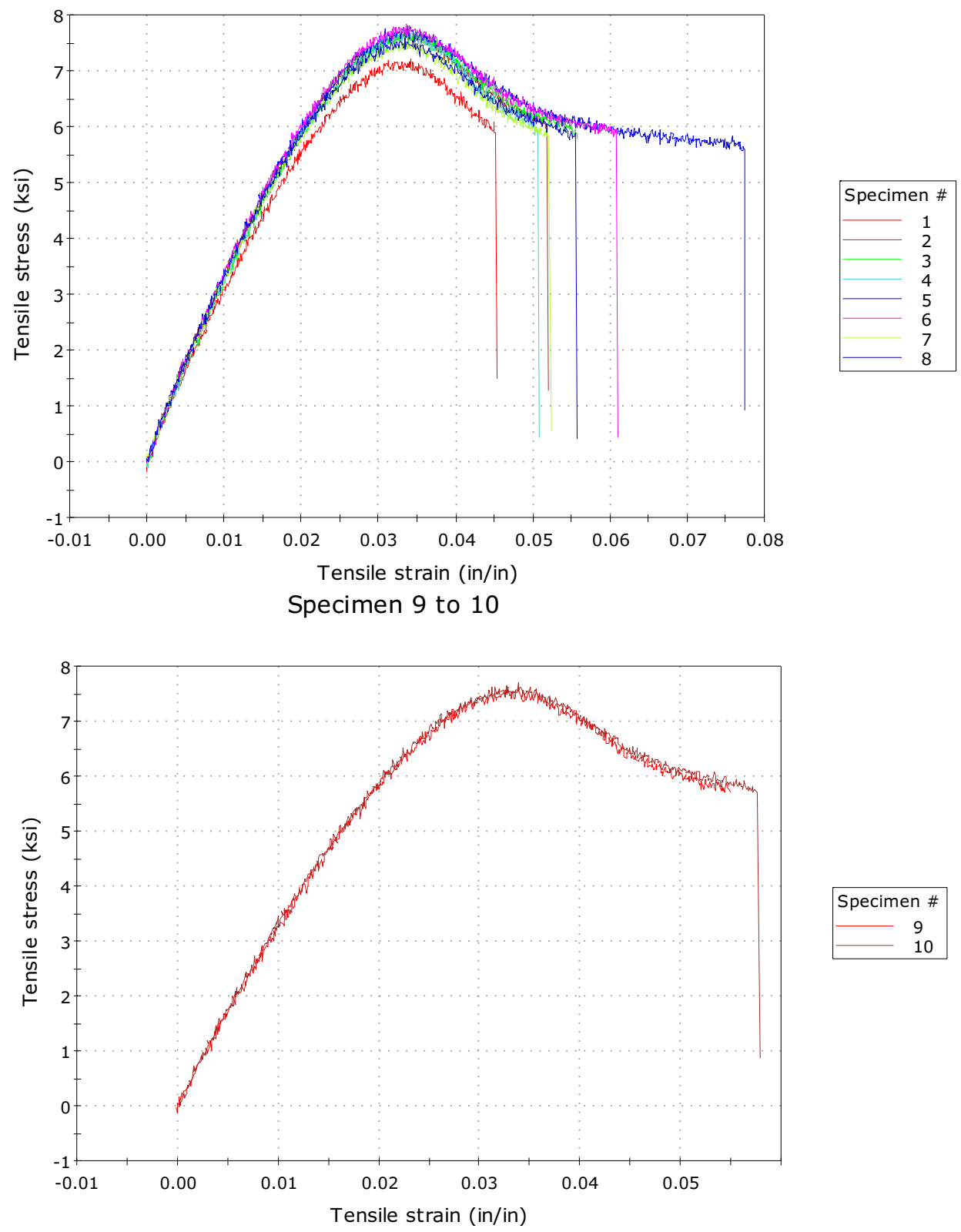

Figure C-7: Stress-Strain plots for the raw Watershed sample set 
Table C-5: Instron data for the raw Watershed sample set

\begin{tabular}{|c|c|c|c|c|}
\hline \multirow{2}{*}{ Specimen } & $\begin{array}{l}\text { Maximum } \\
\text { Load }\end{array}$ & $\begin{array}{c}\text { Maximum } \\
\text { Tensile stress }\end{array}$ & $\begin{array}{c}\text { Strain at } \\
\text { Maximum Load } \\
\end{array}$ & $\begin{array}{c}\text { Modulus (Automatic } \\
\text { Young's) }\end{array}$ \\
\hline & (lbf) & (ksi) & (in/in) & (ksi) \\
\hline 1 & 112.58391 & 7.20537 & 0.03423 & 340.93276 \\
\hline 2 & 121.12485 & 7.75199 & 0.03358 & 354.67675 \\
\hline 3 & 119.95372 & 7.67704 & 0.03552 & 352.84569 \\
\hline 4 & 120.53527 & 7.71426 & 0.03301 & 347.52747 \\
\hline 5 & 121.95027 & 7.80482 & 0.03372 & 364.07841 \\
\hline 6 & 122.27186 & 7.8254 & 0.03368 & 367.21916 \\
\hline 7 & 117.40511 & 7.51393 & 0.03342 & 356.03604 \\
\hline 8 & 118.52264 & 7.58545 & 0.03339 & 355.07777 \\
\hline 9 & 118.40472 & 7.5779 & 0.03267 & 360.85716 \\
\hline 10 & 120.36107 & 7.70311 & 0.03387 & 351.68484 \\
\hline Mean & 119.31134 & 7.63593 & 0.03371 & 355.0936 \\
\hline Standard Deviation & 2.83561 & $\begin{array}{c}0.1 \\
8148\end{array}$ & 0.00077 & 7.72072 \\
\hline Coefficient of Variation & 2.37665 & 2.37665 & 2.28397 & 2.17428 \\
\hline Mean + 1 SD & 122.14695 & 7.8174 & 0.03448 & 362.81432 \\
\hline Mean - 1 SD & 116.47573 & 7.45445 & 0.03294 & 347.37289 \\
\hline
\end{tabular}



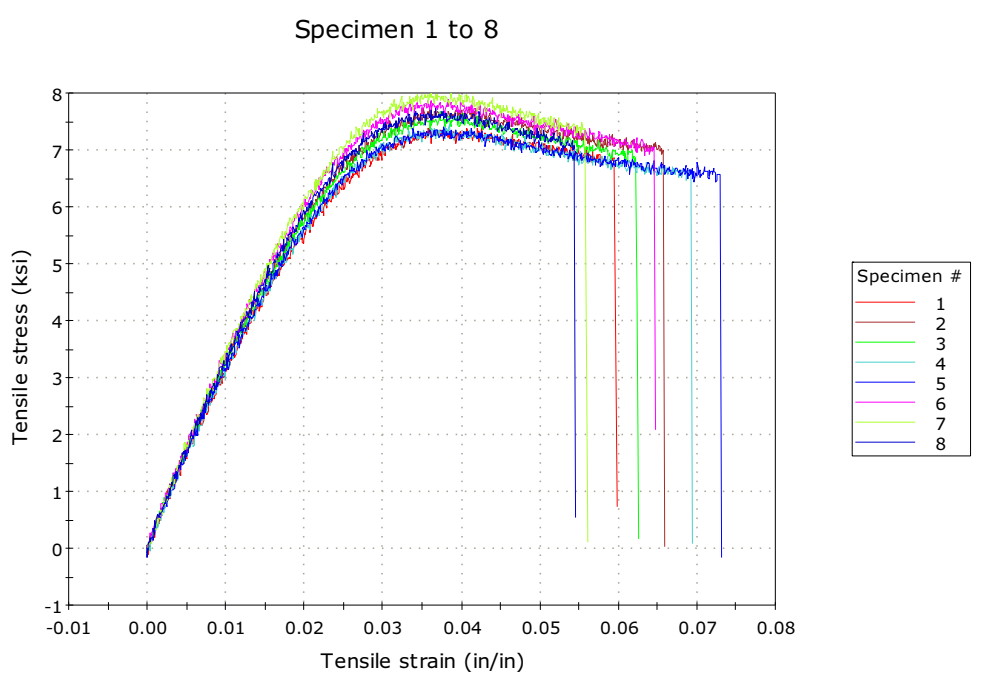

Specimen 9 to 16
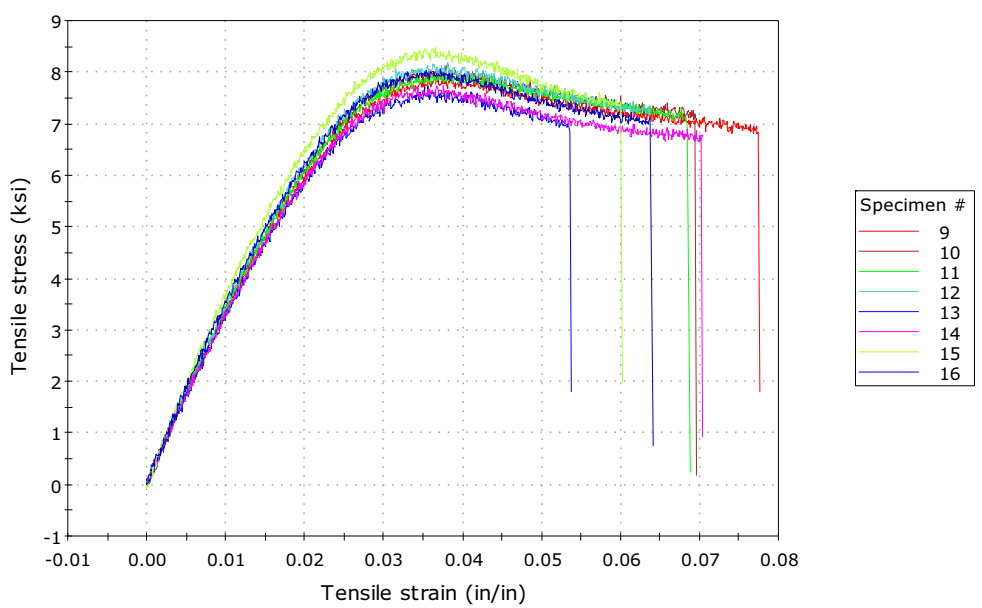

Specimen 17 to 20
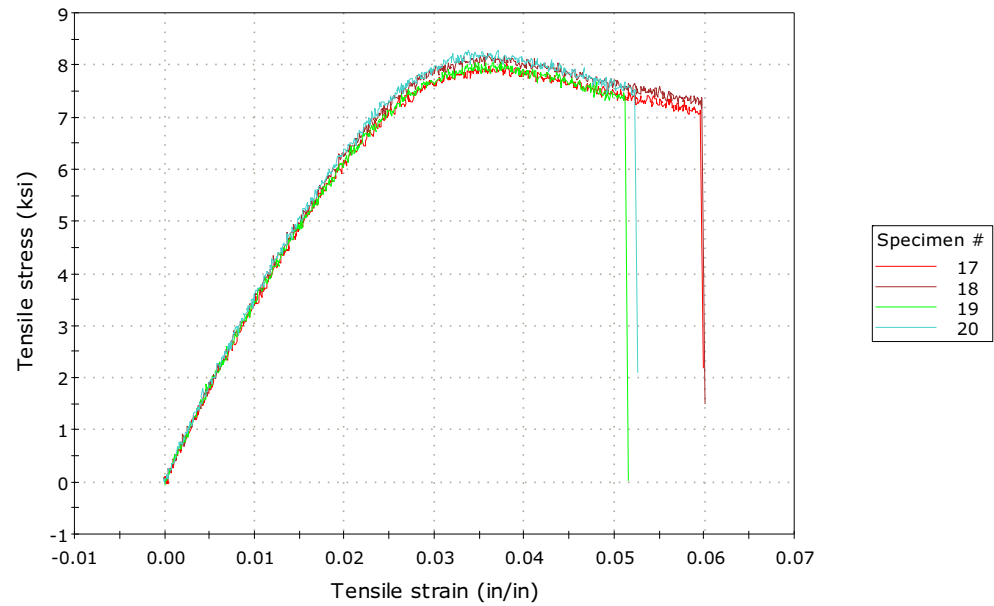

Figure C-8: Stress-Strain plots for the outgassed Watershed sample set 
Table C-6: Instron data for the outgassed Watershed sample set

\begin{tabular}{|c|c|c|c|c|}
\hline \multirow{2}{*}{ Specimen } & $\begin{array}{l}\text { Maximum } \\
\text { Load }\end{array}$ & $\begin{array}{c}\text { Maximum } \\
\text { Tensile stress }\end{array}$ & $\begin{array}{c}\text { Strain at } \\
\text { Maximum Load } \\
\end{array}$ & $\begin{array}{c}\text { Modulus (Automatic } \\
\text { Young's) }\end{array}$ \\
\hline & (lbf) & (ksi) & (in/in) & (ksi) \\
\hline 1 & 115.98742 & 7.4232 & 0.04258 & 318.23404 \\
\hline 2 & 121.14897 & 7.75353 & 0.04104 & 358.79705 \\
\hline 3 & 119.75273 & 7.66417 & 0.03737 & 345.3943 \\
\hline 4 & 116.54485 & 7.45887 & 0.03857 & 321.62816 \\
\hline 5 & 115.91238 & 7.41839 & 0.03784 & 326.72444 \\
\hline 6 & 123.40815 & 7.89812 & 0.03831 & 341.16986 \\
\hline 7 & 124.94911 & 7.99674 & 0.03876 & 362.65925 \\
\hline 8 & 120.58082 & 7.71717 & 0.03679 & 342.81443 \\
\hline 9 & 124.39705 & 7.96141 & 0.03859 & 356.78419 \\
\hline 10 & 126.8465 & 8.11818 & 0.03784 & 360.86406 \\
\hline 11 & 124.43993 & 7.96416 & 0.03418 & 355.53619 \\
\hline 12 & 127.77376 & 8.17752 & 0.03813 & 368.47289 \\
\hline 13 & 120.92654 & 7.7393 & 0.03564 & 337.5868 \\
\hline 14 & 120.87026 & 7.7357 & 0.03767 & 352.78119 \\
\hline 15 & 132.44756 & 8.47664 & 0.03657 & 394.72942 \\
\hline 16 & 125.89513 & 8.05729 & 0.03725 & 359.15452 \\
\hline 17 & 125.66197 & 8.04237 & 0.03806 & 357.58285 \\
\hline 18 & 128.23739 & 8.20719 & 0.03602 & 366.26814 \\
\hline 19 & 126.10684 & 8.07084 & 0.03756 & 365.07658 \\
\hline 20 & 129.24236 & 8.27151 & 0.03384 & 366.22714 \\
\hline Mean & 123.55649 & 7.90762 & 0.03763 & 352.92428 \\
\hline Standard Deviation & 4.52998 & 0.28992 & 0.00199 & 18.01797 \\
\hline Coefficient of Variation & 3.66632 & 3.66632 & 5.28117 & 5.10534 \\
\hline Mean + 1 SD & 128.08647 & 8.19753 & 0.03962 & 370.94225 \\
\hline Mean - 1 SD & 119.02651 & 7.6177 & 0.03564 & 334.9063 \\
\hline
\end{tabular}


Specimen 1 to 8
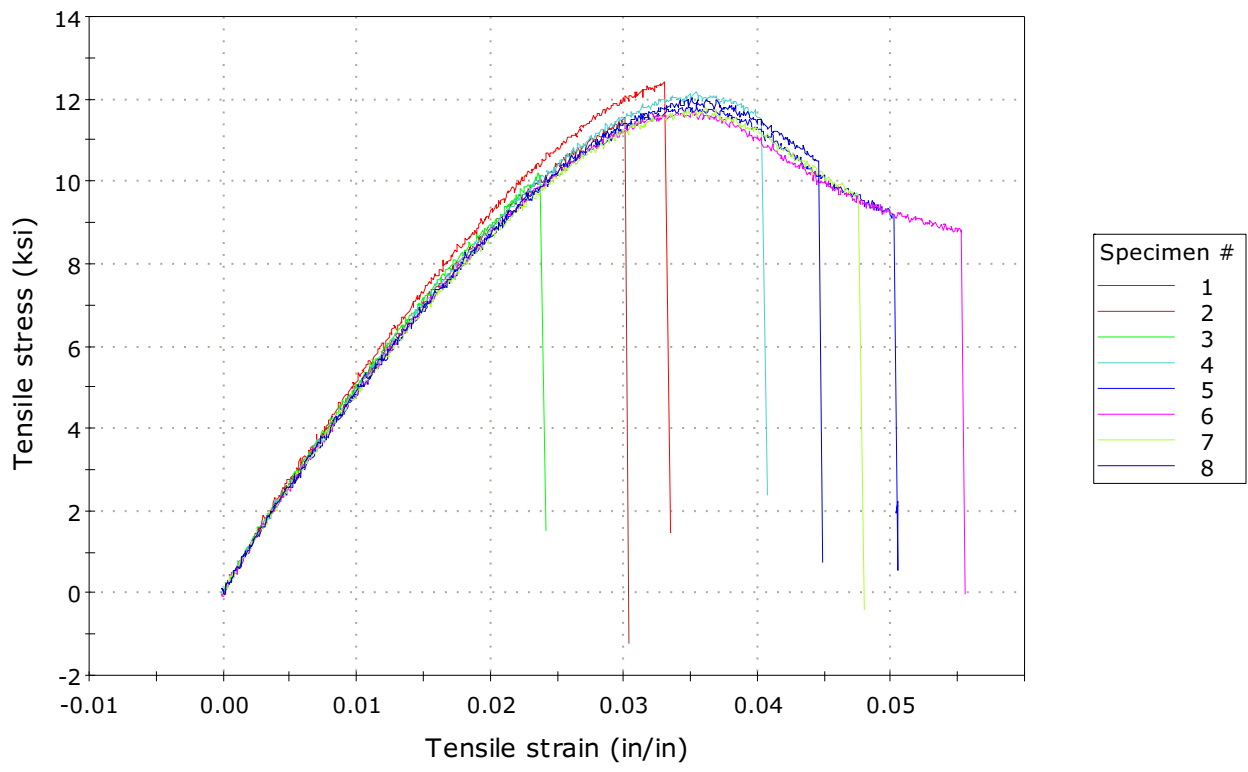

Specimen 9 to 10

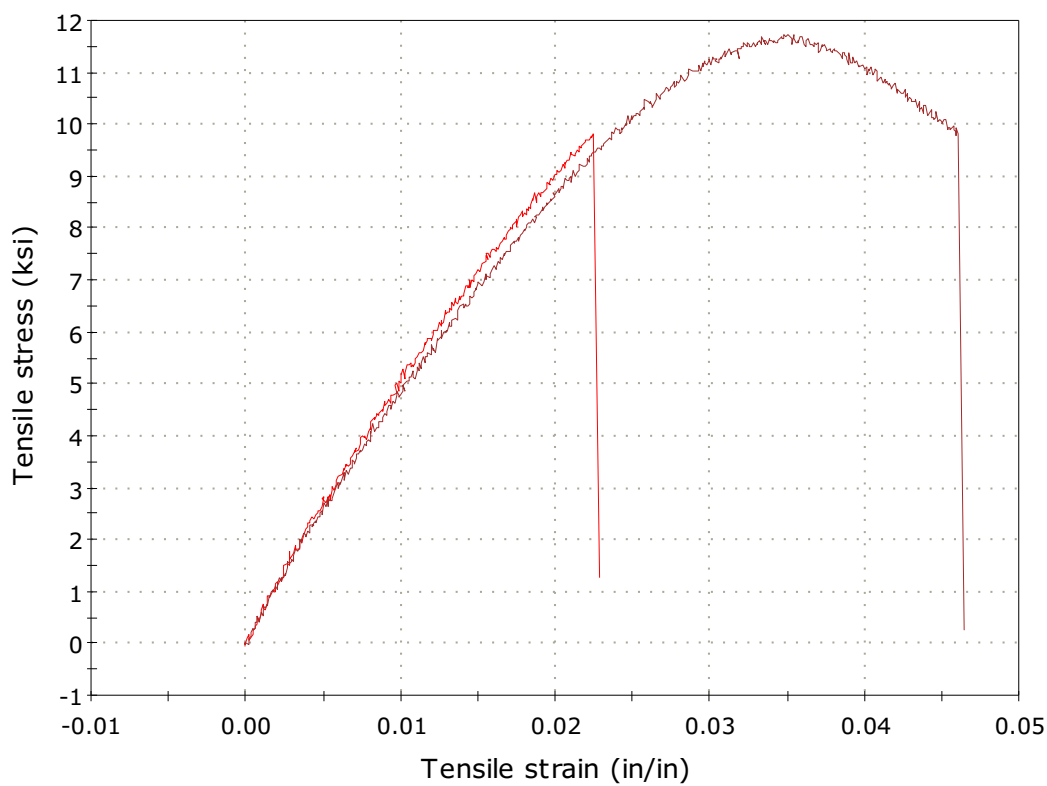

Specimen \#

Figure C-9: Stress-Strain plots for the raw Prototherm sample set 
Table C-7: Instron data for the raw Prototherm data set

\begin{tabular}{|c|c|c|c|c|}
\hline \multirow{2}{*}{ Specimen } & $\begin{array}{c}\text { Maximum } \\
\text { Load }\end{array}$ & $\begin{array}{c}\text { Maximum } \\
\text { Tensile stress }\end{array}$ & $\begin{array}{c}\text { Strain at } \\
\text { Maximum Load }\end{array}$ & $\begin{array}{c}\text { Modulus (Automatic } \\
\text { Young's) }\end{array}$ \\
\cline { 2 - 5 }$(\mathrm{lbf})$ & $(\mathrm{ksi})$ & $(\mathrm{in} / \mathrm{in})$ & 5.03307 & 555.125 \\
\hline 1 & 193.65451 & 12.39389 & 0.03001 & 521.05135 \\
\hline 2 & 180.50945 & 11.5526 & 0.02336 & 556.74352 \\
\hline 3 & 159.45591 & 10.20518 & 0.03528 & 540.56604 \\
\hline 4 & 190.2912 & 12.17864 & 0.03537 & 527.38025 \\
\hline 5 & 184.79734 & 11.82703 & 0.03524 & 534.28966 \\
\hline 6 & 182.78471 & 11.69822 & 0.03604 & 506.81919 \\
\hline 7 & 183.854 & 11.76666 & 0.03517 & 535.64161 \\
\hline 8 & 188.00521 & 12.03233 & 0.02242 & 568.36034 \\
\hline 9 & 153.64046 & 9.83299 & 0.03511 & 526.17747 \\
\hline 10 & 183.45469 & 11.7411 & 0.03211 & 537.21544 \\
\hline Mean & 180.04475 & 11.52286 & 0.00516 & 18.55366 \\
\hline Standard Deviation & 13.04318 & 0.83476 & 16.087 & 3.45367 \\
\hline Coefficient of Variation & 7.24441 & 7.24441 & 0.03727 & 555.7691 \\
\hline Mean + 1 SD & 193.08792 & 12.35763 & 0.02694 & 518.66178 \\
\hline Mean - 1 SD & 167.00157 & 10.6881 & & \\
\hline
\end{tabular}


Specimen 1 to 8
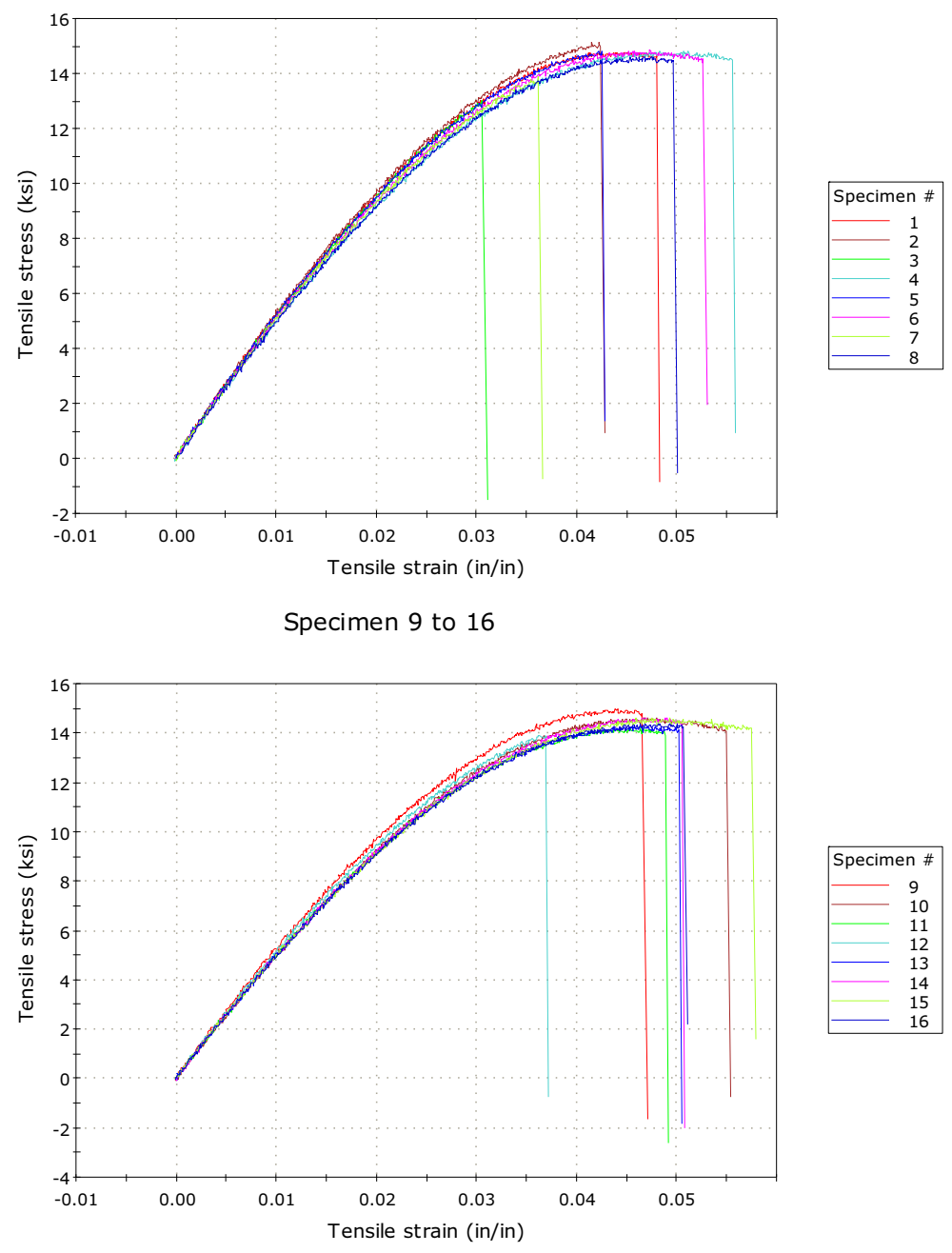

Specimen 17 to 20
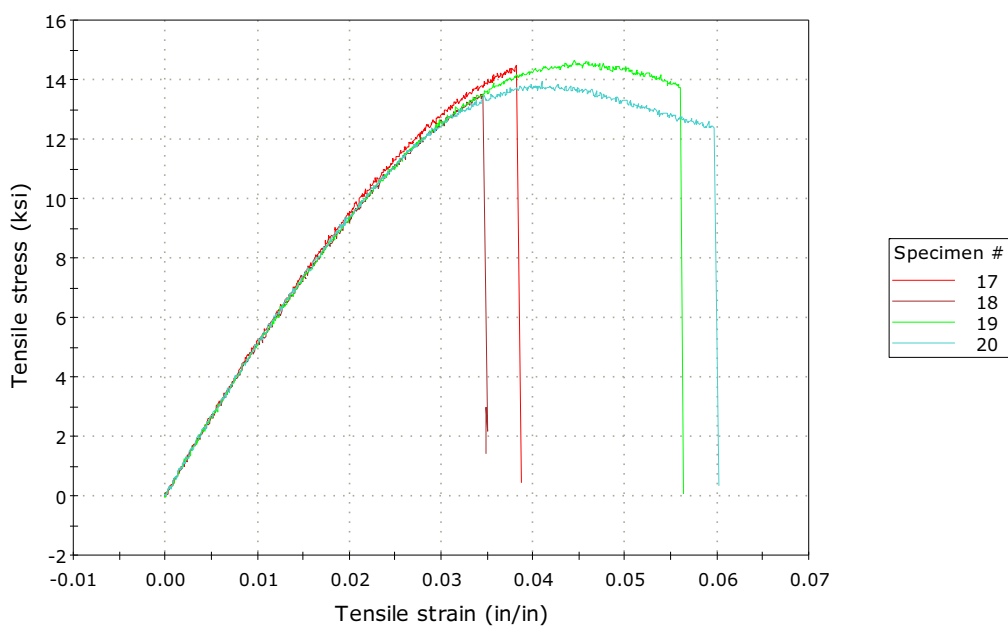

Figure C-10: Stress-Strain plots for the outgassed Prototherm sample set 
Table C-8: Instron data from the outgassed Prototherm sample set

\begin{tabular}{|c|c|c|c|c|}
\hline \multirow{2}{*}{ Specimen } & $\begin{array}{l}\text { Maximum } \\
\text { Load }\end{array}$ & $\begin{array}{c}\text { Maximum } \\
\text { Tensile stress }\end{array}$ & $\begin{array}{c}\text { Strain at Maximum } \\
\text { Load }\end{array}$ & $\begin{array}{c}\text { Modulus (Automatic } \\
\text { Young's) }\end{array}$ \\
\hline & (lbf) & (ksi) & (in/in) & (ksi) \\
\hline 1 & 230.73136 & 14.76681 & 0.04233 & 540.04039 \\
\hline 2 & 236.41549 & 15.13059 & 0.04143 & 532.35422 \\
\hline 3 & 203.5247 & 13.02558 & 0.03051 & 518.51538 \\
\hline 4 & 231.3665 & 14.80746 & 0.04825 & 511.7569 \\
\hline 5 & 231.24054 & 14.7994 & 0.04256 & 529.29604 \\
\hline 6 & 232.17048 & 14.85891 & 0.0472 & 519.72523 \\
\hline 7 & 216.68316 & 13.86772 & 0.03622 & 510.50889 \\
\hline 8 & 228.34622 & 14.61416 & 0.04631 & 522.63747 \\
\hline 9 & 233.61764 & 14.95153 & 0.04388 & 527.32735 \\
\hline 10 & 228.62225 & 14.63182 & 0.0471 & 507.22585 \\
\hline 11 & 221.99478 & 14.20767 & 0.04666 & 505.56924 \\
\hline 12 & 217.1977 & 13.90065 & 0.03619 & 520.51608 \\
\hline 13 & 222.62189 & 14.2478 & 0.0446 & 500.42766 \\
\hline 14 & 228.32746 & 14.61296 & 0.04904 & 514.91787 \\
\hline 15 & 228.22562 & 14.60644 & 0.0475 & 503.82012 \\
\hline 16 & 224.53536 & 14.37026 & 0.0469 & 511.09914 \\
\hline 17 & 226.14064 & 14.473 & 0.03833 & 537.4919 \\
\hline 18 & 211.30454 & 13.52349 & 0.03421 & 516.26664 \\
\hline 19 & 229.043 & 14.65875 & 0.04446 & 527.3959 \\
\hline 20 & 217.78193 & 13.93804 & 0.0409 & 540.68667 \\
\hline Mean & 224.99456 & 14.39965 & 0.04273 & 519.87895 \\
\hline Standard Deviation & 8.20001 & 0.5248 & 0.00522 & 12.10801 \\
\hline Coefficient of Variation & 3.64454 & 3.64454 & 12.20846 & 2.32901 \\
\hline Mean + 1 SD & 233.19457 & 14.92445 & 0.04795 & 531.98696 \\
\hline Mean - 1 SD & 216.79456 & 13.87485 & 0.03751 & 507.77093 \\
\hline
\end{tabular}


Specimen 1 to 8
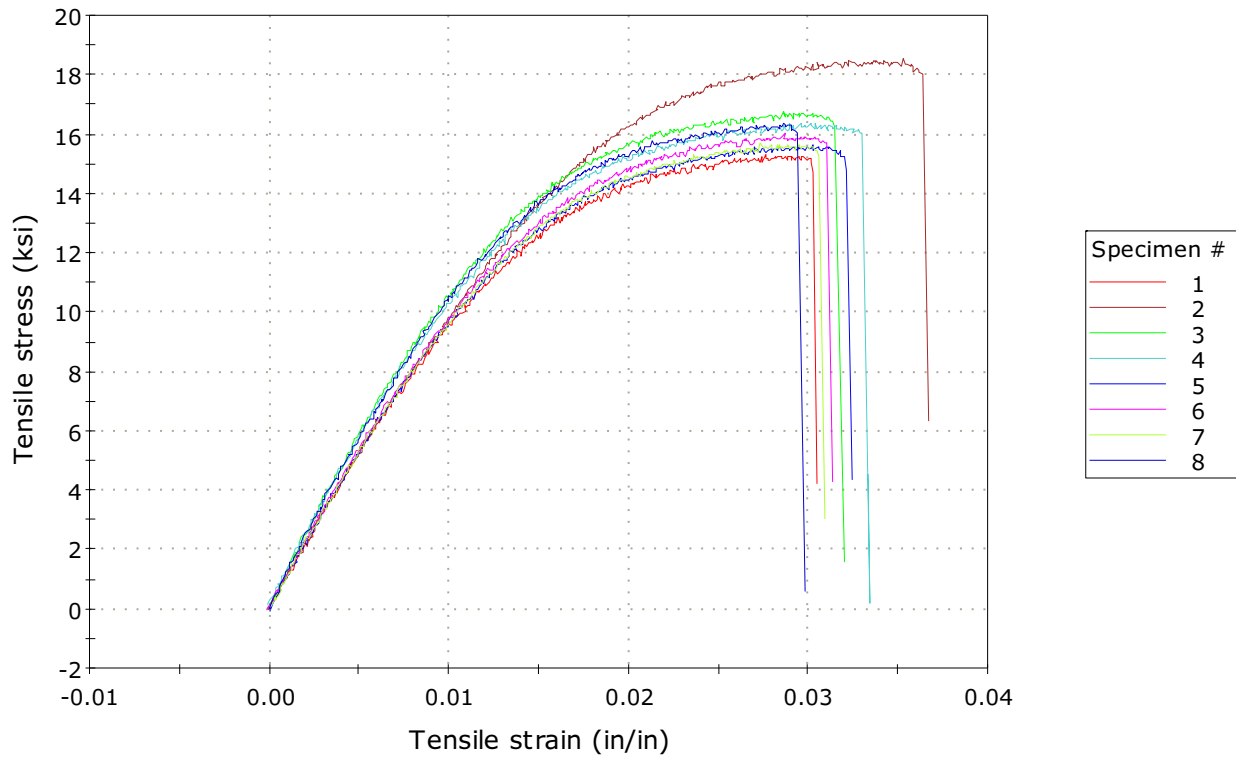

Specimen 9 to 10

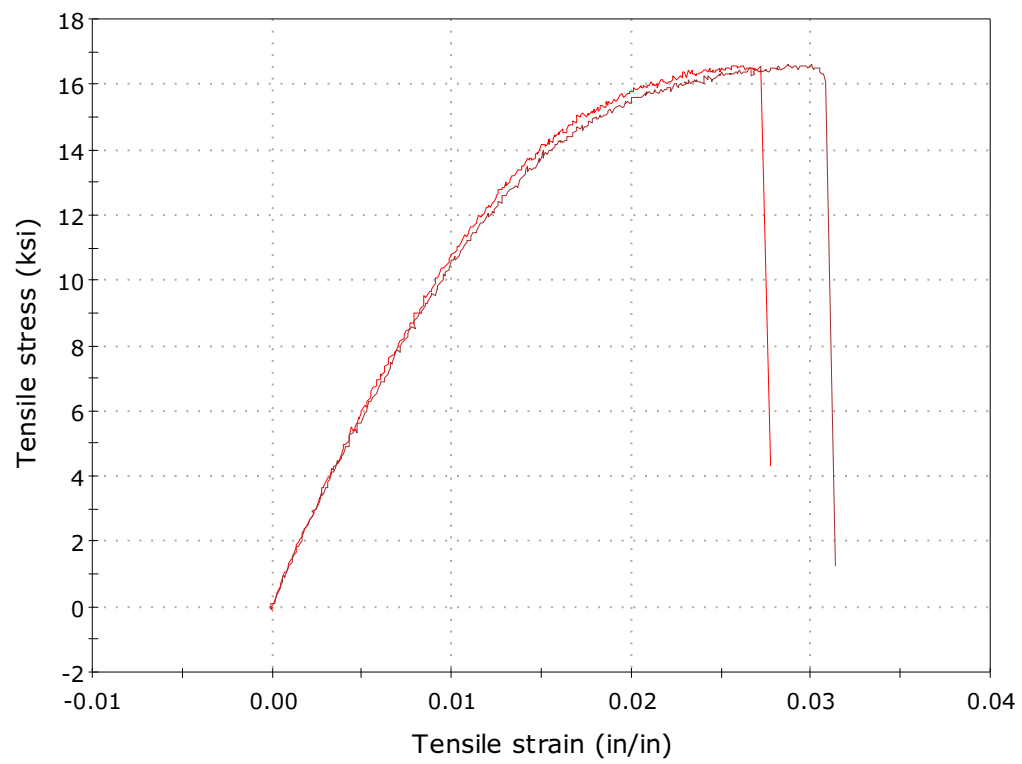

Specimen \#

Figure C-11: Stress-Strain plots for the raw WindformXT sample set 
Table C-9: Instron data for the raw WindformXT sample set

\begin{tabular}{|c|c|c|c|c|}
\hline \multirow{2}{*}{ Specimen } & $\begin{array}{c}\text { Maximum } \\
\text { Load }\end{array}$ & $\begin{array}{c}\text { Maximum } \\
\text { Tensile stress }\end{array}$ & $\begin{array}{c}\text { Strain at } \\
\text { Maximum Load }\end{array}$ & $\begin{array}{c}\text { Modulus (Automatic } \\
\text { Young's) }\end{array}$ \\
\cline { 2 - 5 }$(\mathrm{lbf})$ & $(\mathrm{ksi})$ & $(\mathrm{in} / \mathrm{in})$ & 0.02762 & 1089.9891 \\
\hline 1 & 239.52421 & 15.32955 & 0.03531 & 1043.01365 \\
\hline 2 & 289.99804 & 18.55987 & 0.0286 & 1195.02796 \\
\hline 3 & 262.11603 & 16.77543 & 0.03036 & 1142.99968 \\
\hline 4 & 255.58772 & 16.35761 & 0.03023 & 1064.39883 \\
\hline 5 & 244.37221 & 15.63982 & 0.02871 & 1067.30592 \\
\hline 6 & 250.21982 & 16.01407 & 0.02747 & 1109.10169 \\
\hline 7 & 245.46026 & 15.70946 & 0.02852 & 1187.36818 \\
\hline 8 & 256.22286 & 16.39826 & 0.02603 & 1215.09191 \\
\hline 9 & 259.12255 & 16.58384 & 0.0302 & 1197.41316 \\
\hline 10 & 259.24047 & 16.59139 & 0.02931 & 1131.17101 \\
\hline Mean & 256.18642 & 16.39593 & 0.00252 & 64.37606 \\
\hline Standard Deviation & 14.00218 & 0.89614 & 8.61003 & 5.6911 \\
\hline Coefficient of Variation & 5.46562 & 5.46562 & 0.03183 & 1195.54706 \\
\hline Mean + 1 SD & 270.18859 & 17.29207 & 0.02678 & 1066.79495 \\
\hline Mean - 1 SD & 242.18424 & 15.49979 & & \\
\hline
\end{tabular}


Specimen 1 to 8
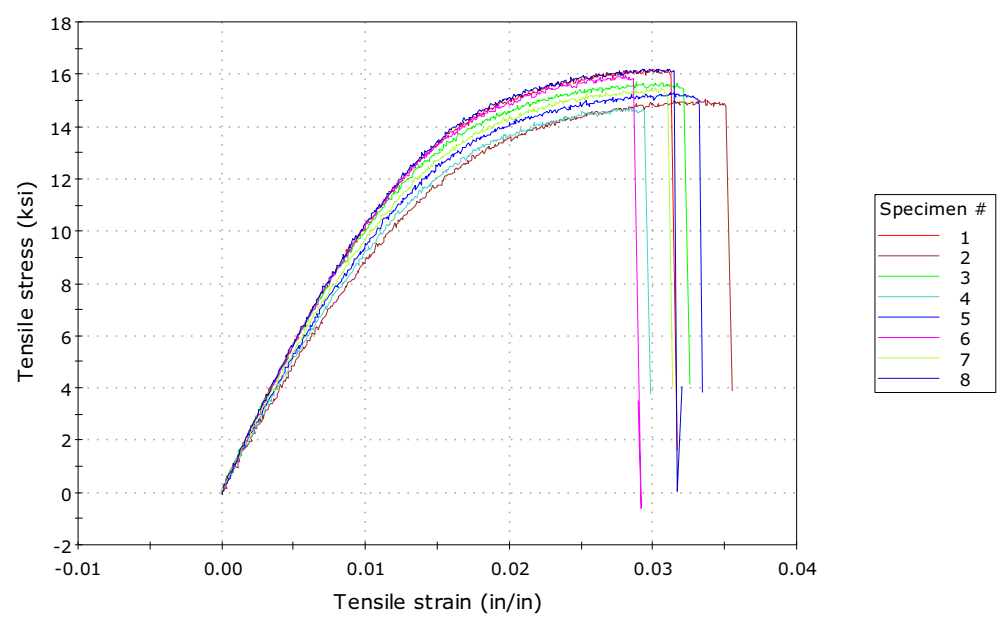

Specimen 9 to 16
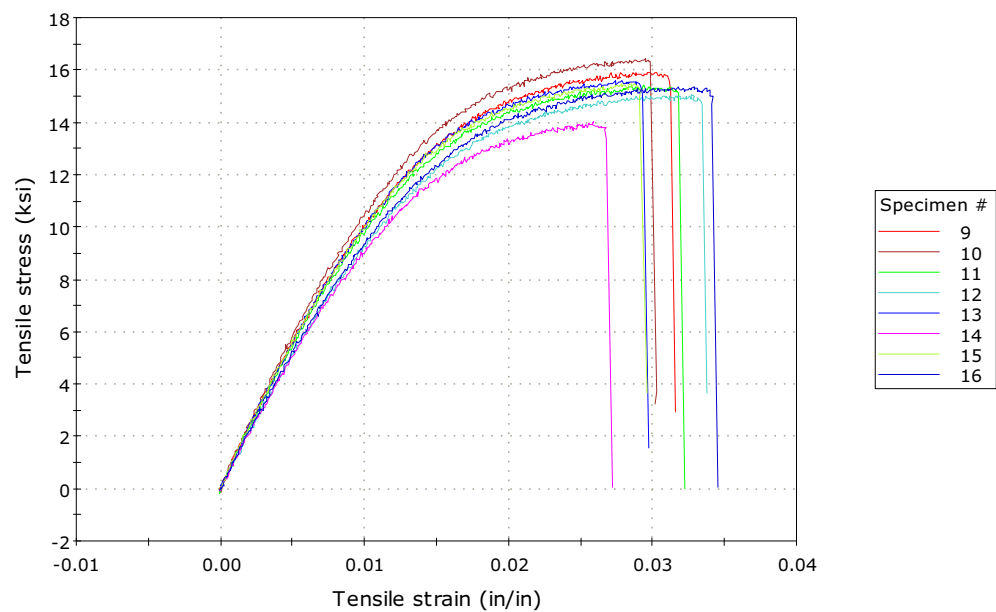

Specimen 17 to 20
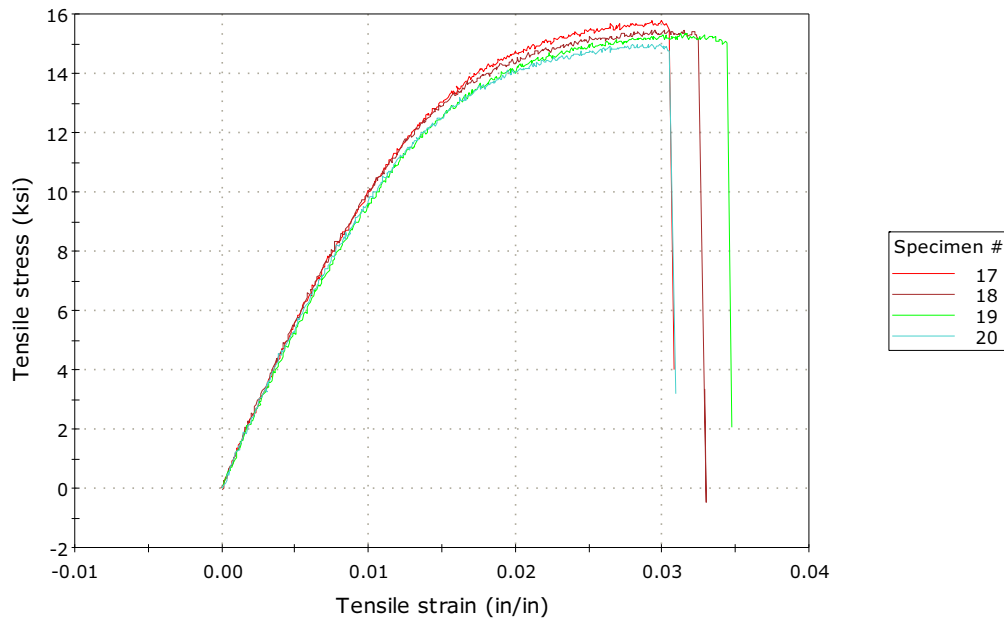

Figure C-12: Stress-Strain plots for the outgassed WindformXT sample set 
Table C-10: Instron data for the outgassed WindformXT sample set

\begin{tabular}{|c|c|c|c|c|}
\hline \multirow[t]{2}{*}{ Specimen } & $\begin{array}{l}\text { Maximum } \\
\text { Load }\end{array}$ & $\begin{array}{c}\text { Maximum } \\
\text { Tensile stress } \\
\end{array}$ & $\begin{array}{c}\text { Strain at Maximum } \\
\text { Load }\end{array}$ & $\begin{array}{c}\text { Modulus (Automatic } \\
\text { Young's) }\end{array}$ \\
\hline & (lbf) & (ksi) & (in/in) & (ksi) \\
\hline 1 & 252.98819 & 16.19124 & 0.02937 & 1171.60912 \\
\hline 2 & 234.85577 & 15.03077 & 0.03356 & 1007.90677 \\
\hline 3 & 245.19495 & 15.69248 & 0.02875 & 1173.90539 \\
\hline 4 & 229.87646 & 14.71209 & 0.02849 & 1034.64141 \\
\hline 5 & 239.1919 & 15.30828 & 0.0315 & 1073.62218 \\
\hline 6 & 249.44264 & 15.96433 & 0.02813 & 1167.05501 \\
\hline 7 & 242.13982 & 15.49695 & 0.03027 & 1108.8304 \\
\hline 8 & 253.49469 & 16.22366 & 0.02927 & 1170.64531 \\
\hline 9 & 248.75121 & 15.92008 & 0.02971 & 1144.80079 \\
\hline 10 & 256.55517 & 16.41953 & 0.02955 & 1181.16279 \\
\hline 11 & 240.99013 & 15.42337 & 0.02942 & 1127.54211 \\
\hline 12 & 235.35692 & 15.06284 & 0.03269 & 1058.89003 \\
\hline 13 & 243.65399 & 15.59385 & 0.02758 & 1172.67595 \\
\hline 14 & 219.0415 & 14.01866 & 0.0258 & 1070.24236 \\
\hline 15 & 241.95223 & 15.48494 & 0.02781 & 1135.97098 \\
\hline 16 & 239.73861 & 15.34327 & 0.0329 & 1050.93957 \\
\hline 17 & 246.60727 & 15.78287 & 0.02932 & 1143.25035 \\
\hline 18 & 241.62528 & 15.46402 & 0.03153 & 1187.29975 \\
\hline 19 & 239.86724 & 15.3515 & 0.03157 & 1121.79717 \\
\hline 20 & 234.3573 & 14.99887 & 0.02809 & 1110.0604 \\
\hline Mean & 241.78406 & 15.47418 & 0.02977 & 1120.64239 \\
\hline Standard Deviation & 8.72177 & 0.55819 & 0.002 & 54.3192 \\
\hline Coefficient of Variation & 3.60725 & 3.60726 & 6.70323 & 4.84715 \\
\hline Mean + 1 SD & 250.50583 & 16.03237 & 0.03176 & 1174.96159 \\
\hline Mean - 1 SD & 233.0623 & 14.91599 & 0.02777 & 1066.32319 \\
\hline
\end{tabular}




\section{Appendix D: Material Data Sheets}

\begin{tabular}{|c|c|c|c|c|c|}
\hline \multicolumn{6}{|c|}{$\begin{array}{l}\text { P400 - Plastic Material ABS } \\
\text { FDM } 1600,1650,2000 \text {, and } 8000\end{array}$} \\
\hline \multirow{3}{*}{$\begin{array}{l}\text { FDM System } \\
\text { Parameters }\end{array}$} & \multicolumn{5}{|c|}{ FDM Tip Inner Diameter } \\
\hline & \multicolumn{2}{|c|}{1600,1650} & \multirow{2}{*}{$\begin{array}{l}2000 \\
0.010^{\prime \prime}\end{array}$} & \multicolumn{2}{|c|}{$2000 / 8000$} \\
\hline & $0.012^{\prime \prime}$ & $0.025^{\circ}$ & & $0.012^{\prime \prime}$ & $0.016^{*}$ \\
\hline $\begin{array}{l}\text { Speed inches/sec } \\
\text { (maximum) }\end{array}$ & 0.800 & 0.800 & 1.000 & 1.000 & 1.500 \\
\hline (recommended) & 0.800 & 0.800 & 1.000 & 1.000 & $1.000-1.3000$ \\
\hline $\begin{array}{r}\text { Road Height } \\
\text { (maximum) }\end{array}$ & $0.016^{\circ}$ & $0.020^{\prime \prime}$ & $0.010^{\prime \prime}$ & $0.012^{\prime \prime}$ & $0.014^{\prime \prime}$ \\
\hline (minimum) & $0.004^{\prime \prime}$ & $0.010^{\prime \prime}$ & $0.007^{\prime \prime}$ & $0.007^{\prime \prime}$ & $0.010^{\prime \prime}$ \\
\hline (recommended) & $0.010^{\prime \prime}$ & $0.012^{\prime \prime}$ & $0.007^{n}$ & $0.007^{\prime \prime}$ & $0.012^{\prime \prime}$ \\
\hline $\begin{array}{l}\text { Road Width } \\
\text { (maximum) }\end{array}$ & $0.040^{\circ}$ & $0.060^{\prime \prime}$ & $0.030^{\prime \prime}$ & $0.040^{\prime \prime}$ & $0.040^{\prime \prime}$ \\
\hline (minimum) & $0.012^{\prime}$ & $0.030^{\prime \prime}$ & $0.010^{\prime \prime}$ & $0.012^{\prime \prime}$ & $0.016^{\prime \prime}$ \\
\hline $\begin{array}{l}\text { Liquefier Temp }{ }^{\circ} \mathrm{C} \\
\text { (maximum) }\end{array}$ & 270 & 270 & 290 & 270 & 270 \\
\hline (minimum) & 270 & 270 & 290 & 270 & 270 \\
\hline (recommended) & See Spool & See Spool & SeeSpool & See Spool & See Spool \\
\hline $\begin{array}{l}\text { Envelope Temp }{ }^{\circ} \mathrm{C} \\
\text { (maximum) }\end{array}$ & 70 & 70 & 70 & 70 & 70 \\
\hline (minimum) & 70 & 70 & 50 & 70 & 70 \\
\hline (recommended) & 70 & 70 & 60 & 70 & 70 \\
\hline $\begin{array}{l}\text { Room Temp }{ }^{\circ} \mathrm{F} \\
\text { (maximum) }\end{array}$ & 82 & 82 & 82 & 82 & 82 \\
\hline
\end{tabular}

It is recommended to use the parameter values indicated in bold for perimeter roads. The values in this table may also be applied to fill and support roads if desired.

\begin{tabular}{|c|c|c|}
\hline \multicolumn{3}{|c|}{ Material Specifications ${ }^{*}$} \\
\hline Tensile Strength (psi): & 5,000 & Unnotched Impact ( $\left(\mathrm{tt}^{*} \mid \mathrm{b} / \mathrm{in}\right):-$ \\
\hline Flexural Strength (psi): & 9,500 & Elongation (\%): \\
\hline Tensile Modulus (psi): & 360,000 & Hardness (Shore D): \\
\hline Flexural Modulus (psi): & 380,000 & Softening Point (R\&B) (F): $\quad 220$ \\
\hline Notched Impact (ft"lb/in): & 2.00 & Specific Gravity $\left(\mathrm{GMS} \mathrm{CM}^{3}\right): 1.05$ \\
\hline
\end{tabular}



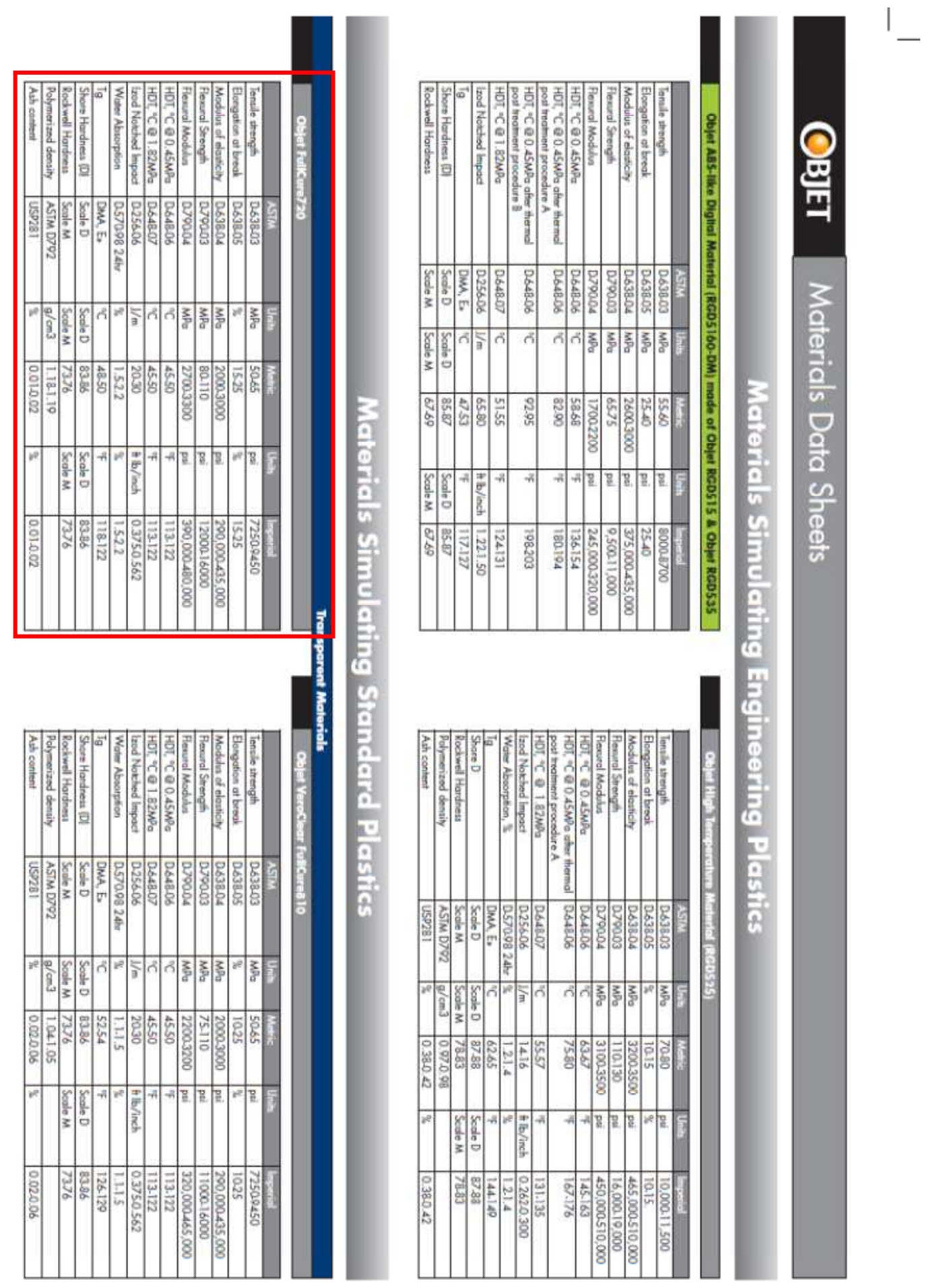


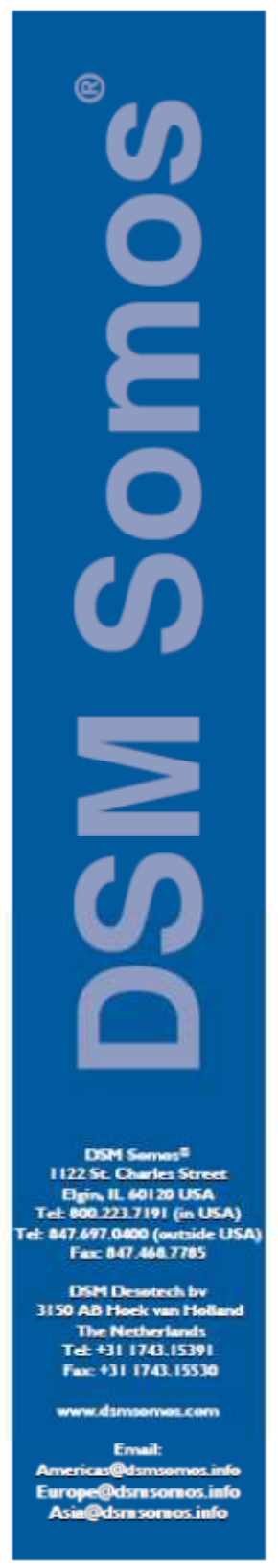

\section{WaterShed ${ }^{\circledR}$ XC 11122}

Transparent, durable, strong, water-resistant resin for stereolithography For Solid State (355 $\mathrm{nm}$ ) Laser Systems

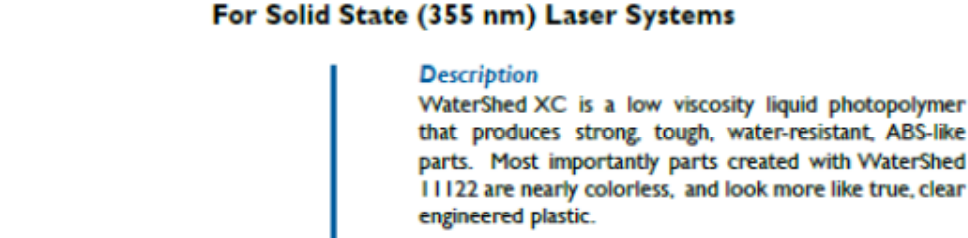

In addition WaterShed $X C$ has been formulated with the DSM Somos Oxetane Advantage ${ }^{T M}$ - an advanced chemistry platform that produces parts with outstanding water resistance and high dimensional stability.

Application

WaterShed XC III 22 offers many properties that mimic traditional engineering plastics including ABS and PBT This makes the material ideal for many applications in the automotive, medical and consumer electronics markets and include:

- Lenses

- Packaging

-Water flow analysis

- RTV patterns

- Durable concept models

-Wind tunnel testing

- Quickcast patterns

Physical Properties - Liquid Appearance Optically clear

Viscosity $\quad-260 \mathrm{cps}$ at $30^{\circ} \mathrm{C}$

Density

$\sim 1.12 \mathrm{~g} / \mathrm{cm}^{3}$ at $25^{\circ} \mathrm{C}$

Optical Properties at $355 \mathrm{~nm}$

E. $\quad \sim 11.5 \mathrm{~m} / \mathrm{cm}^{2}$

D. $\quad 0.16 \mathrm{~mm}$ ( $\sim 0065$ inch)

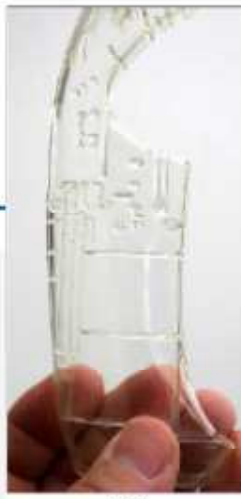

11120

$E_{10} \quad 54 \mathrm{~m} / \mathrm{cm}^{2}$

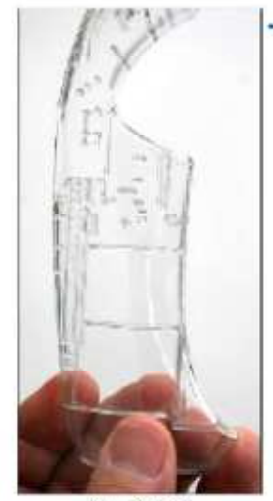

Wiershed XC Photo courtesy of Dynacept

astiproduct 


\section{Mechanical Properties (Metric)}

\begin{tabular}{|c|c|c|c|c|}
\hline $\begin{array}{l}\text { ASTM } \\
\text { Method }\end{array}$ & Description & $\begin{array}{c}\text { WaterShed } \\
11122\end{array}$ & $\begin{array}{c}\text { ABS }^{*} \\
\text { (transparent) }\end{array}$ & $\begin{array}{l}\text { Polybutylene } \\
\text { Terephthalate" }\end{array}$ \\
\hline \multirow[t]{4}{*}{ D638M } & Tensile Strength & $47.1-53.6 \mathrm{MPa}$ & $45.7 \mathrm{MPa}$ & $55 \mathrm{MPa}$ \\
\hline & Elongation at Break & $11-20 \%$ & $41.6 \%$ & $20 \%$ \\
\hline & Elongation at Yield & $3.3-3.5 \%$ & N/A & $3.5-9 \%$ \\
\hline & Modulus of Elasticity & $2,650-2,880$ & $2,000 \mathrm{MPa}$ & $2,700 \mathrm{MPa}$ \\
\hline \multirow[t]{2}{*}{ D790M } & Flexural Strength & $63.1-74.2 \mathrm{MPa}$ & $73.5 \mathrm{MPa}$ & $80 \mathrm{MPa}$ \\
\hline & Flexural Modulus & $2,040-2,370 \mathrm{MPa}$ & $2,300 \mathrm{MPa}$ & $2,500 \mathrm{MPa}$ \\
\hline D256A & Izod Impact-Notched & $0.2-0.3 \mathrm{~J} / \mathrm{cm}$ & $1.6 \mathrm{ycm}$ & $1.2 \mathrm{~J} / \mathrm{cm}$ \\
\hline D542 & Index of Refraction & $1.512-1.515$ & 1.52 & N/A \\
\hline D2240 & Hardness (Shore D) & $\mathrm{N} / \mathrm{A}$ & N/A & $98-120$ (Rockwell R) \\
\hline DI004 & Graves Tear & $150,288 \mathrm{~N} / \mathrm{m}$ & N/A & $\mathrm{N} / \mathrm{A}$ \\
\hline D570-98 & Water Absorption & $0.35 \%$ & $0.20-0.45 \%$ & $0.16 \%$ \\
\hline
\end{tabular}

\section{Thermal \& Electrical Properties (Metric)}

\begin{tabular}{|c|c|c|c|c|}
\hline $\begin{array}{l}\text { ASTM } \\
\text { Method }\end{array}$ & Description & $\begin{array}{c}\text { WaterShed } \\
\text { III22 }\end{array}$ & $\begin{array}{c}\text { ABS }^{*} \\
\text { (transparent) }\end{array}$ & $\begin{array}{l}\text { Polybutylene } \\
\text { Terephthalate }\end{array}$ \\
\hline \multirow[t]{4}{*}{ E831-00 } & C.T.E. $-40^{\circ} \mathrm{C}-0^{\circ} \mathrm{C}$ & $66-67 \mu \mathrm{m} / \mathrm{m}={ }^{\circ} \mathrm{C}$ & \multirow{4}{*}{$60-130 \mu \mathrm{m} / \mathrm{m}-{ }^{\circ} \mathrm{C}$} & \multirow{4}{*}{ 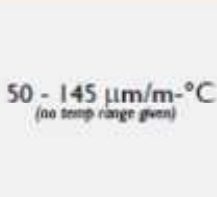 } \\
\hline & C.T.E. $0^{\circ} \mathrm{C}-50^{\circ} \mathrm{C}$ & $90-96 \mu \mathrm{m} / \mathrm{m}-{ }^{\circ} \mathrm{C}$ & & \\
\hline & C.T.E. $50^{\circ} \mathrm{C}-100^{\circ} \mathrm{C}$ & $170-189 \mu \mathrm{m} / \mathrm{m}-{ }^{\circ} \mathrm{C}$ & & \\
\hline & C.T.E. $100^{\circ} \mathrm{C}-150^{\circ} \mathrm{C}$ & $185.189 \mu \mathrm{m} / \mathrm{m}-{ }^{\circ} \mathrm{C}$ & & \\
\hline \multirow[t]{3}{*}{ DI50-98 } & Dielectric Constant $60 \mathrm{~Hz}$ & $3.9-4.1$ & 3.7 & \multirow{3}{*}{ 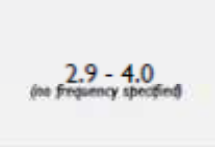 } \\
\hline & Dielectric Constant IKHz & $3.7-3.9$ & & \\
\hline & Dielectric Constant $1 \mathrm{MHz}$ & $3.4-3.5$ & 3.7 & \\
\hline DI 49-97a & Dielectric Strength & $15.4-16.3 \mathrm{kV} / \mathrm{mm}$ & $13.8-19.7 \mathrm{kV} / \mathrm{mm}$ & $14.7-30 \mathrm{kV} / \mathrm{mm}$ \\
\hline EI545-00 & $\mathrm{Tg}$ & $39-46^{\circ} \mathrm{C}$ & & $41^{\circ} \mathrm{C}$ \\
\hline \multirow[t]{2}{*}{ D648-98c } & HDT@ $0.46 \mathrm{MPa}$ & $45.9-54.5^{\circ} \mathrm{C}$ & $94-207^{\circ} \mathrm{C}$ & $150^{\circ} \mathrm{C}$ \\
\hline & HDT@1.81 MPa & $49.0-49.7^{\circ} \mathrm{C}$ & $86.4-194^{\circ} \mathrm{C}$ & $61.3^{\circ} \mathrm{C}$ \\
\hline \multicolumn{2}{|c|}{ 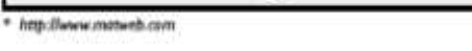 } & & & Non Not \\
\hline \multicolumn{4}{|c|}{ The ProtoFunctionar' Materials Company } & \\
\hline \multicolumn{4}{|c|}{$\overline{\text { DSM Somos }^{\circ}}$} & DSM \\
\hline
\end{tabular}




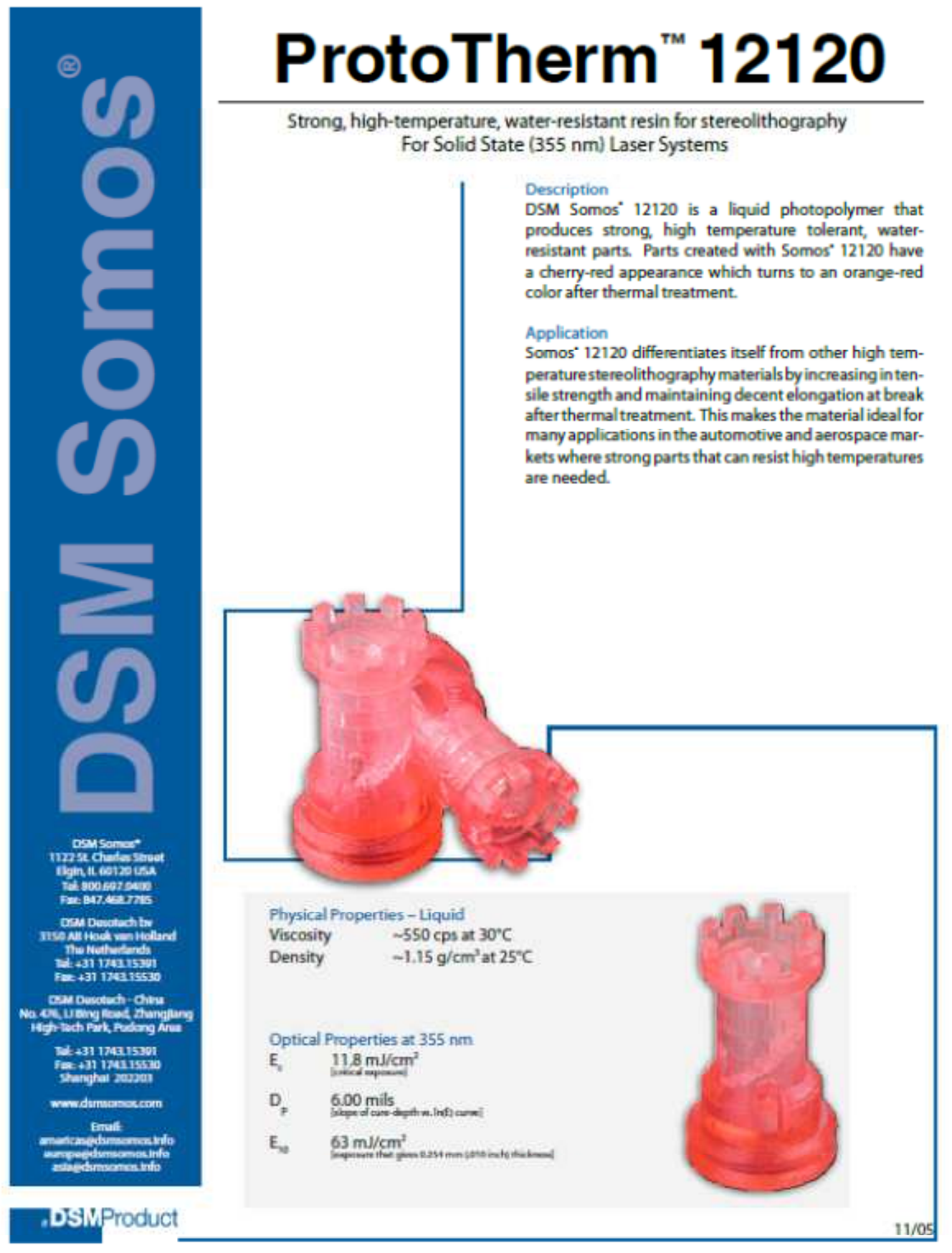




\section{Mechanical Properties (Metric)}

\begin{tabular}{|c|c|c|c|c|}
\hline $\begin{array}{l}\text { ASTM } \\
\text { Method }\end{array}$ & Description & $\begin{array}{l}12120 \\
\text { UV Postcure }\end{array}$ & $\begin{array}{l}10 \% 5 \text { Glass Filled } \\
\text { Polycarbonate? }\end{array}$ & $\begin{array}{l}12120 \\
\text { Thermal } \\
\text { Postcure }\end{array}$ \\
\hline \multirow[t]{4}{*}{$\mathrm{D} 638 \mathrm{M}$} & Tensile Strength & $70.2 \mathrm{MPa}$ & $55-85 \mathrm{MPa}$ & $77.0 \mathrm{MPa}$ \\
\hline & Elongation at Break & $4.00 \%$ & $2-14 \%$ & $4.50 \%$ \\
\hline & Elongation at Yield & N/A & 496 & N/A \\
\hline & Modulus of Elasticity & $3,520 \mathrm{MPa}$ & $3,102-5,302 \mathrm{MPa}$ & $3,250 \mathrm{MPa}$ \\
\hline \multirow[t]{2}{*}{ D790M } & Flexural Strength & $109 \mathrm{MPa}$ & $93-124 \mathrm{MPa}$ & $103 \mathrm{MPa}$ \\
\hline & Flexural Modulus & $3,320 \mathrm{MPa}$ & $2,300-5,300 \mathrm{MPa}$ & $3,060 \mathrm{MPa}$ \\
\hline D256A & Izod Impact-Notched & $0.115 \mathrm{~J} / \mathrm{cm}$ & $0.5-3.0 \mathrm{~J} / \mathrm{cm}$ & $0.168 \mathrm{~J} / \mathrm{cm}$ \\
\hline D2240 & Hardness (Shore D) & 85.30 & $N / A$ & 86.70 \\
\hline D570-98 & Water Absorption & $0.37 \%$ & $0.1-0.3 \%$ & $0.24 \%$ \\
\hline
\end{tabular}

\section{Thermal \& Electrical Properties (Metric)}

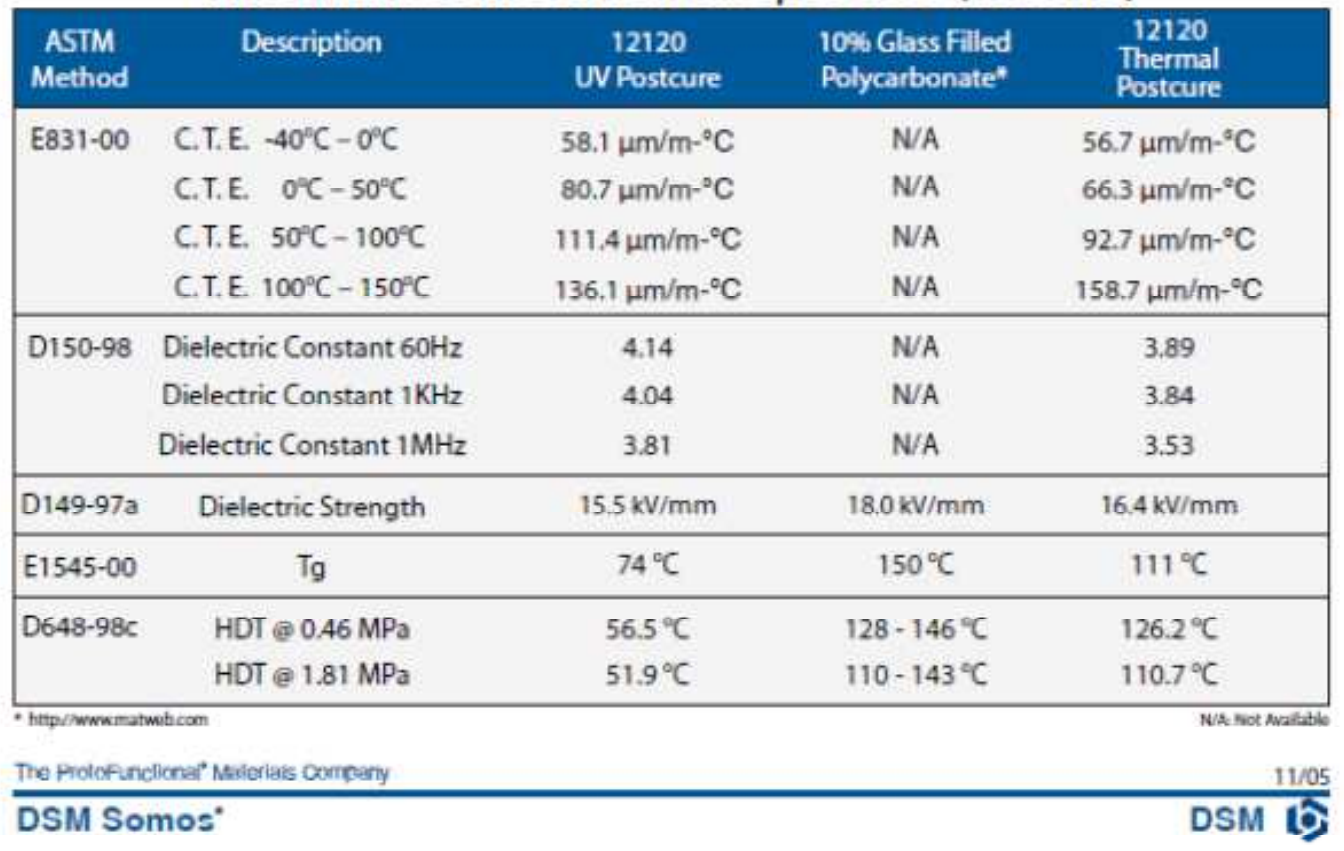




\section{WINIFOFRX}

Glass of material: Polyamide besed material

TECHNOLOGY: Selective Laper Sintering

Windform ${ }^{\circ} \mathrm{XT}$ is a composite polyamide besed, carbon fibre filled material.

It's a rapid prototyping composite material of new generation, whose advanced mechanical properties make this material the excellent parther in Rapid Manufacturing or Direct Digital Manufacturing.

In the world of fast production, today, you will not find any other materials comparable to this one.

Appearance: opeque black coloured compound polyemide and carbon besed material with brilient reflexes. Windform" $\mathrm{XT}$ ia characterized by stiffness and extremely high UTS, excellent surface finish, resistance to extreme wear and optimal reproduction of detail. Windform" XT offers an alluring, black, sparkling look, appreciable in many design applicationg. Windform ${ }^{6} X T$ is particulenly suited to applications which require superior mechenicel properties, extremely high performance, in rapid timing.

\section{Appucations:}

Aerodynamic applications in wind tunnel, on race track and an road, functional prototypes far racing and on road applicationg.

The product's versatility and the technology used allow countiess possibilities of utilization.

WHERE TO FINO WINDFOAM" PaODUCTS

CAP Technology produces Windform" XT parts and it also ships the material throughout Europe, the USA, and Japen.

CAP Technology and its pertners can affer customized service es regards time and delivery conditions, according to customer's requests anywhere in the world.

\section{HOW TO GET WINDFOFM" PRODUCTE}

For any further information, quotations, and delivery times, please visit the afficial website vwww.windform.it or send an information request to info@crp.eu.

CRP will contact you to angwer all your questions.

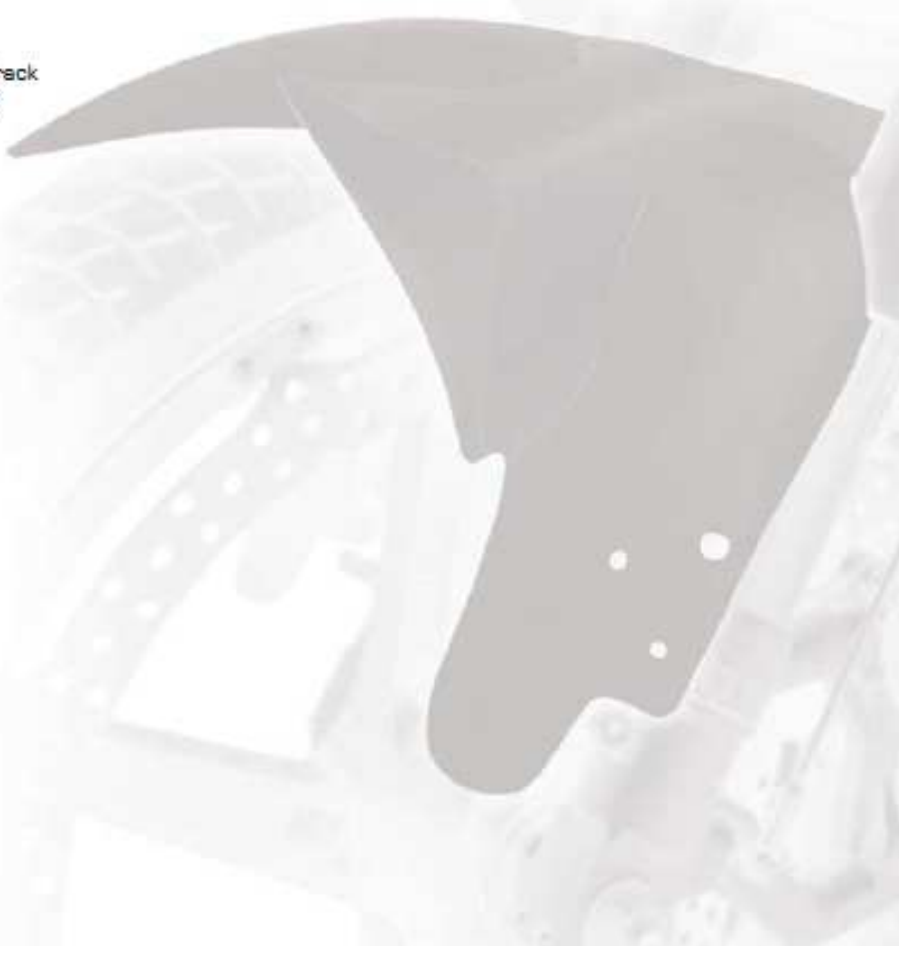




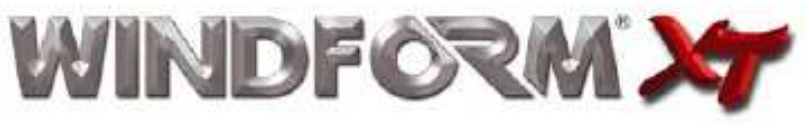

Cere Tecnnelagy arit

Vie Cozare Deile Ch
41100 Modene $M$

Te +39058 021135

Fex +3905902507

uww.crptechnology com
Waw whatormit

\begin{tabular}{|c|c|c|c|}
\hline $\begin{array}{l}\text { Properties } \\
\text { WINDFORM }^{*} \times T\end{array}$ & Test Method & SI Unity & Windtom ${ }^{2} \times T$ \\
\hline \multicolumn{4}{|l|}{ General Propertie: } \\
\hline Denaty $\left[20^{\circ} \mathrm{C}\right]$ & & $\mathrm{g} / \mathrm{cm}^{2}$ & 1,101 \\
\hline Colour & & & DARK \\
\hline \multicolumn{4}{|l|}{ Thermal Properties } \\
\hline Mating Faint & ASTM D 3410 & $\tau$ & 179,33 \\
\hline Hat, 1. a $\mathrm{Mpa}$ & АЕTM D 040 & c & 175,4 \\
\hline Vicet 10lN & ASTM D 1250 & 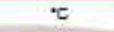 & 170.1 \\
\hline \multicolumn{4}{|l|}{ Mechanical Pageremtise } \\
\hline Tanale Etrangth & 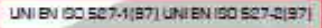 & Mps & 77.95 \\
\hline Tarale Modutus & 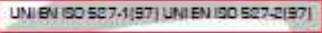 & Mps & 7320,8 \\
\hline Elongation at brsek & 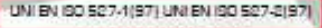 & $\%$ & 20 \\
\hline Fexure: Etrength & UNe EN $10014125=2000$ & Mps & 131,20 \\
\hline Fexurel Maduluz & UNe EN $10014125=2000$ & Mgs & 5240,5 \\
\hline 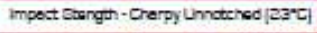 & AETM DCSE . UNIEN DO 179:1990 & $x 3 / m^{2}$ & 32,4 \\
\hline 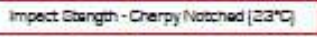 & ASTM DLSB - UNIEN $\subseteq 0$ 17E:1990 & $\kappa 3 / \pi^{\prime \prime}$ & 4,73 \\
\hline 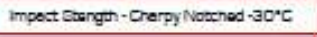 & AETM DESB . UNIEN DO 179:1990 & $x 3 / m^{*}$ & 4,00 \\
\hline \multicolumn{4}{|l|}{ Surface Finusin } \\
\hline Attar ELE Froceaz & & Reum & 8,0 \\
\hline Atter finlening & & Ras um & 1.8 \\
\hline \multicolumn{4}{|l|}{ Paopeates pera Denvetr Unit } \\
\hline UTE per denaty unt & & Mpog/ om" & 7071 \\
\hline Tanele modulus per denaty unt & & $\mathrm{Mpeg} / \mathrm{cm}^{3}$ & 00492 \\
\hline
\end{tabular}

Note These are al indicebve values, deta wers genersted trom the testing of pgrts produced with the Whatorme $x T$ metariale under optims procesaing conation:

Itendand Technicel Descalle toc Accureocy vercue Toverance

inchio.3 mm

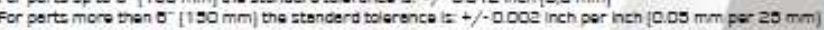

